\title{
Enculturing innovation : Indian engagements with nanotechnology
}

Citation for published version (APA):

Sekhsaria, P. (2016). Enculturing innovation : Indian engagements with nanotechnology. [Doctoral Thesis, Maastricht University]. Maastricht University. https://doi.org/10.26481/dis.20160310ps

Document status and date:

Published: 01/01/2016

DOI:

10.26481/dis.20160310ps

Document Version:

Publisher's PDF, also known as Version of record

\section{Please check the document version of this publication:}

- A submitted manuscript is the version of the article upon submission and before peer-review. There can be important differences between the submitted version and the official published version of record.

People interested in the research are advised to contact the author for the final version of the publication, or visit the DOI to the publisher's website.

- The final author version and the galley proof are versions of the publication after peer review.

- The final published version features the final layout of the paper including the volume, issue and page numbers.

Link to publication

\footnotetext{
General rights rights.

- You may freely distribute the URL identifying the publication in the public portal. please follow below link for the End User Agreement:

www.umlib.nl/taverne-license

Take down policy

If you believe that this document breaches copyright please contact us at:

repository@maastrichtuniversity.nl

providing details and we will investigate your claim.
}

Copyright and moral rights for the publications made accessible in the public portal are retained by the authors and/or other copyright owners and it is a condition of accessing publications that users recognise and abide by the legal requirements associated with these

- Users may download and print one copy of any publication from the public portal for the purpose of private study or research.

- You may not further distribute the material or use it for any profit-making activity or commercial gain

If the publication is distributed under the terms of Article $25 \mathrm{fa}$ of the Dutch Copyright Act, indicated by the "Taverne" license above, 


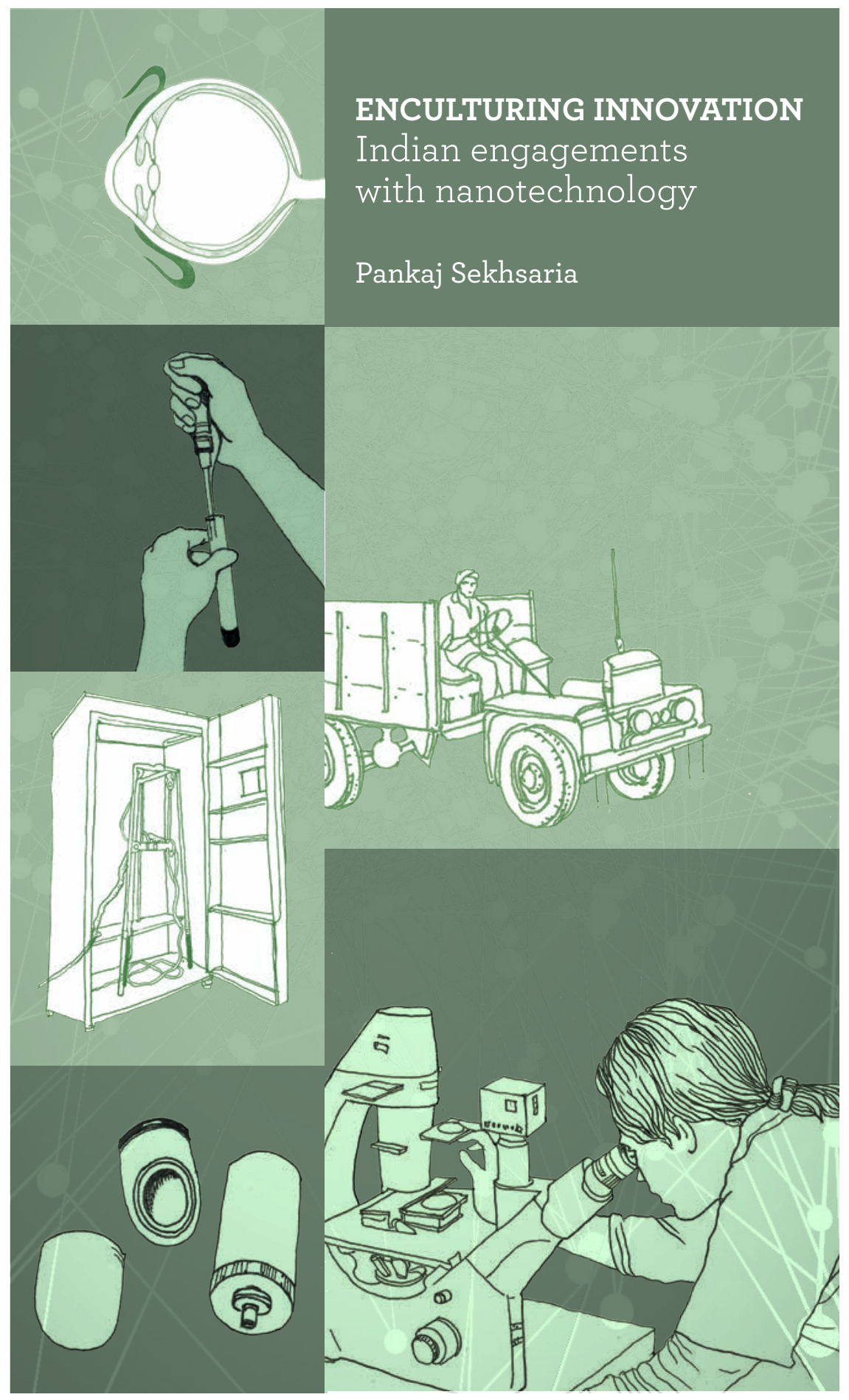




\section{Enculturing Innovation}

Indian engagements with nanotechnology

Pankaj Sekhsaria 
(C) 2016, Pankaj Sekhsaria, Maastricht, the Netherlands

All rights reserved.

Sekhsaria, Pankaj

Enculturing Innovation - Indian engagements with nanotechnology

Design \& Layout: Narendra Kulkarni

Cover Design: Charutha Reghunath

Printed at: K. Joshi Offset Printers, Pune 411030, India.

Production of this thesis has been supported by:

The Faculty of Arts and Social Sciences, Maastricht University

The Graduate School of Science Technology and Modern Culture (WTMC) 


\section{Enculturing Innovation \\ Indian engagements with nanotechnology}

\section{DISSERTATION}

to obtain the degree of Doctor at the Maastricht University, on the authority of the Rector Magnificus Prof. Dr. L.L.G. Soete in accordance with the decision of the Board of Deans, to be defended in public on Thursday, 10 March 2016 at 12:00 hrs.

Pankaj Sekhsaria 


\section{Supervisor}

Prof Dr. ir. W.E. Bijker

\section{Co-supervisors}

Dr. Aalok Khandekar

Dr. Ragna Zeiss

\section{Assessment Committee}

Prof. Dr. ir. Harro van Lente (Chair)

Dr. Jessica Mesman

Dr. Kornelia Konrad (University of Twente)

Prof. Dr. Sally Wyatt 
to

Annapurna, Wiebe and Latha

without whom this thesis would never have happened 



\section{Table of Contents}

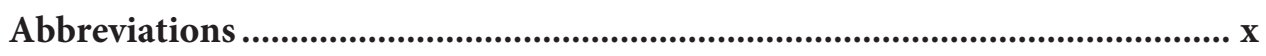

List of Images, Figures and Tables.................................................................. xiii

1 Setting the Stage ....................................................................

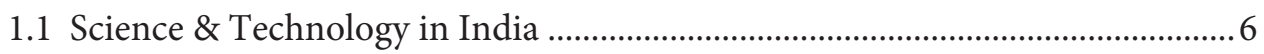

1.2 Nanotechnology - an overview..........................................................................13

1.3 Laboratory studies, culture of a laboratory, technological culture....................21

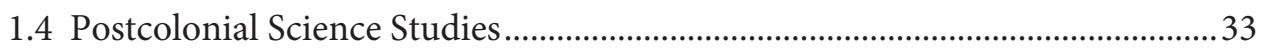

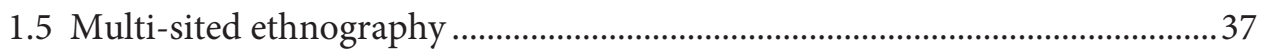

1.6 Chapter summaries......................................................................................... 40

2 What is innovation inside the laboratory? .....................................43

2.1 Evaluating the lab, evaluating what happens inside the lab ................................43

2.2 The Indian context - STIP 2013 ....................................................................... 45

2.3 Schumpeter's enduring legacy..........................................................................50

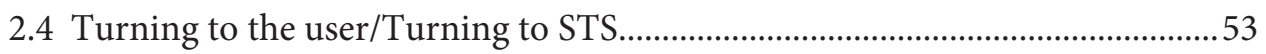

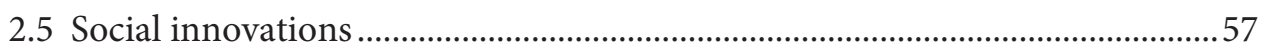

3 Technological jugaad: the making of an Indian Scanning Tunneling Microscope..........................................................................65

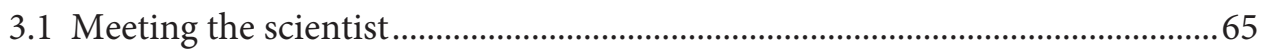

3.2 1986-2014: Dharmadhikari's STM journey........................................................69

3.3 Jugaad and its many avatars ...............................................................................

3.4 Technological jugaad that made the STM …………............................................. 81

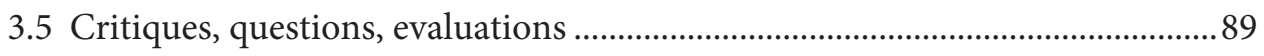

3.6 Characterising technological jugaad ...............................................................96

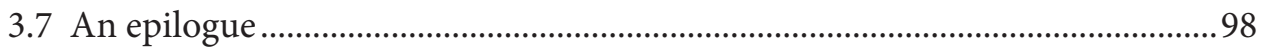


4 Collaborative explorations: different disciplines and worldviews in a nanobioscience lab................................................................103

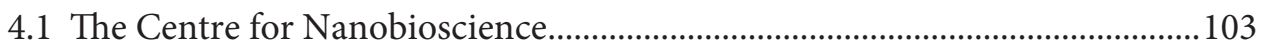

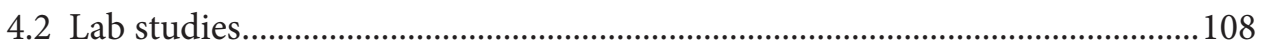

4.3 Individual responses to collaborative challenges...............................................112

4.4 A response from within the discipline/ A physicist in a biology lab .............116

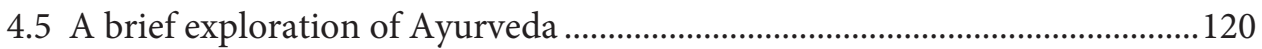

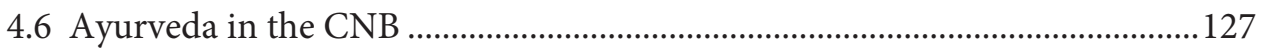

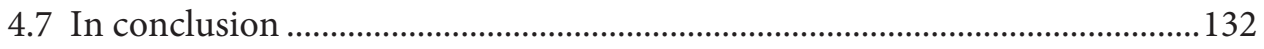

5 User's Matter: A low cost nano-silver option for water-purification .......................................................................... 135

5.1 Research and development at ARCI...............................................................135

5.2 The Social Construction of Technology..............................................................138

5.3 The challenge of clean water in India ................................................................... 141

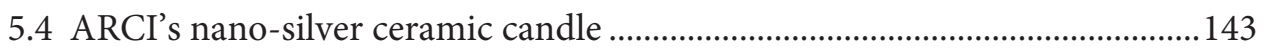

5.5 Social construction of the (water filter) failure ...................................................154

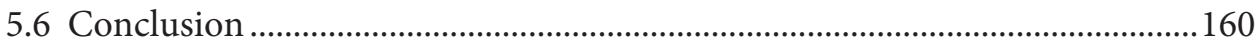

6 Reconfiguring subjectivities: Nanotechnology for the treatment of Retinoblastoma..................................................................................161

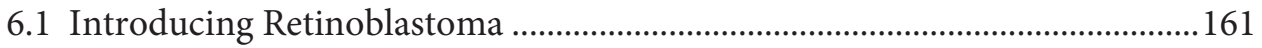

6.2 The Retinoblastoma-nanotechnology interface - the LVPEI story ................. 166

6.3 The girl as the disadvantaged child ...................................................................... 169

6.4 Responding to these challenges - the creation of the clinicianscientist-social activist ...................................................................................... 172

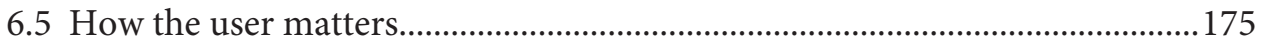

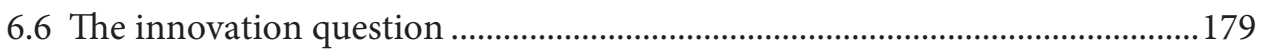


7 Conclusion: Enculturing nanotechnology, Enculturing Innovation .....................................................................181

7.1 Enculturing innovation: the six inter-related steps .........................................181

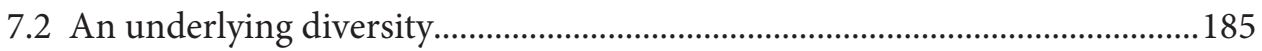

7.3 De-centred/De-centring Cultures of Innovation ...............................................189

\section{Annexures}

A) Photo feature: Scientists and their favourite instruments

B) Details of programmes supported and outputs generated from the DST supported NSTI and Nano Mission programs (2001-2011)

C) Conferences on Nanoscience and technology held in India in the year 2010 .

D) Some of the nanotechnology-based products commercialized by Indian SMEs/Institutions.

E) List of Interviews

Acknowledgements ........................................................................216

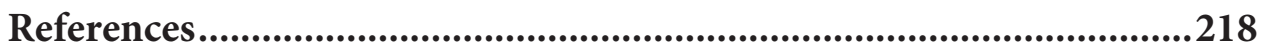

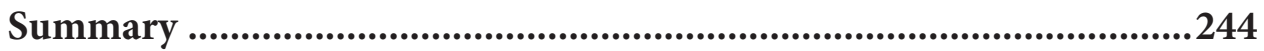

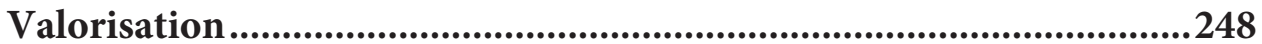

Curriculum Vitae ...................................................................252 


\section{Abbreviations}

AIIMS

ARI

ARCI

AFM

AYUSH

BAMS

CKMNT

C-MET

$\mathrm{CNB}$

CSIO

CSIR

DAE

DBT

DeITy

DOS

DRDO

DST

GoI

HIV

ICMR

ICONSAT

ICT

IISc

IISER

IIT

INMAS

ISO

ISRO

JNNURM
All India Institute of Medical Sciences

Agharkar Research Institute

International Advanced Centre for Powder-Metallurgy and New Materials

Atomic Force Microscope

Ayurveda, Unani, Siddha and Homeopathy

Bachelor's Degree in Ayurvedic Medicine and Surgery

Centre for Knowledge Management of Nanoscience and Technology

Centre for Materials for Electronics Technology

Centre for Nanobioscience

Central Scientific Instruments Organisation

Council for Scientific and Industrial Research

Department of Atomic Energy

Department of Biotechnology

Department of Electronics and Information Technology

Department of Space

Defence Research and Development Organisation

Department of Science and Technology

Government of India

Human immunodeficiency virus

Indian Council for Medical Research

International Conference on Nano Science and Technology

Information and Communication Technology

Indian Institute of Science

Indian Institute of Science Education and Research

Indian Institute of Technology

Institute of Nuclear Medicine and Allied Sciences

International Organisation for Standardization

Indian Space Research Organisation

Jawaharlal Nehru National Urban Renewal Mission 


$\begin{array}{ll}\text { LOD } & \text { Limit of Detection } \\ \text { LVPEI } & \text { LV Prasad Eye Institute } \\ \text { MD } & \text { Doctor of Medicine } \\ \text { MDGs } & \text { Millenium Development Goals } \\ \text { MIS } & \text { methyl isocynate } \\ \text { MIT } & \text { Ministry of Information Technology } \\ \text { MRI } & \text { Magnetic Resonance Imaging } \\ \text { MSc } & \text { Master of Science } \\ \text { MST } & \text { Ministry of Science and Technology } \\ \text { MTech } & \text { Master of Technology } \\ \text { NATAG } & \text { Nano Applications and Technology Advisory Group } \\ \text { NCRB } & \text { National Crime Records Bureau } \\ \text { NGO } & \text { Non Governmental Organisation } \\ \text { NMC } & \text { Nano Mission Council } \\ \text { NNI } & \text { National Nanotechnology Initiative } \\ \text { NPSM } & \text { National Programme on Smart Materials } \\ \text { NRL } & \text { Naval Research Laboratory } \\ \text { NS\&T } & \text { Nano Science and Technology } \\ \text { NSAG } & \text { Nano Science Advisory Group } \\ \text { NSTI } & \text { Nanoscience and Technology Initiative } \\ \text { NSTM } & \text { Nano-materials Science and Technology Mission } \\ \text { PAMAM } & \text { Poly (amido-amine) } \\ \text { PC } & \text { Planning Commission } \\ \text { PDMS } & \text { Polydimethyl siloxane } \\ \text { PoU } & \text { Point of Use } \\ \text { QD } & \text { Quantum Dot } \\ \text { R\&D } & \text { Research and Development } \\ \text { RSG } & \text { Relevant Social Group } \\ \text { S\&T } & \text { Science and Technology } \\ \text { SIPS } & \text { Special Incentive Package Scheme } \\ \text { SCOT } & \text { Social Construction of Technology } \\ \text { SDGs } & \text { Sustainable Development Goals } \\ \text { SGOT } & \text { Serum Glutamic Oxaloacetic Transaminase } \\ \text { NAT } & \end{array}$


SGPT

SHRISHTI Science, Research and Innovation System for High Technologyled path for India

STIP Science Technology and Innovation Policy

STM Scanning Tunneling Microscope

STS

TEM

TRSAS

UGC

$\mathrm{UN}$

UNESCO The United Nations Educational, Scientific and Cultural

USA

UV

XRD Organization

Science and Technology Studies

Transmission Electron Microscope

The Royal Swedish Academy of Sciences

University Grants Commission

United Nations

United States of America

Ultra Violet

X-Ray Diffraction 


\section{List of Images, Figures and Tables}

\section{Figures}

Figure 1:

The Nanoscale

Figure 2:

Reconfiguring the subjectivities of the user and the producer 178

\section{Tables}

Table 1:

Table 2:

The structure of the thesis

Top 10 proposed nanotechnology applications relevant for achieving the MDGs

Table 3:

A broad overview of NS\&T policy evolution in the Indian context

Table 4:

Illustrating the interpretive flexibility in the constitution of the water filter

\section{Images}

Image 1:

The International Conference on Nano Science and

Technology (ICONSAT-2010), IIT Bombay in February 201020

Image 2:

The Science Technology and Innovation Policy 2013

Image 3:

$200 \AA$ x $200 \AA$ Om on gold surface

Image 4:

$250 \AA$ x $250 \AA ̊$ 'STM' on gold surface

Image 5:

The Scanning Force Microscopy Laboratory

Image 6:

A work bench in the lab

Image 7:

A work bench in the lab

69

Image 8:

A model of the 1st STM built at IBM, Zurich

70

Image 9:

The 1st STM Meeting in Spain in 1986

72

Images 10, 11:

Image 12:

Two versions of the jugaad vehicle from North India

One of earliest STMs that was installed inside a refrigerator shell

Image 13: Using a bungee chord to help in additional vibration isolation

Image 14: A table top STM placed on the inflated tube of a car tyre for vibration isolation

Image 15: The experimental set up of the Ultra High Vacuum STM-AFM

Image 16: A picture from the $2006 \mathrm{PhD}$ thesis of SB Iyyer showing the STM set up

Image 17: Picture of experimental set up from SB Iyyer's $2006 \mathrm{PhD}$ dissertation

Image 18: $\quad$ CV Dharmadhikari with Sumati Patil, his last PhD student in the university 
Image 19: The dismantling of the STM laboratory - a July 2013 picture 100

Image 20: The Agharkar Research Institute 104

Image 21: The Centre for Nanobioscience 104

Image 22: Researchers in conversation in the corridor at the CNB 109

Image 23: The Meeting Room at the CNB 110

Image 24: A PDMS based micro-channel assembly, fabricated in house at the CNB 113

Image 25: Shailaja Agrawal working in the Laminar Flow 113

Image 26: A physicist in a biology lab: Dhananjay Bodas and Shailaja Agrawal 118

Image 27: The Puritech brand of nano-silver enabled ceramic candle water filter 136

Image 28: A cross-section of the nano-silver ceramic candle 136

Image 29: $\quad$ Certificate from Vimta Labs 146

Image 30: English poster for the Puritech Water Filter 149

Image 31: Information pamphlet about the Puritech Water Filter 149

Image 32: Telugu poster for the Puritech Water Filter 150

Image 33: Puritech poster on an auto rickshaw 150 
I first met Dr. M. Javed Ali, an ocular oncologist at the L.V. Prasad Eye Institute in the city of Hyderabad, in August 2010. It was a few months after I had begun my doctoral research project and I had come to ask him about his clinical and research practice, the challenges they faced and the innovations they were attempting in using nanotechnology to treat Retinoblastoma, a cancer of the eye of little children. Many things he told me that day were interesting and insightful, just as they were in the nearly 80 other interviews that I conducted at half a dozen institutions over the following three years. I choose, however, to begin with the following quote from Javed Ali's first interview because it goes straight to the heart of the challenges at hand even as it sets up the literal and metaphorical stage for the performance of this thesis:

Nano would alter the rate of removal of the eyes, because after some time when it is not responding, the only option is to remove the eye (...). With nano, those eyes (...) [can be] saved [and] it has a big implication even if (...) vision is not there (...). It has tremendous social implications because in this country if a girl child has an eye removed, however good she is, she cannot marry anybody who has two eyes, or who has two hands, or who has two legs. (...) For a girl child, to remove the eye, which we do (...) quite often in such situations, has enormous social implications - for her own life and then her trauma of facing (...) society and the trauma of her knowing that her parents cannot face this society (Javed Ali, Interview, 14 August 2010).

This was a clinician involved in a nanotechnology related research project in the laboratory, the 'clinician-scientist', and yet, as he spoke (and as the quote reveals), he sounded very much the social worker, even a social activist, dealing with a complex Indian reality of the girl child and of gender discrimination. Javed Ali gave me a number of examples during this and subsequent interactions where he had seen religious beliefs, medical malpractices, poverty of families and many such factors becoming impediments in the treatment of Retinoblastoma in both, boys and girls. What stood out, of course, was how the girl child was discriminated against. In a bad scenario the eye infected with Retinoblastoma would be removed completely. The child would be left one eyed, but there would be no more threat to her life. This the parents would not allow - they could not have a one-eyed girl because no one 
would marry her when she was of a marriageable age. They would rather let her die.

The details of what Javed Ali told me were heart rending at best and grotesque at worse, and I was struck by both, the content of what he was saying as also the intensity of his emotion. Together, they took me quickly into a completely unexpected domain - a valuable lesson that clinical practice, scientific research and innovation do not happen just in clinics and laboratories; that their footprints are much larger, their complexities much more subtle and multi-layered.

My interactions with Javed Ali and the others at LVPEI were an early reminder that an intervention, even if directed explicitly at a particular point, has manifestations and implications at many others. It suggested, as a corollary, that chances of success would be greater if those innovating and intervening were aware of, and engaged with the many-layered realities of the situation. If the parents refuse to bring the girl child for treatment what is the use of a technology and a cure that a clinic or a lab might have to offer? Was the clinician dealing with an infected eye or was he dealing with a complex social reality? How could one be separated from the other? The problem is as much social as it is technical; the solution lies as much in the clinic as it does in the laboratory and in the domains of law, culture, society and politics. Innovation, Javed Ali was telling me through his experience and through the empirics of his own practice, has to be multi-nodal, multi-layered and multi-scalar.

It was not an insight I understood immediately, but it was something I kept going back to during the entire course of my research project. This thesis, through the stories of the L.V. Prasad Eye Institute and the other laboratories I engaged with is, in a sense, an explication of this idea of innovation. Javed Ali had laid out the broad framework, albeit inadvertently, that my research then gradually filled in. It shows how techno-scientific knowledge practices are implicated within and influenced by the cultural, social and political systems and logics in which the laboratories and the scientists are located. It is, as the title indicates, an account of the 'enculturing of innovation' in India through ethnographies of the laboratory that engage with the science and technology of, at, and for the nano scale. It describes and interprets how people, their technical and social institutions and their combined practices influence and negotiate a particular technology in understanding it, using it and mobilizing it to achieve desired outcomes.

This dissertation responds to three broad questions with the overall endeavor being to understand of the 'cultures of innovation' in nanoscience and technology (NS\&T) in India:

1) What is the character of techno-scientific knowledge practices within Indian NS\&T laboratories? 
2) What is the role of scientific laboratories in processes of innovation in contemporary Indian contexts?

3) How are these to be understood within the broad political, social, cultural and developmental contexts of contemporary India?

The empirical material at the heart of this effort is a set of four case studies that explore the wide repertoire of contexts, sources, resources, people, ideas, materials, instruments and knowledge systems that the labs are engaging with and mobilizing in manifold ways. These labs exhibit significant similarities and overlaps with each other at the same time as they show distinct singularities. There are certain dimensions that unify, but much else that demonstrates variety, multiplicity and plurality. It is diversity that emerges as the central thread with each case study showing, in its own way, how the societal and cultural context and processes of socialization (Collins, 1987) lead to the enculturing of nanotechnology and of innovation. There is an implicit acceptance and accommodation, within the laboratories, of this diversity (also see A. Prasad, 2006, p. 226), and significant overlaps can be seen here with the insights gained from feminist studies of S\&T: that diversity is a resource and can help create robust and sustainable knowledge systems (cf. Harding, 1998).

Using the learnings from the empirical material and the diversity it points to, the thesis concludes with the following six inter-related steps of how and why innovation is encultured:

a) Innovation is an iterative, non-linear process where differently located social groups and actors, different knowledge systems and different ways of knowing and doing, all play an important role; it does not necessarily start with the producer and end with the consumer and neither does it begin with an invention that is discarded in the end as waste or obsolete.

b) Innovation has to be historically and culturally situated, even as we recognise that it endlessly transforms the different cultural logics that bring it into being in the first place.

c) The scientific laboratory is an important site of innovation.

d) Empirically and conceptually, innovation in the laboratory straddles different domains, and dominant metrics of citations, patents and commercialisation are insufficient to capture the depth, breadth and richness of the innovation processes.

e) Innovation in the laboratory is a multi-scalar process; the three scales that become obvious through the empirical material in the thesis are respectively, i) the micro (within the laboratory), ii) the institutional that gives rise to inter-disciplinarity and iii) the macro where social and cultural processes are inextricably inter-twined with the scientific and the technical.

f) Processes that allow wider participation are more likely to lead to successful innovations, particularly when S\&T is being increasingly 
mandated to find solutions that are directly needed and relevant in society.

While the title suggests that the thesis is about 'Enculturing Innovation', it is as much about innovation as already encultured. The title could well have been 'Encultured Innovation - Indian engagements with nanotechnology' because this is what the thesis is documenting. The narratives also explicate the details of what has already happened, of how the social and the cultural have already influenced research and innovation in the past. I choose, however, to use 'enculturing' to foreground the process by which this happens, the fact that it is continuous, dynamic and constantly adapting, and that it is iteratively influenced by and influencing what is inside the laboratory and around it as well.

Leading on from the enculturing of innovation inside the laboratory there are two salient insights this thesis offers: a) diversities within and between laboratories are reflective of the larger socio-political-cultural milieu within which the Indian S\&T system and the labs themselves are located, and b) different cultures of innovation exist in parallel, and acknowledging this multiplicity challenges the idea that only some ways of innovating or only one particular culture of innovation can be successful. I, therefore, characterize cultures of innovation as being de-centred in different ways.

There is, both, a challenge and an opportunity here with the larger normative implication being that this diversity and multiplicity is not an impediment but an asset that can be explicitly mobilized in our pursuit of knowledge and scientific understanding and for the solutions needed in society.

\section{The structure of the thesis}

Table 1: The Structure of the thesis

\begin{tabular}{|l|l|l|l|l|}
\hline $\begin{array}{l}\text { Case Study/The } \\
\text { Laboratories }\end{array}$ & $\begin{array}{l}\text { The STM story/ } \\
\text { Dept of Physics, } \\
\text { Pune University, } \\
\text { Pune }\end{array}$ & $\begin{array}{l}\text { In a } \\
\text { nanobioscience } \\
\text { lab/CNB, ARI, Pune }\end{array}$ & $\begin{array}{l}\text { Water } \\
\text { filters/ ARCI, } \\
\text { Hyderabad }\end{array}$ & $\begin{array}{l}\text { LVPEI, Hyderabad } \\
\text { \& SN, Chennai/ } \\
\text { Retinoblastoma } \\
\text { and the girl child }\end{array}$ \\
\hline Social context & $\begin{array}{l}\text { Resource } \\
\text { constrains }\end{array}$ & $\begin{array}{l}\text { Traditional } \\
\text { practices and } \\
\text { knowledge } \\
\text { systems }\end{array}$ & Social exigency & Patriarchy \\
\hline $\begin{array}{l}\text { Scale at which } \\
\text { innovation } \\
\text { happens }\end{array}$ & $\begin{array}{l}\text { Innovation in } \\
\text { the lab at the } \\
\text { micro level - lab } \\
\text { practices }\end{array}$ & $\begin{array}{l}\text { Innovation in and } \\
\text { around the lab at } \\
\text { the meso level - } \\
\text { organizational, } \\
\text { institutional, } \\
\text { interdisciplinary }\end{array}$ & $\begin{array}{l}\text { Innovation in } \\
\text { and around } \\
\text { the lab at the } \\
\text { interface with } \\
\text { society }\end{array}$ & $\begin{array}{l}\text { Innovation in } \\
\text { the lab and } \\
\text { simultaneously in } \\
\text { society }\end{array}$ \\
\hline $\begin{array}{l}\text { The conceptual } \\
\text { frame }\end{array}$ & $\begin{array}{l}\text { Technological } \\
\text { Jugaad }\end{array}$ & $\begin{array}{l}\text { Inter-epistemic } \\
\text { collaborations }\end{array}$ & Users matter & $\begin{array}{l}\text { Reconfigured } \\
\text { subjectivities }\end{array}$ \\
\hline
\end{tabular}


Each of the four case studies (Table 1) foreground one particular characteristic of Indian society: a) economic and material constraints - where a university lab takes the lead in developing indigenous Scanning Tunneling Microscopes in situations of severe resource constraints; b) traditional practices and knowledge systems scientists attempt an engagement of nanotechnology with the traditional practice of Ayurveda; c) drinking water as a fundamental exigency - the use of nano-silver based technologies for the development of water filters that are affordable to even the poorest in society and d) patriarchy and the disadvantaged girl child - where a team of clinician-scientists are forced to also become social activists as they seek a nanotechnology based treatment protocol for Retinoblastoma.

While the individual chapters explicate the linkage between NS\&T and the particular social reality, clustering of the different social realities across the chapters creates the broad umbrella of a socio-political-cultural-economic world within nanoscience and technology laboratories conduct their scientific research. The case studies also show that innovation in the laboratory happens at different levels depending on the specific mandates and intentions of the research. While some research is indeed remote from the immediate needs and concerns of the society within which it is located, there is other research in the lab that is specifically mandated towards intervention in society. In both the situations there is convincing evidence that what happens outside significantly influences what happens inside the laboratory. In the latter case, however, there is an additional demand and an added layer of complexity: it is not enough merely to innovate inside the laboratory - culture and society need to be simultaneously engaged with and be innovated if the desired outcomes are to be achieved. There is a resonance one can see here with Joan Fujimura's (1987, p. 258) conceptualization of the different levels of work organization in science: "the experiment as a set of tasks; the laboratory as a bundle of experiments and other tasks; and the social world as the work of laboratories, colleagues, sponsors and other players" This, in fact, is what stories from the laboratories in this thesis also illustrate quite explicitly.

Based on these, the bottom row in the table then highlights the key concept that I use to make sense of nanotechnology's engagement with each of these social realities as mediated through the different laboratories, their mandates and their lifeworlds. This is what is also reflected in the titles of the respective empirical chapters. Before going into the details of the case studies (Chapters 3-6), however, I shall use Chapter 1 to locate the empirics of my research work. In the next section in this chapter will first discuss the role and perception of science \& technology in the modern Indian state and present the current status of the nanotechnology landscape in the country. It is the fear of 'missing the nano bus' that has driven the interest in India and substantial investments have indeed been made by the state for research and development in this field. Interwoven into this narrative is an account of the development, the 
limitations and the challenges faced in India by the academic fields of the history and sociology of science. The key influences here have been the distinctively positivist understanding of science and technology by the establishment on the one hand and people's movements that have sought to challenge these perceptions on the other. The section that follows this discussion will deal with the broad idea of culture and within that, the 'culture of a laboratory' and also of 'technological culture'.

I then discuss the three other key conceptual and methodological frames that the thesis uses. The first is 'laboratory studies' where I will discuss the history of ethnographies in the lab and highlight some of the key insights that have been gained from these ethnographies, including that of the culture of a laboratory. I also make the case here for more ethnographic studies of the laboratory in India on account of the information and insights this can provide us of research practices and cultures. I will then discuss 'multi-sited ethnography', which has evolved as a response to the increased complexity in the world, and where an engagement with just one site is unable to provide a full understanding of the logics and structures through which systems are constituted. The final discussion will focus on 'postcolonial science and technology in India', where the postcolonial is much more than merely a temporal entity. It is a useful frame to help understand not just the developments of S\&T in India, but also the narratives of these developments themselves. Locating nanotechnology within this frame helps to understand and contextualize the multiple demands of history, the changing social-contract of S\&T, and of globalization that are being made in a contemporary context.

\subsection{Science \& Technology in India}

One way to understand the development of science \& technology (S\&T) in India would be to follow the narratives of their history as these are seen to be closely linked, even significantly influenced, by the different developments in S\&T (Chakrabarti, 2004; D. Raina, 2003). This history has been dependent, due to institutional configurations, on the institution of science itself (D. Raina, 2003 (also see Habib \& Raina, 2007)) and

tend[ed] to serve as an apology for science in India, both past and present (...) The object called science emerges, therefore, as a positivist given, and scientific activity as a pilgrimage of truth, both feeding into and feeding from the Nehruvian vision of science and technology as the vehicle of development (D. Raina, 2003, pp. 109, 116-117).

This, in Raina's analysis, is the reason why critical scholarship in the history or the sociology of science has failed to emerge in India (D. Raina, 2003, p. 117). The precursors of the state-science alliance that have characterized much 
of India's post independence history can be traced easily to the colonial period itself. One can also discern two significant watersheds in this post independence period. The 1st was in the 1980s - a response to the negative experiences of 'development' and the resultant public movements that catalyzed what some scholars have called the post-positivist phase (D. Raina, 2003). The 2 nd was seen in the early 1990s with the opening up of the Indian economy and the processes of globalization. These are the multiple and complex legacies of the past that nanotechnology has inherited and they will be part of the historical narratives that I explore in the following sections.

\section{Understanding histories}

Different scholars have used different axes to understand the history of S\&T in India. One prominent axis is temporal; the other epistemological, and both have a bearing on our understanding of nanotechnology today. While the temporal structuring helps us understand nanotechnology's genealogy at the same time as locating it in the contemporary context, the epistemological axis explores and classifies the nature of the encounter between western science and the local contexts in India - an element that is as salient today as it was in the 19th century.

Shiv Visvanathan (1985) has, for instance, identified three phases in the introduction of Western science in India - the Great Surveys of the late eighteenth century, the establishment of universities in the presidency towns of Calcutta, Bombay and Madras and the eventual rise of the industrial research laboratory. One might add a fourth, post 1990s phase, wherein science and the scientific laboratory have had to negotiate a world of rapid economic globalization at the same time as they've been key constituents of these very processes (V.V. Krishna, 2013). Dhruv Raina identifies, on broadly overlapping lines, the following four phases in the evolution of the studies of science in India: "British and French Orientalists studies of the sciences in India; pre-independence nationalist studies; the phase of post-colonial reconstruction (...) and the post positivist phase" (D. Raina, 2003, p. 20). Put together this indicates that the three most relevant frames that nanotechnology occupies today are respectively, the post-positivist, the post-colonial and one with globalisation at its centre. Each of these will be deliberated upon in the discussions that follow.

An illustrative example along the other, epistemological, axis is Pratik Chakrabarti's identification of four broad trends in the 19th century Indian involvement with science:

One identified the East as essentially spiritual and passive and the West as a materialist but superior civilization. The second attempted to locate modern Western thought within Indian tradition in order to establish the legitimacy of the latter. The third was a slow and cautious 
fusion of traditional art and Western thought towards the rejuvenation of native society. The fourth was the effort to reorganise traditional practices to counter the assault of an alien and hegemonic colonial system (Chakrabarti, 2004, p. 15).

Raina similarly offers four frames in the historical studies of science and technology in India: the nature of interaction between traditional forms of knowledge and new knowledge; the interplay between local cultural embodiments and structures of imperialism in the context of the politics of knowledge; the programmes of historical reconstruction in post-colonial societies that were driven by the desire to reclaim the "undistorted self" and the idea of scientific and technological knowledge as essential components of the historiography of modernity (D. Raina, 2003, p. 19).

The frames offered above either overlap or supplement each other and are clearly relevant for nanotechnology too. While Chakrabarti's engagement is with a 19th century situation, his analysis is applicable for a 21st century nanotechnology as well. The articulations and the challenges that are emerging, for instance, from Ayurveda's contemporary encounter with nanotechnology can be neatly mapped onto Chakrabarti's formulations and this will be illustrated in detail in Chapter 4 of the thesis. The relationship between traditional and new knowledge, the nature of post-colonial science and society and the imperatives of modernity - some of the themes that Raina discusses - are also very much part of the current debate and narrative of nanotechnology.

One also sees that the current narratives have deep historical roots and there are at least two issues that Raina (2003, p. 2) raises in this context. "Was the production of the history of sciences," he asks firstly, "a cultural activity intended to legitimate the assimilation of modern science within the rubric of the modern Indian state - both colonial and post-colonial?" He answers this in the positive using the illustration from the early years of the 20th century where "practicing scientists and scientist historians - [B.N. Seal (1915) with his focus on the inductive sciences, and P.C. Ray (Ray, 1902, 1907), from an experimentalist's perspective (D. Raina, 2003, p. 27)] - refashioned a nationalist historiography that fed into the nationalist movement, legitimated the assimilation of modern science, and resulted in the institutionalization of science in modern India" (D. Raina, 2003, p. 14). A group of these scientists working at the turn of the 19th century were at the vanguard of creating a modern scientific and technological research system in India. They occupy an important place in the narrative of the institutionalization of modern science in India on account of the challenge they had taken upon themselves - that of bridging the modern "science [that] they were pursuing and the [traditional] forms of knowledge that were part of cultural life of the region" (Habib \& Raina, 2007b, p. xxxi). A key effort, Raina argues, was to "challenge a hegemonic conception of the history of science, such 
that the history of sciences of the non-West would not be subordinate texts to the mainstream discourse of the history of Western science" (D. Raina, 2003, p. 2). Emerging from this analysis, Raina notes, are pointers to the (forging of) relationships between the nationalist movement, the emerging bonds between science and the modern state, the policy discourse, academic representations and images of science (p. 2). Chakrabarti $(2004$, p. 12) notes similarly that nationalism in India was closely intermeshed with "science, as the great denominator of nineteenth-century European knowledge".

The post World War II period, which is also the beginning of the postcolonial $^{1}$ era in India, was the period when science came to occupy a central place in contemporary culture around the world and to be considered ideologically transcendent. It allowed politicians who invested in science (and technology) to be seen as promoting no other ideology but that of development and modernization (D. Raina, 2003, pp. 33-34). This led to the emergence in India of "a strong politico-epistemological contract between the state and science catalyzed by a Bernalist-Nehruvian vision of science" (Varughese, 2014, p. 22). Led by Jawaharlal Nehru, the country's first Prime Minister, the creation of S\&T institutions, and the use and advancement of S\&T became central to the development and destiny discourse (N. Tyabji, 2011). This is well illustrated, for instance, in Nehru's inaugural address at the 34th Indian Science Congress held in Delhi in January 1947, a few months before independence:

I invite all of you who are present here, young men and old in the field of Science in India, to think in these terms of India's future and become crusaders for a rapid bettering of the 400 millions in India. (...) The first objective, it seems to me, from any point of view and more especially from the point of view of Science, is to help in the building of a free and self-reliant India. India today has made its mark in the world of Science, more especially in Theoretical Physics and some other departments also. We have done well when we have hardly tapped the talent in India. We have only scratched the barest surface of the Indian people, and yet have done tolerably well and now, when I think of what we can do, and will do no doubt, when we open the doors of opportunity to a large number of people in India, then the kind of picture I see rather overwhelms me. If we could tap, say even five per cent of the latent talent in India for scientific purposes, we would have a host of scientists in India (Nehru, 2003).

This was at the heart of what Amulya Reddy has referred to as the "Nehruvian dictum: more science and technology $\rightarrow$ more industrialization $\rightarrow$ less poverty" (A. Reddy, 2009b, p. 9), which in turn led to the creation of the "state scientist

1 I use 'postcolonial' in the temporal sense in this particular instance. For a discussion on the wider framing of the postcolonial see Section 1.4 of the thesis. 
- science workers whose larger goals and objectives were drawn from the imperatives of state needs" (Abraham, 2000, p. 169). It also catalyzed that "[initial] period of liberation (...) where India, like its Prime Minister, felt it had a tryst with the future (...) [that] 'belonged to those who made friends with science"' (Visvanathan \& Parmar, 2012, p. 35 (2002)). The belief in the power and capacity of S\&T for the progress of the country became one of the key features of the modern Indian state (GoI, 1958, 2003; MST, 2013; A. Reddy, 2009b) and is illustrated explicitly, for instance, in the Scientific Policy Resolution of 1958 (GoI, 1958), independent India's first such policy articulation:

The key to national prosperity, apart from the spirit of the people, lies, in the modern age, in the effective combination of three factors, technology, raw materials and capital, of which the first is perhaps the most important, since the creation and adoption of new scientific techniques can, in fact, make up for a deficiency in natural resources, and reduce the demands on capital. But technology can only grow out of the study of science and its application (...). Science has developed at an ever-increasing pace since the beginning of the century, so that the gap between the advanced and backward countries has widened more and more. It is only by adopting the most vigorous measures and by putting forward our utmost effort into the development of science that we can bridge the gap. It is an inherent obligation of a great country like India, with its traditions of scholarship and original thinking and its great cultural heritage, to participate fully in the march of science, which is probably mankind's greatest enterprise today (GoI, 1958).

Every Indian citizen has also been charged in the country's constitution ${ }^{2}$ with the responsibility of developing a "scientific temper" along with "humanism and the spirit of inquiry and reform". This, in the hope that it will bring about some reconciliation in a country characterized simultaneously by unfathomable poverty and disparities on the one hand and spectacular diversity and richness on the other.

Starting in the 1970s and early 1980s, a series of public movements ${ }^{3}$ highlighted these contradictions and the conflicts further by challenging the predominant idea of development, and raising important questions of the ideas of modernity and progress (D. Raina, 2003, p. 37; Varughese, 2014). While policy makers and a majority of the scientific community were (and still are)

2 Part IV-A, Article 51-A (h) in the 42nd amendment to the Indian Constitution, 1976.

3 Some of the more prominent among these include the Kerala Sastra Sahitya Parishad (Kerala Science Literary Movement) led people's science movement in the southern state of Kerala (Nanda, 2003; M. Zachariah \& Sooryamoorthy, 1994); the movement opposing the dams in the valley of the Narmada river in Central India (Sangvai, 2002) and also those arising from the gas leak disaster at Union Carbide's plant in Bhopal (Fortun, 2001; Hazarika, 1987; Jasanoff, 1994). 
committed to the technocratic image of S\&T in social transformation (cf. GoI, 2003; MST, 2013), scientists associated with social movements started to voice their opposition to this positivist conception of science. There was an increased acknowledgement of the complexity of issues and this went together with the acceptance of "science's inability to account for the technical, socio-economic and cultural consequences of the problems at hand" (Varughese, 2014, p. 22) (Also see (Nanda, 2003)).

The social studies of science that have emerged in India are on account of these engagements with politics and with the movements, and one wherein most researchers ended up treading a "tightrope strung between research and activism" (D. Raina, 2003, pp. 37-38). The following period, that Raina (2003, p. 38) refers to as the post-positivist phase, "has been marked by a quest for new (...) historiographies for studying the history of scientific and technological knowledge, [the quest for] alternative sciences" and also "by a moving away of emphasis from expert knowledge embodied in large scientific institutions to social movements contesting government legislation, wherein scientific or technological knowledge is implicated" (D. Raina, 2003, p. 43).

There has also been in India, as Abha Sur (2011, p. 28) summarises, "a view of science imbued with the promise of progress and enlightenment and an assertion of science as a value-neutral knowledge system; on the other hand, there are constructs of science as an essentially alien, violent, and hegemonic order." She points also to the existence of a parallel though linked discourse where, till recently, the history and philosophy of science in India, "has been conceptualized in two broad frameworks. One exalts tradition and sees the enterprise of science as a continuation of the colonial onslaught in India, violating indigenous scientific tradition and practices. The other rejects tradition as moribund and superstition and embraces modern science as a means of salvation out of the morass of economic and social stagnation" (Sur, 2011, p. 183).

What has characterized the landscape of S\&T in contemporary India is, indeed, a frame of strongly oppositional narratives. We have on the one hand Nehru's evocative and much repeated articulation that large dams (and all that they signify) were the temples of modern India (Bonner, 1990; Tiwari, 1987) - what Rohan D'Souza (2012b, p. 11) has called the "hagiographies about how modern technology controls or dominates nature for the triumph of human possibilities". We continue in India to live as much by that vision as by the equally powerful and evocative post-positivist phase narratives of the 'tombs of modern India' (D’Monte, 1985; S. Datta, 2013; Tiwari, 1987) that had also been referred to as "steam roller development" Raina (2003, p. 3). This is a narrative born out of the many disruptive and violent experiences created from the womb of modern S\&T, best illustrated in the millions of displaced lives and livelihoods in big dam submergences, mining projects and industrial expansion (I. Munshi, 2012; Sangvai, 2002; N. Tyabji, 2011; Visvanathan \& Parmar, 
2012 (2002); Visvanathan, 2001) and the nightmare that was Bhopal $1984^{4}$ one of the world's largest industrial disasters (Fortun, 2001; Hazarika, 1987; Sathyamala \& Jayaprakash, 2012; B. Sharma, 2006). Amit Prasad (A. Prasad, 2006) notes that one of the key concerns of STS and science studies scholars in India like J.P.S. Uberoi (J.P.S. Uberoi, 1984), Ashis Nandy (Nandy, 1995) and Shiv Visvanathan (Visvanathan, 1997) has been this violence, which according to them is intrinsic to modern science. It is a concern that has prompted them to articulate the idea of the "alternative sciences that are non-dualist and without the [violent] characteristics of modern science" (A. Prasad, 2006, p. 220).

These hagiographies and the counter-narratives have indeed been an integral part of my education as well; first the hagiographies inside school and the university, followed by the opposing narratives in the ensuing two decades that I have now spent outside the education system. There is no denying, for instance, the fact that modern S\&T has played and continues to play an important role in the marginalization of traditional knowledge systems. Yet, that is not what this modern S\&T is only about and as Chapter 4 of the thesis will show, there is an interesting conversation being attempted in some laboratories between modern nanotechnology and traditional Ayurveda. There is a set of scientists, for instance, who articulate their intention as one that seeks to use nanotechnology to bring back to Ayurveda a larger acceptance if not its past glory. One may not fully understand or even agree with this postulation, but it offers an intersection for conversations and explorations that are not characterized by the polarities mentioned above. While one might also accept that modern S\&T is violent and hegemonic, there is no denying that there are deep rooted prejudices, violations and violence embedded in the traditional structures of Indian society as well - women are still burnt for not getting enough dowry in their marriages and as I will discuss in Chapter 6, families would rather let their little infant die because a one-eyed girl is an unacceptable liability in her youth. It cannot be, therefore, that all tradition and cultural practices are good and desirable, and that modern S\&T is all violent and destructive. There is a large middle space that exists between the two polarities, a space that has not been given the attention it needs and deserves.

There are two things in the above discussion that are important for this thesis: first, that the dominance of the positivist image of S\&T has prevented the emergence of critical scholarship in the history and social studies of science in the Indian academy; and second, that the social studies of science that did indeed emerge were from an engagement with politics and social movements that were often in opposition to the state and to the scientific establishment. Together

4 Estimates of how many people died in the accident and its aftermath vary from between 5,000 and 20,000 people. At least half a million people are estimated to have been exposed to the poisonous gas, methyl isocynate (MIC) that leaked from the Union Carbide plant on the night of 2-3 December 1984, and the impacts and the fallout continue to be seen even today. 
they provide an important insight into the polarized nature of the debates and discourses in India around science, technology, education and development. The narratives are, as we have seen, historically and socially contingent, and they have played an important role in the constitution of the contemporary S\&T landscape of which nanotechnology is now an integral part.

The intensity and dominance of these narratives, I would like to argue, have also had another important consequence. This is linked to a third point that emerges from the two mentioned above and one that becomes immediately relevant for the thesis and its methodologies. Dhruv Raina (2003, p. 121) has noted that there has been a "gross neglect of the history of techniques and technology" in the Indian context and this, he argues, is a result of the "fixation for the mixed sciences or textual reading of science" and the continued ideological representation of technology as applied science, or even a lower kind of knowledge. There is also, as Amit Prasad (2006, p. 219) notes, "a surfeit of academic analyses of science as well as government policy documents on scientific research in India, but these provide little insight into how particular techno-scientific researches are conducted in India".

There is a deficit here in the efforts at entering the black boxes of science and technology to understand the techno-scientific practices and research. There are only few studies of the intersections of the many worlds within science \& technology on the one hand and of society's complex interfaces with this science $\&$ technology on the other. A vast space outside of the oppositions, debates and contestations remains uncharted and this is the space this thesis seeks to work in by exploring the gradations and the nuances of these otherwise large and largely un-probed terrains. The field of empirical engagement in this particular instance is that of nanoscience and technology and that is the arena I explore in the following section.

\subsection{Nanotechnology - an overview}

Understandings and definitions of nanotechnology are not all uniform. According to an UNESCO document (UNESCO, 2006, p. 5) (Figure 1): "the simplest and broadest definition is that nanotechnology is research conducted at the nanoscale $\left(10^{-9}\right.$ metres, one billionth of a meter. For reference a human hair is roughly 20,000 nanometers in diameter)." One of the more popular definitions of nanotechnology is the one proposed by the United States of America National Nanotechnology Initiative (NNI, 2001):

Nanotechnology is the understanding and control of matter at the dimensions between approximately 1 and 100 nanometers, where unique phenomena enable novel applications. Encompassing nanoscale science, engineering and technology, nanotechnology involves imaging, measuring, modeling and manipulating matter at this length scale. 


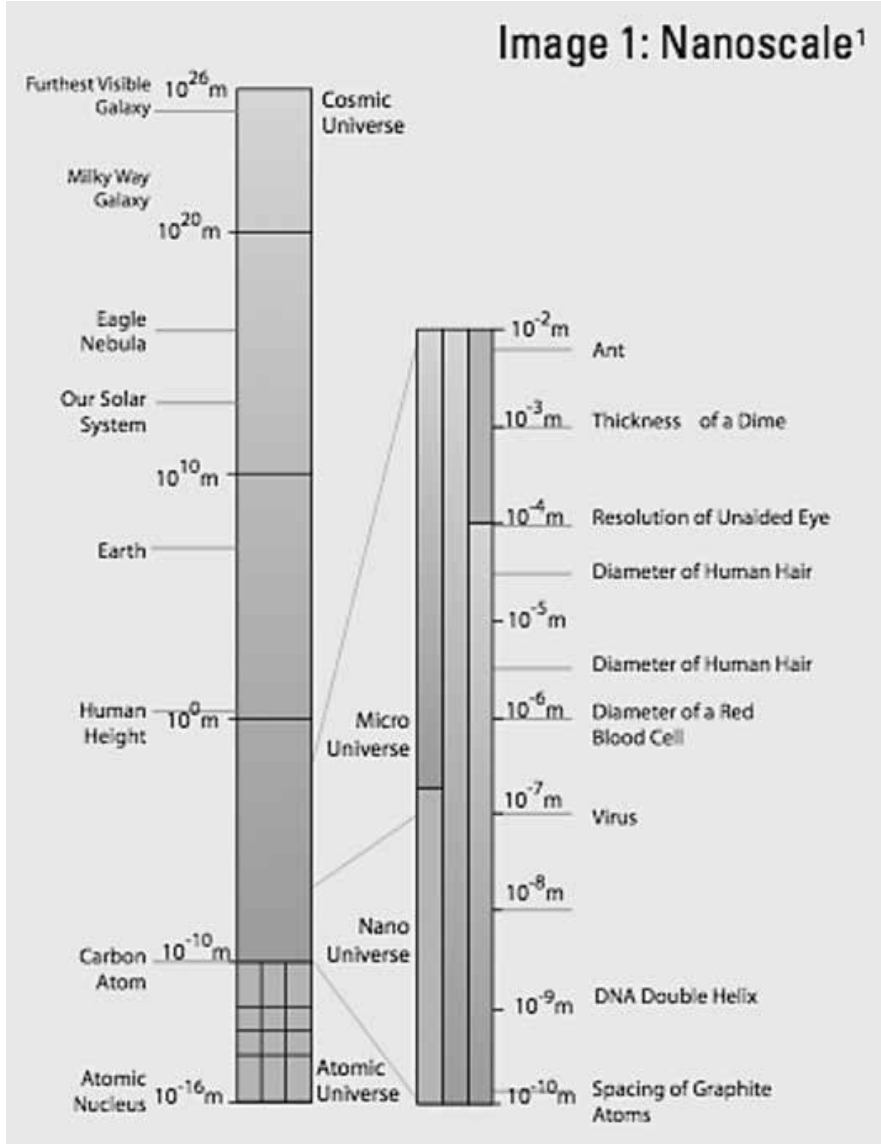

Figure 1: The Nanoscale (UNESCO, 2006)

These variations ${ }^{5}$ are, in fact, an important characteristic of emerging fields in S\&T and it has been argued that this "is a good indication that nanotechnology (like other emerging sciences such as biotechnology) will likely confuse the settled categories of pure and applied research and of publicly and privately funded research" (UNESCO, 2006, p. 4).

With prospective applications in diverse arenas such as health, drug delivery, food processing, water purification, electronics, information and communication technology, energy, food and agriculture (Barker et al., 2005; Hassan, 2005; UN, 2005), nanotechnology is seen as being the next "transformative technology comparable to the steam engine in the 18th century, electricity in the 20th century and the Internet in contemporary society" (Hassan, 2005, p. 65). It was even assigned an explicit role, for instance, in achieving the United Nations

5 See Palmberg, Dernis \& Miguet (2009, p. 19) for a listing of the different definitions of nanotechnology such as those used in Japan and by institutions like the European Union 7th Framework Program, the European Patent Office and the ISO. 
Millennium Development Goals (MDGs) ${ }^{6}$, one of the most important of which was to halve extreme poverty in the world by the year 2015 (UN, 2005). (See Table 2 for a listing of the top 10 proposed nanotechnology applications relevant for achieving the MDGs).

While some movement has been made towards achieving these MDGs (SSD, 2015; UN, 2015), there is little to be said for nanotechnology's contributions. This was already visible even a decade ago when the report of the UN Millennium project report of 2005 itself discussed the influence of platform technologies ${ }^{7}$ beyond 2015: "The Goal timeline of 2015 is but the first step in the long march to sustainability in this century. Beyond 2015 the impacts of these platform technologies will be even more marked" (UN, 2005, p. 75, emphasis added). This conclusion immediately follows the section in the report that talks in detail (over five pages) of the various promises and possibilities offered by nanotechnology for achieving the MDGs: "Nanotechnology may have a significant impact on all areas of human endeavor" (p. 71); "Nanotechnology can contribute new tools with which to address sustainable development problems" (p. 71); "Costeffective agricultural applications of nanotechnology could decrease malnutrition, and childhood mortality" (p. 72); "Applications of nanotechnologies addressing health in developing countries are especially promising" (p. 72) (all emphasis added).

The focus, clearly, is on the promises and what 'maybe' possible in the future, and not on what has already been delivered - a reflection that "characterisations of nanotechnology have long occupied the space of the future, as in future benefits, future uses, and future scientific discoveries that might lead to a new world order" (Selin, 2007, p. 198). The rhetoric has been so strong and the expectations generated so promising, that countries across the globe have committed significant resources for research and development in NS\&T. Funding of NS\&T research by governments world wide is reported to have increased from US\$ 377 million (approx. Rs. ${ }^{8}$ 1,885 crores; Euros 315 million $^{9}$ ) in 1997 to more

6 The eight MDGs are (1) Eradicate extreme poverty and hunger; (2) Achieve universal primary education; (3) Promote gender equality and empower women; (4) Reduce child mortality; (5) Improve maternal health; (6) Combat HIV/AIDS, malaria and other diseases; (7) Ensure environmental sustainability and (8) Develop a Global Partnership for Development.

The MDGs have now been replaced by the sustainable development goals (SDGs), a new, universal set of 17 goals, targets and indicators that UN member states will be expected to use to frame their agendas and political policies over the next 15 years ("Sustainable development goals: all you need to know," 2015).

7 Platform technologies in the UN report include Information and Communication Technology (ICT), biotechnology, nanotechnology, and new materials... whose combined impacts are expected to have profound implications for long-term economic transformation (UN, 2005, p. 47).

81 US\$ = Rs. 50; 1 Euro = Rs. 60. By the time I was finishing my research and writing this thesis in mid-2015, the value of the US Dollar had jumped to about Rs. 64 and that of the Euro to Rs. 72. In the thesis, however, I use the earlier mentioned values of Rs. 50 and Rs. 60 respectively. 10 million $=1$ crore. 
Table 2: Top 10 proposed nanotechnology applications relevant for achieving the MDGs (SalamancaBuentello et al., 2005)

\begin{tabular}{|c|c|c|}
\hline No. & Applications & Examples \\
\hline 1 & $\begin{array}{l}\text { Energy } \\
\text { storage, } \\
\text { production, } \\
\text { and } \\
\text { conversion }\end{array}$ & $\begin{array}{l}\text { - Novel hydrogen storage systems based on carbon nanotubes and other } \\
\text { lightweight nanomaterials } \\
\text { - Photovoltaic cells and organic light-emitting devices based on quantum dots } \\
\text { - Carbon nanotubes in composite film coatings for solar cells } \\
\text { - Nanocatalysts for hydrogen generation } \\
\text { - Hybrid protein-polymer biomimetic membranes }\end{array}$ \\
\hline 2 & $\begin{array}{l}\text { Agricultural } \\
\text { productivity } \\
\text { enhancement }\end{array}$ & $\begin{array}{l}\text { - Nanoporous zeolites for slow-release and efficient dosage of water and } \\
\text { fertilisers for plants, and of nutrients and drugs for livestock } \\
\text { - Nanocapsules for herbicide delivery } \\
\text { - Nanosensors for soil quality and for plant health monitoring } \\
\text { - Nanomagnets for removal of soil contaminants }\end{array}$ \\
\hline 3 & $\begin{array}{l}\text { Water } \\
\text { treatment and } \\
\text { remediation }\end{array}$ & $\begin{array}{l}\text { - Nanomembranes for water purification, desalination, and detoxification } \\
\text { - Nanosensors for the detection of contaminants and pathogens } \\
\text { - Nanoporous zeolites, nanoporous polymers, and attapulgite clays for water } \\
\text { purification } \\
\text { - Magnetic nanoparticles for water treatment and remediation } \\
\text { - } \mathrm{TiO}_{2} \text { nanoparticles for the catalytic degradation of water pollutants }\end{array}$ \\
\hline 4 & $\begin{array}{l}\text { Disease } \\
\text { diagnosis and } \\
\text { screening }\end{array}$ & $\begin{array}{l}\text { - Nanoliter systems (Lab-on-a-chip) } \\
\text { - Nanosensor arrays based on carbon nanotubes } \\
\text { - Quantum dots for disease diagnosis } \\
\text { - Magnetic nanoparticles as nanosensors } \\
\text { - Antibody-dendrimer conjugates for diagnosis of HIV-1 and cancer } \\
\text { - Nanowire and nanobelt nanosensors for disease diagnosis } \\
\text { - Nanoparticles as medical image enhancers }\end{array}$ \\
\hline 5 & $\begin{array}{l}\text { Drug delivery } \\
\text { systems }\end{array}$ & $\begin{array}{l}\text { - Nanocapsules, liposomes, dendrimers, buckyballs, nanobiomagnets, and } \\
\text { attapulgite clays for slow and sustained drug release systems }\end{array}$ \\
\hline 6 & $\begin{array}{l}\text { Food } \\
\text { processing } \\
\text { and storage }\end{array}$ & $\begin{array}{l}\text { - Nanocomposites for plastic film coatings used in food packaging } \\
\text { - Antimicrobial nanoemulsions for applications in decontamination of food } \\
\text { equipment, packaging, or food } \\
\text { - Nanotechnology-based antigen detecting biosensors for identification of } \\
\text { pathogen contamination }\end{array}$ \\
\hline 7 & $\begin{array}{l}\text { Air pollution } \\
\text { and } \\
\text { remediation }\end{array}$ & $\begin{array}{l}\text { - } \mathrm{TiO}_{2} \text { nanoparticle-based photo catalytic degradation of air pollutants in self- } \\
\text { cleaning systems } \\
\text { - Nanocatalysts for more efficient, cheaper, and better-controlled catalytic } \\
\text { converters } \\
\text { - Nanosensors for detection of toxic materials and leaks } \\
\text { - Gas separation nanodevices }\end{array}$ \\
\hline 8 & Construction & $\begin{array}{l}\text { - Nanomolecular structures to make asphalt and concrete more robust to } \\
\text { water seepage } \\
\text { - Heat-resistant nanomaterials to block ultraviolet and infrared radiation } \\
\text { - Nanomaterials for cheaper and durable housing, surfaces, coatings, glues, } \\
\text { concrete, and heat and light exclusion } \\
\text { - Self-cleaning surfaces (e.g., windows, mirrors, toilets) with bioactive coatings }\end{array}$ \\
\hline 9 & $\begin{array}{l}\text { Health } \\
\text { monitoring }\end{array}$ & $\begin{array}{l}\text { - Nanotubes and nanoparticles for glucose, } \mathrm{CO}_{2} \text {, and cholesterol sensors and } \\
\text { for in-situ monitoring of homeostasis }\end{array}$ \\
\hline 10 & $\begin{array}{l}\text { Vector and } \\
\text { pest detection } \\
\text { and control }\end{array}$ & $\begin{array}{l}\text { - Nanosensors for pest detection } \\
\text { - Nanoparticles for new pesticides, insecticides, and insect repellents }\end{array}$ \\
\hline
\end{tabular}


than US\$ 5700 million (approx. Rs. 28,500 crores; Euros 4,750 million) in the year 2006 (ETC, 2008). Cientifica (2011) has estimated that the total money spent for NS\&T research by governments, corporations and other forms of private investment would be nearly a quarter of a trillion US dollars by the year 2015 . This trend is visible not just in richer countries of the world such as in Europe, the USA, Japan, Australia and Singapore but also prominently in countries like India, Brazil, China, Iran and South Africa (Amit Kumar, 2014; Palmberg, Dernis, \& Miguet, 2009). The belief and the articulation, in India certainly, has been that nanotechnology will bring significant benefits to large sections of the population in key development related sectors such as health, water, and energy (S Kulkarni, 2012; CNR Rao, 2011; Subba Rao, 2006).

\section{Nanotechnology in India}

India's case, driven to an extent by the fear that the 'nano bus' will otherwise be missed (Beumer \& Bhattacharya, 2013; "India in danger of missing 'nano bus': PM's Scientific advisor," 2011), is illustrative. The Government of India (GoI) launched a Nano Science and Technology Initiative (NSTI) in the year 2001-02 through its Department of Science and Technology (DST). An estimated Rs. 125 crore (approx. Euros 21 million) were spent as part of the initiative for the period 2002-2007 (Asthana, 2011) ${ }^{10}$. This was followed by a much larger program called NanoMission ${ }^{11}$ where the government committed (again through the DST) an unprecedented Rs. 1,000 crores (approx. Euros 168 million) for research in NS\&T for a five year period starting May 2007 (Asthana, 2011; DST, 2007). An extended Phase 2 of NanoMission was subsequently approved in 2012 with a budgetary allocation of Rs. 650 crores (PIB, 2014) (See Table 3 for a broad overview of NS\&T policy evolution in the Indian context).

The flagship NanoMission is steered by a Nano Mission Council (NMC) that is chaired by CNR Rao, a prominent scientist who has been the Chief Scientific Advisor to the Prime Minister of India. The technical programmes are guided by two advisory groups - the Nano Science Advisory Group (NSAG) and the Nano Applications and Technology Advisory Group (NATAG). The primary objectives of the NanoMission include infrastructure development for N\&ST research; promoting public-private partnerships and nano applications and technology development centres; human resource development; international collaborations and nurturing academia-industry partnerships (DST, 2008; Amit Kumar, 2014).

This concerted focus and availability of resources has generated substantial interest and activity in the field of NS\&T research in the country. The DST, in line with the objectives of NanoMission, took up a number of initiatives

10 According to Bhattacharya et al. (2012) Rs. 60 crore (Euros 10 million) had been allocated for the NSTI.

11 For more details see the NanoMission website: www.nanomission.gov.in 
Table 3: A broad overview of NS\&T policy evolution in the Indian context (Adapted from Kumar (2014))

\begin{tabular}{|c|c|}
\hline Year & Key points \\
\hline 1997 & $\begin{array}{l}\text { The committee on Emerging Technologies set up by the Department of Science and } \\
\text { Technology (DST) to fund research for three years. The Science and Engineering } \\
\text { Research Council also initiated a program on nanocrystalline material }\end{array}$ \\
\hline 1998 & $\begin{array}{l}\text { The 9th Five Year Plan (1998-2002) document of the Planning Commission, Government } \\
\text { of India, highlighted the creation of national facilities and core groups to promote } \\
\text { research in frontier areas of S\&T including superconductivity, robotics, neurosciences } \\
\text { and carbon and nano materials (Gol, 1998) }\end{array}$ \\
\hline 2000 & $\begin{array}{l}\text { The National Programme on Smart Materials (NPSM), a five year programme with } \\
\text { a budgetary allocation of Rs. } 90 \text { crore, was launched jointly by five government } \\
\text { departments, viz. Defence Research and Development Organisation (DRDO), Council of } \\
\text { Scientific and Industrial Research (CSIR), Department of Space (DoS), DST and Ministry } \\
\text { of Information Technology (MIT) in the year 2000. }\end{array}$ \\
\hline $\begin{array}{l}2000- \\
01\end{array}$ & $\begin{array}{l}\text { Special initiative by the Department of Science and Technology (DST) to generate and } \\
\text { support end-to-end processes, products and technologies involving nanomaterials. This } \\
\text { was followed in } 2001 \text { by the setting up of an 'Nanomaterials: Sciences and Devices' } \\
\text { Expert Group (DST, 2001) }\end{array}$ \\
\hline 2001 & $\begin{array}{l}\text { The need for a Nano-materials Science and Technology Mission (NSTM) was identified } \\
\text { and proposed for the 10th Five Year Plan (2002-07) period. A strategy paper was } \\
\text { created by the DST for supporting long term basic research and application oriented } \\
\text { programmes in nanomaterials (DST, 2001; Gol, 2002) }\end{array}$ \\
\hline 2001 & $\begin{array}{l}\text { Launch under the aegis of the DST, of the National Nanoscience and Nanotechnology } \\
\text { Initiative (NSTI) with the motive of creating research infrastructure and promoting basic } \\
\text { research in nanoscience and technology (Asthana, 2011) }\end{array}$ \\
\hline 2004 & $\begin{array}{l}\text { Nanotechnology Development program initiated by the Department of Electronics and } \\
\text { Information Technology (DelTy) to create infrastructure and promote basic research in } \\
\text { nanoelectronics and nanometrology }\end{array}$ \\
\hline 2007 & $\begin{array}{l}\text { A Special Incentive Package Scheme (SIPS) launched by DelTy for the semiconductor } \\
\text { fabrication and micro and nanotechnology manufacture industry. }\end{array}$ \\
\hline 2007 & Programme on nanobiotechnology introduced by the Department of Biotechnology \\
\hline 2007 & $\begin{array}{l}\text { Launch of the Nano Science and Technology Mission (NanoMission) under the aegis of } \\
\text { the DST, to foster, promote and develop nanoscience and nanotechnology to benefit } \\
\text { the country. Rs. 1,000 crores were earmarked as the budget for the mission for the 11th } \\
\text { Five Year Plan period of 2007-2011 (Gol, 2007) }\end{array}$ \\
\hline 2012 & A Nanoelectronics Innovation Council set up by the DelTy \\
\hline 2012 & $\begin{array}{l}\text { Approval in the 12th Five Year Plan (2012-17) for Phase II of NanoMission with a budget } \\
\text { allocation of Rs. } 650 \text { crores (PIB, 2014). }\end{array}$ \\
\hline
\end{tabular}

which includes, among others, the funding of nearly 250 research projects for the ten year period from 2001 to 2011, helping establish Master of Science (MSc) and Master of Technology (MTech) programs in nanotechnology in a number of institutions, supporting the creation of more than a dozen 'Units and Centres of Excellence' in NS\&T in different parts of the country, creating the 
Institute of Nanoscience and Technology in Mohali in North India, orchestrating national dialogues, synergizing of R\&D efforts, facilitating academia-industry collaborations and also facilitating international interactions such as the biannual International Conference of Nano Science and Technology (ICONSAT) (Asthana, 2011) (For an overview see Annexure B). ${ }^{12}$

A number of other central government institutions - the Department of Electronics and Information Technology (DeITy), Department of Biotechnology (DBT), Council for Scientific and Industrial Research (CSIR), Defence Research and Development Organisation (DRDO), Indian Council for Medical Research (ICMR), Indian Space Research Organisation (ISRO) and the Department of Atomic Energy (DAE) - have also independantly invested substantial resources in NS\&T research in the last decade (Bhattacharya, Pushkaran, Shilpa, \& Bhati, 2012). The DBT, for instance, has been supporting work in the area of nanobiotechnology R\&D with a focus on applications in the fields of food/ agriculture, animal husbandry, environmental management, healthcare and allied areas like bioengineering and water filtration (DBT, 2008; Amit Kumar, 2014). The DeITy has established Centres for Materials for Electronics Technology (C-MET) in Pune, Hyderabad and Thrissur for R\&D involving nanomaterials. The department also invested a total of US $\$ 100$ million in nanoelectronics R\&D for the period 2004-2011 and set up a Nanoelectronics Innovation Council in 2012 (Amit Kumar, 2014) (also see Table 3).

The number of NS\&T related publications by Indian scientists has also increased steadily - from 355 in 2001, to 1413 in 2006, to 4911 in 2012 (Purushotham, 2013). In 2011, India was ranked 6th in terms of its global contribution to NS\&T publications (6\% of global output), a significant improvement from its 13 th rank in 2000 when its contribution was $2 \%$ of the global output. International patent applications in nanotechnology by Indian assignees too have increased correspondingly - from seven in the year 2001 to 32 in 2006, to 114 in 2010 (Asthana, 2011; Bhattacharya, Shilpa, \& Pushkaran, 2012). ${ }^{13}$

The popularity of the field can be also be ascertained from the increasing number of conferences, workshops and seminars that are being held in India (See Annexure $\mathrm{C}$ for a listing of NS\&T related conferences and seminars held in India in the year 2010). An overview of the International Conference on Nano Science and Technology - 2010 (ICONSAT-2010) that was held at the Indian Institute of Technology (IIT) - Bombay, in February $2010^{14}$ (Image 1) is also instructive of this popularity. The organizers received nearly 1100 abstracts, mostly from students, 90\% of whom were from within India (Anon, 2010).

12 For a detailed listing of projects funded by NanoMission see www.nanomission.gov.in

13 For a more detailed bibliometric analysis related to Indian NS\&T publications, citations and patenting see Patel and Chander (2012); Bhattacharya et al. (2012) and Patel (2012).

14 I attended the conference as an observer. 


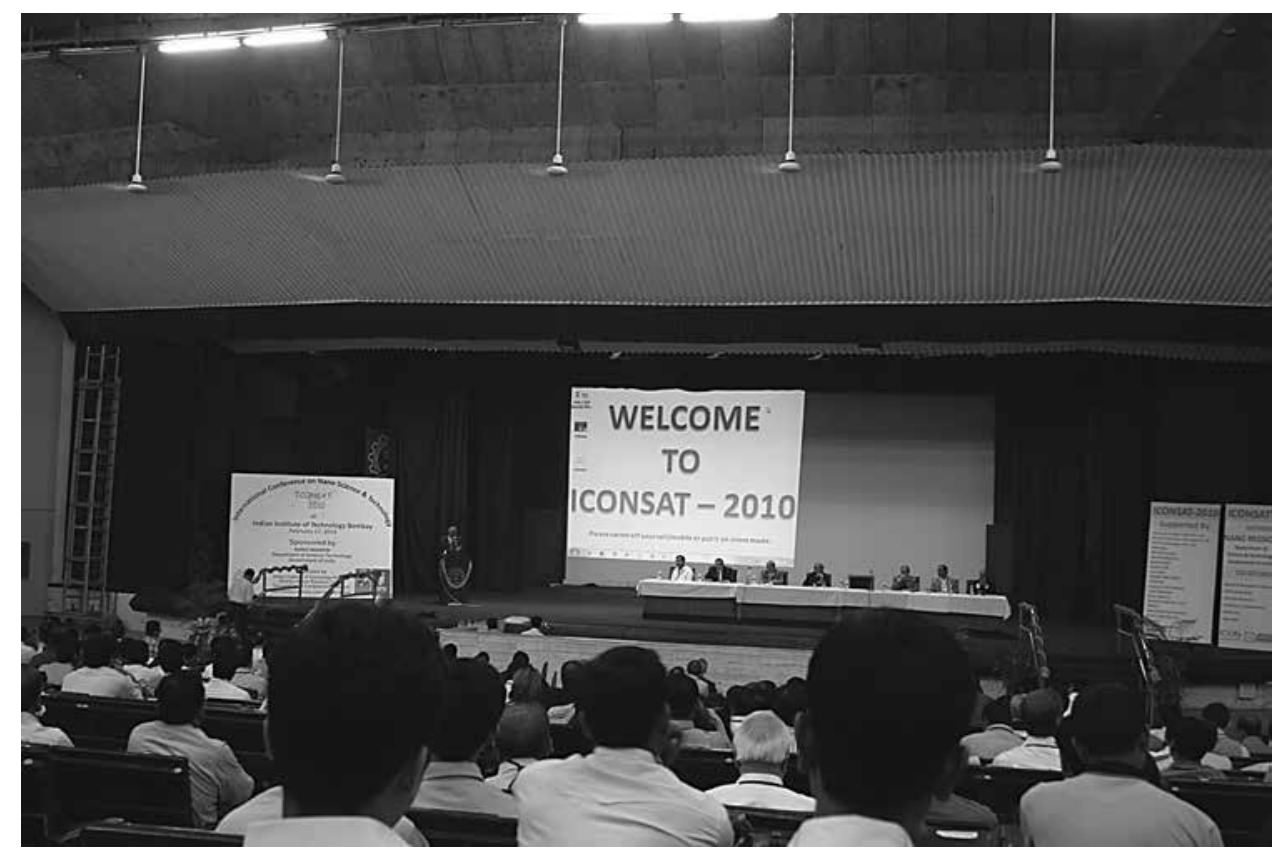

Image 1: The International Conference on Nano Science and Technology (ICONSAT-2010) that was held at IIT Bombay in February 2010 (Pic: Author)

There are now also two (non academic) periodicals that are devoted exclusively to issues of NS\&T: Nano Digest ${ }^{15}$ which was started in 2009 and is privately published and Nanotech Insights ${ }^{16}$ that was started in 2010 by the Centre for Knowledge Management of Nanoscience and Technology (CKMNT) which was set up with partial financial support from NanoMission. An increasing interest is to be seen in industry as well - Purushotham (2012) estimates that there are at least 500 companies (100 being in the area of pharma/nano biopharma) that are working on nanotechnology and related products, and that about 50 companies have already commercalized such products (see Annexure $\mathrm{D}$ for a detailed listing).

One important detail in the policy context here is related to the funding that has been made available. Of the Rs. 1,000 crores allocated for NS\&T research and development when NanoMission began in 2007, nearly 50\% (Rs. 500 crores; approx. Euros 84 million) had not been spent when the first phase of the program came to a close in May 2012 (Bhattacharya, Pushkaran, et al., 2012; Amit Kumar, 2014). The challenge in India, it emerges then, is not that of limited financial resources but of multiple deficits in the capacity of the research establishment that includes colleges, universities, government institutions and industry to

15 http://www.nanodigestmag.com/; accessed 10 January 2014

16 http://www.ckmnt.com/newsletter.html; accessed 10 January 2014 
utilize the resources that are already available. While dealing with these deficits and challenges will have to be a key focus for the future, the issue I would like to point to is a different one even though it is related.

The point is that the macro-picture of publications, citations, patents and even the funding - all characteristic of contemporary S\&T in a globalizing world - has been broadly mapped and has also been discussed and debated to some extent. This, however, is only one dimension of the scientific and technological culture and more is needed to gain a more comprehensive understanding of this culture and also that of innovation and research in S\&T. Accounts are needed of the happenings in and outcomes from the laboratories where the money is used or should have been potentially spent; where the nanoscience \& technology are being researched and developed and where an important part of the innovation process is located. There is a need to explore the laboratories to see what's happening inside, to understand what the scientists are thinking and doing, and to comprehend how the laboratories and the institutions are negotiating the multi-faceted and multi-dimensional challenges they face. It is the overall frame of this discussion that I turn to in the next section.

\subsection{Laboratory Studies, culture of a laboratory, technological culture}

The idea that the laboratory as a space is culturally inflected, and that there exists a 'culture of a laboratory' has emerged primarily from ethnographic studies in that space (Collins, 1985; Knorr Cetina, 1981; Latour \& Woolgar, 1986; Lynch, 1985; T Pinch, 1986; Traweek, 1988). Also known as laboratory studies - "the study of science and technology through direct observation and discourse analysis at the root where knowledge is produced (...) - the scientific laboratory" (Knorr Cetina, 1995, p. 140), it is one of the major heuristic innovations in STS and is also a key methodology I have used for my research.

Drawing on their pioneering ethnographic study of an endocrinology laboratory in the United States of America (USA), Latour and Woolgar describe the culture of a laboratory as

the correspondence between a particular group, network, or laboratory and a complex mixture of beliefs, habits, systematized knowledge, exemplary achievements, experimental practices, oral traditions, and craft skills. Although referred to as "culture" in anthropology, this latter set of attributes is commonly subsumed under the term paradigm when applied to people calling themselves scientists (Latour \& Woolgar, 1986, p. 54).

Sharon Traweek follows a similar line of analysis to identify two distinct "cultural models" in the groups of high energy physicists she worked with - that of "an 
entire household" in the Japanese context and of "a sports team" in the American context (Traweek, 1988, pp. 148-149). She shows explicitly how culturally and socially charged the nature of the laboratory space is, even if the scientists may not see or acknowledge it.

These outcomes and understandings are contingent upon the method of the anthropologist, whose work is to

collect life histories, stories about knowledge, legends, myths, and theology, as well as information about networks, generational relations, negotiation, leadership, and followership, conflict, change, and stability; they also observe the construction of artifacts ("material culture") and collect descriptions of them (...) - the goal is a thick description of settings, language, tone of voice, posture, gestures, clothing, distance, arrangement of movable objects, and how all this changes from one interaction to another (Traweek, 1988, p. 9).

The outcome of this anthropological fieldwork, Traweek (1988) notes, is an account of four domains of life of the community being studied: the means by which the group subsists - its ecology; the social organization of the group; the nature of the development cycle - i.e. how skills, values and knowledge are transmitted to those who have joined the group recently; and the group's cosmology which is an account of group's system of knowledge, skills and beliefs, what is valued and what is denigrated.

Following from this and drawing on David Schneider (1976) and Clifford Geertz (1976), she describes culture as “a group's shared set of meanings, its implicit and explicit messages, encoded in social action, and how to interpret experience (...). An ethnography," she continues, "describes patterns of explanation and action, the meanings people make between certain actions, feelings, ideas, things, and their environment; these patterns make up the culture." (Traweek, 1988, pp. 7-8)

Our key concern here is with the idea of 'culture', which can be understood, broadly, as an entire way of life of a group or community of people as constructed by its activities, beliefs, customs, symbols, discourses (cf. Fischer, 2007; Geertz, 1973; P. Smith, 2001). While this is an elegantly simple and useful explanation, the challenge in an Indian context arises from the simultaneous existence of an innumerably large number of communities and their distinctly different 'ways of life'. Culture in the Indian context, therefore, has a particular valence, and the complexity that arises on account of the great diversities of ecology, religion, caste, class, language, ethnicity, geography and history interfacing with each of the elements that constitute culture can only be imagined. Different sets of people live cheek-by-jowl and yet construct their lives and communities in drastically different ways. These lives also constantly intersect with each other in complex ways, making culture a subject fraught with tensions and challenges - it can be 
as much a unifying force as it can be divisive. One important dimension of this society and culture has been syncretism which allows for and creates space for the different cultures to live on simultaneously (Aiyar, 2015; L. Tyabji, 2015): these people, communities and cultures would not be able to survive otherwise. The implications for a culture of innovation are also quite clear then - people and communities that live life in different ways will seek to solve problems in different ways.

The same was visible in the laboratories as well. Relationality, complexity, symbols, transformation and meaning making, all key constituents of (an understanding of) culture (Fischer, 2007), are visible in different ways in each of the laboratories, and the culture of innovation that they constitute is characterized, we will see, by a diversity of methods, resources and knowledge systems; deep embedding in the local; and simultaneous border crossings of language and of meaning.

\section{Ethnographies in the laboratory}

Ethnographies in the laboratory (Collins, 1985; Knorr Cetina, 1981; Latour \& Woolgar, 1986; Lynch, 1985; T. Pinch, 1986; Traweek, 1988) allowed many new insights into the work of knowledge creation inside the lab in particular and in science and technology, in general. These ethnographies privileged for the first time "the context of discovery" over "the context of justification" that had been the preferred context of studying science by philosophers of science (Knorr Cetina, 1995, p. 141). The context of discovery, also known as the context of knowledge production, privileges the local and contingent over the general and the abstract, and pays attention to how an idea occurs and the process by which it is brought to fruition. The context of justification is focused, on the other hand, on the assessment and evaluation of the knowledge claims made, and on the logic by which a claim is accepted (Knorr Cetina, 1995; Shapin, 1995). It is this context of discovery that will be prefaced in the case studies here, with a substantial part of the attention being paid to the local and to the contingent to the specific contexts within which the laboratories exist and perform.

In going beyond the understanding of "large scale effects of science", such as those of the "size and general form of scientific growth (...), the economics of its funding (...), the politics of its support and influence (..), and the distribution of scientific research throughout the world" (Latour \& Woolgar, 1986, p. 17), lab studies achieved many things at the same time. They challenged and simultaneously extended the methods used and insights gained from the existing ways of doing science studies and were lauded for their courage and attention to the details of what happens inside the laboratory (Doing, 2008). As a methodology they followed the study of scientific controversies for the sociological contextualization of science. The focus in these lab studies was on the study of "unfinished knowledge" and of the "real-time processes" (Knorr 
Cetina, 1995, pp. 140-141) of scientific and technological knowledge creation before the facts are formed.

Latour and Woolgar (1986) reported from inside one specific endocrinology laboratory about the "daily activity of working scientists" (p. 40), and how the "craft character of scientific activity" (p. 29) becomes "transformed into "statements about science" (p. 30), "lead[ing] to the construction of facts" (p. 40). They showed that chaos and disorder characterize the world of science and research, that the main task of the scientist is "producing ordered and plausible accounts out of a mass of [these] disordered observations" (p. 36) and, further, that "it is impossible to prove that a given statement is verified outside the laboratory since the very existence of the statement depends on the context of the laboratory" (p. 183). Evidence was provided that phenomena are not just dependent on material instrumentation, but that they are "thoroughly constituted by the material setting of the laboratory" (p. 64); that "objects (...) are constituted through the artful creativity of scientists" (p. 129) and that the "facticity of an object is relative only to a particular network or networks (p. 106, emphasis added).

They illustrated their point by positing the relationship between somatostatin, (which inhibits growth-hormones), and an individual's growth hormones as one that cannot be established in the absence of a laboratory, and more specifically without a radio-immunoassay inside the laboratory. It is not their claim "that somatostatin does not exist, nor that it does not work, but that it cannot jump out of the very network of social practice which makes possible its existence" (Latour \& Woolgar, 1986, p. 183). In the case of high energy physics too, the traces that physicists work with come into being only on account of the detectors they build for the purpose; they would not exist otherwise (Traweek, 1988). The chaos, disorder and the craft character of science (Collins, 1985; Latour \& Woolgar, 1986) were also evident to me during the course of my research, and are central to the narrative of the 'in-house' and indigenous construction of the Scanning Tunneling Microscope in Chapter 3.

Sharon Traweek's (1988) study of the community of high energy physicists in the USA and in Japan presented an account of their social organization, developmental cycle, cosmology and material culture. Training of novices, issues of gender and those of national culture are related key themes of her study. There is a similarity, she notes, between the nature of the physicists and of the physics they do as both emerge through a process of exclusion and from a context of disorder, randomness, instability and irregularities. The key task for the experimentalist who has a big mass of data, for instance, is to decide "what part of their data can be considered valid and what must be "cut", discarded as "noise" (Traweek, 1988, p. 125).

In his studies of the replication of the TEA Laser, the efforts at detecting gravitation waves and experiments in the paranormal, Harry Collins (1985, 
p. 5) unpacked the "particular way scientists come to perceive, describe, and understand new natural phenomena in a uniform way". The key here is the ability to perform without necessarily being able to describe or explain - this is the "embodied tacit knowledge" (Polanyi, 1958; Shapin, 1995, p. 306), which provides the link between manual and cultural skills. Collins' focus was on the scientist's effort at building "new bits of knowledge" (Collins, 1985, p. 6) by processes of replicating instrumentation and replicating the experiments. He offers the enculturational model which is premised on the idea of "understanding" and where transmission of knowledge takes place by "socialization, not verbalization" (Collins, 1987, p. 330). Science is developed by the acquiring of skills as opposed to the algorithamical model, which relies on formal instruction: "the locus of knowledge is not the written word or symbol but the community of expert practitioners" (Collins, 1985, p. 159). We will see the relevance of tacit knowledge very explicitly in Chapter 6, where the researchers involved had to give up a line of research completely because their primary task involved replicating the results from another scientific publication and this they were unable to do.

\section{The lab plays a larger role in society}

These and the other studies of the laboratory allowed for knowledge production to be looked at as 'constructive' rather than 'descriptive' and for the idea of constructionism as constitutive of scientific practice (Knorr Cetina, 1995). The attempt was "to bring science to the same epistemological level as other knowledge-making activities" (Collins, 1985, p. 185). The laboratory was shown to be the workplace and the set of productive forces by which "scientific activity" fought a "fierce fight to construct reality" (Latour \& Woolgar, 1986, p. 243) and "constructionist ideas were [themselves] reinvented in the studies of scientific laboratories" (Knorr Cetina, 1995, p. 149, emphasis added). Central to life in the laboratory are the inscription devices, those machines that "transform pieces of matter into written documents" (Latour \& Woolgar, 1986, p. 51). They allow scientists to create immutable mobiles (Latour \& Woolgar, 1986), the "representations... [that are] durable, transportable and relatively easy to compare to each other" (Sismondo, 2004, p. 67).

Lab studies contributed centrally to making the laboratory a theoretical notion in our understanding of science. They showed that the lab is "itself an important agent of scientific development [because] laboratories rarely work with objects as they occur in nature but with object images or with their visual, auditory, electrical and [other] traces" (Knorr Cetina, 1995, pp. 144-145). The work of high energy physicists, was shown for instance, to be entirely about detecting traces that would not exist without the detectors that the scientists constructed for the purpose (Traweek, 1988). Traces such as these need to be interpreted, and the "difference[s]" that emerge can be dismissed as a "minor noise" or could be considered a "major discrepancy" (Latour \& Woolgar, 1986, p. 
145). The objects are changed as they are manipulated in time and space, creating "scientific representations [that] are the result of material manipulations... [and] are supposed to be the direct result of interactions with the natural world" (Sismondo, 2004, p. 66). The natural world is brought to a human scale, made manipulable and stable through various instruments at the disposal of the scientist in the laboratory.

A reconfiguration is also seen in the social order, where "laboratories install "reconfigured" scientists who become "workable" (feasible) in relation to these objects" (Knorr Cetina, 1995, p. 146). For a number of doctoral students I met during the course of my research, for instance, getting into the laboratory and the higher education system was as much an issue of social mobility as it was of doing science and producing knowledge. Not knowing English became a key impediment and overcoming the impediment a key challenge - reconfiguration could be seen as a constant dynamic. Laboratory studies have shown how the "constructors" themselves are reconfigured, not as a result of the political strategies of specific agents but as the outgrowth of specific forms of practice (Knorr Cetina, 1995, p. 147). It leads to the creation, in a related though different context, of "engineer-sociologists" (Callon, 1987, p. 84), where "the engineering and the sociology are inseparable, because neither the technical vision nor the social vision will come into being without the other, though with enough concerted effort both may be brought into being together" (Sismondo, 2004, p. $65)$.

The laboratory thus plays a larger role is society by becoming a device for shaping and constructing it: "construction of an audience willing to believe in the knowledge produced by laboratories, willing to implement its results and willing to link up with scientific "findings"', in what Knorr Cetina summaries as "construction with laboratories and the construction of accepted knowledge" (1995, pp. 159-160). Society has to be enrolled and sometimes re-structured as in the case of Louis Pasteur where his work was located as much in the laboratory as it was in reconstituting society and space/s outside the laboratory to ensure the reproducibility of his scientific results (Latour, 1983).

Laboratory studies showed how scientific knowledge production could be empirically investigated (Knorr Cetina, 1995); that everything - the artifact, the appropriate method, sufficiency of one or many measurements for reliability, the best environment for a scientific experiment and proper experimental replication - are all negotiable in the making of scientific knowledge; and that "processes of construction are often rhetorical" using as they do a number of "literary (...) and representational techniques of persuasion" (Knorr Cetina, 1995, p. 154).

Lab studies also revealed the existence of "epistemic cultures" (Knorr Cetina, 1995, p. 158) or the "culture of knowledge settings" (Knorr Cetina, 2007, p. 362) on account of the "disunity in the sciences with respect to their 
construction mechanism" (Knorr Cetina, 1995, p. 158, 1999, 2007). The idea of distinct epistemic cultures is based on the differences seen in the construction of the machineries of knowledge production, in the culture of the labs and on their specifically situated micropractices. An explicit illustration of this and the challenges this entails is visible in Chapter 4 where we see the attempts being made by modern nanotechnology to engage and converse with Ayurveda, a traditional system of medicine that has a diametrically opposite epistemic foundation. It underlines the fact that "science and expertise (...) are pursued by specialists separated off from other specialists by long training periods, intense division of labour, distinctive technological tools and particular financing resources (Knorr Cetina, 2007, p. 364). There is no such thing, therefore, as an epistemic unity and it is diversity and differences that characterize the sciences and work in the laboratory.

\section{Importance of the local}

One key theme in STS in general and lab studies in particular, has been the importance of place and the relevance of the local to the process of knowledge creation (Henke \& Gieryn, 2008; Knorr Cetina, 1995; Shapin, 1988, 1995). "The power of laboratories," Knorr Cetina (1995, p. 156) implies, "is the power of locales" and construction, therefore, is local - "with local means and resources, with the equipment that stands around, the chemicals available, the technical skills and experience offered on the spot." For Shapin (1995, p. 306) too, "science is undeniably made in specific sites, and it discernibly carries the marks of those sites of production" even though the "localist perspectives of science" have never been evaluated well. Henke and Gieryn (2008) take the example of mathematics in Göttingen in the early decades of the 20th century to explicate how in some instances "places ratify scientific claims" (p. 357). They argue further that even contemporary science, though increasingly globalized, can be seen as "emplaced science: [because] research happens at identifiable geographic locations amid special architectural and material circumstances, in places that acquire distinctive cultural meanings" (p. 353). This underscores the relevance of the 'context of discovery' even as it underlines the reversal of practice and challenges the narrative that the local and the situated are not important in the case of science or of knowledge production in a more general context.

While the local was brought into focus in a manner that had not been done before, a key critique of lab studies notes that this focus came at a cost - this was the inattention to the larger world in which the laboratory itself is located and to the macro-structures that shape everyday practices in the laboratory (Kleinman, 1998). There was a failure to acknowledge that scientific problem solving, the "doability" (Fujimura, 1987, p. 258), needs an alignment of the three different levels of work organization: a) the experiment in the laboratory; b) the lab where the experiments are performed; and c) the larger social world in which all of 
this is situated (Fujimura, 1987, p. 258). The work of a scientist, Fujimura (1987) notes, is twofold: first, production, which is the carrying out of well-defined tasks, and second, articulation, which is the pulling together of everything to ensure the production tasks are carried out. Both need to be carried out simultaneously and iteratively if success is to be achieved.

Daniel Lee Kleinman (1998), while agreeing with the broad focus and thrusts of the pioneering lab studies, is critical of their exclusive focus on agency and their enabling situations, and the inability of these studies to account, therefore, for the alignment work as outlined by Fujimura (1987). These studies, Kleinman (1998, p. 286) notes, "tend[ed] to ignore, underplay, or dismiss the possibility that historically established, structurally stable attributes of the world may systematically shape laboratory practice." Kleinman's is an ethnography of a laboratory that is "more generally concerned (...) [with] the world in which a particular lab and many other university laboratories are embedded" (Kleinman, 1998, p. 291). He argues here that "laboratory science [needs to be seen] as existing on a continuum ranging from relative insulation from the effects of the university-industry relations aimed at producing commercializable science to deep immersion in such relations, [and that the pioneering lab studies were] focus[ed] on sites at the insulated end of the continuum" (Kleinman, 1998, p. 294). He notes that labs exist at different points of the spectrum and there is a need to separate context from content, the outside from the inside and for an acknowledgement that the "structures, interests, actors, and identities" (p. 290) of the already constructed world influence construction in the world of science. Amit Prasad (2006) notes, on similar lines, that few linkages have been drawn between empirical studies of techno-scientific practice and the larger national and international contexts and further, that there are few cross-cultural studies of techno-scientific practice, of understanding the alignment and enrolling work that scientists need to do.

Distinct overlaps are visible in the foregoing narrative of the laboratory and of lab studies and the insights generated through my own field work - in the challenges of instrumentation and the construction of instruments (Chapter 3); through the imbrication of laboratory logics with societal ones (more particularly in Chapters $5 \& 6$ ), the general idea of the lab as a productive space that runs through all the empirical material, and the iterative relationship between the laboratories and the already constructed societal and cultural contexts within which they are located. What this shows in the overall analysis is the situatedness of technoscientific knowledge-practices - a situatedness that is local, but one that is constantly and dynamically influenced by the world around it.

In a delightful postscript in the 2nd edition of their pioneering lab study, Laboratory Life, Latour and Woolgar (1986) discuss many issues that came up before and after their study was first published in 1979. They stress the value of 
the in situ study of laboratory practice, but with a caveat that attention needs to be paid to its limitations, particularly the claim that a lab study allows access to the truth and to a more accurate picture of science. Few in situ studies of what happens inside the laboratory are available in an Indian context even though there is a huge science and technology enterprise here. Scientists occupy important positions in the structures of the establishment and in the imaginaries of the nation and yet, or perhaps because of this (cf. A. Prasad, 2006; D Raina, 2003), we are "ignorant of the details of the [myths and rituals] among [the] the tribes of scientists" (Latour \& Woolgar, 1986, p. 17). What do scientists do? How is science done? What happens inside laboratories? What are their practices? How does the historical and the social impact the laboratory? These and other such questions of the laboratory and of laboratory practice have hardly been explored in the Indian context and it is a further reflection of why we don't have a substantive tradition in the critical social studies of S\&T here (Section 1.1). It is this gap that this thesis seeks to fill.

\section{Reflexivity and the scientific text}

The second point that Latour and Woolgar make in their postscript is related to the need and the implications of reflexivity:
Reflexivity is thus a way of reminding the reader that all texts are stories. This applies as much to the facts of our scientists as to the fictions "through which" we display their work. The story like quality of texts denotes the essential uncertainty of their interpretation: the reader can never know for sure." We mentioned already the value of ethnography in stressing this uncertainty. Here we see the reflexivity is the ethnographer of the text." (Latour \& Woolgar, 1986, pp. 282-284).

Traweek (1988, p. ix) has argued similarly that "it is crucial for the anthropologist to write themselves into their accounts and to describe the conditions under which they formed their interpretations". Reflexivity is a central element in qualitative research even as there are many meanings and interpretations of the term ${ }^{17}$. To be reflexive is to explicitly situate oneself within the research, to be aware of one's own positions and interests, to accept that the research is "coconstituted" and to be alive to the processes by which knowledge is acquired, interpreted and presented (Finlay, 2002a, 2002b; Guillemin \& Gillam, 2004; Lynch, 2000). Reflexivity is key, therefore, for ethnographic studies inside the

17 Lynch (2000) offers six broad categories (the number is 15 if one includes the sub-categories) of reflexivities: mechanical, substantive, methodological, meta-theoretical, interpretive, and ethnomethodological: Finlay's (2002a) typology is comprised of five variants of reflexivity: introspection, intersubjective reflection, mutual collaboration, social critique, discursive deconstruction. 
laboratory and one might even argue that there can be no lab study without reflexivity being embedded in the way the study is both, performed and written.

I can also relate very well to the puzzlement and bemusement the scientists experienced when Latour first set out to study them in their laboratory (Latour \& Woolgar, 1986). The scientists I was studying and working with were also intrigued when I first approached them. This was not just the experience of these scientists - I was quite bewildered and excited myself (also see Traweek (1988, p. 10)) when I first learnt that these kind of ethnographic studies could be conducted inside a laboratory.

Of particular interest to me also is the idea of "all stories as texts" and of "reflexivity as the ethnographer of the text" (Latour \& Woolgar, 1986, pp. 282284). Having been a photographer, a long time journalist and, more recently, a novelist (Sekhsaria, 2014), stories and texts of certain kinds have always interested me. Different texts have been different kinds of stories, and yet it has been new to look at and understand the 'scientific and the scientist's text' also as a story. ${ }^{18}$ And I have had many different experiences of engaging with the scientific text during the course of the research for this thesis. I saw first hand, for instance, a six-week process of reconstruction by scientists of a text that was eventually published as an article in a scientific journal (S. Agrawal, Morarka, Bodas \& Paknikar, 2012) (see Section 4.4). In another lab I helped a doctoral student structure and construct some text that made up the chapters of his doctoral thesis. In one case a scientist was upset that his story had not been told at all in an article that I had published (Sekhsaria, 2013a) and in another, the scientist concerned was offended because my story of his lab and his work was not how it should have been. In his opinion, the narrative I had written was a biased one because I had not given his perspective the importance he thought it deserved.

These were all different engagements with the scientists' text and where my role went beyond that of being the observer and the ethnographer. I was influencing the scientists and I had to be aware of the contours of this transaction just as I had to be aware of how it was influencing my own understanding of the scientist, the science and the scientific text. Needless to say, the text of this thesis itself is a specific outcome of my own entry into the labs and the experiences I had there.

\section{Technological Cultures}

Understanding the 'Culture of Innovation', which is the primary aim of this thesis, implies that the laboratory has to be located within the wider context of history and of society and attention has to be paid to the inter-relationships of the two because there is no insulated or isolated laboratory (Kleinman, 1998). The challenge is quite an explicit one:

18 Traweek (1988) goes a step further, in fact, when she presents the scientists' machines themselves as texts. 
The problematic of analyzing national of wider societal cultures of science (as opposed to laboratory cultures) for the followers of empirical studies of science is, however, not simple. This partly because close attention to trajectories of techno-scientific research with the empirical studies of science, has come the cost of an inability of (or at least difficulty) to draw linkages at the level of nation states or at the international level, which is of paramount concern to postcolonial studies (A. Prasad, 2006, p. 221).

The postcolonial is important and I will discuss it in detail in the following section. What I would like to point to here is that my research can be seen as a response to Prasad's call - to study the techno-scientific practices inside the laboratories and link them at the same time with the wider national and societal cultures - what Wiebe Bijker has articulated as the 'Technological Culture' (Bijker, 1995a, 2006) ${ }^{19}$. The attempt is to link the inside with the outside, the micro with the macro and to study the cultures of innovation as a corollary of how innovation is encultured.

Bijker uses the idea of the 'technological culture' "to highlight, that characteristic traits of our culture are pervasively and irrevocably technological; that our technologies are thoroughly cultural; that we can understand our modern, high-tech society by recognizing how its dominant cultural values and its technology shape each other" (Bijker, 2006, p. 62). The unit of analysis used to study a technological culture is a "technological system or a (part of) modern, technology dominated society, (...) [which is to be] studied with specific attention to the cultural dimensions" (Bijker, 2006, p. 54). This is complementary, also, to Harry Collin's (Collins, 1985, 1987) “"enculturational model” of knowledge, in which knowledge is equated with culture and hence has an irretrievably social element" (Bijker, Hughes \& Pinch, 1987, p. 308). The enculturation can happen within the limited confines of an individual laboratory - the culture of the laboratory; it can also happen within the frame of an open and a much larger societal context.

Bijker notes that there has been a trend in STS, where research has grown from being focused on scientific controversies and technological artefacts and systems to address larger issues of social, political and cultural relevance, then to other systems of beliefs like indigenous knowledge and to social technologies and users - the trajectory has been "from the study of the (local) cultures of science and technology to the study of the technological culture at large" (Bijker, 2006, p. 53). It is evident that Bijker writes from within his own context of an European "high-tech society", but the articulation is very relevant more generally as well, including, most certainly, to an Indian context and society that this thesis is about. 'Technological culture' can be used to highlight the inextricable

19 Bijker (1995a) is in Dutch. I have used the translated version as it appears in Bijsterveld (2010). 
meshing of the medical, technological and social in the case of the girl child with Retinoblastoma when Bijker says that an analysis of this technological culture will show "how social interaction is mediated through technologies, and how technologies can only function when embedded in societal institutions." (Bijker, 2006 , p. 54). The case studies that make up this thesis illustrate, from within their respective micro-contexts, how a society's cultural values shape technology just as technology shapes society and it's values. The contingent and the general, the local and the global are simultaneously implicated, and in showing how innovation is encultured within the respective practices and cultures of individual laboratories, I am able to make a case for a more general and representative 'Culture of Innovation'.

There is, also, a very insightful relationship that Bijker posits between vulnerability and innovation as two sides of the same technological culture: that "vulnerability seems to be a conditio sine qua non for innovation, as it is the inevitable result of the instability and dynamic development that Schumpeter (1939) identified as prerequisites for innovation. The relation has also been made vice versa: that innovation makes vulnerable" (Bijker, 2006, p. 52). And if studying technological culture allows an understanding of the vulnerability of technological systems and societies (Bijker, 2006), it is only a step away from using it to understand processes of innovation as well.

This is particularly important in the context of development and the impacts of modern science and technology in contemporary India. The impacts of technological change and of the current paradigm of development are not all uniform, and can even be damaging as we have seen already in Section 1.1 (also see Khandekar, Beumer, Mamidipudi, Sekhsaria \& Bijker, 2016, forthcoming). Large sections of the population, which are often more vulnerable to begin with, don't benefit at all. Their vulnerability increases, in fact, when the little they may have in terms of access to natural resources for livelihoods gets taken away or rapid economic and technological changes that they are unable to deal with, are set in motion (cf. D'Souza, 2012a). It is for this reason that questions such as 'development for whom, at whose cost?' and 'who pays the price of development? (Fernandes, 2008; Hardikar, 2005; S. Sharma, 2014) have become central to the discourse and the debate around development. The implication is that innovation and technological interventions can increase vulnerablility and deprivation, and this needs serious accounting for. It underlines a complex relationship between innovation, development, change and vulnerability and one that is intersected simultaneously by history and time, place and space, and notions of tradition, rationality, belief and modernity. It is this I turn to now through an engagement with the thematic of postcolonial (science) studies. 


\subsection{Postcolonial Science Studies}

The contemporary dynamics of international power equations, the incessant global flows of finance, people and ideas and the increasing inter-connectedness, have all had significant implications on the processes of knowledge production and of knowledge hierarchies around the world. Geographies such as classrooms, hospitals, bilateral development agencies, NGOs, and corporate bodies are now, all, playing an important (though still largely unacknowledged) role in the production of technoscience, albeit in relation to the laboratory (W. Anderson \& Adams, 2008). It is important to acknowledge these historical and geographical trajectories on account of the significant influence that they are beginning to exercise and it is here that the frame of postcolonial studies (W. Anderson \& Adams, 2008; W. Anderson, 2002; Seth, 2009) is an appropriate frame.

The genealogy is indeed, historical, because the attempts at deconstructing, even challenging, the hegemony of a rationality that is exclusively Western and/ or scientific are not new (Kaplinsky, 2009; Schumacher, 1973; Singer et al., 1970). The social turn in science helped achieve a number of things that are relevant in the present context: it highlighted the discursive power of science, emphasized the ways in which Western science and colonialism were co-constituted (Seth, 2009), gave a voice, particularly in the non-West, to groups, communities and knowledge forms that had remained on the margins (Habib \& Raina, 2007b, p. xxxiii) and allowed for the possibilities of 'alternative modernities' (W. Anderson \& Adams, 2008; Akhil Gupta, 1998). Politics of knowledge has come, therefore, "to be constituted as a legitimate domain of investigation" and it has been accepted that not all the knowledge that has been swept away under the colonial mat was worthless (D. Raina, 2003, p. 37). In the postcolonial period, Raina (2003) argues, it is the postcolonial frame that has emerged as the most recent and one that accommodates a lot of diversity as well.

Notably, the postcolonial itself is many different things at the same time (W. Anderson, 2002; Seth, 2009). It is a "productively ambiguous intellectual site (...), a time period (after the colonial); a location (where the colonial was); a critique of the legacy of colonialism; an ideological backing for newly created states; a demonstration of the complicity of Western knowledge with the colonial project; or an argument that colonial engagement can reveal the ambivalence, anxiety and instability deep within Western thought and practice" (W. Anderson, 2002, p. 645). Importantly, "the 'postcolonial' does not imply the end of colonialism; rather, it signals a critical engagement with the present effects - intellectual and social - of centuries of 'European expansion' on former colonies and their colonizers" (W. Anderson, 2002, p. 644). It questions the notion of a universal objective European rationality that was at the heart of the colonial enterprise, and in the process provincializes Europe (the centre) to bring it at par with all the other provinces of the empire (W. Anderson, 2002; Habib \& Raina, 2007b). It is both, a call for and a way of acknowledging, even celebrating, the messiness, 
contingency, lack of planning and arational character of modernity (Turnbull, 2003); it is a tool, at the same time, of destabilizing the binaries of the colonial and the national that have been instituted by modernity (Akhil Gupta, 1998). Post-colonial studies have enabled a "decentred, diasporic or 'global' rewriting of earlier nation-centred imperial grand narratives" (Hall, 1996, p. 247), and the post-colonial project is one of "a rephrasing of technoscience within the framework of globalization" (Hall, 1996, p. 250). The colonial itself becomes available as an analytic because analysis and studies "predicated on the nationstate" are not sufficient anymore to explain the "co-production of identities, technologies and cultural formations that are characteristic of an emerging global order" (W. Anderson \& Adams, 2008; W Anderson, 2002, p. 643).

Key issues of concern in the post-colonial frame of studying technoscience include those of location, locality and the global; of the movement, travel, transfer and translation of technoscience; of shifting social boundaries of race, class and gender; the claims of science to be universally valid; and of heterogeneity, messiness, indigenous knowledge systems, and alternative modernities (W. Anderson \& Adams, 2008). Employing a postcolonial frame to studying S\&T requires us "to be sensitive to dislocation, transformation, and resistance; to the proliferation of partially purified and hybrid forms and identities; to the contestation and renegotiation of boundaries, and to recognize that practices of science are always multi-sited (Marcus, 1998)" (W. Anderson \& Adams, 2008, p. 184). This, in addition to mounting evidence of the "globally distributed and entangled" nature of contemporary technoscience (W. Anderson \& Adams, 2008, p. 185).

One can discern here a productive coming together of the different conceptual and methodological traditions of laboratory studies, of multi-sited ethnography and of post colonial studies. There is an inevitable meshing as each tries to mobilise history, time, space (and a lot more) and even each other to understand and explicate the one world in which they all operate.

\section{Postcolonial S\&T in India}

Post-colonial science (and by extension, technology) in the Indian context has evolved from and emerged at the intersection of many divergent, even opposing perspectives of the colony, of modernity, of science and technology and of the very idea of the nation state itself (Abraham, 2000, 2006). A key player in this has been the "state scientist" (Abraham, 2000, p. 169) who, while responding to the call of nation development also sought to deliver science of a quality at par with the best, but with resources that were only a fraction of what were available to their counterparts in the West. The science had to be distinctly Indian at the same time as it was international. Abraham notes that modernity and the postcolonial should not be seen merely as chronological categories, and while the modern was generally understood to be about the West, the aim was to still 
create a modernity that was distinctly Indian. He uses the trope of "landscape" to explain how the geographical localities and specificities of prominent "Big Science" projects in India ${ }^{20}$ were mobilized to "transform the contemporary social world in order to produce a future that had naturalized the signs of development and modernity" (Abraham, 2000, p. 185, emphasis added). That the relationship between the scientist and the state has been fraught with tensions is stating the obvious. The question to be asked in the era of big science is whether the scientist has no choice but to accept the state and if "the state must accept the scientist only to the extent that the scientist accepts the state?" (B. Zachariah, 2014, p. 20). The so called 'Haldane Principle' that the state would fund academic research, but the agenda would be set by academics", Zachariah notes further, "is now routinely broken by governments, who openly articulate the need for research to meet the state's requirements" (B. Zachariah, 2014, p. 20). Recent times have also been witness to the emergence of a new contract between science, society and the state (V.V. Krishna, 2013; Mallick, 2014; D. Raina, 2014) and it is, now, no more about the state scientist, the agenda of national development or the quest for international scientific credibility alone. The current reality is far more heterogeneous and messy than it has ever been in the past.

A number of additional influences are also visible today in the narratives and discourses of science, technology and of the production of knowledge: "the societal role of science and [the] university has being redefined in terms of academic capitalism, the entrepreneurial university, mode 2 [(Gibbons et al., 1994; Nowotny, Scott \& Gibbons, 2001)] and triple helix models [(Leydesdorff \& Etzkowitz, 1998; Leydesdorff, 2005)] of knowledge production" (Mallick, 2014, p. 33). None amongst these is, perhaps, more prominent than that of globalization - the increasingly un-hindered movement of ideas, capital and human resources across national boundaries that kicked-in in the Indian context with the process of the liberalization of the economy in 1991. This is the period in which "the post World War-II consensus on science and the state began to come asunder... [even in] most parts of the developing world [that had been] drawn into the frame of science and development during [the preceding] decades of decolonization" (D. Raina, 2014, p. 12). This has created a new set of demands of S\&T - visible as they are in the increasing prominence of the metrics of publishing and patenting, in the expectations of commercial viability and commercialization possibilities of research outputs, and in the discourses around innovation - all this even as the agendas of societal relevance and contributing to development remain conspicuously foregrounded. This is in line with the changes being seen in public science organisations all over the world where different sites of

20 The examples he uses include the construction in 1996 of the Giant Metre-Wave Radio Telescope, near the city of Pune in Western India; the neutrino detection experiments in a disused gold mine at Kolar in the southern Indian state of Karnataka and India's first underground nuclear test in 1974 at Pokhran in the state of Rajasthan. 
knowledge production have been transformed, and new relationships are being forged between the university and a variety of stakeholders and clients (Mallick, 2014; D. Raina, 2014). It is a manifestation of what Krishna (2013, p. 10) has described as the "changing social contract between science and society (...) with the onset of [the] contemporary phase of globalization from the 1990s."

The future that Abraham's $(2000,2006)$ postcolonial science had sought to produce can be seen as occupied in the present by emerging technologies like nanotechnology, albeit with many layers of complexity added on. Not only are the boundaries of resources, scale, discipline and epistemologies being pushed within the laboratory, much continues to change in the linkages with the outside world as well. It is not enough anymore, as we have seen already, to respond to the call for S\&T to be a partner in development or for S\&T to contribute to the building of a powerful nation state; the demands of commercialization, a globalizing science, a more demanding civil society and the changing social contract of science have also to be negotiated with. It is asking for the simultaneous negotiation not just of different histories and expectations but also multiple temporalities, locations and geographies. The challenges are serious and even unprecedented, but then so are the opportunities.

One finds many resonances of this postcolonial rubric in the case studies that make up this thesis and in the final conclusions that I will seek to draw - in the binary of the metropole and the periphery; in the hybridities that are neither colonial nor national; in the circulation of knowledge, ideas and people; in the scientist's constant negotiating between demands of the state, of the market and of the universe of science itself; and of the synergies being attempted between traditional forms of knowledge and a modern nanoscience and technology.

We have seen in Section 1.2, for instance, how investment in nanotechnology in India has been driven by the idea of not missing the nano-bus. There is other evidence to show that the old categories of the centre and the periphery are being displaced and that Europe is indeed been provincialized. Countries like China and Korea (and to an extent India) are much ahead of many European countries where investment in NS\&T research and outputs such as scientific publications, patents and applications are concerned (cf. Amit Kumar, 2014; Palmberg et al., 2009). There is, on the one hand, the attempt to 'catch-up'; on the other, one sees the simultaneous ambition and confidence that a country like India can be a leader in the field of nanotechnology. The pull of the west still lures the Indian nanotechnologist but there is also the counter-veiling imagination of a modern, scientific and wealthier India that keeps her and him here. Another instance is the discussion around jugaad, a concept that is central to the empirical practice and conceptualizations in Chapter 3 in this thesis. While a large body of scholarship and policy making in India rejects jugaad on various counts (Krishnan, 2010; Prahalad \& Mashelkar, 2010; Vadukut, 2011), its acceptance and avowal in academies of the west (Giridharadas, 2010; Radjou, Prabhu \& Ahuja, 2012) 
illustrates the messiness and the counter-narratives that postcolonial studies point towards. The themes of the relationship between the old and the new and of a new modernity are also seen in nanotechnology's engagement with Ayurveda (Chapter 4) and in another way, in the re-engaging with and re-configuring new meanings and uses for waste (Chapters $3 \& 5$ ).

The existence of the de-centred cultures of innovation that the thesis points to towards the end also reflect and overlap with the postcolonial idea of decentred, alternative, and multiple modernities (W. Anderson \& Adams, 2008; Akhil Gupta, 1998) - albeit with some differences. The point is that all these different cultures of innovation exist already and have attracted far less attention and recognition than they deserve. The challenge lies in creating the frames and the spaces that will not just accommodate but also acknowledge and accept these diversities.

\subsection{Multi-sited ethnography}

I come now to multi-sited ethnography (Marcus, 1995), the final methodological frame that this thesis is based on. Multi-sited enthnography has been a direct response to the increased complexity of today's world that is not amenable anymore "to prevailing ways of describing and understanding [it]" (Fortun, 2003 , p. 172), and where the logics through which structures are constituted and the systems through which they operate are not visible at any one site. It is also, at the same time, a response from within the discipline of anthropology to remain relevant and connected to the world it studies (Fortun, 2003). It is an ethnography that is not restricted to a single location because of the imperative to study the "circulation of cultural meanings, objects, and identities in diffuse timespace" (Marcus, 1995, p. 96). The sites of the research too have to be diverse and include, among others, "people, technologies, biographies, and even discourses" (Khandekar (2010), quoting Metcalf (2001)). The research, therefore,

is designed around chains, paths, threads, conjunctions, or juxtapositions of locations in which the ethnographer establishes some form of literal, physical presence, posited logic of association or connection among sites (Marcus, 1995, p. 105).

Multi-sited ethnography is credited with having brought about a certain revival of comparative studies where

comparison emerges from putting questions to an emergent object of study whose contours, sites and relationships are not known beforehand, but are themselves a contribution of making an account that has different, complexly connected real world sites of investigations" (Marcus, 1995, p. 102). 
In my case too the nanotechnology and innovation association among the sites I studied was already decided, yet my research did move along unexpected trajectories - revealing answers, surprises, narratives and consequences that emerged from within the logics of the different sites. This, Marcus argues "stimulates accounts of cultures composed in a landscape for which there is as yet no developed theoretical conception or descriptive model" (Marcus, 1995, p. 102).

Though multi-sited ethnography maps the terrain, its goal it not to represent holistically. All sites are not treated uniformly and this results in a variability of quality and accessibility. The aim is to bring disparate sites into the same frame of analysis ethnographically and posit relationships between them. This "requires considerably more nuancing and shading as the practice of translation connects the several sites that the research explores" (p. 100) and navigating through these multiple sites implies that the researcher can not engage each with the same intensity. Multi-sited ethnographies can be conceptualized, constructed and executed via a number of modes - 'follow the people', 'follow the thing', 'follow the metaphor', 'follow the plot, story or allegory', 'follow the life or biography', and/or 'follow the Conflict' (Marcus, 1995). These are not necessarily independent of each other and they have all been used either individually or in different combinations during the course of my research as well.

This thesis, as has been outlined already, is based on empirical work in five laboratories located in three metropolitan cities in India - Pune, Hyderabad and Chennai. While the project spanned a four-year period from January 1, 2010 to December 31, 2013, the empirical work itself was carried out from about the middle of 2010 to the middle of 2013. The research is based on qualitative research methods such as open-ended interviews, historical analysis and laboratory ethnography located firmly within the well-established traditions of Science and Technology Studies (STS). It has been an exercise in multi-sited ethnography (Fortun, 2003; Marcus, 1995) with the scientific laboratory as the locus of the investigation.

A certain spatial and geographical multiplicity - many laboratories situated in physically distinct places and settings - was central to the way the project was conceived. While this was contingent to answering the research questions posed, it was in no way sufficient. The idea of the research site needed to be expanded beyond geographical locations because the question was about innovation and the cultures of innovation. The imperatives, inspirations and implications of the different labs had to be accounted for - their institutional structures and mandates were different; the languages they used were different; the nodes of their interaction with the larger world were different. These worlds had to be threaded together, and while it was all centrally about nanotechnology and about innovation, in another sense it was all about me, the researcher from the outside. Laboratories and scientists who may have never met though they all did 
nanotechnology were threaded together by my quest to research (the cultures of) innovation. I was the one circulating through these spaces, joining them with each other as I asked and tried to answer the questions.

\section{Multi-sited ethnography and laboratory studies}

Multi-sited ethnography overlaps with laboratory studies in a salient way and has a particular relevance in the context of studying postcolonial technoscience:

The recent emergence of richly textured, multi-sited studies of modern technoscience attests to the importance of both situation knowledge and tracking its passage from site to site - to understand what Redfield calls the "different spatial and temporal frames in which the "local" takes "shape". These new studies, whether at what used to be called the 'centre' or at what used to be called the 'periphery', draw as much on an anthropological mode of inquiry as they do from the historical and sociological methods more common in science studies (W. Anderson, 2002, p. 652).

Marcus has also noted that the development of multi-sited ethnography emerged from an engagement with and participation in a number of interdisciplinary (...) arenas such as media studies, feminist studies, various strands of cultural studies, and science and technology studies (STS), particularly those studies that "push[ed] the ethnographic dimensions of this field beyond the pioneering lab studies to more complex (and multi-sited) social and cultural time-spaces" (Marcus, 1995, pp. 103-104). The specific works that Marcus refers to when suggesting this movement include among others, Latour (1987, 1988), Haraway (1991), Teitelman (1989), Rabinow (1989) and Zonabend (1993). The overlaps are particularly visible in the importance that both lab studies and multi-sited ethnography give to the idea of the local and also that of constructivism.

A more recent overview of lab studies (Doing, 2008), however, brings in a different dimension to the discussion. Doing notes, quoting Marcus (Marcus, 1995), that "the trend in anthropology towards multisite ethnography has contributed to discouraging the kind of extended, on-site investigation of a particular work site practiced by the early lab studies" (Doing, 2008, p. 292, fn 6). As a result of this, Doing argues, lab studies did not "pursue particular episodes of fact making" (2008, p. 289) and failed, therefore, to deliver on the promise that was held within them. There in an inversion one sees here of the assignment of responsibilities: multi-site ethnography that was inspired in part by the initial set of lab studies is now held responsible (at least in part) for not allowing lab studies to deliver what they claimed and promised to deliver. 
This underlines some of the challenges that this thesis has had to deal with as well, particularly in doing justice to the importance of place and situatedness at the same time as going multi-sited. If the detailed ethnography in a laboratory gives depth, focusing on the details of only one (or two or three sites) comes at the cost of width and of moving into multiple arenas. The reverse is true, of course; casting the net too wide inevitably raises the concern whether a particular place has been studied and understood enough and if more time and energy should not have been put in there.

The effort here has been to strike a balance: the individual lab study (even if not in as much detail) across multiple sites is a necessity if cultures of innovation have to be understood. While the physical site of each lab study is important for its specificity and its context, the various elements of multi-sited ethnography help in unhooking and liberating the site from within this physicality. The particular remains anchored but can also chart multiple territories, allowing for associations and connections across boundaries and specific contexts. The particular and the general are both vital and it is in the mapping of their associations and of threading them together that the possibilities of telling a larger story emerge.

\subsection{Chapter Summaries}

In Chapter 2 that follows, I take the thesis agenda of exploring the cultures of innovation as a starting point to lay out a conceptual framework for studying innovation. I will discuss three prominent discourses in innovation - a) the Joseph Schumpeter influenced idea of innovation that revolves around the entrepreneurial firm, markets and around profits; b) user-driven innovation and how users matter as shown by research in different strands of STS and; c) social innovation, which is very much the buzzword today. The key argument is that all these different discussions on innovation need to be looked at simultaneously if the larger technological culture of innovation is to be understood.

Chapter 3 is an account of the development of one of the earliest Scanning Tunneling Microscopes (STMs) in India in the late 1980s at the University of Pune in the western part of the country. I discuss this development in the context of jugaad, an articulation and manifestation of innovation that can be found in the street, in industry as well as the modern scientific laboratory across large parts of urban and rural India. I call it 'technological jugaad', a form of innovation where reconfiguring materiality, bridging ways of knowing and operating in situations of resource constraint are some of its main characteristics.

Chapter 4 is a journey through the Centre for Nanobioscience (CNB) at the Agharkar Research Institute (ARI), Pune, where research is focused, as the name suggests, at the intersection of biology and nanotechnology. Innovation happens here at the micro level in the laboratory but also pushes disciplinary boundaries as biology interfaces with other disciplines, mainly chemistry and physics. The thrust of the chapter lies is articulating the contours of what I call an 
inter-epistemic collaboration - where modern nanotechnology seeks to interact and also find a language of engagement with the traditional knowledge system and medical practice of Ayurveda. The chapter argues that many innovation possibilities exist because different practices and multiple knowledge systems continue to endure and live on in parallel in India even today.

Chapter 5 presents the account of the development of a low cost nano-silver based water filter in a government lab in the city of Hyderabad. What looks like a promising technology that is affordable and beneficial to those at the bottom of the pyramid, has however failed quite emphatically in the market. The case study uses the Social Construction of Technology (SCOT) framework to look at the development of the water-filter in the laboratory and its performance in the market through the heuristics of the relevant social group. One way of analyzing and understanding the failure is to see that the eventual user, the consumer, was almost completely left out from the very beginning; that innovating in society and in the market in addition to that in the laboratory are all needed simultaneously, particularly when the final output is expected to play a role outside the laboratory.

Chapter 6 is the story in which Javed Ali, who has been quoted right at the start of this thesis, appears again. This is the account of two tertiary eye care centres with a commitment to translational research and where a team of clinician-scientists is attempting to develop a nanotechnology based protocol for the treatment of Retinoblastoma. Here one sees concurrent challenges at multiple levels and of the need to simultaneously innovate in the laboratory, in the clinic and in society if a solution is to be found. I use the idea here of multiple (non) users to show how the girl child with a tumour in the eye is an aggregate of (at least) four different users and how this multiplicity, in turn, creates new subjectivities in the clinic and in the laboratory. The clinician who becomes the clinician-scientist because of the mandate of the institution is forced to become the clinician-scientist-activist when the patient and her family walks in.

The concluding Chapter 7 emphasises the enculturing of nanotechnology and of innovation as we have seen it unfold in the deliberations on innovation, the Indian context and through the different case studies. The discussion (as also the thesis) is summarized through a set of six points that distill the rationale, the idea and the markers of the 'enculturing of innovation'. I also discuss the policy implications by comparing the conclusions of this thesis with the key thrusts of India's Science Technology and Innovation Policy (STIP) (MST, 2013) and also the recent articulations, by prominent Indian researchers, on the state of science and technology in India ("Priorities for science in India," 2015).

I conclude finally by illustrating how this enculturing of innovation and the diversity that characterizes it, helps us to conceptualize cultures of innovation as 'de-centred', challenging the idea that only particular ways of doing things or a particular culture of innovation can lead to success. I do this by revisiting the idea of technological jugaad (Sekhsaria, 2013a, 2013b) and discussing it in light of 
existing concepts such as bricolage (Levi-Strauss, 1966), user-driven innovation (von Hippel, 1988, 2005) and juakali (UNEVOC, 1998) to suggest that socially embedded forms of innovation have parallels and similarities across geography, culture and language. The key point is that diversities exist within and between systems and cultures; that these diversities are an asset that need to be mobilized further and also that they offer us important pivots - as much to understand the cultures of innovation in science and technology as to understand science and technology itself. 


\section{What is innovation inside the laboratory?}

\subsection{Evaluating the lab, evaluating what happens inside the lab}

The endeavor of this thesis is to understand and articulate the Culture of Innovation with the locus of investigation being the laboratory. The frames that I have sketched out in the preceding chapter provide us with key points of engagement with the contemporary laboratory - lab studies, for instance, help understand the construction of facts in the laboratory; a look at historical developments contextualizes the expectations from and the growth of S\&T in a postcolonial Indian state; and a view through the window of a globalizing world explains how the logics of quantitative evaluations, societal relevance and commercial viability have significantly infiltrated the thinking and the working in laboratories. It is to a discussion on innovation that I now turn to in this chapter.

I would like to stress here the plurality of the narratives of innovation because innovation itself is not just one thing. None of the narratives can, however, give us a complete picture by themselves and what is needed, therefore, is to bring them together for a comprehensive understanding of innovation in the laboratory. There are three prominent strands of discussion that I will focus on here: the market, firm and profit centred idea of innovation; the constructivist ideas of innovation that have emerged from within STS in the last three decades; and the idea of social innovation that has come prominently into focus in recent years.

These ideas and understandings were all visible in the work of the laboratories I engaged with and in the many conversations I had with the scientists. One prominent drift in the discussions, for instance, was of the need for developing applications that are socially relevant. Many researchers even articulated a position that it was wasteful to keep investing in basic science without the benefits ever reaching the large mass of this largely poor country. In many other conversations commercialization was highlighted as the primary measure of innovation and success, sometimes even eclipsing the novelty of the methods used or the value of the scientific knowledge gained in the research effort. Most discussions on innovation with these scientists veered quickly to issues of publications, patents, royalties and the success or failure in the attempts to commercialize ${ }^{21}$. It reflects the "redefinition" of the societal role of science and

21 This is one important part of the "cycles of credit" - the analytical construct deployed to understand and explain the motivations of scientist. Other parts of the cycle include, among others, financial gain, positions and recognition that the scientists continually re-deploy and exchange with each other in their quest for growth and credibility (cf. Latour \& Woolgar, 1986 ch. 5). 
the university, which now includes concepts like the "entrepreneurial university and academic capitalism" (Mallick, 2014, p. 33). It is also in line with Mallick's findings from interactions with senior scientists that, post 1995, there has been an "increasing emphasis on contract, industry sponsored and/or user related work and simultaneously a decline in funds for basic research" (Mallick, 2014, p. 37). While there can be a disagreement on the specific issue of availability of funds for basic research in India ${ }^{22}$ (nanotechnology is good case in point; see Section 1.2), the changing emphasis and expectations are visible. The standard and caricatured image of invention and discovery as the primary purpose of science in the laboratory has been supplanted with a lot more and in many complex ways.

The issue of commercial viability and profit is particularly illustrative because it has deeply infiltrated discussions in and around the scientific laboratory and the discourse of S\&T policy in India. Raina (2014, p. 14) notes that the increased socialization of science in the contemporary world has led to the entanglement of "questions of accountability, social responsibility and innovation (...) in a variety of ways, [and yet] the dominant discourse around innovation very frequently refers to market innovation". Clearly, many more questions about commercialization and profit are being asked of the scientist and the laboratory today than they have ever been, and this thematic came up repeatedly in the articulations of the scientists I interacted with. Yet, there was the implicit and explicit acknowledgement by these very scientists that the laboratory is not the 'firm', the primary activity here is not economic and the key motive is not (and should not be) profit. When the work in the laboratory is over, when the results are out, when knowledge, the technology and/or the product exit the lab and enter a particular world of circulation and production - once all this has happened - one can argue that questions of profit, economics and financial sustainability will inevitably infiltrate that existence. But what about everything that happens till that stage is reached? What is innovation outside the realm of economics and outside the discourses of profit? What is innovation inside the lab? What are the frameworks one might use to understand this innovation? What explanation and understanding might one have of the journeys through laboratories - of the making of Scanning Tunneling (and other) Microscopes in resource poor contexts; of giving new meaning and a new lease of life to the obsolete; of nanotechnology treating a cancer of the eye, but also attempting to treat a social reality; of modern science and technology attempting to dialogue with a culture and a knowledge system that is from a different episteme?

22 Also relevant to note here is the dominant role the public sector continues to play in funding and supporting S\&T in India. A 2006 survey revealed that 62\% of support for research and development came from central S\&T agencies that are directly under the union government (NSTMIS, 2006). Successive governments have, over the years, promised and also delivered substantive budgetary increases for the S\&T establishment (cf. R. Raina, 2014). 
Detailed discussions with the researchers along these lines showed an ambivalence on their part about the prominence of a commercial metric. The undercurrent of a tension became visible in the researchers' urge to explore the frontiers of scientific knowledge (the basic science), the simultaneous imperative of doing applied science and developing technologies that would be socially relevant, and in the articulation of the logics of commercialization and of profit. There was a new reality at this intersection and I could sense that the scientists and their institutions were themselves grappling with its challenges and opportunities.

An important question would be to understand how these laboratory and institutional level micro-experiences are reflected in the meta narratives of innovation and of science \& technology policy. A good starting point would be to map the thrusts of India's latest Science Technology and Innovation Policy (STIP) (MST, 2013) onto the experiences in the labs and the spaces that it is supposed to be about, and to see how the macro and the micro interact and interface with each other. This mapping, as the subsequent section will illustrate, underlines a significant mismatch and considerable slippage.

\subsection{The Indian context - STIP 2013}

The Science Technology and Innovation Policy (STIP) (Image 2), which was released at the 100th edition of the Indian National Science Congress in Kolkata in January 2013 notes that

Scientific research utilizes money to generate knowledge and, by providing solutions, innovation converts knowledge into wealth and/or value. Innovation thus implies S\&T-based solutions that are successfully deployed in the economy or the society (...). Paradigms of innovation have become country and context specific (...). The national S\&T enterprise must now embrace S\&T led innovation as a driver for development (MST, 2013, p. 2, emphasis added).

The short, 22 page, document which was released by the then Prime Minister, Manmohan Singh, goes on to conclude with the following 'Policy Vision':

The guiding vision of [the] aspiring Indian STI enterprise is to accelerate the pace of discovery and delivery of science-led solutions for faster, sustainable and inclusive growth. A strong and viable Science, Research and Innovation System for High Technology-led path for Indian (SRISHTI) is the goal of the new STI policy (MST, 2013, p. 16, emphasis added).

The policy advocates that innovation must contribute to development in key sectors such as "energy and environment, food and nutrition, water 


\section{Science, Technology \\ and Innovation Policy 2013}

Government of India
Ministry of Science and Technology New Delhi

Image 2: The Science Technology and Innovation Policy 2013

and sanitation, habitat, affordable health care and skill building and unemployment", and that "Science technology and innovation for the people is the new paradigm of the Indian STI system (...) [which] must, therefore, recognize the Indian society as its major stakeholder" (p. 2). There are also mentions in the policy of social good, inclusion, sustainability, and of endogenous capabilities.

A closer reading reveals, however, that these concerns are perfunctory in the overall scheme of the policy and its primary thrusts. The edifice of innovation and of development is sought to be built on a foundation that is very much economic and technological, and this is clearly visible in some of the specific language used. The predominant focus throughout this policy document is on elements such as economic performance and growth, global competitiveness, high technology (p. 9), increased private sector investment in R\&D and on technology development (p. 11). The role for 'society' is limited, primarily, to being the recipients and beneficiaries of the science, technology and innovation. The focus is not on how people can participate but on creating "delivery systems [for the] diffusion of scientific outputs and technology interventions into social systems" (p. 12, emphasis added) and for the systematic promotion across all sections of society of "the civilization aspect of science, or scientific temper" (p. 15).

A number of authors (Abrol, 2013; Mani, 2013; C.S. Prasad, 2014) have been critical of the policy, its focus and thrust areas. This STI Policy, Dinesh 
Abrol (2013, p. 78) argues in his strong critique, "is quite high on rhetoric and intentions; it is rather weak on the issue of how the government will address the challenge of transformation of the systems of innovation in respect of social inclusion and sustainability". C. Shambu Prasad (2014, p. 55) notes that "India's STIP remains caught in a time wrap (...), [and betrays] a weak understanding of how innovation is shaped in contemporary India and the world". He notes further, that the policy "actually reiterates and reinforces a one-sided relation of science with society - a vision that privileges the know-all technical expert and relies on him/her to deliver goods and scientific temper to the citizen seen as lacking knowledge and scientific temper" (p. 58).

It is also useful in this context to see the following nuanced and multidimensional articulation of innovation by Gillian Marcelle, Executive Director, University of the Virgin Islands Research and Technology Park (RTPark), and a researcher with extensive innovation policy experience in a developing country context:

Innovation is an intentional process of generating, acquiring and applying knowledge aimed at producing economic and/or social value. In developing countries, this process typically takes place through the unfolding over time of a wide variety of learning and capability building processes, rather than through the mastery of science and technological knowledge. Innovation is an investment effort in which, knowledge, financial capital, and other resources including cultural and social capital are deployed over time to create value. Deftly undertaken innovation can lead to the transformation of systems, values and culture as well as the production of new and/or improved products or processes (Marcelle, 2015, p. 4).

Compare this idea of innovation with STIP and the latter's limitations and narrow-focus become quite clear. A perusal of the details of the laboratory (Chapters 3-6) will also illustrate how STIP is unable to account for the richness and diversity of the very labs it is supposed to be about and I will discuss this further in the concluding chapter by analyzing recent articulations made on the state of Indian science by contemporary research leaders ("Priorities for science in India," 2015).

There is also the question of how STIP took shape and what have been its primary influences? Not unexpectedly, the primary thrusts of this policy are in line with the dominant thinking of the S\&T establishment on issues such as innovation, development, the perception of the public and the role of the corporate world in the current Indian context. See, for instance, the striking similarity in the perspective on innovation and even in the language used in STIP and those in recent articulations of R.A. Mashelkar, one of India's most 
prominent and influential science administrators ${ }^{23}$ : “A nation's ability to convert knowledge into wealth and social good through the process of innovation will determine its future" (Mashelkar, 2011b, p. 371). The following two quotes, the first one from his CSIR Founding Day Lecture in September 2011 and the second from an interview he gave me in June 2011 elaborate this idea further:

Let's get into another fundamental. When we do research, we convert money into knowledge. The government keeps on giving us money and we keep on converting it into knowledge in the form of papers, patents, useful knowledge, not so useful knowledge, breakthroughs and so on. But actually it is innovation that converts knowledge into money (Mashelkar, 2011a, p. 227).

We have to realize that when we say (...) innovation converts knowledge into money, (...) all knowledge does not create money. It is only monetisable knowledge that can be monetized to create money. And that monetisability means that you must have ownership and that is where intellectual property came in (Mashelkar, Interview, 08 June 2011).

The historical context is important as well. It is Mashelkar's 11 year tenure (1995 to 2006) as Director General of CSIR that is credited with having brought Indian scientific and industrial research in line with thinking in the west, with the 'market' (Mashelkar, 2011b) and in throwing up a new set of challenges and agendas for the science, technology, and industrial research establishment in the country (Pakrashi, 2003). He changed the "publish or perish" norm of the scientist to the eye catching "patent, publish and prosper" (Mashelkar, 2011b, p. 58). The criterion of commercial and financial viability came, as a result, to be thrust upon the scientific community for the first time in India (D. Raina, 2007) - a good illustration of science's changing social contract with society, post the 1990s (V.V. Krishna, 2013, p. 10). STIP remains truthful to and even brings together, what Edward Constant (1987) has identified as the two traditions of technological change scholarship - one that believes scientific progress to be the key driver of technological change, the other that argues for the role of the market and of entrepreneurship to be considered dominant.

It is also not a coincidence that this attempt to change the image and expectations of the Indian scientist and the scientific establishment followed economic liberalization in 1991 wherein the political establishment took the

23 Mashelkar has been a prominent scientist himself; is highly regarded and respected in political, corporate and S\&T circles; has held a number of important positions in these sectors and is the recipient, most recently (in 2014), of the Padma Vibhushan, the country's 2nd highest award for a civilian. He was Director General of the India's Council of Scientific and Industrial Research (CSIR) from 1995 to 2006. 
first significant steps in opening up and aligning India's socialist economy with the 'open' market ${ }^{24}$. It also marks a significant shift in the perceived role of the scientist - from being a partner in the Nehruvian vision of nation building and creating a scientific modernity - to, now, also that of the scientist-entrepreneur who creates wealth and generates economic value from the science being done in the laboratory (V.V. Krishna, 2013; Mashelkar, 2011b). Mashelkar has, in fact, articulated the "freedom to compete" in an open economy post 1991 as the 2nd of India's three moments of freedom (Mashelkar, 2011b, p. 136) - the 1st one being, of course, India's independence from the British in August $1947^{25}$.

STIP is one of the most prominent recent policy documents of the S\&T establishment in India, which on account of its authority and status is bound to play a key performative role in structuring the priorities and concerns of the scientists themselves. This is in addition to the more obvious and larger implications on the formulation of subsequent policies, on the allocation of resources and through these for the trends and trajectories it sets for future research. STIP has to be understood, it is my argument, as nested very much within the economics and profit centred management and innovation related literature from and about India that has come into prominence more recently. Prima facie, STIP and much of this literature seeks to broaden the scope of the discussions as is visible in some of the language of STIP and in the efforts to conceptualise new articulations such as Frugal Innovation (Bound \& Thornton, 2012), Gandhian Innovation (Prahalad \& Mashelkar, 2010), Reverse Innovation (Govindarajan \& Trimble, 2012) and Jugaad Innovation (Radjou et al., 2012).

While the explicit claims in these formulations are of creating newer, more inclusive understandings of innovation and development, a closer look reveals that in many of the cases, the details do not carry forward the agenda. Gandhian Innovation (Prahalad \& Mashelkar, 2010), is about "how to do more with fewer resources - for more people" while Frugal Innovation (Bound \& Thornton, 2012, p. 6) often has an explicit social mission where

"financial, material or institutional (...) constraints [are turned] into an advantage (...) [resulting in] dramatically lower-cost products and services (...) [that] outperform the alternative, and can be made available at large scale".

Others like Jugaad Innovation and Reverse Innovation, are explicit in their commitment to using these ideas of innovation as solutions for western economies

24 For a multi-sectoral overview of this process of liberalization in India, see Balakrishnan (2011).

25 The third freedom in Mashelkar's articulation came in 2008 when India, led by Prime Minister, Dr. Manmohan Singh, signed Agreement 123, popularly known as the nuclear deal, with the United States of America. Mashelkar calls it the "technology freedom" because it would allow India access to dual use technologies - those that could be used for military as well as for civilian purposes (Mashelkar, 2011b, p. 136; Interview, 08 June 2011). 
and corporates deep in the throes of a serious economic meltdown. Radjou et al. (2012, p. 20) note that "adopting these principals [of jugaad innovation] could also help Western firms innovate and grow in a highly volatile, hypercompetitive environment" and become resilient organisations that think frugally, act flexibly, and generate breakthrough growth (ibid., p. 228). "Reverse Innovation," similarly, "shows leaders and senior managers [of multinational corporations] how to make innovation in emerging markets happen, and how such innovations can unlock opportunities throughout the world" (Govindarajan \& Trimble, 2012, inside flap, front cover). The metrics of evaluation are essentially economic and the thrust, clearly, is on growth, profit making and on expanding markets. The notion of the 'firm' and of economic activity as central to the innovation enterprise continues to be at the heart of the argument.

Part of the problem, Gillian Marcelle (2015, p. 14) notes pertinently, is that most of this theorizing and conceptualizing is done outside of the global south and also that these different conceptualizations end up being "labeled as categories of innovation, rather than (...) challeng[ing] the assumptions regarding the main dominant definitions of innovation." ${ }^{26}$ This is the outcome as also the reason for an inadequate description of the specific conditions in which the innovation actually happens. Further, it points towards a critical lack of focus on the "the functional elements, knowledge flows, cultural and behavioural aspects" of innovation (Marcelle, 2015). For Marcelle, the continued location of the "firm at the centre of innovation policy and theorising remains [the] intractable [challenge]" (ibid., 17). The thinking endures, indeed, that it is not innovation if money is not made and if benefits are not accrued at the earliest. The challenge is to constantly create surplus, the inability of which is an invitation to doom. The problem that the firm seeks to solve, one might argue, is the profit problem and innovation therefore becomes crucial in ensuring this happens. What is striking to note in the present context is the extent of which this thinking has now become a part of the scientist's frame. I have discussed this to an extent already and many more details will be visible in the empirical chapters.

\subsection{Schumpeter's enduring legacy}

There is no doubting the continued influence, in this literature and on this discourse, of the German economist Joseph Schumpeter and his classic and much acclaimed works (Schumpeter, 1934 (2012), 1939, 1942) that are much quoted even today. It is not insignificant that in a recent review of Innovation Studies literature (Fagerberg, Fosaas \& Sapprasert, 2012), two of Schumpeter's works have been listed as among the 20 most influential writings on innovation, and Schumpeter himself occupies the 4th position in a list of the 20 most important

26 Jugaad innovation as conceptualized and presented by Radjou et al. (2012) is an excellent example of this. Also see Sections 3.3 \& 3.4. 
contributors on the subject. What stands out even more prominently is that Schumpeter's writings are the earliest in this listing - The Theory of Economic Development that was published first in German in 1912 (English translation in 1934) and Capitalism, Socialism and Democracy that was published in 1942. The next piece of influential writing in this list does not appear until 1962, which is then followed by a cluster of the most recent in the 1980s and 90s. No one, it might be argued, wrote about innovation before Schumpeter did and as has been noted by Fagerberg et al. (2012, p. 1135), "many ideas that are central in the innovation literature today can be already found in these works".

In his long introduction to a recent edition of Schumpeter's The Theory of Economic Development (Schumpeter, 1934 (2012), pp. xix, xxi, emphasis added). John Elliot notes that Schumpeter defined "innovation" ${ }^{27}(\ldots)$ as the commercial or industrial application of something new - a new product, process, or method of production; a new market or source of supply; a new form of commercial, business or financial organization [broadly, an invention]", and that this innovation which is the "carrying out of new combinations" is the linchpin of economic development. Central to Schumpeter's articulation of this process were the smaller business cycles that characterize capitalism and the larger waves of "creative destruction" that bring unprecedented change and turmoil with the introduction of new, radically different technologies (Kaplinsky, 2009, p. 18).

That much of the work in innovation studies till the 1990s was focused on innovation in firms and industries (Fagerberg et al., 2012; Kaplinsky, 2009) is as much a comment on Schumpeter's influence as it is on the limited scope of research and theorizing that has happened around the subject. As a consequence of this, perhaps, discussions around innovation became and continue to be circumscribed within a particular mode of capitalist production, circulation of goods, resources and values. At the core are technology, markets, entrepreneurship and profit and this, as we have just seen, is central to India's Science Technology and Innovation Policy (MST, 2013) and many of the newer conceptualisations of innovation such as Frugal Innovation, Gandhian Innovation, Reverse Innovation and Jugaad Innovation, which we have discussed in the preceding section.

27 For Schumpeter innovation was "the carrying out of new combinations" broadly understood as: "(1) The introduction of a new good-that is one with consumers are not yet familiar - or of a new quality of a good. (2) The introduction of a new method of production, that one not yet tested by experience in the branch of manufacture concerned, which need by no means be founded upon a discovery scientifically new, and can also exist in a new way of handling a commodity commercially, (3) The opening of a new market, that is a market into which the particular branch of manufacture of the country in question has not previously entered, whether or not this market has existed before. (4) The conquest of a new source of supply of raw materials or half-manufactured goods, again irrespective of whether this source already exists or whether it has first to be created. (5) The carrying out of the new organization of any industry, like the creation of a monopoly position (for example through trustification) or the breaking up of a monopoly position (Schumpeter, 1934 (2012), p. 66). 
Smith and Barfield (1996, p. 1) note, for instance, that "the solution to a basic scientific puzzle or the invention of a new "product" only in a laboratory setting makes no direct economic contribution. Innovation includes not only basic and applied research but also product development, manufacturing, marketing, distribution, servicing and later product adaptation and upgrading". Garcia and Calantone (2002, p. 113) argue on similar lines that

from a macro perspective 'innovativeness' is the capacity of a new innovation to create a paradigm shift in the science and technology and or market structure in an industry. From a micro perspective, innovativeness is the capacity of a new innovation to influence the firm's existing marketing resources, technological resources, skills, knowledge, capability or strategy.

The general 'innovation' has come to be conflated with the more specific 'technological innovation' on the one hand and with the imperative of making profit on the other.

\section{A systems approach}

Fagerberg et al. (2012, p. 1143) note that after 1990 there was a shift in some studies, away from innovation in firms and industries, and "towards the role of innovation in the entire economy... a systems approach". This move was initiated by a series of publications in the late 80s and early 90s (Freeman, 1987; Lundvall, 1992; RR Nelson, 1993) that created the influential idea of the 'National Systems of Innovation'. These offered a "more holistic perspective on the roles of policy, governance and institutions for innovation" and emphasized "the need to study the interactions between the various actors that influence a country's innovation and growth performance" (Fagerberg et al., 2012, p. 1136). This led to an intensification of the systems approach that looked not only at international and national systems, but also those at the regional level (Braczyk, Cooke, \& Heidenreich, 1998; Cooke \& Gomez-Uranga, 1997).

Hessels and van Lente (2008, p. 745) note in their review article that "systems thinking in innovation emphasizes the importance of interactions and feedback mechanism between all actors involved in innovation, including university researchers, industry, product developers, intermediary organizations and end-users." This was a significant shift in the understanding of innovation in that it stressed upon the need of heterogeneity and rejected the linear model of innovation where basic research leads to applied research, then the development of technology and finally, its diffusion (Hessels \& van Lente, 2008). There are interesting parallels in STS scholarship from the same period, particularly, in the ideas of technological systems (Hughes, 1987) and heterogenous engineering (Law, 1987) that stress the importance of systems thinking and of feedback loops 
in the process of technological change and development (see the following section 2.4 for a more detailed engagement).

\section{Disruptive innovation}

A subsequent idea in the study of innovation that gained much traction is that of disruptive technology and disruptive innovation: "innovations that result in worse product performance, at least in the near term (...) [with the] disruptive technology [being] that [which] precipitated the failure of leading firms" (Christensen, 1997, p. xvii). In what might be considered a particularly intuitive analysis that could be applied to nanotechnology, Christensen (p. 156, emphasis added) noted that

Discovering markets for emerging technologies inherently involves failure, and most individual decision makers find it difficult to risk backing a project that might fail because the market is not there; [and that] plans [must be made] for learning rather than (...) for implementation.

He adds further that in the case of identifying and working with disruptive innovation, planning would have to be "discovery driven", requiring managers to "identify the assumptions upon with their business plans or aspirations are based" (p. 157). In an articulation that is very much in line with the Schumpeterian frame, Christensen argues that nothing new is involved in disruptive technologies and these, in fact, "consist of components built around proven technologies and put together (...) a novel product architecture that offers the customer a set of attributes never before available" (p. 215). Though counter-intuitive and strongly influential in relooking at innovation, disruptive innovation is also located clearly within the firm and the market. We will see some prominent reflections of this influence of the market in the different empirical chapters in the thesis - primarily in the discussions on the low cost water filter in Chapter 5, and to a smaller extent, also, in Chapters 3 \& 4.

Discussions around the imperatives of commercialization and of profit were, as I have pointed out already, quite prominent in my interactions and engagements with the scientists, and these cannot, therefore, be ignored. The problem lies in the fact that a large part of this discussion has remained restricted to this frame, when actually the challenges in the laboratory cover a much larger range and diversity of issues and ideas. Understanding innovation from this frame might be a necessity, but is clearly not sufficient. More dimensions have to be brought into the discussion.

\subsection{Turning to the user/Turning to STS}

One of the early influential attempts at shifting the focus away from the firm has been the idea of user-centred innovation and the lead user, where Eric von 
Hippel $(1988,2005)$ showed convincingly how the user is much more important and influential than was believed. While von Hippel's work is situated within the more quantitative and economics-oriented focus of innovation, it showed convincingly how users drive innovation in different ways and how their cultural needs, social norms, and economic conditions all have a bearing on the conceptualisation, manufacturing and marketing of a product.

More directly relevant to this thesis and to work in the laboratory are the more qualitative and constructivist studies of science and technology which are "studying technologies in their "context of use - the society and the web of other artifacts within which technologies are always embedded" (Knorr Cetina, 1995; Oudshoorn \& Pinch, 2003a, p. 2). When the sociologist and the anthropologist first entered the black-box of the scientist's laboratory, the specific intention may not have been to create a different narrative of innovation. In the choice of the lab as the unit of analysis and of qualitative methodologies to studying the lab, however, these approaches have not only given us a new understanding of the lab, they have generated a significantly different discourse around innovation as well.

This was evident even in the earliest efforts of technology studies where, as Bijker et al. (1987, p. 3) note in the introduction of their widely quoted edited collection, "authors (...) [were] concerned with moving away from the individual inventor (or "genius") as the central explanatory concept, from technological determinism and from making distinctions among the technical, social, economic and political aspects of technological development". In conceptualizing different social groups as central to the trajectory of the development and stabilization of a technology and the notion of the technological frame, Social Construction of Technology (SCOT) moved the discourse decisively away from the technologist and the producer. It showed, for instance, that "technological artifacts were open to sociological analysis, not just in their usage but especially with respect to their design and technical 'content"' (ibid., p. 4).

In his account on 'The Evolution of large Technological Systems', Hughes (1987) argued for looking at innovators as system builders. In using the 'systems' metaphor for technology and in articulating the concepts of the "reverse salient" and the "critical problem" he helped to "link the micro- and macro-levels of analysis" (Bijker et al., 1987, p. 4). The reverse salient is a component of a system that lags behind or is out of phase with the rest of the components of the system, and needs to be altered to keep the technological system going this is done by identifying the critical problem that is the one to be eliminated. The idea of "actor-networks" (Callon, 1987) sought, similarly, to reverse the usual relationship between the participant and the analyst, and argued for the engineer to also be looked at as a sociologist. Callon (1987, p. 84) noted that in the particular case of radical innovations, "technical, scientific, social, economic or political considerations [are all] inextricably bound up in an organic whole" from the very beginning. 
Taking the case of 15th and 16th century Portuguese maritime expansion, Law (1987) illustrated and explained technology as being constituted by "heterogenous elements... which range from people, through skills, to artifacts and natural phenomenon" (Bijker et al., 1987, p. 107). In presenting the idea of heterogenous engineering and networks, Law (1987, p. 132) argued, like Callon, for the idea of reciprocity and of symmetry in analyzing components of the system, whether human or otherwise. Ruth Cowan took this a step forward by using these concepts of technological systems and heterogenous and interacting elements, but by looking at the network inside out - from the perspective of the consumer. This, she did by recounting the history of home heating and cooking systems in the United States of America and by "plac[ing] the consumer at the centre of the network". She called it the "consumption junction - the place and the time at which the consumer makes choices between competing technologies" (Cowan, 1987, pp. 262-263). It illustrated and reinforced the important ideas of constructivist sociology of technology such as the need for symmetry in looking at success and failure, the relevance of different social groups and the often seen disjunct between intention and consequences. Johan Schot and Adri Albert de la Bruheze $(2003$, pp. 230, 245) used this idea of the consumption junction to articulate what they called the "mediation junction", to focus on the process of "mediation (...) between production (supply) and consumption (demand)", and where mediation is a process of "mutual articulation and alignment" that is influenced by a number of actors that includes producers, users, the mediators and their institutional loci. This, they argued, is important if we are to gain a better understanding of today's consumer societies where mass production and mass consumption have come to characterize this society and where both are constructed simultaneously through a process of mediation. Collins (1987), through his study of Artificial Intelligence, articulated the algorithmic/ enculturational dichotomy and made the case for the "tacit knowledge component of technical tasks [which] cannot be completely described by algorithms" (Bijker et al., 1987, p. 308). It is this tacit knowledge, Collins argues, that provides the link between manual skills and cultural skills and where cultural skill itself stresses the relationship between manual and perceptual skill. "A machine," he notes, "cannot be understood aside from its end-user and the cultural ambience in which it works. The role of the end use is to insert that part of the iceberg of cultural knowledge [that] cannot be programmed" (Collins, 1987, p. 345).

Cowan's study mentioned above is acknowledged as amongst the earliest (also see Trescott (1979) and Cockburn and Ormrod (1993)) that looked at technology development from a feminist perspective (Oudshoorn \& Pinch, 2003a). They disproved earlier claims that women were passive recipients of technology and showed how, in fact, they actively shape and negotiate meanings and practices in technology (ibid., p. 5). Christina Lindsay (2003)showed further how users perform different roles and can have multiple identities that are 
generally ascribed to designers, and Ronald Kline (2003) challenged the view of resistance to technology as either irrational or heroic. What is considered an act of resistance, Kline showed, can be (and often is) an important aspect of the creation of new technologies and social relations - a throw back, in many ways, on Hughes' (1987) idea of the reverse salient discussed above.

Another important contribution of feminist studies was to show the diversity within the community of users themselves. Different scholars conceptualized them in various ways - the 'end user', the 'lay end user' and the 'implicated actor' - and stressed the importance of "pay[ing] attention to the differences in power relations among the actors involved in the development of technology" (Oudshoorn \& Pinch, 2003b, p. 6). The end user is that individual or group of individuals that is affected downstream by the process of technology development (Casper \& Clarke, 1998); the lay end user refers to those who are left out of the expert discourse (Saetnan, Oudshoorn, \& Kirejczyk, 2000); while the implicated actors are "those silent or not present but affected by the action" (A. Clarke, 1998, p. 267). To this has been added the category of the "non-user" (Wyatt, Thomas, \& Terranova, 2002; Wyatt, 2003), which questions the explanations offered for non-use of a technology and asks whether "the policy assumption that all non-users of a particular technology ${ }^{28}$ wish to become users [is] appropriate?" (Wyatt, 2003, p. 68). The authors identify four different categories of non-use - 'resisters, rejectors, excluded and the expelled' and I use this idea in Chapter 6 to illustrate how all these different non-users can be simultaneously nested in one single entity and why, indeed, it is important to understand the non-users, their contexts and histories if innovation has to succeed and technology has to contribute to solving problems.

These studies are all part of a specific and explicitly user oriented turn in STS. This relatively small, but rich and expanding body of literature (for an overview see Oudshoorn \& Pinch $(2008,2003 \mathrm{~b})$ ) has brought about significant new understandings and perspectives on production, use, consumption and the notion of innovation itself. It builds upon existing studies (briefly discussed above) in social construction of technology, semiotic analysis, feminist narratives and those from within culture and media studies to see how users consume, modify, domesticate, design, reconfigure, appropriate and resist technologies.

\section{Mode 2 Knowledge Production}

The cultural and constructivist turn in science and technology studies has also shown that we cannot take knowledge claims for granted and neither can we take for granted the processes by which knowledge is generated. This idea is at the heart of Mode 2 knowledge production (Gibbons et al., 1994; Nowotny et al., 2001) (for a critique see Hessels and van Lente (2008)) the attributes of which include, among others, that contemporary research is increasingly carried out a) in the

28 The particular technology in this case was the internet. 
'context of application', that is, problems are formulated from the very beginning with a dialogue among large number of different actors and their perspectives; b) that there is an 'heterogeneity' of skills and expertise that is brought to bear upon the problem solving process; c) there is 'transdisciplinarity' which is premised, in particular, on the idea of the 'transgressiveness of knowledge' and there is a co-evolution in the sphere of knowledge production and of societal institutions; d) that 'reflexivity' and 'social accountability' are an integral part of the research endeavor and e) there are novel quality control methods, including those that are from society and are socially relevant.

While this has been observed as an important trend, particularly in economically well-off societies in the west, Kaplinsky (2009) makes some pertinent observations related to developing countries like India. He argues that while there has, indeed, been a shift in thinking to Mode 2 in the developed and industrialised economies in the West and in Japan, Mode 1 continues to dominate thinking in the poorer parts of the world. He takes the specific example of the pharmaceutical industry in India to note that "it has done much to produce cheaper generic drugs to the world, but historically embedded in a Mode 1 framework, has done little to address the needs of the poor in India" (Kaplinsky, 2009, p. 11). There is indeed merit in this argument and also evidence to suggest (some of it being discussed in the preceding sections) that this bias extends to the larger S\&T innovation system in the India and one that is clearly reflected in STIP (MST, 2013) as well. The broader point here is related to the relevance and application of insights from STS to non-western contexts, particularly because of the genesis of STS within the empirics and the academy in the west. Much can be learnt and applied in a country like India, but if it is to be effective it has to be representative and has to be more finely contextualized. It is here that the ideas and articulations that go under the broad rubric of what is now called 'social innovations' become very relevant and this is what I turn to in the next section.

\subsection{Social innovations}

The idea that there was an implicit and an explicit discrimination related to the benefits from S\&T is not really a new one. Alternative discourses and conceptualizations have been made for a very long time and in different kinds of ways. Many of these were catalyzed from the experience that the dominant notions of innovation, focused as they were on modern S\&T and on profit making, had failed to solve some of the world's most pressing problems. The document that came to be called the Sussex Manifesto (Singer et al., 1970) had argued more than four decades ago that the global S\&T system was wasteful and that "technological progress was biased in meeting the needs of rich consumers by generating large scale and capital intensive technologies" (Kaplinsky, 2009, p. 5). Parallel to this was the Schumacher (1973) inspired Appropriate Technology Movement where he called for the development of "intermediate technologies" 
- the technologies that focus on labour intensive innovations and operate at smaller scales that are less likely to damage the natural environment. These ideas had significant impacts in different parts of the world - in the Indian context, for instance, in the work of Amulya Reddy (A. Reddy, 2009a) among others, and in Brazil in the development of the idea of 'social technology' (Fonseca \& Pereira, 2013). It has grown over the years to become a prominent discourse that has come to be centred on the terminology of 'social innovation'. A significant attribute of these different articulations is that they are as much (or more) an outcome of deep engagements with the multiple social realities that constitute the (non-western) world as they are a reaction to the dominant ideas that have been outlined above. They seek, explicitly, to include worlds and worldviews that were made silent and left invisible.

Social innovation has come to be understood as an all encompassing term that can be interpreted and applied at different levels - of innovating and innovation of the social, an innovation of the social agenda and also innovation that accounts for the social dimensions of technology. Social innovation is hardly, if ever, discussed in the context of mainstream S\&T and I find this ironic, if not unfortunate, because these elements of understanding societal needs, developing technologies for society and the relationship between science, technology and society came up repeatedly during my engagement with the laboratories and the scientists that work there.

Social innovation brings in a dimension that is largely ignored in the mainstream of discussions around innovation and could be considered as further stretching the idea of user-centred innovation. An articulation of innovation that is particularly useful from this context comes from Peter Denning who uses innovation to mean "the adoption of a new practice in a community (...). Innovation is therefore a social transformation of a community. (...) [It] requires attention to other people, what they value and will adopt" (Denning, 2004, p. 15).

The thrust in the idea of social innovation is less on what solution is created or how it is to be used, but more on the problem that is to be solved and how a solution is sought for it. It is strongly process oriented. It is broadly a framework where the state, the private sector and civil society have to all come together and foster "cross-sector innovations" to find a solution to the problems that are to be solved (Park, 2013). Specificity of the context is always foregrounded; the processes are long drawn and complex, demanding constant engagement and re-calibration; and final outcomes can never be predicted in advance. These elements are all visible in the empirical material that makes up the thesis - in the efforts, particularly, of developing the low cost water filter (Chapter 5) and in the reconfiguring of subjectivities as a nanotechnology based protocol is developed to treat Retinoblastoma (Chapter 6).

Social innovations are "born from crisis [and come] from a process where the people who will ultimately benefit from a product or a service are given a 
voice in its development" (Rodin, 2013, p. 4). The term, according to Seelos \& Mair (2013, p. 12), is a "crucial organizational topic [and] captures our collective desires to find novel solutions to persistent social needs." Social innovations are "part of a process that [also] build social resilience and allow complex systems to change while maintaining the continuity we rely on for personal, organizational and community integrity and identity" (Westley, 2013, p. 8). A key thrust is on resilience - "the constant capacity of a system to adapt or transform" (ibid., p. 7).

Social innovation advocates the need for a systems approach but where the hitherto ignored dimensions such as social and ecological equity, sustainability, and historical context are as important as the profit motive and technological input. Westley (2013) illustrates this with an example of the race for developing biofuels as a solution for depleting fossil fuels - but where a neglect of these other dimensions has had adverse impacts on the environment and society. It has led to the taking away of land used for subsistence agriculture in poor and developing countries and increased food insecurity for the marginalized in the process. None of the case studies in the thesis illustrate such a drastic contradiction, but it will be seen that accounting for the diversities and multiple stakes that social innovation advocates would have a significant impact on the outputs from the S\&T enterprise and on the problems that are sought to be solved.

\section{Social Technologies}

A specific formulation that deals with these issues in the case of South America in general, but more particularly Brazil, is "social technology" (Fonseca \& Pereira, 2013; Fressoli et al., 2014). It is the outcome of a movement "that advocates development of technologies aimed directly at social inclusion" (Fonseca \& Pereira, 2013, p. 50) and calls for responsibility and diversity in technological development. Social impact and inclusion are considered as the key outcomes and it is "a critical re-invention of the appropriate and intermediate technologies movements" (ibid., p. 52) that had been inspired by Schumacher's ideas.

The social technology movement recognizes the limitations of the process of external design and development that are then applied in local situations. It focuses, therefore, on a process called "socio-technical adequation" and is "a procedure that seeks to revise the techno-scientific knowledge, be it tacit or incorporated in requisites or finalities, [and make it relevant] (...) to the group of societal aspects that structure the relations between science, technology and society" (Dagnino, Brandao and Novaes (2004) quoted in Fonseca \& Pereira (2013, p. 53) $)^{29}$. Criteria that then become important in evaluating technology and technological projects include, among others, "democratic participation, lifecycle analysis, health and environmental safety and ethical issues." (Fonseca \& Pereira, 2013, p. 53). Clearly, the remit and the intention is to widen the idea of technological development and innovation, and include parameters which have

29 Dagnino et al.'s original article is in Portuguese and an English translation is not available. 
hitherto remained outside or on the peripheries of technology development and assessment regimes (Fressoli et al., 2014).

\title{
Grassroots Innovation
}

Another specific (and similar) formulation of social innovation that has a strong resonance in India is that of 'grassroots innovation'. This is an approach that allows and enables

\begin{abstract}
creative communities and individuals [including disadvantaged people living in developing countries] to develop alternative approaches (...) by converting their ideas into products and services [and] by blending modern science and technology, design, and risk capital (Anil Gupta, 2013a, p. 18, 2013b).
\end{abstract}

Embedded in the idea is the explicit acknowledgement that "those at the bottom of the economic pyramid (...) are not, [by implication, also] at the bottom of the knowledge, ethical or innovation pyramids" (Anil Gupta, 2013a, p. 18). The need and the challenge is to build upon those resources in which "these poor people are rich" and to ensure that development is inclusive. While this demands a re-negotiation of the roles and relationships between the state, the private sector and society, Gupta also outlines the need to "first understand and reconceptualise the interface between natural, social, ethical and intellectual capital" (p. 18). Natural capital is the natural resource that "can be saved, consumed or exchanged with or without renewability" and which first came into being when societies started to claim individual or community rights over these resources. Social capital is the manifestation of a "respect for group norms" and is based on principles of "trust, reciprocity and third-party sanctions." Complementary to the idea of social capital is that of ethical capital - the self regulation of an "individual's behavior" in the larger interests of the community and of equity and sustainability. Intellectual capital, on the other hand, is the "knowledge about (...) [how] people regulate their own behavior or that of others in managing [natural and other] resources" (Anil Gupta, 2013a, p. 18). It is the employment of social and ethical capital that is crucial in grassroots innovation that often, though not always, also "reinforce[s] the renewability of natural capital" (Anil Gupta, 2013a, p. 19).

Gupta also notes that one of the key challenges in the use and scaling of grassroots innovations is related to communication - how to reach out the information of the innovations and their possible applications to those who might be able to best use it. The Honey Bee Network ${ }^{30}$ created

30 The Honey Bee Network is one of three entities that make up the Grassroots Innovation Augmentation Network (GIAN). The other two are the Society for Research and Initiatives for Sustainable Technologies and Institutions (SRISTI) and the National Innovation Foundation India (NIF). RA Mashelkar is the Chairperson of the NIF while Anil Gupta is its Vice-Chair. 
by Gupta is an excellent example of how this has been attempted in India:

The network is an organization that seeks out innovations developed at the grassroots, organizes them in readily accessible ways and provides them to people at the grassroots (...) to improve their lives and their communities (Anil Gupta, 2013a, p. 19).

The network has, till date, mobilized nearly 170,000 ideas, innovations, and traditional knowledge practices from all over India following the methods of a honey-bee that collects nectar and helps cross-pollination while also allowing others the use of the honey the community has created together. Gupta (2006) and Gupta et al. (2003) also provide a more detailed account of the networks and processes by which these social and grassroots innovations are being conceptualized, studied, documented and taken forward in India - this is as much the quintessential bottom-up approach of innovation as it is of the lens of looking at innovation.

The standout feature of 'social innovation' is its acknowledgement of and its location deep within the social context. It is striking, however, to see how the world of the laboratory and that of social innovation have remained mutually and (almost) completely exclusive. Those who need social innovation and those who are practitioners of social innovation seem to have little in common with the universe of modern S\&T. The two worlds appear to be moving along parallel tracks and where there is some interface, it only serves to reinforce the idea of 'grassroots' being lower in the hierarchy of power and knowledge. It is for grassroots and social innovations to benefit from processes such as 'scientific' validation and standardization, and from the metrics of patents and commercial success that are markers of the dominant paradigms of innovation. The social innovation framework has also remained restricted in large measure to understanding and documenting what is happening outside formal and institutional S\&T and there is nothing, it seems, in the experiences, knowledge and actions of social innovations and innovators that the modern laboratory might be able to learn from. This is a gap that needs to be bridged and it is here - in an equalizing of the situation - that a key opportunity exists. Urama \& Acheampong (2013) argue that social innovation has rich possibilities of fostering science technology and innovation development, and it should, therefore, to be taken into account in the formulation of formal science, technology and innovation policy. They make the case primarily for the African continent, but there is no reason why their argument should not be applicable in any other part of the world. This broadened and more inclusive approach would be particularly useful in trying to understand a culture of innovation because of the larger context within which the lab exists and within which it seeks to explore the frontiers of science as 
also developing technologies and products. It also demands newer subjectivities and for pushing further the ideas we have discussed in the preceding chapter - the relevance, particularly, of the ethnographies inside the lab and also of the postcolonial studies of S\&T.

It is my experience, through the ethnographies conducted in the laboratories, that some of the realities and concerns so explicitly foregrounded in social innovation are, in fact, deeply embedded and implicated in the lifeworlds of the laboratories and the scientists that inhabit them. They have, however, remained obscured and even invisible, and this is another black box that needs some dwelling into and opening up. And because this is the case, I would like to argue that is in acknowledging and then synthesising these articulations from within Innovation studies, from discourses of user-centred innovation, and also those of social innovation explored above, that a broader, more holistic and inclusive culture of innovation/s can be understood.

This is visible, in fact, in a clutch of already existing notions of innovation from around the world that are local and de-centred - conceptualisations such as jugaad seen in a number of Indian languages (Sekhsaria, 2013a; Varma, 2004); bricolage in the French (Levi-Strauss, 1966); Jua Kali in Kenya (UNEVOC, 1998) and user-driven innovation even within the Western firm (von Hippel, 1988, 2005). These are all firmly rooted in local geographies and specific language cultures and will appear again in latter parts of this thesis. Innovation, it then emerges, is not only about technology, just as it is not only about the firm, just as it is not only about profit and economic growth. The social, culture and political dimensions are just as important as the economic, and empirical manifestations of this exist all around us. What is needed is a blending along different axes and simultaneously, across those axes as well.

Problem solving needs to happen simultaneously on multiple axes, lacking which the outputs generated and the solutions offered are rendered isolated, even ineffective. It is this multi-dimensional aspect of innovation and its social construction that the case studies in this thesis will make visible as we travel through modern scientific laboratories working with an emerging nanotechnology. The solutions sought through this mélange are not just scientific - they are equally political, economic and developmental and just as emphatically.

If, in fact, technology is socially constructed as scholarship in STS has shown already, there is no reason why innovation should also not be so. Let me conclude this chapter, then, by quoting from Helga Nowotny's (2008, p. 140) account on the nature of innovation and its relationship with our societies, our security and our futures:

Innovation's credibility comes from the basic willingness to include the diversity and plurality present in the society. Variation is the precondition; it is cultivated to make selection possible because the 
process of innovation is based on both. Diversity also means that a scientific-technological innovation cannot be successful without social and cultural innovations. The more sweeping and radical the scientifictechnological objects or technologies are, the more cultural and social innovation is needed if the package containing the renewal is to be embedded in the societal context.

This is a deeply reflective meditation on the value of plurality, diversity and the very nature of innovation, and underlines in a discerning and insightful manner the intrinsic inter-relatedness of the challenges at hand. It also captures the key challenges and opportunities offered by the case studies that make up this thesis - be it the construction of a cutting-edge instrument in resource constrained situations; the efforts needed to, first, make a low cost water-filter and then to market it successful; the collaborating of knowledge systems with diametrically opposite epistemic foundations or in negotiating societal ignorance and bias in treating a particular condition of the eye.

Bringing lab studies in conversation with innovation studies, like I have attempted in this thesis, also helps us recognize the huge diversity of practices and knowledges that constitute techno-scientific knowledge-production on the one hand and innovation on the other. Each is important in its own way and each offers opportunities and solutions that can contribute to and complement the other. 



\section{Technological jugaad: the making of an Indian Scanning Tunneling Microscope}

\subsection{Meeting the scientist}

It was in early December 2010 that I first came across the work of the Center for Advanced Studies in Materials Science and Solid State Physics at the Department of Physics in the University of Pune. Headed by Prof. C.V. Dharmadhikari, the research group's interests included, among others, the 'Development and application of the Scanning Tunneling Microscope and Atomic Force Microscope' and 'Development of special techniques for surface diffusion measurements using tunneling and field emission current fluctuations ${ }^{31}$. I had, as a first step, emailed Dharmadhikari with a brief outline of my doctoral project and requested for an opportunity to meet him. A few emails and telephone calls followed and I eventually had an appointment to meet him in the university.

I met him in the canteen of the Department of Physics where we first had a cup of tea along with another colleague of his and then headed to his office. This was a rather small office, much smaller in fact, than I had expected. There was a table and on the other side, the one towards the window, was a chair that Dharmadhikari occupied. As I sat down in one of the two chairs on my side of the room, I looked around. This was a cubicle about 10x10 feet in dimension and the overarching impression I carry of this space is that of paper. Along the right and left walls were waist high cabinets placed on the floor, and the space above was occupied by wall mounted cabinets. The top of these cabinets were heaped with paper and the shelves inside were full too - files, books, loose sheets and stapled sets piled one on top of the other - some in stacks that stood neatly and others that had slipped and scattered like often happens when one set is pulled out in a hurry from the middle of a pile. Even the table that we were sitting at, had only a small patch where the top was visible - the rest was all paper. The only other thing I remember from that room was a computer and a printer that sat by the side.

As we settled down, Dharmadhikari looked at my Maastricht University business card again and asked me about my research. For the next few minutes he listened intently as I tried my hand at explaining what I was trying to do Science and Technology Studies - STS, innovation in nanotechnology research in India, lab ethnography, the Social Construction of Technology, my supervisor's work on the bicycle (Bijker, 1995b; T.J. Pinch \& Bijker, 1987) ${ }^{32}$, the value of such

31 http://physics.unipune.ernet.in/ cvd/ accessed 10 November 2010

32 The discussion on the bicycle work had him visibly perked up 
studies of science and technology, democratization of science and technology, the history of the Scanning Tunneling Microscope and a bit more that I had picked up in the preceding few months of studying STS and exploring the field of nanotechnology itself.

He seemed generally agreeable and I thought it was a good chance to ask formally for an interview that I could record. I asked tentatively and his first reaction was of hesitation, if not outright denial. I pushed a bit, assuring him that I wouldn't use anything without his knowledge and there would be nothing for him to worry about. He gave his nod eventually but it was clear it had been given with reluctance. He attributed his resistance to a very unpleasant experience many years ago, in 1998, when The Indian Express newspaper had carried a report on the development of his in-house STM:

Can you imagine the [University's] Jayakar Library's entire collection of over 4 lakh [four hundred thousand] books on a floppy or for that matter an elephant the size of an ant? Apparently not. But the development of the country's first ever indigenous state-of-the-art scanning tunneling microscope (STM) at the Department of Physics, University of Pune, may well make the fairy tale come true, as not only does it take a fine probe of how a diamond grows - layer upon layer - but can also manoeuvre genes at an atomic level! (Shah, 1998).

The elephant to ant illustration, Dharmadhikari said, he had used only as a "light hearted" analogy in his conversation with the journalist. The way it was reported, however, and the added allusion to "mavoeuver[ing] genes at an atomic level" (Shah, 1998) had conveyed a completely different picture. All kinds of queries came his way and many explanations were demanded, including by some "human rights fellows", as Dharmadhikari referred to them. I didn't figure out how the issue was resolved, but the episode had certainly made Dharmadhikari wary of people walking around with recording devices.

\section{The labs}

Later that afternoon Dharmadhikari took me briefly to his two (physically) small labs - one named the Scanning Tunneling Microscopy (STM) lab and the other the Scanning Force Microscopy (AFM) (Image 5) lab. I met two of his latest PhD students there, was shown a power point of some of the work that had been done in the labs over the years and also the images (Images $3 \& 4$ ) they had made with their instruments. The most striking of these for me was the nano-sized (200 $\AA$ x $200 \AA$ ) image on a gold surface, in the Devnagiri script, of the syllable 'Om' ${ }^{33}$ (Image 3). Striking, because the attempt came across to me a bit like repeating the iconic 1990 image of IBM that had been spelt out with 35 individual xenon

\section{3 ॐ}



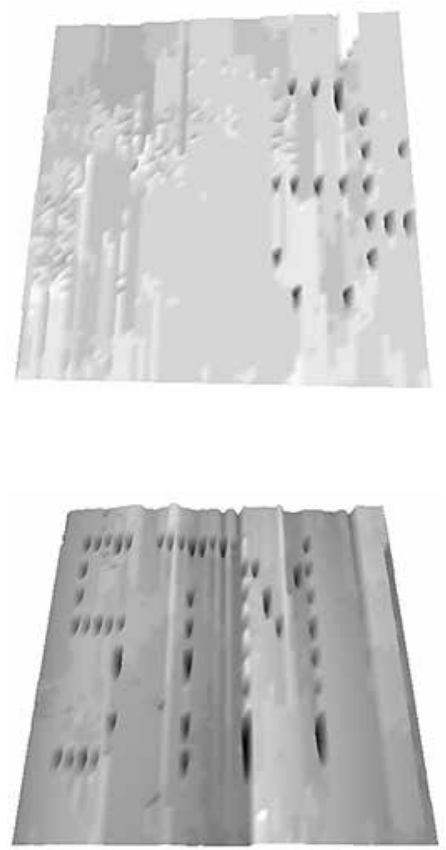

Image 3: $200 \AA \times 200 \AA$ Om on gold surface (Pic: C.V. Dharmadhikari)

Image 4: $250 \AA$ × $250 \AA$ 'STM' on gold surface (Pic: C.V. Dharmadhikari

atoms (Baird, 2004a; Eigler \& Schweizer, 1990) ${ }^{34}$ and striking (retrospectively) also because of the significance that 'Om' has as a religious symbol and in the stories of origin in Hindu religion and mythology.

I experienced the labs (Images $6 \& 7$ ) as a hugely scattered clutter - small spaces that were crammed with chairs, computers, books shelves, cupboards and tables on which one saw a number of things: tools such as pliers, screw drivers, nuts, bolts, small boxes of plastic and aluminium, double sided tape, glue sticks, scraps of paper, sheets of paper, files, books, pens, pencils, circuit boards, streams of wires running from here to there and, of course, a series of big and small instruments. In the corner of one lab was a refrigerator shell (Image 12) and a plywood box, each housing a Scanning Tunneling Microscope (STM) that had been fabricated in this lab. In the other lab I saw a large upturned aluminium vessel of the kind we use to boil water on the gas stove in the kitchen at home. Underneath was a contraption that lay on the inflated tube of an automobile tyre - another STM (Image 14) that too had been made in-house. This set up did not conform at all to the non-scientist's, and also my own, general idea of labs as clean, organized and disciplined spaces (Traweek, 1988, pp. 56-57). It was, in fact, the archetype and the material embodiment of disorder from which the scientific enterprise produces order and meaning (Latour \& Woolgar, 1986; Traweek, 1988).

34 The image can be seen online at http://www.almaden.ibm.com/vis/stm/atomo.html 


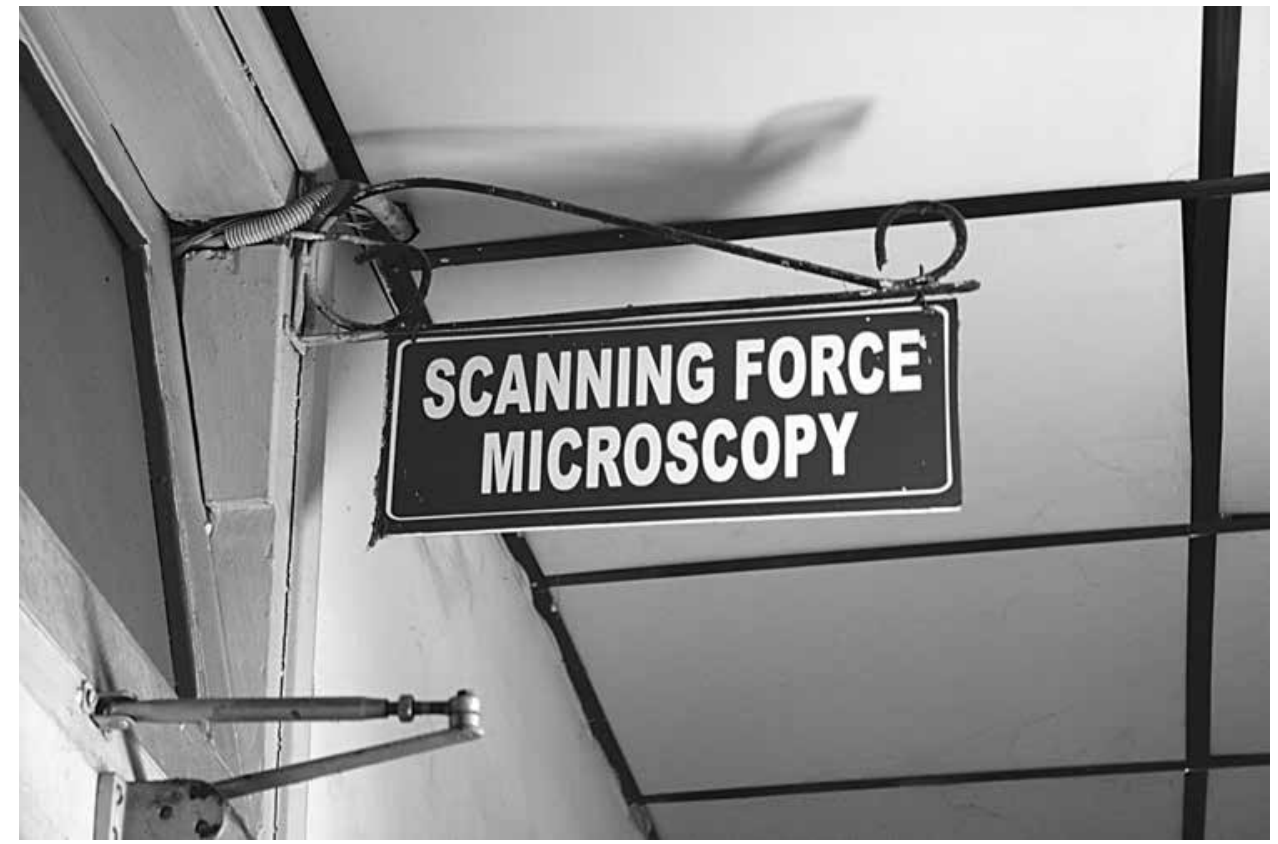

Image 5: The Scanning Force Microscopy Laboratory (Pic: Author)

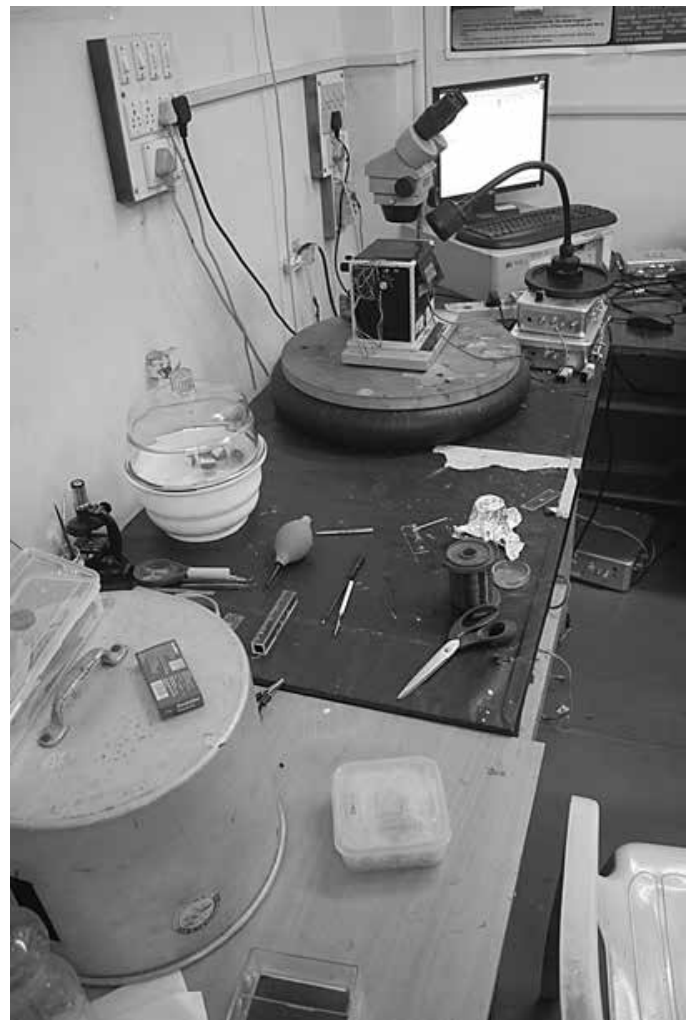

Image 6: A work bench in the lab (Pic: Author) 


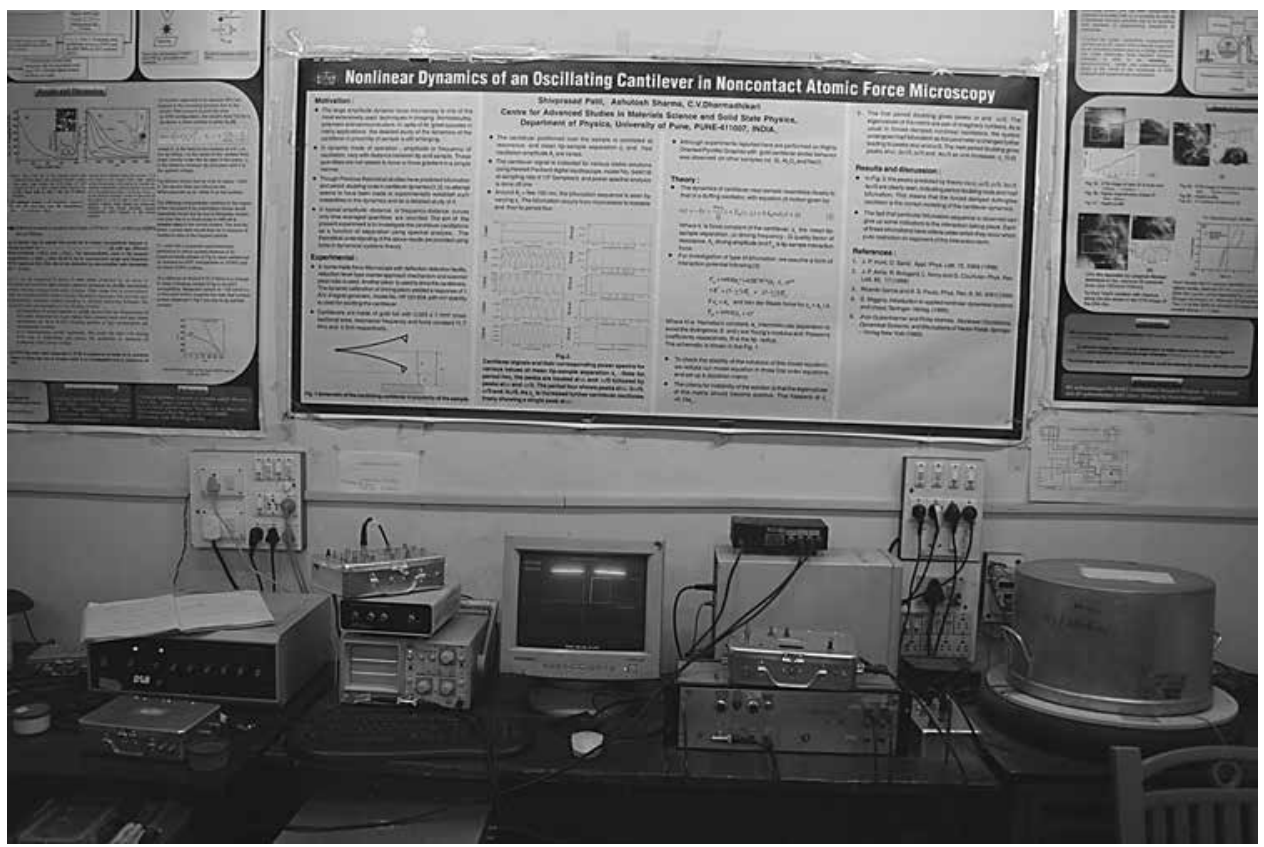

Image 7: A work bench in the lab (Pic: Author)

The short, 30 minute interview that I conducted and this brief tour of the labs that first day laid out, very broadly and in an unstructured manner, the history, trajectory and chronology of Dharmadhikari's STM and AFM journey. This was a journey that started somewhere in the mid 80s (though one can pull it back further into time) and to which my $\mathrm{PhD}$ research became an unexpected and unplanned add-on rather quickly. It helped that Dharmadhikari was himself intrigued about what I was doing - just the fact that someone was interested in the history of his scientific endeavours and also that something like STS even existed at all. What follows in this chapter, then, is an attempt at documenting and structuring the journey of Dharmadhikari, his students and the instruments they made.

\subsection{6-2014: Dharmadhikari's STM journey}

The first significant images from a Scanning Tunneling Microscope had been reported in late 1981 but it wasn't until 1986 that the instrument (Image 8) and its makers, Heinrich Rohrer and Gerd Binning of the IBM Research Laboratory, Zurich in Switzerland, finally gained acceptance and popularity (Binnig \& Roehrer, 1986). The ultimate stamp of recognition came, of course, when the duo were awarded one half of the 1986 Nobel Prize for Physics ${ }^{35}$ for the successful

35 The other half of the prize was awarded to Professor Ernst Ruska for his fundamental work in electron optics, and for the design of the first electron microscope. 


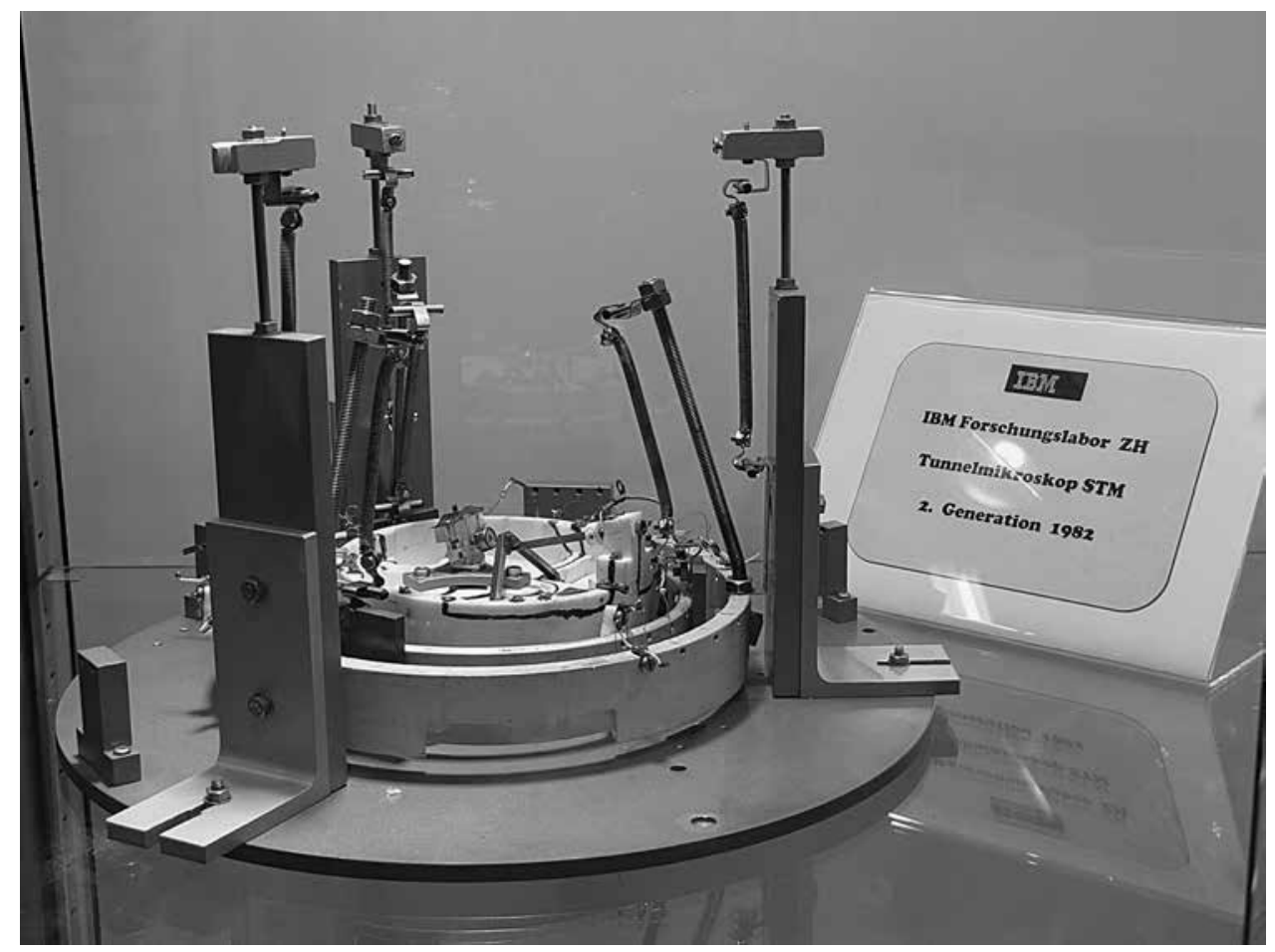

Image 8: A model of the 1st STM built at IBM, Zurich (Pic Courtesy: C.V. Dharmadhikari)

development of the Scanning Tunneling Microscope (Binnig \& Roehrer, 1986; Mody, 2011).

The potential and significance of the instrument, that is universally credited with having spawned the now ever expanding field of nanoscience and technology $(\mathrm{NS} \& \mathrm{~T})^{36}$ was reflected in the press release issued by The Royal Swedish Academy of Sciences (TRSAS) when the award was presented in October of that year:

The reason for their success was the exceptional precision of the mechanical design. One example of this is that disturbing vibrations from the environment were eliminated by building the microscope upon a heavy permanent magnet floating freely in a dish of superconducting lead (...). It is evident that this technique is one of exceptional promise, and that we have so far seen only the beginning of its development. Many research groups in different areas of science are now using the scanning tunneling microscope. The study of surfaces is an important part of physics, with particular applications in semiconductor physics and microelectronics (TRSAS, 1986).

36 For a nuanced refutation of this claim from within the constructivist tradition, see Mody (2011) 
1986 also saw the beginning of Dharmadhikari's STM journey, not because of the Nobel Prize as one might be tempted to believe, but something more complex and serendipitous. It was in 1986 that Dharmadhikari became part, unknowingly of course, of what Mody $(2006,2011)$ has called the 'Instrumental Community', a community that was co-created over time and where probe microscopists were technologists and community builders at the same time:

What initially brought probe microscopists together was a common interest in instrumentation - a new technology for peering at very small objects (...). Yet probe microscopists also set out to create a new instrumentality - a new way of doing things that would propagate beyond their laboratories and change the world (Mody, 2011, p. 6).

The community can also be understood as the first of three different specialities in science as categorized by Law (1973, p. 302): "a technique or method-based speciality [that] constitutes an interacting group of scientists, whose solidarity rests on the basis of shared scientific gadgetry, and its development". It is significant here, particularly in light of Mody's conceptualization, that Dharmadhikari's recruitment to the community was integral, but not central. Integral, because this was the community that became his primary point of reference; not central, because he does not seem to have had any significant influence on the community or its development and also because he remained on the geographical margins of the community that was located primarily in Europe and North America. His contribution to the community of STMers and to the STM itself is acknowledged only marginally even in the scientific community in India, and not at all in the more general history of (nano) science and technology in India, which is rather limited in any case.

Two elements stand out as particularly important in the constitution of this instrumental community as conceptualized by Mody (2011) - first, the significance of the discipline of surface science to STM development and two, the core role played by a set individuals on either side of the Atlantic in constituting and sustaining that community. This included, among others, Heinrich Rohrer and Gerd Binnig of IBM, Zurich, in Switzerland; Nicolas Garcia of Universidad Autonoma de Madrid, Spain; Richard Colton of the Naval Research Laboratory (NRL) Washington, USA; and Paul Hansma from the University of California, Santa Barbara, USA.

These names are important not only for the STM community itself, but also for Dharmadhikari's journey and his recruitment as an STMer. He not only met all of these individuals in the initial, formative period when the STM and the STM community were taking off, but he also happened to be present at the time and at the places where it was all unfolding - meetings, conferences, personal encounters and visits to key laboratories. Dharmadhikari was, most 


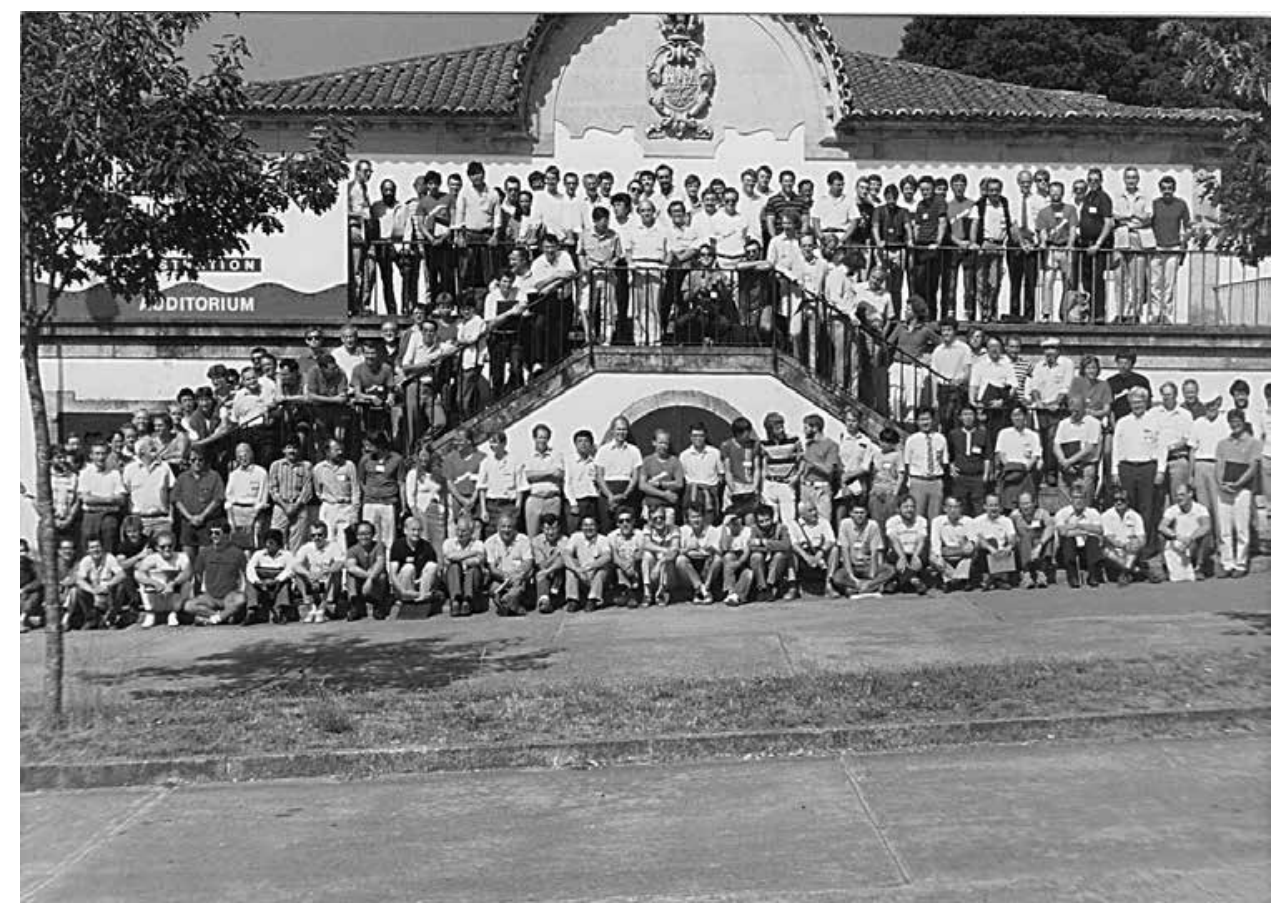

Image 9: The 1st STM Meeting in Spain in 1986. Dharmadhikari (seated) is 7th from left in the 1st row. (Pic Courtesy: C.V. Dharmadhikari)

likely, the only Indian to attend the 1st STM conference that was organized by Nicolas Garcia in Santiago de Campostela, Spain, in July 1986 (Image 9), only a couple of months before Rohrer and Binnig were awarded the Nobel prize. The following year he traveled to the United States of America to attend the 2nd STM conference, organized in Oxnard, California by John Baldeschwieler. While in the USA, he visited among others, the IBM labs at San Jose and Lawrence Berkeley National Laboratory in California and also met Richard Colton who was building his 1st STM while on sabbatical at the California Institute of Technology (Caltech). It was a relationship that built up over the years as they remained in touch and also visited each other's labs when the opportunity arose. In 2005, Colton was even requested by the Assistant Registrar of the University of Pune for an assessment and evaluation of Dharmadhikari's work. Colton not only responded positively, he even recommended that Dharmadhikari be granted professorship (Colton, 2005).

The significance of the travels that allowed for these meetings and exposure cannot be missed if one considers the context of an Indian scientist in the decade of the 1980s. Means of communication were seriously limited and traveling abroad was difficult and expensive if it was possible at all. Foreign exchange needed to travel abroad was a scarce and precious commodity and was strictly 
controlled by the government (R.S. Anderson, 2011). It was only the rich, the powerful or the fortunate who got this opportunity.

\section{Surface Science}

One discipline that was central to the probe-microscopy enterprise and "particularly influential in the invention of the probe-microscopy community," was surface science (Mody, 2004, p. 27, 2011). "Most famously, the 1986 Nobel Prize in Physics," Mody notes, "was awarded to the inventors of the STM largely on the basis of their contribution to the solving of an important question in semi-conductor surface-reconstruction research" (Mody, 2011, p. 16), and that "by the 1970s [already], Bell labs and IBM [had] each employed more than a dozen surface scientists, in addition to numerous junior staff scientists and postdoctoral fellows" (ibid., p. 31). The initial annual STM conferences were, in fact, sponsored by the American Vacuum Society, the professional society of surface scientists (Mody, 2004).

It is significant that this is the disciplinary background that Dharmadhikari belongs to as well. He got his PhD from the University of Pune in 1979 for the 'Design, Development and Application of Field Emission Microscopic Techniques for the investigation of lanthanum hexaboride $\left(\mathrm{LaB}_{6}\right)$ /tungsten emitters'. He then worked, from 1980 to 1984, as a research associate at the James Franck Institute, University of Chicago, USA, with Robert Gomer, one of the best-known names in scanning field emission and ionization. Dharmadhikari was awarded the 1980 Welch Foundation Award by the International Union for Vacuum Science Techniques \& Application and in 1984 he even co-authored a paper with Gomer that was published in the journal Surface Science (Dharmadhikari \& Gomer, 1984). Even today, after having spent a better part of three decades making STMs and working with these instruments, Dharmadhikari often refers to himself as a surface scientist.

In 1986, in fact, Dharmadhikari was visiting Berlin to attend a field emission/field ion workshop when he took what he calls "a detour" to attend the 1st STM conference in Spain and also "[visit] many laboratories (...), [see] many STMs [and the] (...) very hectic work going on in Europe. But," he added, "they [the STMs] were so complicated that I thought I could never make it in India" (Dharmadhikari, Interview, 02 March 2011).

\section{The STM journey in Pune}

In only a couple of years, however, most of this doubt seems to have gone and Dharmadhikari had established himself as an important player in the field. Enthused by what he had seen during his travels in Europe, he even sent a proposal in 1987 to IBM to fund STM development and research in India. Nothing came of it but it indicates the confidence he had in his own capabilities and the promise he perhaps saw for the field. When a joint Indo-US project 
titled 'Scanning Tunneling Microscope (STM)' was initiated in 1988 with SS Wadhwa of the Central Scientific Instruments Organization (CSIO), Chandigarh, India and Richard Colton from NRL, Washington, as the principal investigators, Dharmadhikari was even drafted in as one of three Indian players who had experience and could make a significant contribution (Anon, 1996).

It was also in 1988 that Dharmadhikari successfully made and installed his first STM - under a staircase in the department as that was the only place was available at that time. Students had also started working with him on the STM project and the first Master of Science (MSc) project (Bendre, 1987) related to the STM had been completed under his guidance in 1987. The first peer reviewed paper on an aspect of STM construction (Bendre \& Dharmadhikari, 1988) was published in 1988; the first MPhil degree for the "development of a simple electronic control system" for an STM (More, 1990) was awarded in 1990 and the first $\mathrm{PhD}$ was awarded for STM related work under Dharmadhikari's supervision in 1999 (Yehia, 1999). When I first visited the lab in December 2010, three students were in various stages of their doctoral work related to different aspects of Scanning Tunneling and Atomic Force Microscopy.

In this period of nearly three decades (1986 to 2014), Dharmadhikari and his research group made a series of probe microscopes, including most recently, a Photon Emitting - Scanning Tunneling Microscope (peSTM) (Dey, 2010); 12 students completed their Master of Philosophy (MPhil) degrees (see, for instance, Chaudhary, 2002; Dambe, 1995; Iyyer, 1994; SM Patil, 1994; Sawant, 1994) and about an equal number were awarded doctorates, (see Chaudhary, 2011; Dey, 2010; Iyyer, 2006; Yehia, 1999) ${ }^{37}$ - all, while working on various aspects of making these instruments. Many of these students then worked as post-doctoral fellows in leading institutions around the world: Wayne State University and the University of California in the USA; Madrid Microelectronic Institute, Spanish National Research Council (IMM, CSIC), Madrid, Spain; Institute of Molecular Science, Okazaki, Japan; Institute for Nanostructured Materials - Consiglio Nazionale delle Ricerche (ISMN-CNR), Bologna, Italy, and Centre national de la recherche scientifique (CNRS), Marseille, France. Some eventually moved on to permanent positions in prominent institutions in India such as the Indian Institute for Science Education and Research (IISER) and the Defence Institute of Advanced Technology (DIAT), both of which are based in Pune.

The research group has also published nearly 70 papers including many in the world's leading peer reviewed scientific journals such as Applied Physics Letters (Godbole, Sumant, Kshirsagar \& Dharmadhikari, 1997; Sastry, Kumar, Datar, Dharmadhikari \& Ganesh, 2001), Langmuir (Chaki, Singh, Dharmadhikari \& Vijayamohanan, 2004), Surface and Interface Analysis (Datar, Patil, Iyyer \&

37 This is only an indicative listing and no particular significance need be attached to the particular thesis listed here. 
Dharmadhikari, 2004; S. Patil \& Dharmadhikari, 2002) and Advanced Materials (A. Kumar et al., 2001).

\section{History and geography, space and place}

This seemed to me like a substantial body of work and a significant set of outputs. I was, admittedly, amazed, even awed, that it had all followed from the 1st STM that had already been made before the decade of the 80 s was over. I have also seen much admiration in a cross section of different people in India I have spoken to, particularly when I mentioned that the STM is an instrument that is credited with having spawned nanoscience and technology and that the IBM scientists who first made it were awarded the Nobel prize for it in 1986. This admiration can be very easily located in the aspirations and ambitions of the India of today. In a country that is increasingly aspiring to be a super-power in science (and much else) it is a subject of much discussion, concern and even castigation that the only Nobel Prize in science for an Indian working in India is more than eight decades old ${ }^{38}$ (Mashelkar, 2011b; Narlikar, 2003). It comes across as very commendable to this citizenry, then, that an Indian scientist was successful in making a sophisticated instrument at the frontier of sciences in such quick time.

But there is more to this story than just locating Dharmadhikari's endeavours and the development of the STM in an historical perspective. The details of what was contingent at that time and place are just as important. There were certain conditions of a material, temporal and social nature that, in retrospect, came together in recruiting Dharmadhikari into this instrumental community and allowed him the success that he achieved. Based on this discussion one might even argue that there would have been no STM in Pune had Dharmadhikari not been a surface scientist to begin with and if he did not have the access to the key centres of STM development in the early years. These were perhaps necessary conditions, but it also worth asking whether they were sufficient by themselves.

It is important to note that Dharmadhikari's first encounter with the STM had left him feeling that it was too "complicated" and expensive for him to be able to make it in India. That he was able to in spite of this initial reaction, is more than evident from the brief historical account outlined above and this nicely sets the stage for some very interesting and important questions: What was the context and actions that allowed this to happen? How did he overcome the factors of the 'complicated' and the 'expensive'? What materials, people and skill-sets did Dharmadhikari recruit for this purpose? How did he find what he needed and how did he use what he found?

Many people I spoke to, including Dharmadhikari himself, noted that there was a culture of making instruments in the Physics Department at the University

38 The 1930 Nobel Prize for Physics was awarded to C.V. Raman for his work on the scattering of light that is now known as the Raman Effect. 
of Pune from the very beginning. This was inspired quite explicitly by the larger ambition of building the (postcolonial) modern state that was both, self reliant and also scientifically and technologically advanced (cf. Abraham, 2000; R.S. Anderson, 2011; D. Raina, 2003), the context of which has been discussed in Section 1.1. The big constraint was the serious shortage of resources available for scientific research (Balaram, 1999; Mashelkar, 2011b), which in turn led to an overarching national policy (and rhetoric) where scientists and technologists were exhorted from the highest political levels to achieve self-sufficiency and self-reliance. This is evident in the various policy documents that have been discussed in the preceding chapters and in the many statements politicians have made over the years. What India's first prime minister, Jawaharlal Nehru (2003), said at the time of independence (Section 1.1) was reiterated in different ways by politicians in the decades that followed:

\begin{abstract}
Self-reliance must be at the very heart of S\&T planning. There can be no other strategy for a country of our size and endowments (...) Considerations like security, time factor, performance guarantee and costs often compel us to buy advanced technology from the international market. But in the ultimate analysis, neither true defence nor true development can be bought or borrowed. We have to grow them ourselves (Prime Minister Indira Gandhi quoted in Menon (1982, p. 1276).
\end{abstract}

While is it important to underline this national context (also see D Raina, 2007) and its influence on science and scientific activity, my focus will be on the specifics of Dharmadhikari's instrument building - on the 'nuts and bolts' of his efforts, and the details of how he overcame the obstacles of complexity and cost to build his instruments in the context and the resources that were available to him. These are at the heart of the 'culture of innovation' I had set out to study and what follows is an account of precisely these details: the how and what of these STMs, the materials, processes and people that were recruited in the process, the bridges that were built and new meanings that were generated. To get an understanding of this, however, we have to first take a detour into the world of a quintessentially Indian idea - the idea of jugaad.

\title{
3.3 Jugaad and its many avatars
}

It might be relevant to mention here that almost no conversation on innovation in India, particularly in the upper half of the country, can happen without a reference to jugaad. It is a term that is as often maligned as it is used with pride and it tends, therefore, to sidetrack discussions on invention, innovation and creativity. It was for these reasons that I had made a conscious decision when I began that I would not engage with jugaad at the outset and see where 
the discussions and learnings around innovation take me. As it turned out, and not unexpectedly I can say in retrospect, there can be no escaping jugaad. One might want to give it a miss, but it will not allow itself to be overlooked. I tried and to put it very simply, failed. And failed quickly. I may dare say that no research, discussion or deliberation on innovation in an Indian context can afford to ignore this jugaad, not even in the context of a modern scientific laboratory.

Jugaad is a word in many Indian languages such as Hindi, Marathi, Gujarati, Punjabi, Oriya and Mythili that are spoken north of the Vindhya Mountain range; it is also a term that does not appear to have an easy equivalent in English. It is not just an inextricable part of these local vocabularies, it is an integral part of the way life is lived and the world negotiated. It means different things to different people in different contexts: it is used to explain the process of reconfiguring materialities to overcome obstacles and find solutions; it could mean working the system to one's advantage; it is used as a synonym in certain contexts for gambling and corruption; and across large parts of Western and Northern India there is a self-rigged vehicle, that also goes by the name of Jugaad. Here it becomes as much a noun as it is a verb - concept, process and product all rolled into one at the same time - an idea characterized by plasticity and an articulation that has a wide range of meanings and usages that revolve primarily around problem solving or solution finding.

It is not surprising then that jugaad comes up repeatedly in discussions related to innovation with as many translations and interpretations as there are authors - "creative improvisation" (Krishnan, 2010); "developing alternatives, improvisations and make dos" (Prahalad \& Mashelkar, 2010, p. 3); "an arrangement or a work-around, which has to be used because of lack of resources" (Rangaswamy \& Sambasivan, 2011, p. 558); and "creative adaptation" and adjust (Cappelli, Singh, Singh \& Useem, 2011, p. 95). One of the most comprehensive and evocative rendering of what jugaad means in its multiple facets is provided by writer-diplomat and prominent chronicler of contemporary India, Pavan Varma ${ }^{39}$ :

There is an Indian expression and, like others, is quite impossible to adequately translate: jugaad. People are encouraged to use some jugaad when faced with a blank wall, or a difficult situation. Jugaad is creative improvisation, a tool to somehow find a solution, ingenuity, a refusal to accept defeat, initiative, quick thinking, cunning, resolve and all of the above (Varma, 2004, p. 72).

39 I would like to thank Rishikesha Krishnan to draw my attention to this work by Pavan Verma. It is striking to note, however, that Varma's exposition of jugaad appears not in the 'Technology' chapter in his book, but the chapter titled 'Wealth'. The 'Technology' chapter deals only with India's much discussed Information Technology (IT) sector. 
The diversity and the richness is evident in the different ways jugad is translated, interpreted and used.

\section{Celebrating jugaad}

One strain of discussion in the popular media has an evidently feel good and celebratory air about jugaad - what might be described in the words of Philip et al. (2012, p. 14) as "pleasurable or strategic essentialism," and may be explained as a process of making a virtue out of necessity. The popular news magazine India Today, for instance, notes in the editorial of a special issue on innovation that,

The best translation of that word [jugaad] is a combination of innovation and enterprise (...). Jugaad to Indians was both instinct and inspiration. The drive for a better way out, after all, is in India's bloodstream (Purie, 2010, p. 1).

The editorial of another edited volume of case studies on innovation by the business news weekly Businessworld, notes similarly that innovation for many Indians is "jugaad - the way of finding solutions to great problems using little more than ingenuity and a can-do spirit" (P Datta, 2010, p. 4).

The celebratory slant notwithstanding, it is evident that jugaad in these publications is dealt with only in a perfunctory manner. The term appears only in the editorial notes in both the publications and that too only in passing. The India Today issue, for instance, profiles 20 innovators and innovations that range across diverse fields such as traditional pottery, modern medicine in the time of the swine flu epidemic and the development of a pedal power driven machine for washing clothes. Jugaad, however, does not find a mention anywhere in any of the detailed accounts of these innovations. The Businessworld compilation similarly discusses 23 case studies under the broad headings of 'Business/Process Innovation', 'Social Innovations' and 'Organisational Innovations', but makes no mention of jugaad at all.

Another illustrative account with jugaad is seen in the New York Times article by journalist Anand Giridharadas (2010) and in the book, Jugaad Innovation (Radjou et al., 2012) - both, strikingly celebratory of their respective ideas and interpretations of jugaad. Giridharadas offers the concept and particularly the automobile named jugaad (see next section for a detailed account of the jugaad automobile), as the great innovative capacity of Indian genius and the alternative to the crises of the recent economic meltdown. Giridharadas claims that "jugaad is a way of life (...) that has anticipated important movements of the 21 st century, from open-source technology to cultural fusion", and yet he appears to deny it agency when he positions the global economic order as the primary paradigm within which innovation or its variants are allowed to perform. 
Radjou et al., too discuss jugaad from within a corporate and need-tomake-profit framework: "in today's consumer-driven economy we know that it's more important to commercialize technology" (Radjou et al., 2012, p. 11). They outline six principles of jugaad - i) seek opportunity in adversity, ii) do more with less, iii) think and act flexibly, iv) keep it simple, v) include the margin, and vi) follow your heart - all made with an explicit aim of helping "Western firms innovate and grow in a highly volatile and competitive environment" (p. 20). They use the category and the concept of jugaad retrospectively and in my opinion, too widely and expansively than it should be. Theirs is the classical imposition of the analyst's category, and what the actors have to themselves say of their own work and their innovation has no space here. My disagreements with Radjou et al. will also be starkly evident in my characterization of Technological Jugaad (Section 3.6). While Radjou et al. ask for the "margins to be included" when they talk of jugaad innovation, my contention is that jugaad in an Indian context is located primarily in the margins - where then is the question of including the margins? Further, and as I have noted above, they offer jugaad innovation to the western entrepreneur as a solution in a competitive and volatile business environment, while my contention is that survival, and not commercialization, is the primary intention of jugaad. The jugaad might eventually become a commercial success, but in the first instance it lies outside the broad framework of the market place. If survival in the competitive business environment is what Radjou et al.'s jugaad is about, one might see some overlap and agreement, but our frames and world views remain diametrically opposite just like our points of entry into the discussions and the conclusions reached.

\section{An embarrassment called jugaad?}

On the opposite end of feel good spectrum of jugaad is the recent, wide ranging and damning account by Thomas Birtchnell (2011) where he makes two key points - first, the underlying chauvinism in the increasing wide usage and adoption of jugaad that he links to the projection of India's future hegemonic potential; and second, that "jugaad impacts on society in negative and undesirable ways $(\ldots)$ [and] (...) is wholly unsuitable both as a development tool and as a business asset" (ibid. p. 357).

Located on another axis, away from the celebration and the chauvinism, is a space where jugaad encounters much skepticism and even denial (P. Datta, 2010; Krishnan, 2010; P. Munshi, 2009; Prahalad \& Mashelkar, 2010). The inside flap of Porus Munshi's book (P Munshi, 2009) notes, for instance, that "India is known as a country not of innovation but of improvisation - or 'jugaad' as they say in Hindi". In a recent issue of the business newspaper, Mint, the editorial argues that "it is time we moved from the glorification of jugaad to the celebration of true scientific innovation" ("The Missing Revolution," 2012). Prominent lawyer and politician, 
P. Chidambaram, was quoted similarly when he was Finance Minister of India in 2012 , as saying that

Jugaad is not innovation. It is a very corrupt way of looking at innovation. We are quite adept at getting things done. But what we really need is to appreciate and reward genuine innovation ("Jugaad in not innovation: P.C.," 2012).

The use of jugaad here is seen more in its negation - it is what innovation is not and should not be; it can be, at best, only a stepping-stone to the 'real', the genuine and a more systemic paradigm of innovation. Rishikesha Krishnan (2010) argues, for instance, that the journey that needs to be made is clearly away from jugaad and towards 'systematic innovation'. He acknowledges that innovation results from a complex interplay of policies, institutions and incentive structures and, further, that innovation systems of countries are influenced by "historical, political, cultural, social and economic factors and philosophies" (ibid., p. 44). Yet he notes:

industrial innovation abilities in India can't be strengthened without a more widespread belief in the scientific method... [that] underlies research and all forms of systematic experimentation and exploration. Unfortunately, India remains stuck in a more unscientific paradigm of innovation, often labeled as jugaad (ibid., p. 170).

There is neither a conceptual nor an empirical engagement with jugaad in the entire manuscript and yet it is dismissed emphatically. Prahalad and Mashelkar (2010, p. 6) also dismiss jugaad similarly because "the term (...) has the connotation of compromising on quality." They prefer to use the term 'Gandhian Innovation' for examples such as the development in 1991 of a super computer by an Indian firm at a cost of US\$20 million and the much more recent 'Tata $\mathrm{Nano}^{30}$, the world's cheapest car available at a price of US\$ 2000 (Chacko, Noronha \& Agrawal, 2010 $)^{41}$. It is an articulation that comes across as conflicting with Gandhi's own accounts of and vision for science, society and technology (C.S. Prasad, 2001) and the more recent articulation seen in the Gandhi inspired 'Knowledge Swaraj: An Indian Manifesto on Science and Technology' where the effort has been to provide

an earthy fragrance that brings together the ordinary majority, and with an innovative spirit that breaks the vicious cycles that many sectors have

40 This has nothing to do with nanoscience or nanotechnology.

41 The car that was hailed as innovative and a big success when it was launched is now acknowledged, even by its producers and promoters, as a near complete failure in the market (cf. Madhavan, 2013; McLain, 2013). 
been trapped in (...). Indian citizens are thus seen as active contributors in the knowledge society and not as mere recipients of science and technology (SET-DEV, 2009, p. 5).

While jugaad itself does not find mention in the manifesto, it is evident that it will get a far more enthusiastic welcome in this framework of innovation in and for science and technology.

The position that the various authors have taken is evident and yet there are two elements that, though unstated, stand out in common in almost all these narratives. Firstly, there is little, if any, empirical engagement with the jugaad that is being discussed. Second and this is of particular relevance in the context of this thesis, there is no discussion at all of jugaad in relation to research and development in the S\&T enterprise of the country. If jugaad is indeed inferior, unsystematic and a compromise on quality as noted by a number of authors above, it is not a surprise that it has no place in discussion about formal S\&T in the mainstream; S\&T research is believed, after all, to be the holy grail of innovation, creativity and progress.

Herein lies a significant paradox, the exposition of which is the key contribution of this particular case. Jugaad, as I found out and the subsequent narrative will illustrate, appears to be alive and kicking in the modern scientific laboratory and the scientific method, and there is no compromise on the quality of the output either. Importantly, I am not using jugaad here to describe and characterize only what I as an STSer saw and interpreted in the laboratory; it was a term and an idea that the analyst (myself) and the actor (Dharmadhikari, the principle scientist) came to accept together as a concept that could be used.

The lesson is a clear one - S\&T cannot be separated from the other aspects of the society and culture of its location. If jugaad exists in all domains of Indian life be it industry, social enterprise, business processes, or rural innovation and adaptation, there is no reason why its imprint will not be found in S\&T research and development as well.

\subsection{Technological jugaad that made the STM}

Perhaps, the best-known jugaad product in India is an automobile (Images 10 \& 11) that is found across the northern and western parts of the country. It is created using a non-standardized manufacturing process, is not registered with the relevant authorities and does not exist, therefore, within any formal legal frame. The interesting thing is that every such vehicle differs from the other, and the only thing that binds them together is that each is fabricated locally and by assembling different parts that are generally procured from other scrapped vehicles - engines, tyres, wooden planks, steering wheels, seats and even agricultural water pumps. There is no restriction on what is used and it generally depends on what is available at 'that place' at 'that time', leading also to names 

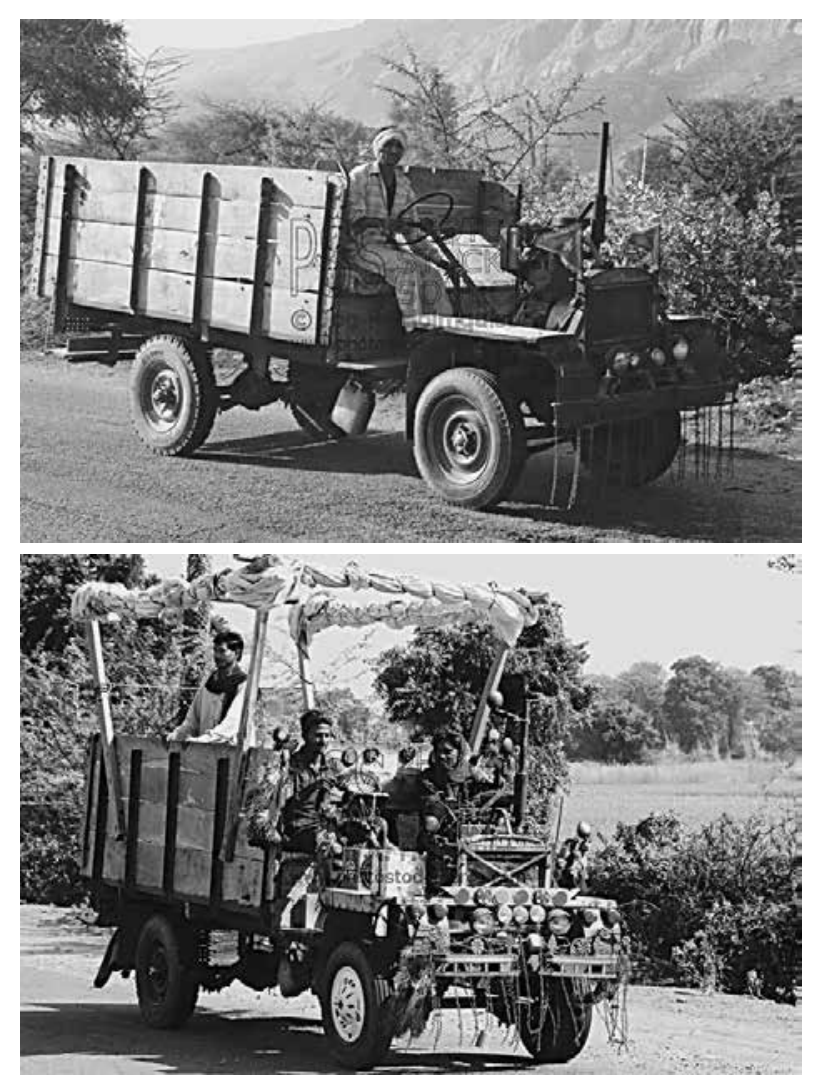

Images 10 \& 11: Two versions of the jugaad vehicle from North India (Pic Courtesy: The Internet)

that are varied and different - Jugaad (Jolly, 2009) and Maruta (Purie, 2010) in parts of northern India and Chakda in certain regions of western India (Varma, 2004 , p. 73). The automobile so created is, generally, a locally crafted solution to an immediate problem such as a bottleneck in transporting agricultural produce to the nearest mandi (whole sale market for farm produce) or to transport people in a landscape of limited connectivity and mobility choices. These automobiles, were in fact, recently banned by the Supreme Court of India because they were not registered, not insured and failed to meet certain quality parameters (Anand, 2012; “S.C. Bans Farmers' 'Jugaad,"” 2013).

Another well documented though less prevalent form of jugaad is the use of an existing artifact for purposes completely different from what is was originally created for - "materials put to uses few could have imagined" (Philip et al., 2012, p. 13). The best known example of this is again found in parts of north India where washing machines are used to prepare lassi, the popular local drink made from churning curd, sugar and water at high speeds.

Similar examples have been presented in Kline \& Pinch (1996), which is an account of the different uses the automobile was put to in North America in 
the early part of the 20th century; in Radjou et al. (2012), of an interesting recent case where Chinese farmers were seen using washing machines to clean their vegetables and by R.N. Reddy (2013) where he describes how in recycling and re-using electronic waste in the city of Bengaluru in south India, the informal recyclers learn new skills, extend the life and meaning of thrown away products and also make money in the process.

There are many such examples of jugaad found all over India even though the word itself may be found, as mentioned earlier, only in vocabularies in the northern parts of the country. Evidently, this jugaad is a locally crafted solution to an immediate problem. It is often a personalized survival tactic in situations of obvious resource constraints and/or denial (Rangaswamy \& Sambasivan, 2011; Varma, 2004), and this is a characteristic that is fundamental and crucial to keep in mind.

\section{Reconfigured materiality and technological jugaad}

There is one thing that stands out in most of these cases of localized and contingent improvisation and innovation, and it lies at the heart of what I am proposing as 'technological jugaad'. It is the element of reconfigured materiality that is implicated very centrally in the processes involved - in putting materials to uses not imagined initially, giving them fresh meaning and purpose, and creating new worth and value. My key intention is to narrow down from what is otherwise a many possibilities and broad-spectrum interpretation of jugaad, to focus attention on the making of the instruments by Dharmadhikari and his research group. It is this concept of reconfigured materiality and technological jugaad that I saw operating prominently in this probe microscope making enterprise of more than two decades and the following three quotes from different, though related, sources illustrate how this was done in Dharmadhikari's laboratories:

There was a huge magnet and I got a bobbin - a plastic bobbin from a tailor and we had a coil on that. That coil was put in a magnet and we hammered it with a wooden hammer. Then we looked at the resonance frequency. Simple technique (...). Now with (...) the latest vibration system we are getting the same resonance frequency after 20 years (...). Then we developed one [STM] in a fridge [Image 12]. I had a student from the Middle East. He said I am leaving and what do I do with my fridge? He gave it to me - we removed the compressor and it was a good acoustic shell (...). It's a totally new concept - it was used for nanotechnology (Dharmadhikari, Presentation ${ }^{42}, 11$ March 2011).

42 The presentation was made at a 'National Workshop on Scanning Probe Microscopy: Techniques and Applications' organized in March 2011 at the University of Pune to felicitate Dharmadhikari on his retirement. 
Like some of the piezos we used from (...) ink jet printers. The older models used piezos, so we took out those piezos and used those. Or the buzzer element. Jugaad is something like the spectrometer we used for the tunneling and photon microscopy - we got it from junk, repaired it, improvised and used it - this is a jugaad (...). I used to go to juna bazaar [junk market] and find out how much is the resolution of stepper motors. [For] (...) the older, hard disc stepper motors we found out that [the] information is not available. To develop techniques to measure how many steps it goes, (...) I think is jugaad, because you find one technique, you use another one, (...) plug them together and once you do it, you have all the technology that they already invented - [but now] for something else (Dharmadhikari, Interview, 02 March 2011).

STM operated in air is susceptible to (...) acoustic pickups, so (...) [the first] STM (...) was encased in a plywood box (Image 16) lined with foam and glass wool pillows. The thickness of the plywood used is 20 $\mathrm{mm}$. [In the 2nd STM] the vibration isolation was achieved by keeping the STM head on a steel round base plate (...) [and] the whole system is suspended with "bungy" cords (Image 13) using [a] tripod- stand (Images $12 \& 16$ ). It was found that resonance frequency of the system is $\sim 2 \mathrm{~Hz}$. To protect the STM from acoustic noise, the total system is encased in a fridge-case (from which compressor was removed), since the fridge case (Image 12) has [a] metal frame [and] shields the STM from high frequency noise. [The] body has glass wool insulation, which protects the STM from acoustic noise. It was found that the acoustic signal inside the fridge is less than $2 \mathrm{~dB}$ (Iyyer, 2006, pp. 51-52).

Discarded refrigerators (Iyyer, 2006) (Image 12), stepper motors from junked computers, tubes from car tyres (Datar, 2004; SV Patil, 2002) (Image 14), bungee chords (S.V. Patil, 2002) (Image 13), viton rubber tubing (Dey, 2010), weights from the grocers' shop, aluminium vessels generally used in the kitchen, a tuning fork from inside a wrist-watch condensor (Kolekar, 2013) (Image 15) and bobbins from sewing machines are a few examples of what went into the making of the first prototype and the other probe microscopes that followed. For Dharmadhikari, one has to innovate with whatever resources, knowledge and infrastructure one has in hand because no other option is available. The parallel with the examples of technological jugaad - the jugaad automobile and the use of the washing machine mentioned earlier, is immediately evident - existing materials and artifacts are used in completely new ways and/or are combined with each other to construct and operationalise a new idea or concept. It is not just reconfigured materials but also the thinking and processes involved that contribute. 

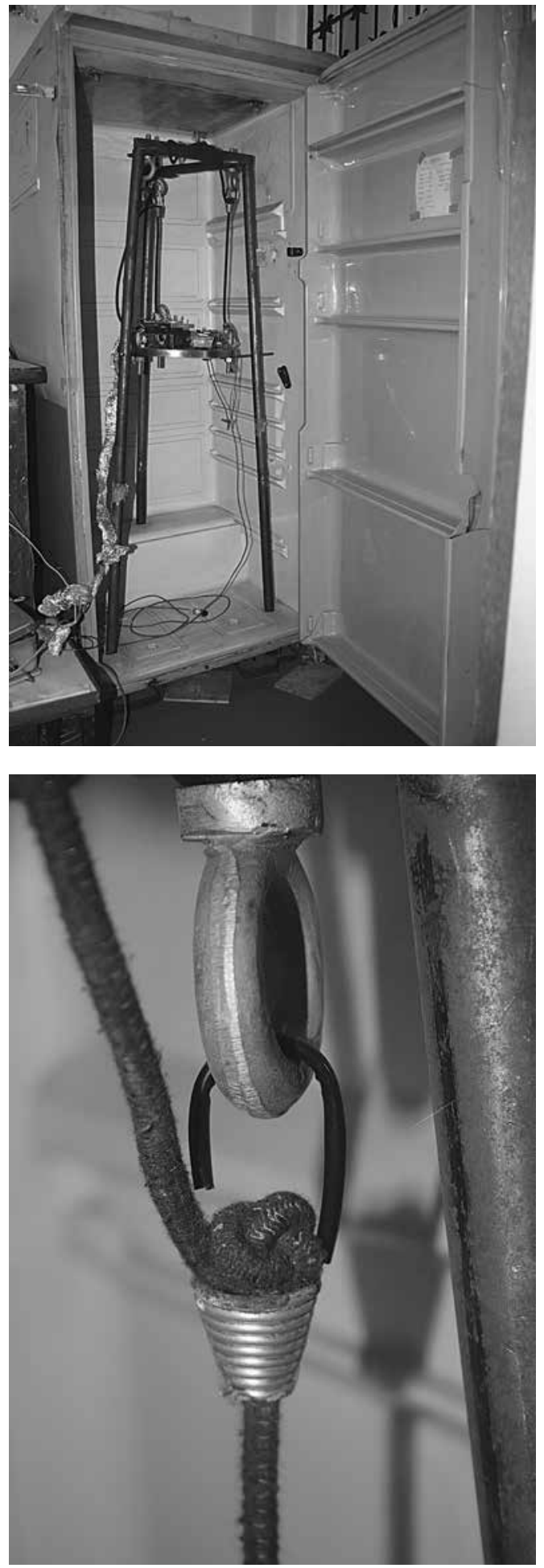

Image 12: One of earliest STMs that was installed inside a refrigerator shell (Pic: Author)

Image 13: Using a bungee chord inside the refrigerator to help in additional vibrational isolation (Pic Author) 


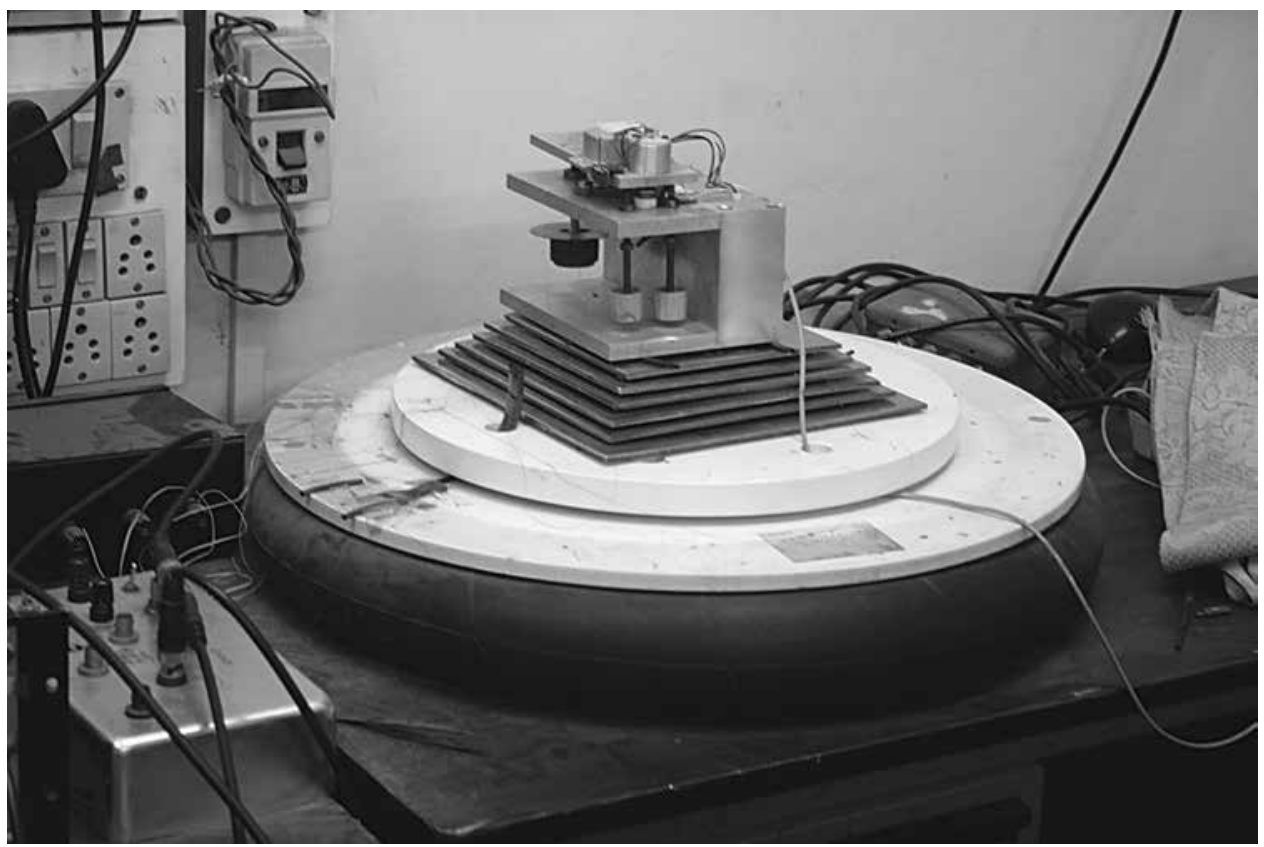

Image 14: A table top STM placed on the inflated tube of a car tyre for vibration isolation (Pic: Author)

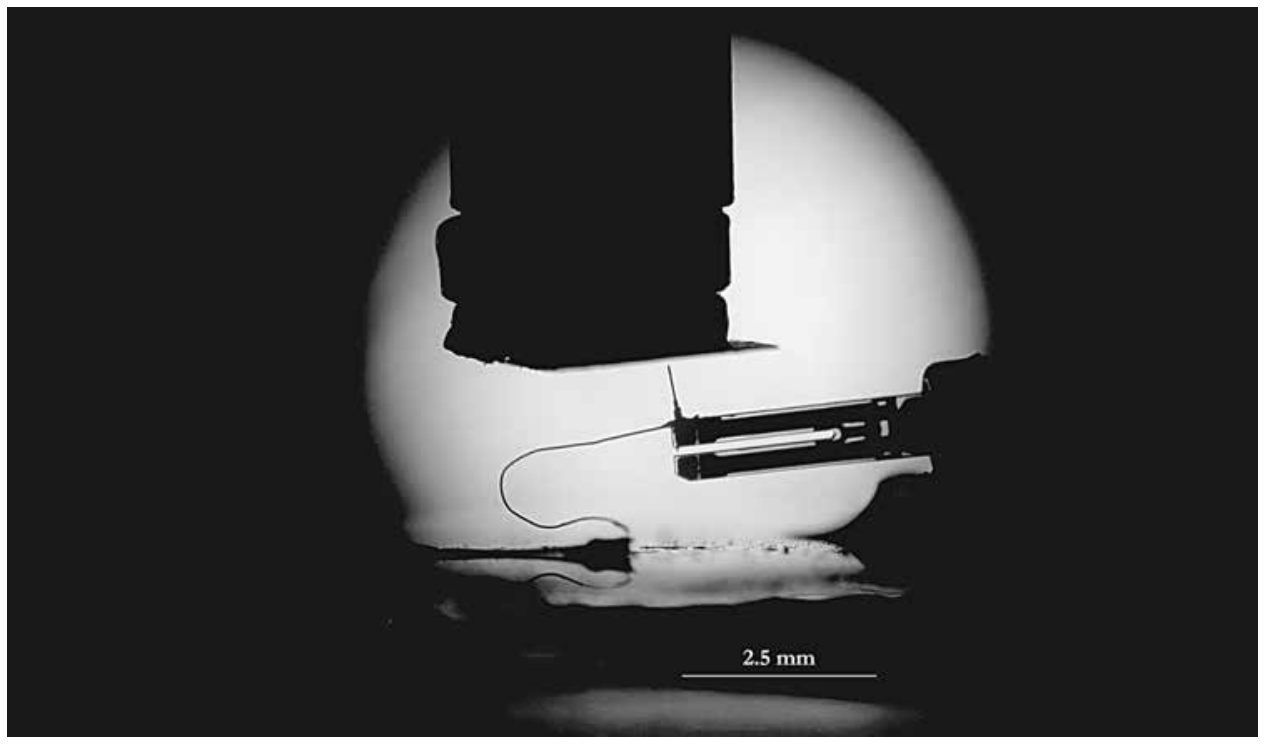

Image 15: The experimental set up of the Ultra High Vacuum STM-AFM, the latest in the series of instruments made by Dharmadhikari and his students. Attached here to the bottom of the peizo scanner is a vertical CNTs sample. The vertical wire attached to the top prong of the tuning fork (length: $2.4 \mathrm{~mm}$ ) is the STM-AFM tip made of tungsten. The horizontal curved wire attached to the tungsten tip is a copper wire providing the electrical connection. The tuning fork used has been pulled out from a wrist-watch (Pic: Author) 


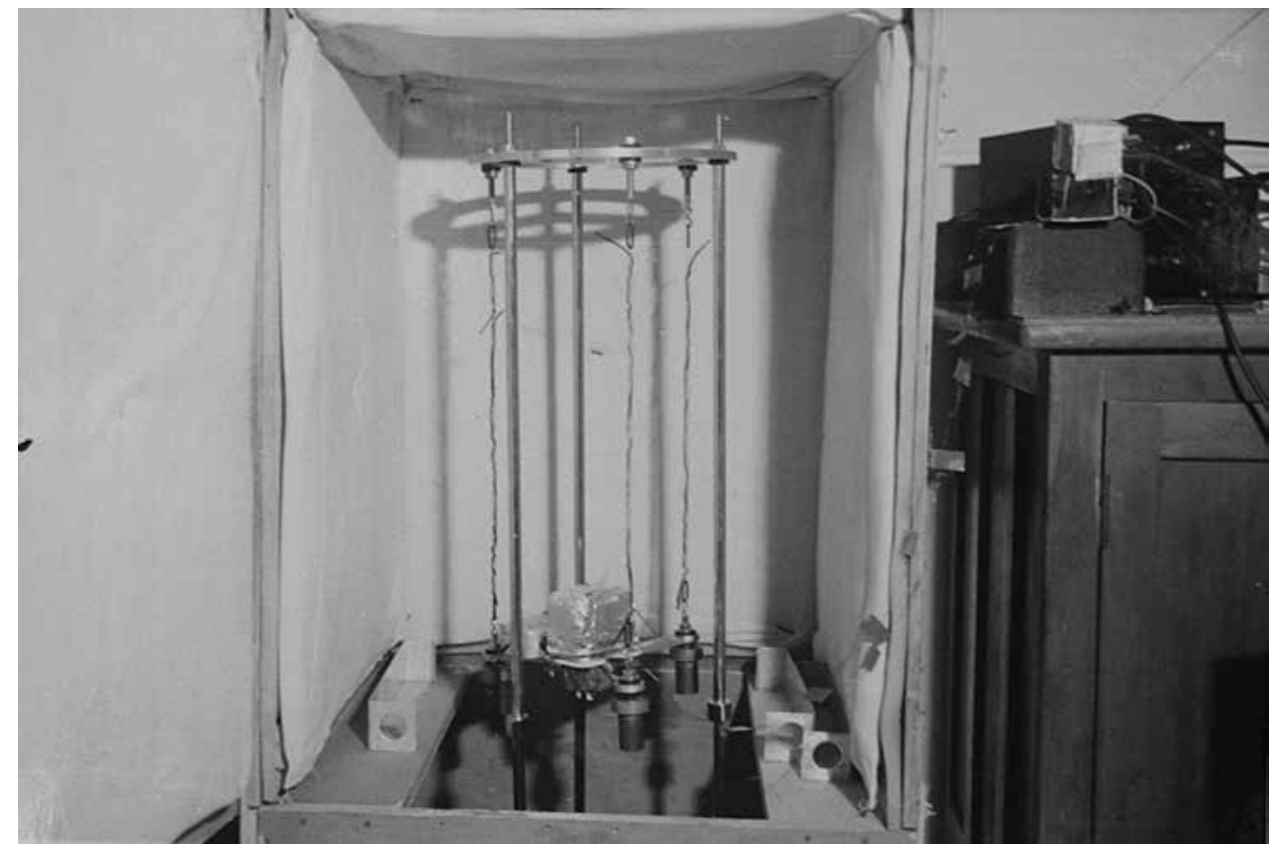

Image 16: A picture from the 2006 PhD thesis of S.B. Iyyer showing the STM set up. This STM was assembled inside a padded up plywood box to isolate vibrations

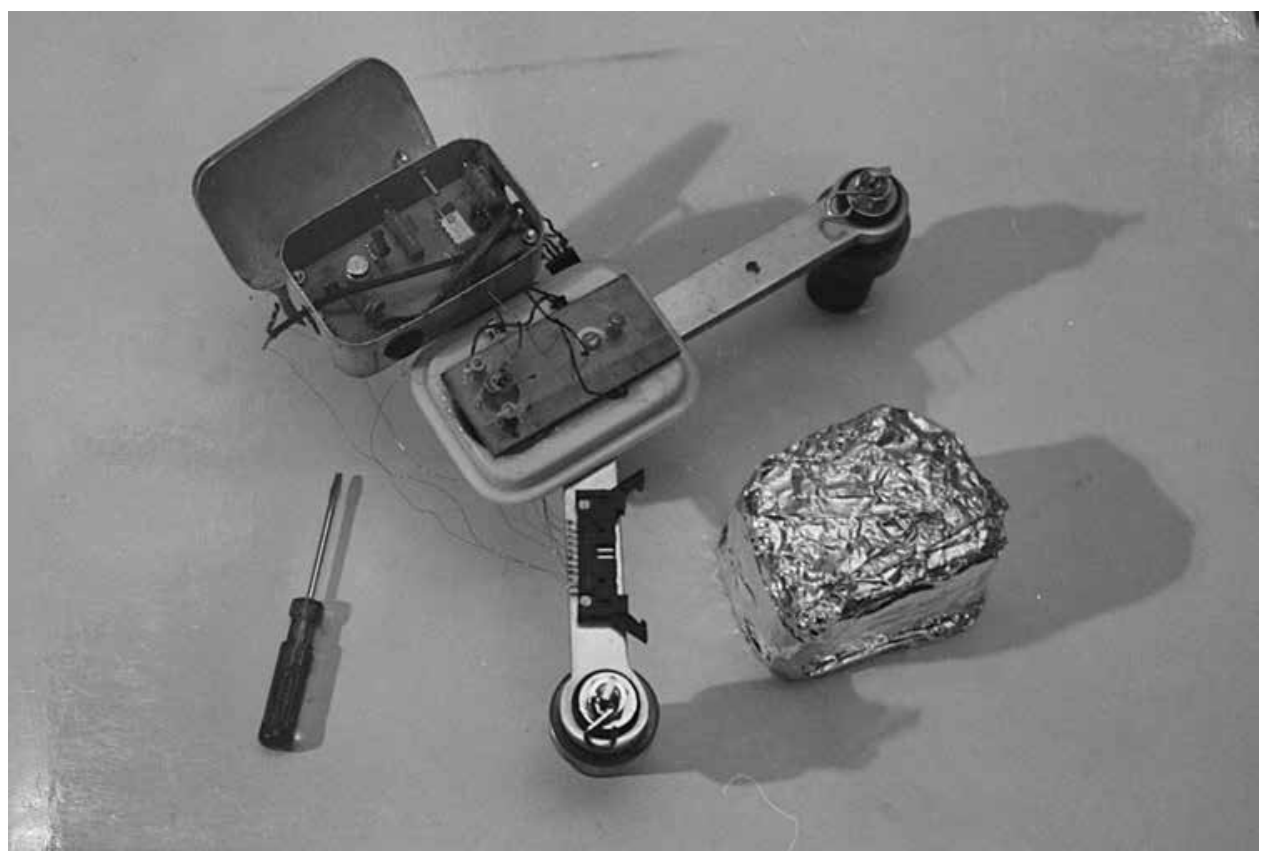

Image 17: A picture from the $2006 \mathrm{PhD}$ thesis of S.B. Iyyer 


\section{Embedded in the local geography}

Crucial to success was a knowledge of the market as well - not just for the STM as a product, but also for the STMer as a consumer of the materials, skills and knowledge that were needed for making the STMs. It was also not good enough to only know what materials or skills were needed; one also needed to know where these could be found. A knowledge of the geography of the place and the relationships that built it was essential. Where would the old computers be found? Which small time workshop would make the springs of just the right tension? Who would make the few components that had to be custom made? Where was the acoustics expert who would help design an ideal casing for the STM?

While an obvious resource constraint certainly drove the innovative and creative endeavors of Dharmadhikari and his team, it is not sufficient to explain everything. There are at least a few other elements involved and an important one, as Dharmadhikari emphasized a number of times, was the overall atmosphere of the city of Pune:

There [was in Pune] a lot of awareness, support, software development, computers; engineering schools were coming up [and there were a] lot of R\&D set ups. (...) We have [many] success stories in Pune (...) and [there were] these younger people who started their own companies with very modest budgets. [For] (...) any problem (...), right from image processing [to] development of hard [ware] (...) [they] would interact with us. My students will go and work in their factories and (...) it gave us a tremendous platform to work. That is Pune (Dharmadhikari, Interview, 4 March 2011).

Not only were there a large number of educational institutions in Pune, but there was also a thriving small and medium industry enterprise located in the city and its suburbs where people were willing to try out new ideas, take risks and help others when something interesting was being attempted.

And there was also the other set of people - a small, but critical set of scientists in nearby institutions who were the users of Dharmadhikari's instruments, of the knowledge that he and his research group produced and the different skills they developed. It was a mutually beneficial relationship as Dharmadhikari pointed out:

A lot of people who were doing nano wanted to look at nano particles, DNA, all kinds of combinations of nanostructures (...). Many times we did not get results and we ended up improving and developing newer techniques (...) My first interaction in nanotechnology was because of the people [who] were unable to get images on commercial instruments and so they approached me and I obliged them by some results or the other (Dharmadhikari, Interview, 4 March 2011). 
Almost every laboratory in India would have approached us (...). Those who got good results thought their samples are very good [and] those whose results were bad said [there was a problem with our instrument]. (...) The important thing I noticed was they were coming in large numbers and it was the best way to test your instrument and improvise (Dharmadhikari, Presentation: 11 March 2011).

Evidently, Dharmadhikari was well embedded in this elaborate geography and network of relationships and this was needed if he was to effectively capitalize on and tap into it for achieving the ends he wanted to.

\section{Other ways of doing}

The other important dimension that stands out for the diversity and richness of the skills recruited, and the relationships used was the incorporation of and collaboration with what one might call other ways of knowing or knowledge systems - the 'unexpected' players. This included, among others, a small time entrepreneur with a spark erosion machine, a road side workshop for aluminum sand dye casting and the procurement of springs from a workshop owner who would not understand the spring constant, but could deliver the needful based on the Dharmadhikari's explanation of the requirements and the tacit knowledge embedded in his fingers. In another marginal case, Dharmadhikari even enrolled the traditional plating technique of kalai, the practitioners of which travel from house to house in rural and urban areas offering tin plating services to housewives and restaurants for their copper and brass utensils.

Use of materials and skill sets that are available in and contingent to the context come across as key elements of Dharmadhikari's efforts and his success. It was not just part of knowing and being embedded in the geography and extended network of relationships, but also an acceptance and acknowledgement that capacity, skill and knowledge can be found in other domains as well.

\subsection{Critiques, questions, evaluations}

Discussions with Dharmadhikari, with a set of scientists that either knew him or his work, and a perusal of literature in the context of Dharmadhikari's instrument building underlined many important critiques and questions. While some of these were of a general nature, others were specific to Dharmadhikari, his style of working and the instruments he and his students made.

These critiques and questions can be located within three broad domains. The first was the institution of the university - broader issues of the state of India's universities, their challenges, capacities and outputs ${ }^{43}$; the imperative of

43 The primary body governing higher education in India is the University Grants Commission ((UGC) (www.ugc.ac.in). There are roughly 600 universities in India that includes a combination of central and state universities (both state supported and private), deemed universities (also 
teaching and the demands of research; the shortage of resources and the visible tension between the universities and the network of centrally funded research laboratories. It is a situation captured well in Dhruv Raina's (2003, p. 134) observation that "in the last few decades mission oriented science has grown at a faster rate than science in the academic sphere". Many of the university scientists I spoke to noted that these national research laboratories not only got a major chunk of the research funding made available by the government, they also took away the cream of the students that were trained in the university departments. This was a vicious circle - good students didn't stay back because the incentives and infrastructure were not good enough and at the same time, the absence of good researchers and research meant that the claim for more resources was a difficult one to make (cf. D. Raina, 2007; N Tyabji, 2011).

The 2nd domain of discussion revolved around the personal - on lines of what Lorenz-Meyer (2012, pp. 253-254) has conceptualized as the tension between the enterprising laboratory and the vocational laboratory:

the binary opposites of East and West, local and global, static and dynamic that buttress (...) the superiority of the Western enterprising laboratory by equating it with outstanding international performance and excellence.

A similar binary was articulated by a senior scientist when he spoke of the "relaxed and non-ambitious way of Dharmadhikari's approach," where wisdom and knowledge mattered more than science, and where research was becoming all about publishing and moving aggressively up the career ladder. Dharmadhikari, he said, was the old school professor who did pioneering work but was bogged down by his personality and the university system that neither gives incentive to scientists to excel nor pushes them to the limits of their potential and capabilities. In this, he felt, Dharmadhikari lost out and achieved much less than what he actually could have.

While these two domains are crucial as the context of Dharmadhikari's work, my main thrust will be on exploring the 3rd domain of the discussions. This is about the instruments themselves and the issues that were raised around their construction, their operation and use, the results that they produced and the potential they (did not) have.

state and privately supported) and others like the Indian Institutes of Technology (IITs) that are called Institutions of National Importance (P. Banerjee, 2009; Deloitte, 2012; Hiriyakkanavar, 2015). The S\&T research infrastructure includes about 40 laboratories under the Council for Scientific and Industrial Research (CSIR) that are concentrated on applied research and a number of other laboratories concentrated on both basic and applied science that come under respective S\&T departments of the Government of India such as the Department of Science and Technology (DST), the Department of Biotechnology (DBT), Department of Space (DoS) and the Department of Atomic Energy (DAE) (P. Banerjee, 2009; Hiriyakkanavar, 2015). 
In March 2011, the Physics Department at the University of Pune organized a national seminar on STMs to felicitate Dharmadhikari who had retired only a few months earlier. Those attending came from prestigious institutions from different parts of the country. All who spoke at the seminar and this included senior scientists, collaborators, his students, the incumbent and former Heads of the Physics Department, and Vice-Chancellors of the University of Pune, paid glowing tributes to Dharmadhikari - not surprising considering that this was a public forum. They were unanimous in their opinion that he had been innovative and pioneering. Many recollected and emphasized how his lab was the only destination in those early days for anyone who wanted to learn about or do something with scanning tunneling microscopy. In more private conversations, however, at least a couple of these speakers, (again, not surprisingly), were distinctly more circumspect with their praise.

From these conversations and the other interviews I conducted, a broad consensus emerged that Dharmadhikari had indeed made a significant contribution to the development of nanoscience and nanotechnology in the country. Murali Sastry, one of India's more prominent nanoscientists is convinced, for instance, that Dharmadhikari's instruments were pivotal in the progress of his own research career, and for that matter, the field in the country. Sastry was at the National Chemical Laboratory, Pune, when he first collaborated with Dharmadhikari and his STMs in the middle 1990s. The two of them and their students collaborated over a long period of time thereafter, jointly publishing research articles in leading journals (see, for e.g., Dey, Pethkar, Adyanthaya, Sastry \& Dharmadhikari, 2008; A. Kumar et al., 2001; Sastry et al., 2001) and also jointly supervising $\mathrm{PhD}$ students (Chaudhary, 2011). The relationship and the benefits were mutual. Dharmadhikari acknowledged the challenges offered by Sastry in improving and improvising his instruments, while Sastry believes that he would have lost at least five years in his research work if Dharmadhikari's instruments were not here. It was crucial that those instruments, even with all their limitations, were available in those early years.

\section{The commercialization question}

One of the most consistent critiques of Dharmadhikari's work was related neither to the quality of his instruments nor to the (jugaad) way he made them, but the fact that he never tried to commercialise them. 'If these were such good instruments and they were producing good results why did he not take them to the market?' was a constant refrain. This was articulated most sharply by NA, a noted scientist and science administrator intimately familiar with the Department of Physics at the University of Pune and more specifically, the work of Dharmadhikari as well: 
I feel that this entire approach and the development of an instrument could have been taken to a still higher order of proficiency and acceptability - [and to a] very clear and easily accessible instrument. Now, I think, this is where the group lost the lead (...). Your mind is always occupied with prototype instruments and prototype research - pure research - you see. So, I think that is where that convergence got lost (...) [This] is a very qualitative judgement because I have not seen each and every research paper that has come. But whatever I have [seen] (...) gives me the feel[ing] that, yes there is an expertise, yes we had an early bird advantage, yes we created a prototype, we created many of them - every version a bit advanced version, but we could not convert that advantage into a production of such an instrument (NA, Interview, April 2011).

This concern and questioning is linked directly to the ingress of the market paradigm and neo-liberal economic agenda (VV Krishna, 2013; Mashelkar, 2011b), which, as we have seen (Sections 2.2 \& 2.3), has made deep inroads into the laboratory and in S\&T policy. While there is nothing wrong with the framework itself, the question might be about its appropriateness in this particular context. The preoccupation and the engagements with entrepreneurship, profit and a certain mode of economic and industrial production are sought to be imposed on a completely different endeavor without in any way factoring those imperatives. Forcing the question of commerce and the market on a scientist or a researcher who has no claims to or interest in entrepreneurship is akin to asking of a mass produced product why it does not have a differentiated identity or an individualized aesthetic? The limitation lies in the frame of the innovation discourse and the question, therefore, needs to be asked of this framework as well, and not just of the scientist or the scientific enterprise.

\section{Changing the terms of the conversation}

Is it not that Dharmadhikari and his students were not aware of or were not engaged with the commercialization question themselves. Their experiences and responses were, in fact, very alive and sensitive to the idea of commercial viability - only their terms and frames of reference were different.

The practicality and viability of possible commercialization initiatives were put into sharp perspective by Shivprasad Patil who made an Atomic Force Microscope as part of his doctoral work under Dharmadhikari's supervision and currently heads the Nano Mechanics Lab at the Indian Institute of Science Education and Research, Pune:

In India it is rather difficult to (...) spin off companies like what they do in western countries (...). The reasons are many and just not because 
of the funding or because of our structure (...). If you look at mobile phones, there is a huge market (...), but suppose I want to make an AFM and sell it, there is no huge market for such things (...). You [also] have to have the support system in universities itself - incubation and other things and these things don't happen in India as much as they happen in the western world (Patil, Interview, 2011).

The reality on the ground is surely far more complex than it is made out to be. Dharmadhikari noted that the commercialization idea was considered but his primary response was simpler and more direct as the following three short quotes, all from the same interview, illustrate effectively:

a) We never thought of it [commercialization]. We were so busy in publishing papers (...) doing science and I think the best way to test your instrument is to use it for (...) doing good science...

b) At the same time I realized that doing your (...) own experimentation is always interesting - more interesting, more challenging. [There is] less throughput, of course (...), but in universities this is a better approach because you are training the students...

c)I realized that if I can make simple [instruments] through the students, not only [will] we learn a lot about these techniques, (...) but we were also creating future generations which [was] proven later because most of the students got jobs in [the field of] nanoscience (Dharmadhikari, Interview, 04 March 2011).

The commercialization question, interestingly, was being dealt with by changing the terms of the conversation - "doing science" and "training the students" were at least as important as thinking about the possibilities of commercialization. For Dharmadhikari and his students this was indeed the "vocational" and not the "enterprising" laboratory (Lorenz-Meyers, 2012).

\section{A pedagogic tool}

This training-of-students perspective also fits in well with the considerable discussion that exists in literature on instrument making and doing things oneself as a pedagogic tool (D. Kaiser, 2005; Mody, 2004; Rasmussen, 1997), including in the specific case of probe microscopy in the USA (Mody, 2004, 2005). In a more general context, Mody \& Kaiser (2008, p. 380) point out that at "the level of institutions, decisions over which equipment to build and which lines of research to support are also interwoven with decisions of which type of training to offer." Interestingly enough and we see it in Dharmadhikari's case, the converse is also true - the kind of training capacity and expertise that is available with the institution and senior scientists will decide the kind of equipment that is built and the research that is performed. The (non) availability of certain financial 
and material resources meant that innovation in instrument making here would happen only along certain pathways - the jugaad pathway in this case. The value of this training and opportunity for hands-on-work was most strongly articulated by Dharmadhikari's students themselves. This, for instance, is what Patil had to say:

One thing that people blame you for is reinventing the wheel (...). I don't buy this argument at all because a lot of the people think that if I have a commercial AFM then I can work with it - why develop one? There are various reasons why you should build your own thing (...). If you have [an] AFM [from] the market, your ability of asking the question is itself limited because (...) [of] what a given instrument is able to do (...). No vendor, no one in the world, no company in the world, is going to customize for your needs and if they do they will charge you so heavily, you can't imagine (...). If, (...) right from your $\mathrm{PhD}$, you are building your equipment, there is (...) this freedom, this kind of sublimeness [and] (...) it liberates you (...). The moment you buy one or two crores worth of equipment you are stuck (...) [and] your mind is tied (...) to the instrument. You do only what that instrument allows you to; [you] are scared to use it to its fullest capacity. (...) [What are] artifacts, what is true information, what is the false signal? Those things - you know much better if you build your own stuff. People say you are reinventing the wheel [but] is not so, because it is really helpful at that time (Patil, Interview, 2011).

The training in and experience of doing things one self and the confidence that this helped him gain, held Patil in good stead between 2003 and 2007 when he was a post-doctoral fellow, first at Wayne State University in the USA and then at the Madrid Microelectronic Institute, Spanish National Research Council (IMM, CSIC) in Madrid, Spain. The benefits continue even today as he himself gets into more senior leadership positions and takes his training into his teaching as well. The other point he made is related to evaluation of the work in the lab:

Look at (...) the amount of money that [Dharmadhikari's lab] has taken in and (...) [the output] in terms of publications [and] in terms of training manpower [it has delivered]. Publication is not the only thing that you should judge the research group by, [but also] training manpower. I think it is tremendous (Patil, Interview, 2011).

Sastry (Interview, 14 March 2012) echoed the sentiment when he too noted that publications should not be the sole measure of one's scientific output. There is a lot of, what he called, "down time" in building an instrument, something for which there is never any acknowledgement! Naba Mondal, senior professor at 
the Tata Institute of Fundamental Research and Director, Neutrino Observatory Project, notes similarly in the specific context of high-energy physics that young researches are not taking up instrument building because the pay-off time is long, they lose out in terms of publications when compared to peers working in the lab or doing theoretical research and that it is necessary, therefore, to create "metrics that recognize instrument development and retain these skills" (Mondal, 2015, p. 155).

This issue is also directly related to one of the main challenges that scientists and science administrators around the world are beginning to face and write about today - two prominent examples being David W. Piston, Director of the Biophotonics Institute of the Vanderbilt University School of Medicine, USA, and P. Balaram of the Indian Institute of Science (IISc), Bengaluru and former editor, Current Science. In a short comment in Nature, Piston (2012, pp. 440441) notes how "over-reliance on automated tools is hurting science" and also that "the research community must take more responsibility for teaching the coming generations (...) how to build, implement and troubleshoot their own experiments at the most basic level."

Agreeing with Piston's observations, Balaram (2012a, pp. 1241-1242) rues the absence in India of

trained technicians with a high level of competence in operating and maintaining facilities, [as a consequence of which] major facilities are sub-optimally used and sophisticated instruments are rarely exploited to their full potential.

He notes further in a subsequent editorial that:

many new institutions that are being created find it easier to acquire equipment than to recruit faculty (...). As Indian laboratories in academic institutions accumulate the increasingly expensive tools and technologies of science, it may be important to remember that tools are only as good as the workmen who handle them (Balaram, 2012b, pp. 1383-1384).

This, one may argue, is precisely the kind of challenge that Dharmadhikari's way of doing science and training students is capable of taking up and taking up successfully if one sees the capacities and the confidence of those who have trained with him.

This also raises the larger question of the state of instrument building itself in laboratories in India today. All I spoke to were of the opinion that this culture and these capabilities (and not just about probe microscopy) were always limited and restricted to a few research groups in any case. Even that culture is being lost now, fading away, thanks partly to issues around the increased availability 
of funding for research, for procuring (read import of) sophisticated instruments and to a reward system that does not recognize those who make these instruments - the "down time" is indeed not being acknowledged. It is symptomatic of a failure to recognize that "scientific instruments (...) and other material products (...) are constitutive of scientific knowledge in a manner different from theory, and not simply "instrumental" to theory." (Baird, 2004b, p. 1).

The issue is very relevant in India today when the state is providing unprecedented resources for scientific research (DST, 2007; Manupriya, 2011; A. Reddy, 2009b, p. 70). The case of NS\&T research is particularly illustrative of this changing scenario as has already been illustrated earlier in Section 1.2 - in the constitution of NanoMission and the allocation of substantial amounts of money through various arms of the Government of India. Will the availability of these resources now change the way research in done in institutions and universities in India? Will those making instruments now stop making them because there is enough money to buy one off the shelf? Will the quality and quantity of scientific output improve significantly?

There are many questions that are beyond the scope of this present study but would be very interesting and worthwhile areas of investigation and research. Some of these are about the jugaad, some are about science itself and what happens in the laboratory, and others emerge when jugaad enters the laboratory and intersects with the science that is happening there.

\subsection{Characterising technological jugaad}

The account so far has presented technological jugaad as a function of the milieu in which innovation and technological development is located. It is contingent on the influences, practices and ways of knowing which, as the STM example explicates, allows and even encourages reconfiguring of material objects in varied, though co-existing worlds. The junk market, then, becomes as important a resource for economic survival in rural India as it is for cutting edge science in the modern physics laboratory. Technological Jugaad can therefore be looked upon as a Culture of Innovation that is located within the larger technological culture (Bijker, 1995a, 2006) (see Chapter 1) and is a manifestation of how users matter (Oudshoorn \& Pinch, 2008, 2003a) (Section 2.4) within the specific social, political and cultural context.

Using the detailed foregoing discussion and the extended inferences drawn from the same, I will conclude this chapter now by characterizing technological jugaad. I account for it by eight characteristics that I present here mainly as signposts; pointers that can initiate further empirical research, help in gaining information and insights, and also promote further discussion:

i) Reconfiguring materiality: One of the cornerstones of the technological jugaad that we have seen, be it the automobile in rural North India or the STM in a modern physics lab, is the reconfiguration of materiality - giving new meaning 
to old objects (old refrigerators, discarded computers, sewing machine bobbins, water pumps) and finding uses that they were not initially created for.

ii) Problem solving: Technological jugaad mainly involves finding a solution to an immediate problem. The immediacy of the problem is often linked to economic survival. It may not be exactly the same in a physics laboratory, but can still be understood as an explicit manifestation of the imperative of continued existence. In that sense, then, it is different from invention or an activity of leisure such as pursuing a hobby.

iii) Driven by resource constraints: One of the key conditions driving technological jugaad is resource constraint or denial. There is, therefore, no option but to find new meanings and uses for existing objects - a direct linkage to the first characteristic of reconfiguring materiality just as it is linked to the last one of - 'a culture of recycling'.

iv) Bridging knowledge systems and ways of knowing: This paradigm of innovation, as we have seen, particularly in the case of the physics lab, embodies an important element of interdisciplinarity. There is an awareness of what is happening elsewhere and, importantly, the capacity and the willingness to bring in ways of doing things that are located outside and, therefore, not considered part of the system.

v) Liminality: In an earlier version of this conceptualization, including in recently published work (Sekhsaria, 2013a), I had articulated this characteristic as 'legally grey'. Following subsequent discussions with colleagues ${ }^{44}$, I realize, that it is not about legality alone. Liminality would be a much better characterisation because the production process as well as the final objects created, like in the case of the STM and the jugaad automobile, lie across the borderlines of spaces such as law, regulations and standardization.

vi) Not (intended) for commercialization: Available evidence, albeit limited, suggests technological jugaad does not have much success in upscaling and commercialisation. Commercialization, in fact, is not the primary intention of jugaad, though there is no reason why it should not become successful commercially. In the first instance, however, it lies outside the broad framework of the market place.

vii) An activity of the commons: The intellectual and material sources that are needed to find solutions are not owned by anyone in particular and belong, as a corollary therefore, to everyone. Technological jugaad can be seen, then, as drawing upon a 'commons' that is both conceptual and material, and where the resources exist all around - both in its usage and its availability for use (Sekhsaria, 2011, p. 22).

viii) A culture of recycling: There is a way of looking at waste and a culture of recycling that is central to the jugaad enterprise. This is linked to conditions of a society where resources are scarce and access is limited. One has to make the best

44 I would like, in particular, to thank Samir Passi. 
of what is available and this is also linked to formal and informal systems where waste, scrap and junk are indeed available for reuse in most towns and cities.

Evidently, many of these characteristics are integrally and inextricably linked to each other. Established categories get disrupted in the process because there is no more a universal entity or quality called waste. It is contextual, even cultural, as it helps re-engage with the idea of waste as "matter out of place" (Douglas, 1966) as also waste being a misplaced resource (Gregson \& Crang, 2010; GTZ, 2000; Venkateswaran, 1994).

The inter-associations are constantly dynamic and interdependent as they flow simultaneously in multiple dimensions - sometimes in parallel and sometimes in outright opposition even as they continue to intersect and weave their way through. Does a culture of recycling, for instance, allow for reconfiguring materials and giving them new meaning? Is it a situation of serious resource constraint that forces a culture of recycling or then, is it because people are embedded in and constitute multiple systems of doing and knowing that they are able to find relevance and new uses for objects and systems discarded as waste or obsolete? A larger understanding lies in a combination of the answers, and studying different situations might reveal the existence of many different, though subtly tuned permutations and options.

It would also be relevant to note here in the context of a (technological) culture of innovation that a large section of India's population lives in poverty and with seriously limited access to financial and material resources. Even more, a major chunk of the economic activity and employment is to be found in the informal sector (Kapila, 2010; Varma, 2004) where there is no social security and neither any security related to employment or work (Kapila, 2010, p. 881). It is this context of resource deprivation and/or denial that jugaad forms a bulwark to the livelihood and survival support system of millions, It is a value that is lost upon a number of critics who, as we have seen already, summarily dismiss jugaad on various counts. Technological jugaad might not perform precisely the same function inside a modern laboratory, but it is, undeniably, a part of the same continuum.

\subsection{An epilogue}

A brief history of the STMs in Pune has been told, jugaad has been introduced and technological jugaad has been conceptualized as a culture of innovation embedded in a social, cultural and historical reality. Having explored the lab, then having travelled into and through the world outside, I will re-enter Dharmadhikari's lab one last time for a final look. This one will be inside-out and not surprisingly, leads to a whole new set of questions and challenges on the one hand and raises others that have remained barely hidden below the surface. They are linked in particular to the issue of the future of the instruments that Dharmadhikari and his students made and which this chapter has been all about. 


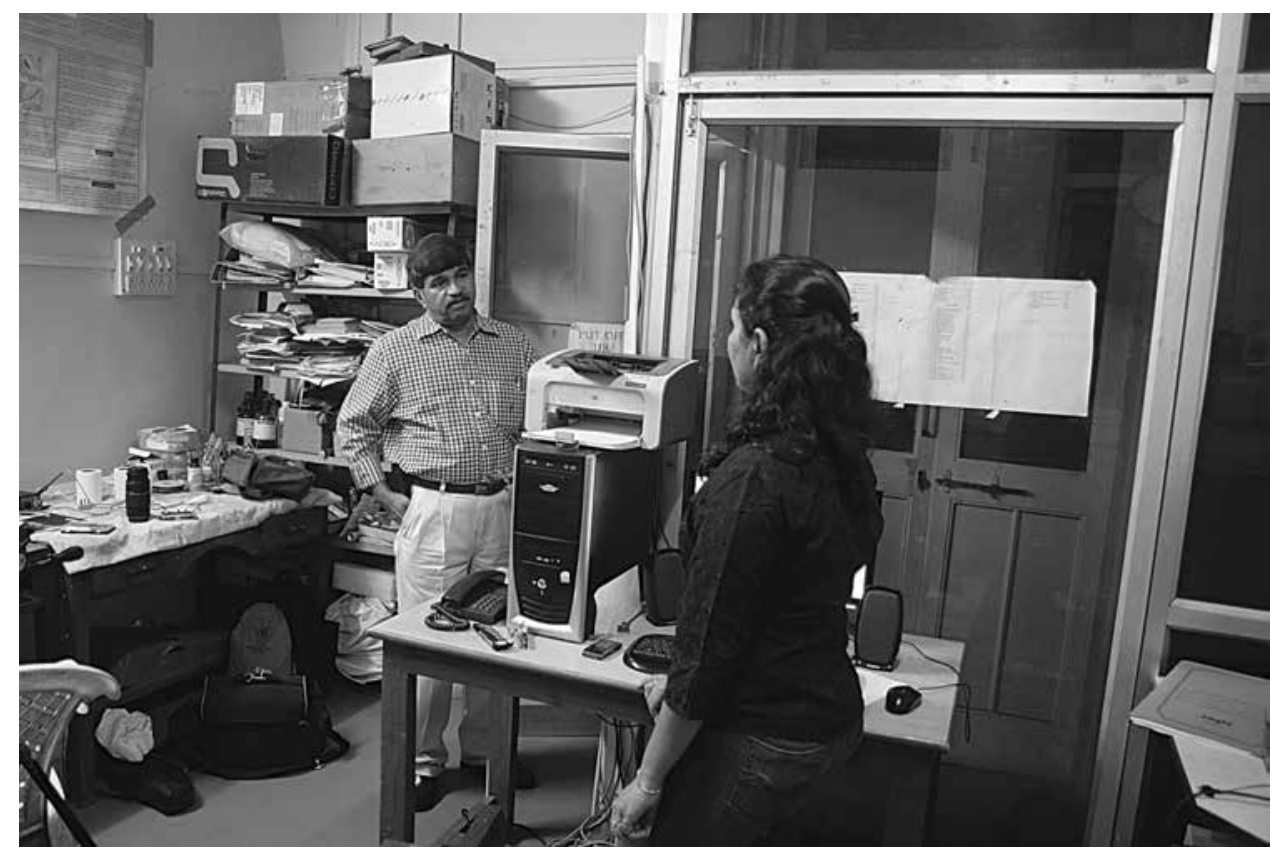

Image 18: Dharmadhikari with Sumati Patil, his last PhD student in the University of Pune (Pic: Author)

Key to this is the historically contingent reality of Dharmadhikari's retirement from the University, something that happened around the time I first met him in December 2010.

I started to understand the challenges and the deeper relevance of this about a year later, in conversations with him and Sumati Patil ${ }^{45}$, Dharmadhikari's last doctoral student at the university ${ }^{46}$ (Image 18). This was, in fact, a critical juncture in the life of the STM/AFM labs that Dharmadhikari had created so many years ago. The sense I got was that the instruments that the research group had built and Patil was presently working with, were on course for a very uncertain future. With Dharmadhikari having now retired, Patil noted, no one knew what would happen to the lab space and the instruments when the lab finally 'closes down'. Financial and material resources, I realized suddenly, were not the only constraints that scientists and researchers have to contend with. Lab space - the real estate of the S\&T world - was just as scarce and contested a commodity. There are many examples, and not just from this laboratory or university, where labs and instruments made therein have met an inglorious end.

Much, it dawned on me, could happen in the coming two-three years these 'historic' pieces of equipment could move to some new place, they could

45 Not related to Shivaprasad Patil mentioned earlier.

46 Sumati Patil finished her doctoral dissertation in 2014. 


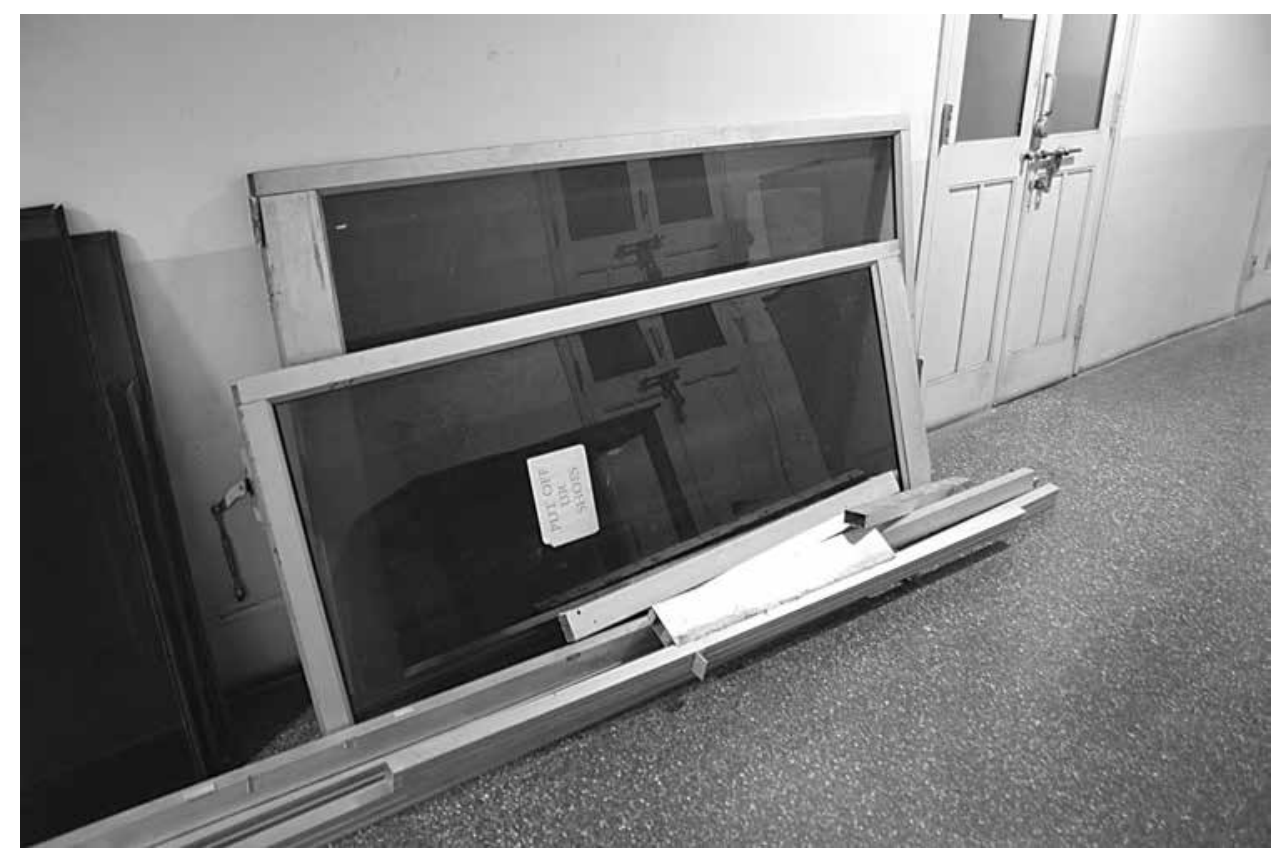

Image 19: The dismantling of the STM laboratory - a July 2013 picture (Pic: Author)

be taken out of the lab and left to waste in the corridor or some go-down, be scrapped, or they could find a new lease of life under a new professor/researcher who will shepherd them into the future. Patil and I also discussed briefly the existence, possibility and the need of a space like a museum where equipment of this kind could be given a decent disposal/burial if I am allowed to use those terms in this context. Even if they are not actively used, they would at least be available for others, particularly the next generation, to see what happened in this lab and how things were done here. It had the potential of being an asset to the department and to the university, to showcase their achievements and their history. The idea, I think, is a good and a relevant one but it has to contend with the merciless march of time as well.

By the time I was writing the final version of this thesis, Dharmadhikari's last two students in the university (Patil included) had finished their doctoral research and had moved on. More importantly, the movement of the instruments and the space they had occupied had also started. When I visited the Physics department in the university in July 2013, one of the two lab spaces had already been withdrawn. There was no STM lab anymore and everything that made up that lab had been moved to the AFM lab.

During a telephonic conversation a few months later, Dharmadhikari told me with a sense of agitation and of resignation that it was all over - that the 
AFM lab had also been pulled apart, that the instruments and the materials had been dumped somewhere, and the space had been vacated for someone else to move in. 25 years of an intense scientific enterprise had been brought to a quick and ignominious end.

What insight, I wonder as I conclude this chapter, does this final episode of a laboratory's journey offer us? It clearly opens up a number of new questions, just as it simultaneously answers and closes down existing ones. I am not going there in this thesis, but there can be no doubt that a detailed exploration into this final episode of laboratory life will provide us important understandings into the Culture of Innovation that not only allowed for the instruments to be created in a particular way, but one that allowed the instruments to be created at all in the first place. 



\section{Collaborative explorations: different disciplines and worldviews in a nanobioscience lab}

\subsection{The Centre for Nanobioscience}

The Centre for Nanobioscience (CNB) is one of two laboratories ${ }^{47}$ that constitute the Microbial Sciences Division at the 77 year old Agharkar Research Institute $(\mathrm{ARI})^{48}$ (Images $20 \& 21$ ) in the city of Pune in western India (ARI, 2013). Set up in the year 2007 by microbiologist Kishore Paknikar ${ }^{49}$, the CNB is the youngest of the labs at the ARI and was created out of the erstwhile 'Metal-Microbe Interactions' Group of the Microbial Sciences Division at the institute. Its areas of research interest include Biomimetics, Nanomedicine, Microfabrication and nanotechnology in agriculture and environment. The web page of the CNB states that

the Group [has] pioneered a new approach for the synthesis of metalbased nanomaterials, viz. 'Materials Science and Engineering through Microbiology'. (...) The research program at the [CNB now covers] the entire gamut [of nanobioscience research] - from nanomaterials synthesis and characterization to developing products and processes for the improvement of human health, agriculture, environment etc. (CNB, 2013).

The catalyst for the creation of the CNB, according to its founder Paknikar, was a chance meeting he had with Nobel laureate Jean-Marie Lehn in 1999 at the Strasbourg University in France. Following a presentation Paknikar made on his work on metal-microbe interactions, Lehn asked if he could possibly find a biological way of making nano-particles as that would help solve many of the environmental problems related to the physical and chemical methods of their production. Paknikar picked up the cue on returning to India and systematically screened his big collection of metal interacting micro-organisms to see if these could indeed be done. He started with yeasts, which in many cases convert metals to semi-conducting metal sulphides.

When the commonly used yeast, Saccharomyces, was challenged with the toxic metal Cadmium it was quickly converted to the non-toxic Cadmium Sulphide (CdS). And since this is deposited in the nano-sized vacuoles of the

47 The other one is Microbiology.

48 The two other divisions that make up the ARI which is primarily a life sciences institute are the Plant Sciences Divisions and the Animal Sciences Division (ARI, 2013).

49 Paknikar is currently Officiating Director, Agharkar Research Institute. 


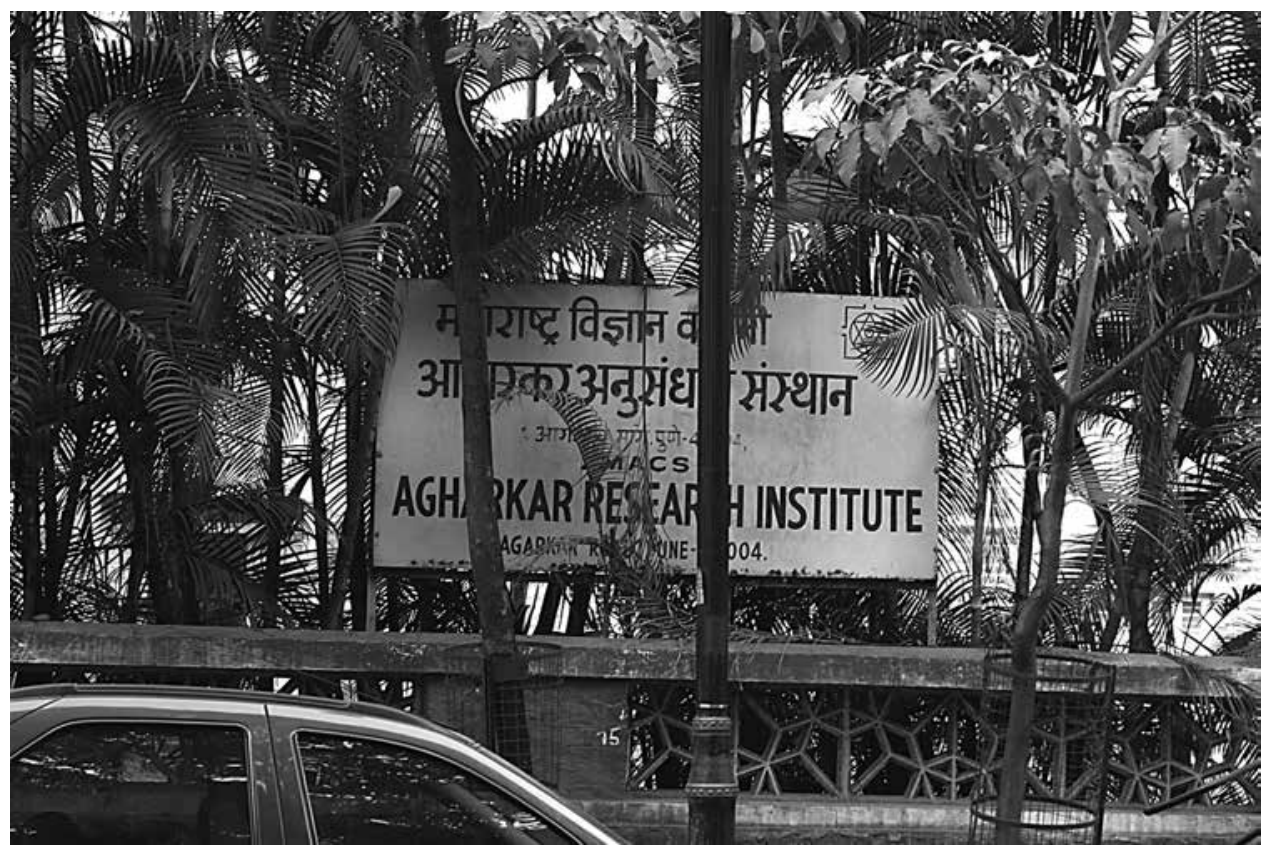

Image 20: The Agharkar Research Institute (Pic: Author)

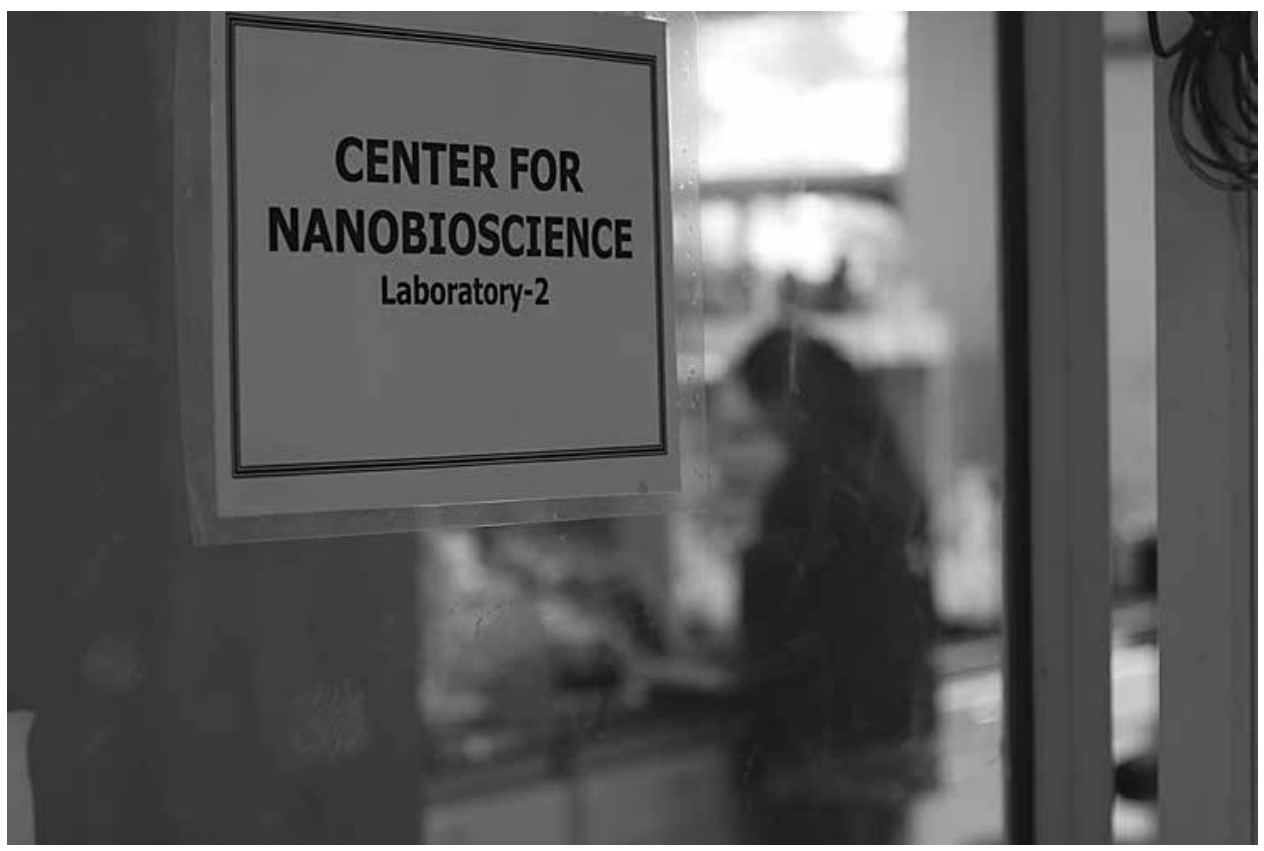

Image 21: The Centre for Nanobioscience (Pic: Author) 
cell, there was a physical compulsion, Paknikar inferred, for the CdS to be nano-sized as well. His research group then used the CdS they had synthesized to successfully fabricate and test a simple electronic device - the diode, and published their first paper on the subject in the year 2002 (Kowshik, Deshmukh et al., 2002). It is claimed to be one of the earliest reports of the successful use of micro-organisms for the synthesis of semi-conductor nano particles and of their use in the fabrication of a functional electronic device.

They were similarly successful in synthesizing Lead Sulphide (Kowshik, Vogel, Urban, Kulkarni \& Paknikar, 2002) and then in using different microbes for the successful synthesis at the nano-scale of about 10 different metals including gold and silver (Kowshik et al., 2003). The team soon realised, however, that there was a limitation to this process in that it was not possible to achieve scale and to get a large yield of the nano-particles. This led to a change in strategy. As Paknikar explained:

Nano-particles, synthesised by any method - chemical, physical, whatever, (...) are highly unstable. They rapidly agglomerate. To stop that you normally have to add a chemical capping agent and many of these (...) are toxic (...). Instead of using those sorts of chemical capping agents, micro-organisms are using natural polymers as capping agents, which are environment friendly. (...) So what we do now is we change our strategy. We started synthesising the nano-particles using chemical methods but capped [them with] a biological material. And then we filed international patents on this. And we have patents in almost 20 countries for this process. So this is our basic platform technology - we call it 'bio-stabilisation of nano particles'.

That then was the end of this curiosity-based research. Finally, I am interested in developing applications. So we said, okay, can we (...) develop some applications based on this? The easiest for me was to look at the anti-microbial activity of silver because silver has been known [as an] anti-microbial for 1000s of years [(Pradeep \& Anshup, 2009)] (Paknikar, Interview, 23 December 2010).

This led to the development of a nano-silver based gel, S-Gel, which according to the researchers is the first of its kind derma product for burns, wounds, diabetic ulcers, and bed sores (Jain et al., 2009; Paknikar, 2006). It is listed by the CNB as one of its most prominent and recognized outputs, and was granted approval by the Drugs Controller General of India in 2008. The product is currently available in the Indian market under the brand names 'S-gel' and 'Silveron', being marketed by Hetero Drugs, Hyderabad and Khandelwal Laboratories, Mumbai, respectively ${ }^{50}$.

50 http://www.aripune.org/nanobioscience-achievements.php, accessed 20 Aug 2015. 


\section{Disciplinary diversity, collaborative work}

The CNB is currently constituted by about 20 researchers, a majority of whom are doctoral students researching various intersections of biology and nano. In the seven years of its existence, the Centre has delivered $15 \mathrm{PhDs}$ and about 40 articles $^{51}$ in a range of peer reviewed scientific journals. The Centre has also been granted more than 20 national and international patents for work that includes the 'development of eco-friendly methods of synthesizing metal and semiconductor metal sulfide nanoparticles using yeasts' (Kowshik, Vogel et al., 2002; Paknikar \& Kowshik, 2008a, 2008b, 2008c), 'Biostabilising of submicronic particles' (Paknikar, 2007, 2008, 2009), the 'development of Nanocrystalline silver gel for the treatment of burns and wounds' (Paknikar, 2006), development of 'a method and kit for rapid recovery, identification and antimicrobial susceptibility of microorganisms' (Choudhari, 2010) and the ' $\mu$ Spore ${ }^{\circledast}$ DNA preservation technology' (P. Kulkarni, 2010; Paknikar \& Kulkarni, 2011).

A perusal of the academic backgrounds ${ }^{52}$ of researchers at the CNB and a quick listing of the journals where the outputs from the lab have been published, gives a good indication of the disciplinary diversity that constitutes the CNB. While a majority of those who come into the CNB are either microbiologists or biotechnologists, others over the years have included botanists, pharmacologists, those with their basic training in physics and instrumentation and even practitioners of Ayurveda, the traditional system of medicine that continues to be very popular in large parts of India. The journals where the work has been published too have been varied: Applied Biochemistry and Biotechnology (S. Agrawal, Morarka, Bodas et al., 2012) Microelectronic Engineering (S. Agrawal, Morarka, Paknikar \& Bodas, 2012), Journal of Ethnopharmacology (Choudhari, Punekar, Ranade \& Paknikar, 2012) Indian Journal of Experimental Biology (Umrani, Agrawal \& Paknikar, 2013), Nanomedicine (Umrani \& Paknikar, 2013), Journal of Biomedical Nanotechnology (Kale et al., 2007; Paknikar \& Jeremic, 2007) and Gold Bulletin (Brown et al., 2007) to name a few.

There is also a clear perception in the minds of researchers at the CNB, as the three following quotes illustrate, that nanotechnology research and by implication their own work has to be multi and interdisciplinary and has to span existing boundaries:

Biology is functioning at nano scale even in nature. And what is biology? Biology is not a fundamental science like physics and chemistry. Biology is the physics and chemistry of life (...). We can describe all biological processes in terms of physical and

51 The list also includes NS\&T related articles that were published by the group prior to the establishment of the CNB in 2007.

52 This is based on the discipline that the researchers have their Master's degree in. 
chemical processes. All physical and chemical processes govern biological processes. (...) You are talking about atoms and molecules and their interactions. At that level everything merges, all boundaries vanish (Paknikar, Interview, 23 December, 2010).

Actually, they [disciplinary boundaries] vanish. It is really an interdisciplinary thing - it is a combination of physics, chemistry and biology. For eg., (...) if I am developing this particular particle [which is] to be tagged with this particular protein, I need to understand what are the charges, what are the functional groups on that protein and the particles so that [they can] (...) form some bond (...). For this you need knowledge of chemistry. And if you are looking at a metal (...) - a spherical particle or a prismoid particle or a square shape particle - for that you need to know chemistry as well as physics. So if you have some knowledge of it, it will be better for you to manipulate the particles or synthesise the particles according to your convenience, according to whatever functional groups you want. So, for that, it's better to have knowledge of both the fields (Shraddha Deshmukh-Kelkar, Doctoral Candidate, CNB, Interview, June 2011).

It is [about] nanotechnology itself - doesn't mean [that] biology is sufficient for nanotechnology or chemistry is sufficient for nanotechnology. Maybe nanotechnology itself is so interdisciplinary [that] almost everybody needs this knowledge of other things (Shailaja Agrawal, Doctoral Candidate, CNB, Interview, 23 December, 2011).

These articulations are very much in line with what many scholars argue is basic to research in nanoscience and technology itself - its interdisciplinary nature (Jacobs \& Frickel, 2009; Meyer \& Persson, 1998; Porter \& Youtie, 2009; Roco \& Bainbridge, 2002) or certainly the need for "interdisciplinarity in nanoscale research" (Schummer, 2004, p. 18). Exploring the larger discussions and debates around interdisciplinarity is beyond the scope of my thesis but I use the idea as a starting point nevertheless, to emphasise the collaborative nature of the work at the CNB.

This articulation of disciplinary diversity as fundamental to the nano world, the primary focus on application based work at the $\mathrm{CNB}$, and the preceding foundational account of the research group by its founder, all put together, underline the key idea that I seek to explore in this chapter. This is the imperative of collaborative research that is embedded in the rationale, method and in the structure of the CNB. The questions that I will attempt to answer are all linked to this. How does this imperative of collaborative work actually play out in a laboratory that seeks to bring together the worlds of nanotechnology and biology and also those of physics, chemistry and Ayurveda? What happens 
when all the different people, their ideas, their instruments and their histories come together in time and space in the pursuit of the nano-object? What are the methods that scientists employ to deal with the demands of collaborative work? How are conflicts resolved? How does the quest of nano-scale research configure the world of a scientific laboratory? Conversely, how is the scientific laboratory configured to deliver science and technology at the nano scale? It is this multi-faceted and multi-dimensional world of different (nano) scientists at the $\mathrm{CNB}$, their laboratories and their research efforts that this chapter is an account of.

\subsection{Lab studies}

The story of the CNB is different from the other case studies in this thesis, primarily, on account of the nature of my engagement with the lab. While the three others evolved and revolved around a 'specificity' - a particular object (Chapter 3), a technology (Chapter 5) and a particular situation (Chapter 6) respectively, my engagement with the $\mathrm{CNB}$ was more fluid over time and space. It was conducted more in the tradition of lab ethnography (Latour \& Woolgar, 1986; Traweek, 1988) (see Section 1.3) wherein I spent more than a month (35 days) in the lab spread out over a period of three years of intermittent though regular interaction. The account that follows is based on nearly 150 hours of observations, engagements and discussions in the $\mathrm{CNB}$ and 28 open ended interviews of an average length of 40 minutes that were conducted with the researchers there. It was the most consistent and detailed of my interactions amongst all the labs that I worked with for this thesis. Many points about the relevance of lab studies and multi-sited ethnography as also their intersection discussed in Chapter 1 have a direct relevance here. My attempt at the CNB was not to focus on one particular thing or to understand one particular process of fact formation (Doing, 2008; Latour \& Woolgar, 1986); it was to follow what one might call the ebbs and flows of life in a laboratory.

And much, indeed, did transpire in these three years. New researchers joined and old ones moved on; existing ones got their doctorates and new comers who were greenhorns when I visited first had become lab veterans by the time I was finishing (newer greenhorns had also joined, meanwhile); some proposals were rejected while others had their funding approved; exciting research ideas were discarded in favour of even more exciting ideas; research projects could be seen advancing from their conceptualization to execution to their eventual completion and the Centre itself got more space and equipment of its own. And it was not in the professional domain alone that things happened: in the three years of my coming and going I also saw new friendships being forged between those who made up the lab just as some old ones withered away, many of the researchers got married and one of them even became a mother. 


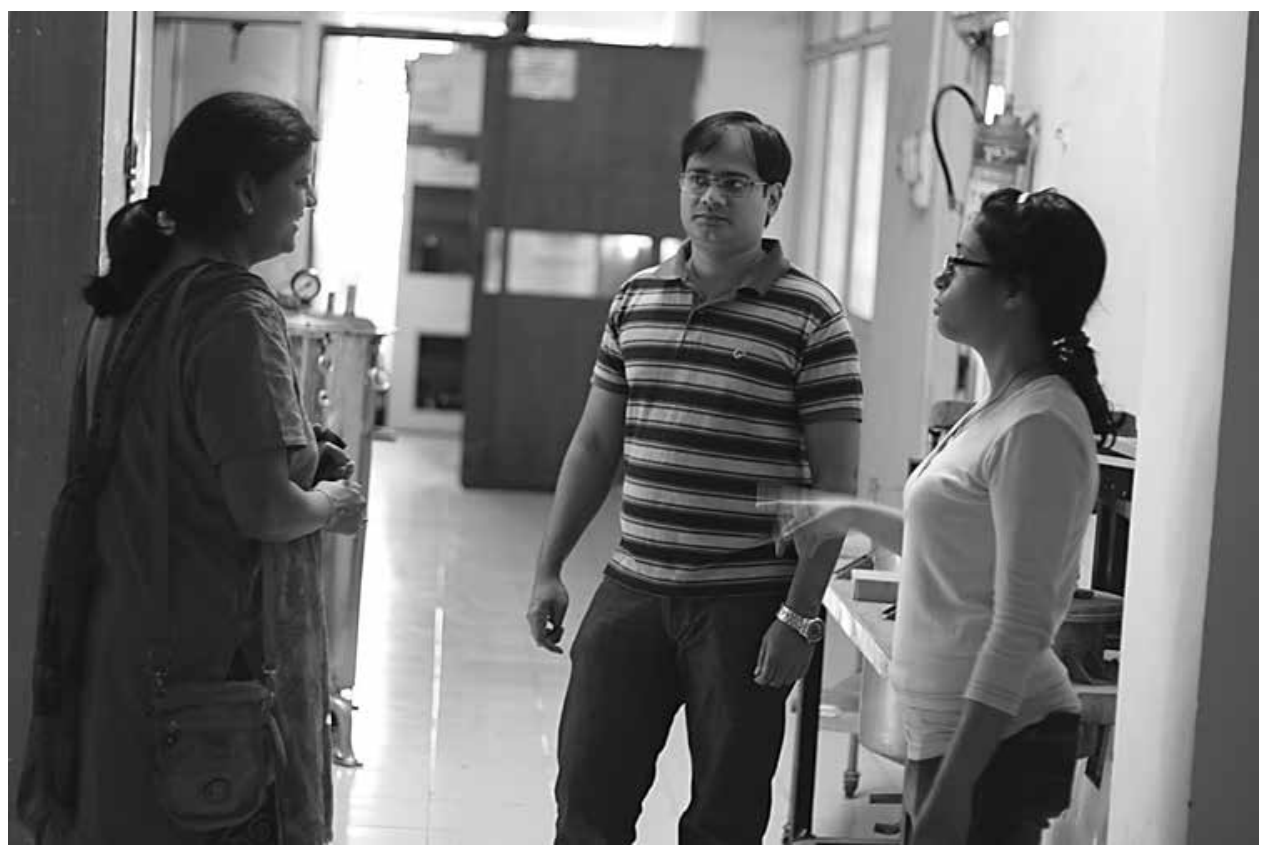

Image 22: Rinku Umrani, Prasad Bhagat and Vaishnavi Kulkarni ( $L$ to $R$ ) in a conversation in the CNB corridor (Pic: Author)

As I started to analyse my detailed lab notes and the transcripts of the many interviews I had conducted here, the richness and diversity started to become more concrete. Patterns and insights were revealed on multiple axes. It was striking that many of the doctoral candidates here actually came from small town India. They were here inspite or, perhaps, because of the poorly resourced (science) education systems that they had passed through; daunted but not deterred; struggling but not defeated, for instance, by the challenges of speaking and working in a language that is not their own; acknowledging that English was indeed the language of modern science and a window to the outside world. It is a reflection of what Aalok Khandekar has articulated as a set of four dynamics to explain the phenomenon of overseas education among Indian engineers - what he calls 'Education Abroad':

(i) The uneven growth of higher education in post-independent India, (ii) the centrality of science and technology to Indian envisionings of modernity, (iii) the perceived supremacy of the US educational system in relation to engineering disciplines among Indian students, and (iv) Ongoing frustrations among Indian engineers with Indian political culture, which they then circumvent by pursuing Education Abroad (Khandekar, 2013, pp. 180-181). 


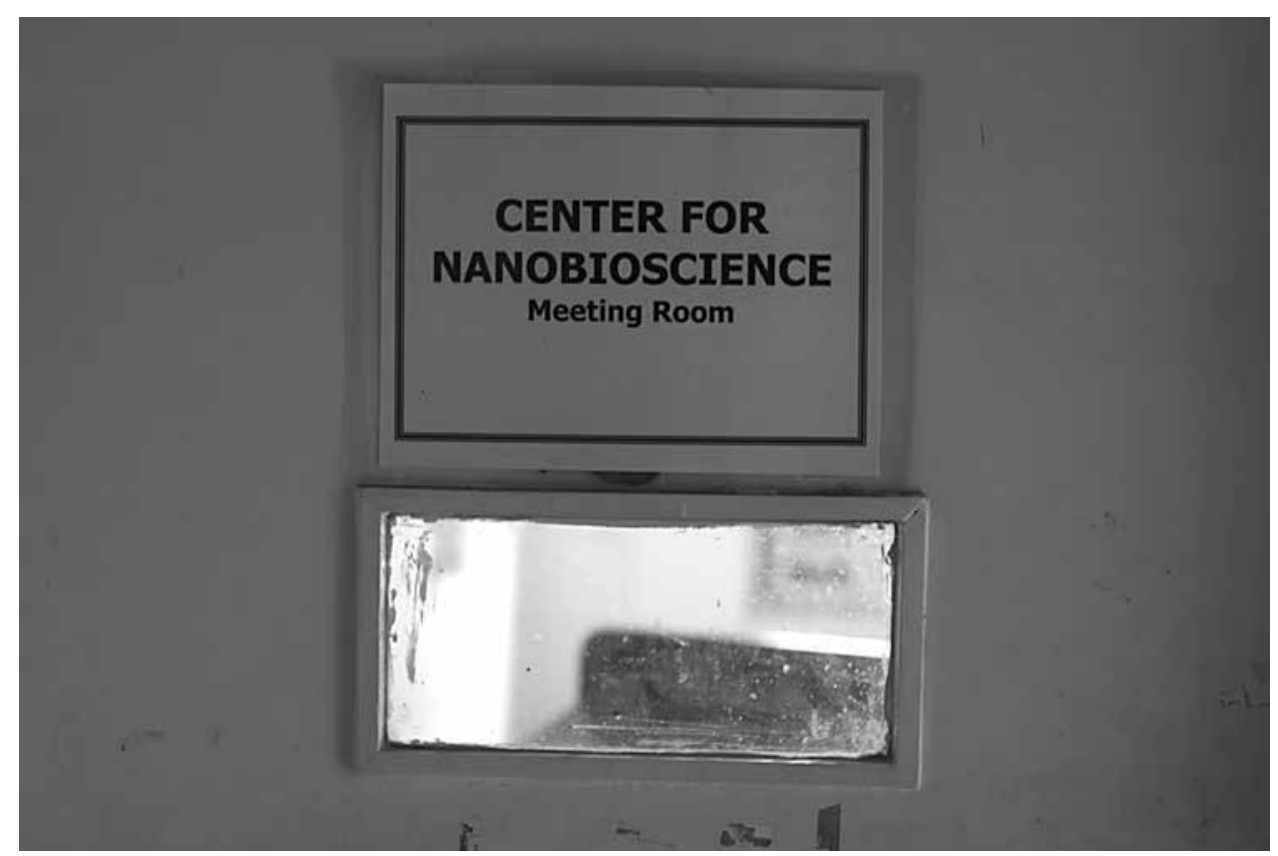

Image 23: The door of the Meeting Room - the venue for the weekly seminars and much more (Pic: Author)

While Khandekar's study is specific to overseas education and to engineers, his formulation works well to understand a more local situation as well. The first two points, for instance, are immediately and directly relevant in the CNB too. The 4th point in turn is germane for the $3^{\text {rd }}$ one because what we witness in a local context is the perceived supremacy of 'an urban and English centric higher education system' where education (in English) and a degree from the university is a vehicle of social, financial and in some cases political mobility as well. Some of those I interacted with at the CNB were, in fact, doing a PhD because they couldn't become medical doctors and others were pursuing a doctorate because getting one would be reaching the pinnacle of a mountain called education.

There were other things too that emerged prominently through the discussions and the observations - regular grouses, for instance, about the lethargy and insensitivity of the administrative mechanism; of the excessive and sometimes mindless bureaucratic hurdles and how a significant amount of the researcher's productive time and energy was wasted waiting for permissions or basic resources. I also learnt interesting things about how the lab space was organized, how learning and research were operationalized and how the researchers related to the equipment they were using. The weekly seminar in the 'Meeting Room' (Image 23) was a standard feature where doctoral researchers in the lab presented a piece of published research to their colleagues. It was a tool not just of mutual learning about new research but also a training space for 
preparing power points and making presentations. Towards the end of my work at the CNB, I conducted a small exercise wherein I requested the researchers to identify equipment in the laboratory they thought was most interesting and to also explain why. It was an attempt on my part to try and see how the scientists I had been engaging with constantly, related to the mass of equipment that constituted their workspace. The request was interpreted almost unanimously about tools and equipment they thought were most relevant (as against interesting) for their research. The answers varied across the spectrum - from the micro-pipette and the humble voltmeter on the one hand to the sophisticated and expensive Atomic Force Microscope on the other (see Annexure A). The exercise generated much banter and discussion, and playful curiosity about what other colleagues would choose.

\section{The STSer}

And the learnings were not only about 'them'. There were constant challenges, lessons and insights for the STSer himself. Early on, I had to make a presentation to the entire lab about STS in general and what exactly I intended to do here. One had the distinct feeling of a blind man trying to direct another group of the blind, but it was an experience that not only built my confidence, it also made me understand the field better. About a year and a half later I presented to the lab the first dimension of my own research that was I doing here. I was presenting to them what I had observed and concluded about them. Needless to say, I was apprehensive and worried how they would receive my findings, how they would evaluate my evaluation of them and also how they would evaluate what I, myself, had been doing here all these months. I need not have been worried, however, as the entire audience of more than 20 researchers thought it was very interesting work and said they'd look forward to more such insights and analysis.

Many hours were also spent in the common room and over glasses of 'cutting-chai' in the canteen where I became the one who was interrogated. My subjects constantly sought to understand more of what I was trying to do, what I was finding out and what I intended to do in my career once my thesis was done. There was warmth and friendliness. I even started to refer to the lab as 'our' lab.

I say all this not just to give a flavor of what I encountered in a laboratory, but also because all of these have something to offer in response to the questions that are sought to be answered. It is also to note that each of these points of engagement and experience could have been chosen to tell the story of the lab because each is as valid, relevant and interesting as the other. What has been foregrounded therefore is not what I began with; it is not what the story was meant to be, anyway. It was only when I attempted to analyse and make sense of the huge mass of notes and information that a few points stood out for their emphasis and their consistency. These emerged as the tropes, if one might use the term, of what this lab and its work was all about. The worlds of nano and biology 
(nano-bio) constituted one set as is evident in the name of the lab itself; a focus on applied and applications based research was another; while the third was that of collaborative work or what some of the researchers called interdisciplinarity. The work and the world of this lab stands at the intersection of these three, and is therefore, also the location and pivot of my own research and findings here.

It is this intersection that I seek to investigate - to show and understand the processes by which different diversities of knowledge, problems, skills and methods are mobilized just as they simultaneously mobilise activity and research in the laboratory, of how collaboration happens across disciplines and leading from there to the intersection of different knowledge systems and also of epistemologies.

\subsection{Individual responses to collaborative challenges}

From what I saw at the $\mathrm{CNB}$, collaborative work and responses to the challenges it throws up varied along two axes: one was the personal; the other is what one might call disciplinary. In the former case the response is at the level of the individual - the individual recalibrates her own understanding, experience and expertise in the face of a challenge. In the 2nd situation too there is a recalibration, but that is at the level of the discipline more than it is at the level of the individual. The two are related, of course, in that there are epistemic implications, but there is enough in-there to show that they are unique and independent at the same time.

I begin with two examples of these individual(ised) responses. First is the case of doctoral candidate at the CNB, Shailaja Agrawal ${ }^{53}$, whom I have already quoted earlier in the chapter. Agrawal, who has a basic degree in biotechnology and a Master's degree in biochemistry, is attempting to develop microfluidic based assays using quantum dots to detect pathogens in food as part of her doctoral work at the $\mathrm{CNB}^{54}$. Helping her do this is one of her supervisors, Dhananjay Bodas, who has a doctorate in Physics and Electronics. He has considerable expertise and experience in the field of micro-fluidics and a particular interest in developing bio-medical micro-devices. One might even argue that Agrawal's project would have been extremely difficult, if not impossible, had Bodas' specific expertise not existed in-house. As Agrawal explained:

The biggest challenge is to understand what is going [on] inside the [micro] channel (...). Why this small channel? Why this number? Why we need that particular type of magnet? What is the magnetic force? How should the magnet be oriented? These small factors (...) and everything is based on an equation. If I want to calculate the flow

53 She has since completed and successfully defended her doctoral thesis.

54 Microfluidics and quantum dots based work is often cited as one of the illustrative examples of interdisciplinarity (cf. Porter \& Youtie, 2009). 


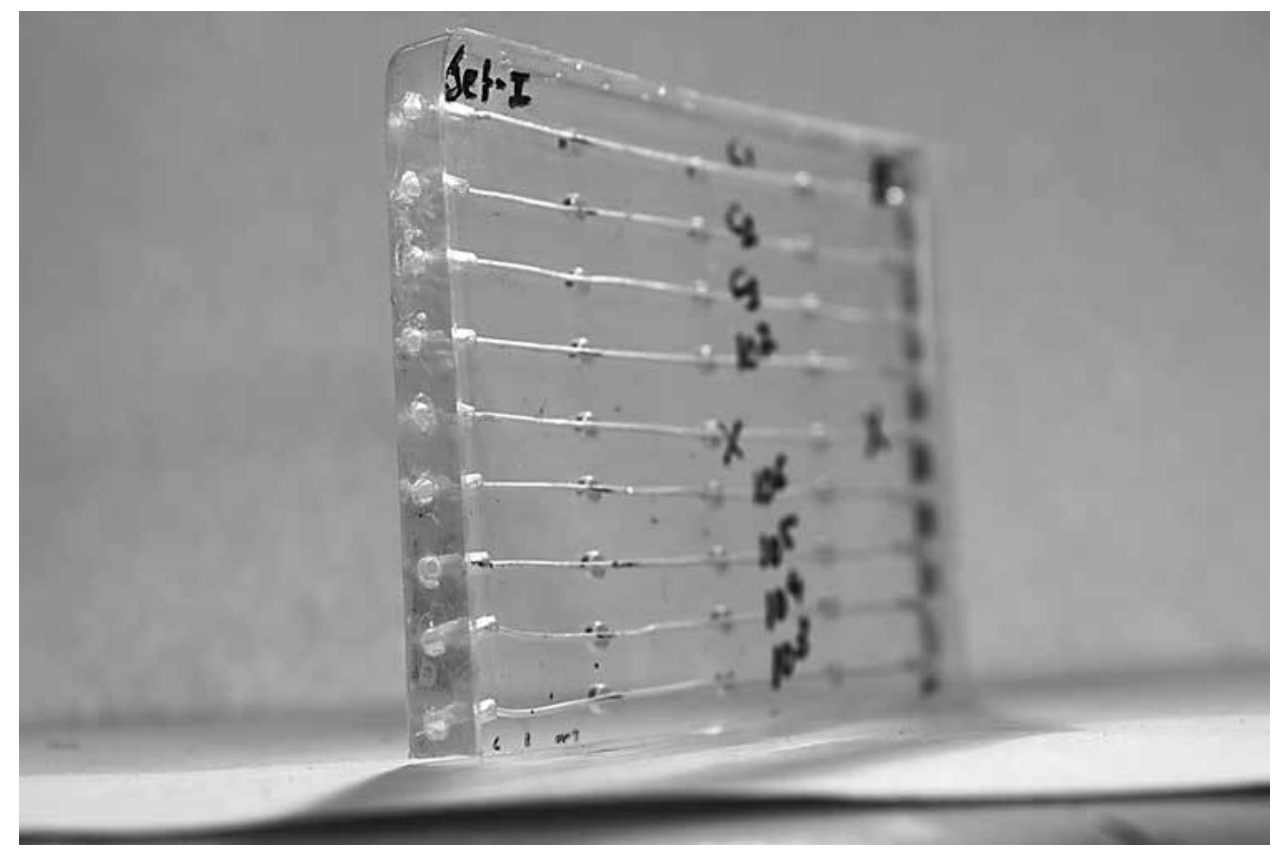

Image 24: A PDMS based micro-channel assembly that has been fabricated in-house at the CNB for experimental purposes (Pic: Author)

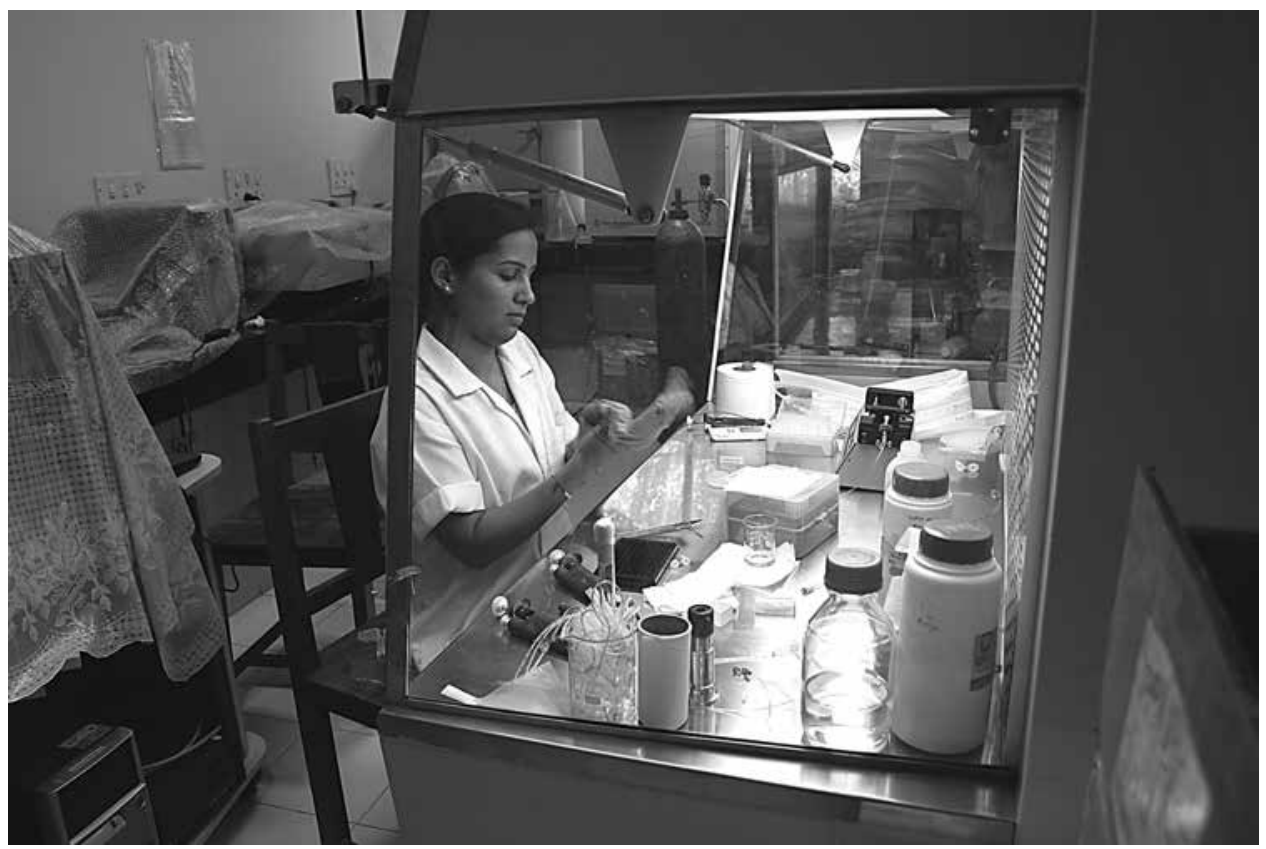

Image 25: Shailaja Agrawal gets ready to work with micro-channels, magnetic nanoparticles and quantum dots in the Laminar Flow (Pic: Author) 
rate, then I have a specific formula and for that I need to calculate the magnetic field of my magnetic nano-particle (...). First of all it's a bit hard for me to work with physics because, you know, biologists are, somewhere, (...) quite afraid of equations and all those things. But it is very interesting (...) because the basic laws on which the cell is working or [a] bio-chemical assay is working, [is] (...) based on physics and also based on chemistry (...) (Agrawal, Interview, 23 December 2011).

There is a certain ambivalence that spills through. The biotechnologist, it appears, would rather not do the equations, the math and the flow rates. There is a tension between not wanting to, but realising that there may be no choice if something has to be achieved. The challenge and (part of) the solution is for Agrawal to bridge the gap. She places the onus on herself to learn the techniques and processes of fabricating the microchannels (Image 24) and to develop proficiency in microfluidics and physics - as she has already been quoted earlier: "maybe nanotechnology itself is so inter-disciplinary [that] almost everybody needs this knowledge of other things." This is what she and many of her colleagues in the CNB have indeed being doing - dealing with the demands of collaborative work by making a move beyond the disciplinary boundaries, trying to understand and learn about what lies on the other side themselves.

A similar, though more decisive-in-his-approach, story might be told of Prabhakar Kulkarni who came to the CNB with a degree in botany and successfully developed the ' $\mu$ Spore ${ }^{\oplus}$ DNA preservation technology' as part of his doctoral work here (P. Kulkarni, 2010; Paknikar \& Kulkarni, 2011) ${ }^{55}$. He bagged the second prize in the India Innovation Pioneers Challenge 2009 for this technology and then also represented India in November that year at the Intel University of California Berkeley Technology Challenge (IBTEC-2009) (Mascarenhas, 2009). The technology he developed offers an alternative to the extremely energy and cost intensive cryogenic methods for DNA preservation, and is based on his findings that sporopollenin - a biopolymer isolated from the outer walls of pollen grains - withstands high temperatures and absorbs UV radiation. The technology now allows for the production of micron-sized sacs of this polymer wherein DNA can be stored for 100s of years at ambient temperature. The idea is to mimic the pollen grain that remains dry, stable and keeps DNA inside alive for millions of years as evidenced in fossil finds of pollen.

The genesis of the idea came from Kulkarni's personal experience - a severe allergy to pollen that caused him, during his Master's years, to sneeze 100-120 times a day, leading him to wonder if the pollen could be used for some other

55 Kulkarni is presently in a leadership position in ReaMetrix India Pvt. Ltd., a Bengaluru based biotech company. 
purpose. Operationalising the idea was a complex and multi-layered task that would involve multiple expertise and many disciplines. The point came through at many different points and in different ways in the interview I conducted with Kulkarni:

That is the nature of nanotechnology. We have to talk to people from different fields. This [the CNB] is a lab that allows people from various different disciplines. There is a physicist, there is a chemist, there are people from molecular biology, microbiology, botany, zoology - various fields. And there are people who have done different kinds of work. (...)

So, the people from different fields, when they sit together (...), that kind of interaction is very important. (...) They might have read something similar or completely synonymous or antonymous [and] (...) that discussion, that interaction, will create another idea among the group. So, it is very important (...) [and] it has contributed significantly (...). If you go in one straight line it is really difficult to solve such a problem (Kulkarni, Interview, 23 December 2010).

An illustrative example of this in Kulkarni's case was the methodology developed to assess the efficacy of his ' $\mu$ Spore ${ }^{\oplus}$ DNA preservation technology' - to check whether pollen, which was stable in nature for millions of years, would remain similarly stable if the technology he had developed was to be used. One option of checking this was to employ accelerated ageing experiments, but these were not considered very reliable:

So, we decided to use the Taguchi ${ }^{56}$ design of experiments (...) [which] are (...) reliability studies [to ascertain if] your product (...) will be useful after 10 days or one year for pharmaceuticals or 10 years in [the case of] instruments. So in the same way, we took that idea (...) and we took (...) another idea from artificial neural networks which is used in software and algorithms and we had a problem which is a kind of a evolutionary problem - paleo-ecological kind of problem. So, we took ideas from all different fields and merged it together and we came up with a mathematical model which says that the mimicked product we have can also be in a stable form for 100s of years (Kulkarni, Interview, 23 December 2010).

The diversity that Kulkarni appears to have assembled and operated through seems wide-ranging and is one reason, we might infer, for the considerable success his work has achieved. The twists and turns that the problem goes through, the challenges that are faced and the innovative solutions needed at every level

56 Taguchi methods are statistical methods used in a diversity of fields such as engineering, biotechnology, marketing and advertising. For an overview see Taguchi (1986) and Roy (2010). 
can only be discerned if the story of the scientist and the technology is sifted through patiently. Kulkarni's story has many parallels with that of Dharmadhikari and his quest for the STM (Chapter 3), just as Agrawal's and Kulkarni's story, together, have much in common with what we will see in Chapter 6 in the L.V. Prasad Eye Institute and Sankara Nethralaya. The institutional mandate of translational research in those institutions, like that of delivering applications at $\mathrm{CNB}$, forces researchers to cross boundaries and engage in collaborative work and thinking that may not happen otherwise. The systems (both institutional and disciplinary) and the individuals that constitute these systems appear to be constantly pushing at each other's boundaries, limitations and inertia to learn something new and from the outside. In an increasingly competitive and demanding world (of science and technology) this might be the intuitive response of scientists and technologists if they are to survive. In the least, one might argue, those who push the boundaries are the ones who will succeed and climb that ladder faster.

\subsection{A response from within the discipline/A physicist in a biology lab}

Let me turn now to the other kind of response, the one which emanates more from within the logic and framing of respective disciplines and their epistemologies and less on the adjustments and accomodations made by individual scientists. This too I will attempt to illustrate with two examples from the work I saw at the CNB.

For the first one we need to return to the collaboration between Agrawal and Bodas discussed above and to a moment on 22 December 2011 when I too was at the CNB. I had been discussing with Bodas some of their microfluidics work when an email from the editor of the journal Applied Biochemistry and Biotechnology popped into his email inbox. It contained, Bodas noted to me, comments from two anonymous reviewers to an article they had submitted seven weeks earlier. Agrawal was the lead author of this article with Paknikar, Amit Morarka (another researcher in the $\mathrm{CNB}$ ) and Bodas himself being the co-authors.

Almost immediately, I noticed all attention divert away from what was going on in the lab, to be now focused completely on the comments that had just been received. For the next hour and a half, including over an extended tea break in the institute canteen, I was witness to a discussion between Agrawal, Bodas and Morarka that was exclusively about these comments and the possible responses. And for the four weeks that followed, I saw the research team engage intensely with redoing the experiments and re-interpreting the results, leading, finally, to the submission of a successful revision. Successful, because this revised version was accepted by the journal 
on February 1, 2012 and published online on February 26, 2012 (S. Agrawal, Morarka, Bodas et al., 2012).

In an attempt to understand what exactly happened in this period, I compared the draft submission to the version that was finally published and also engaged in detailed discussions with the researchers to comprehend the key changes that had been made. The new set of experiments and the subsequent reinterpretation can best be understood from the comments made by the reviewers and the researcher's responses to those comments, both sets of which were generously shared with me by Bodas. First, the reviewers' comments:

i) The data is in-sufficient to support the effectiveness of QDs [Quantum Dots] based detection for water borne pathogens in the circular channels. The data [from the figures] do not represent the sensitive detection of the pathogen; [there] is no clear contrast in the bright field and fluorescence image (...). The background fluorescence is too high to be distinguished from the QDs which [are] labeled to the target pathogens, and

ii) It seems like the LOD [limit of detection] is $10(7) \mathrm{cfu} / \mathrm{ml}$ which is too high [a] value to be applied for pathogen detection.

The researchers agreed with the reviewers as they re-worked in their lab and articulated this in the response they sent along with the redone article:

i) The images supplied earlier were RAW images. The images are now modified with high contrast to clearly state the detection. The graph has been re plotted taking into consideration the modified images, and

ii) The concern of the reviewer is apt regarding the LOD. The graphs of intensity versus cell concentration are re plotted with new sets of experiments. Also fluorometer readings were recorded for confirmation of the intensity versus cell concentration.

Bodas interpreted this for me. The significant difference, he explained, was related to the format of the photographs that accompanied the article. In the first instance (the draft submission) the images submitted were the unprocessed RAW originals. The reviewers' comments prompted the scientists to submit photographs from the redone experiements after processing them with ImageJ, a freely available processing software. The other difference, Bodas noted, was reflected in the graphs. Here too, the comments had prompted the scientists to re-interpret their data and re-present it in a manner that was more in line with what the reviewers had asked for.

Bodas offered the rationale for re-processing the images and re-doing of the graphs from within the window of disciplinary expertise. As has already been 


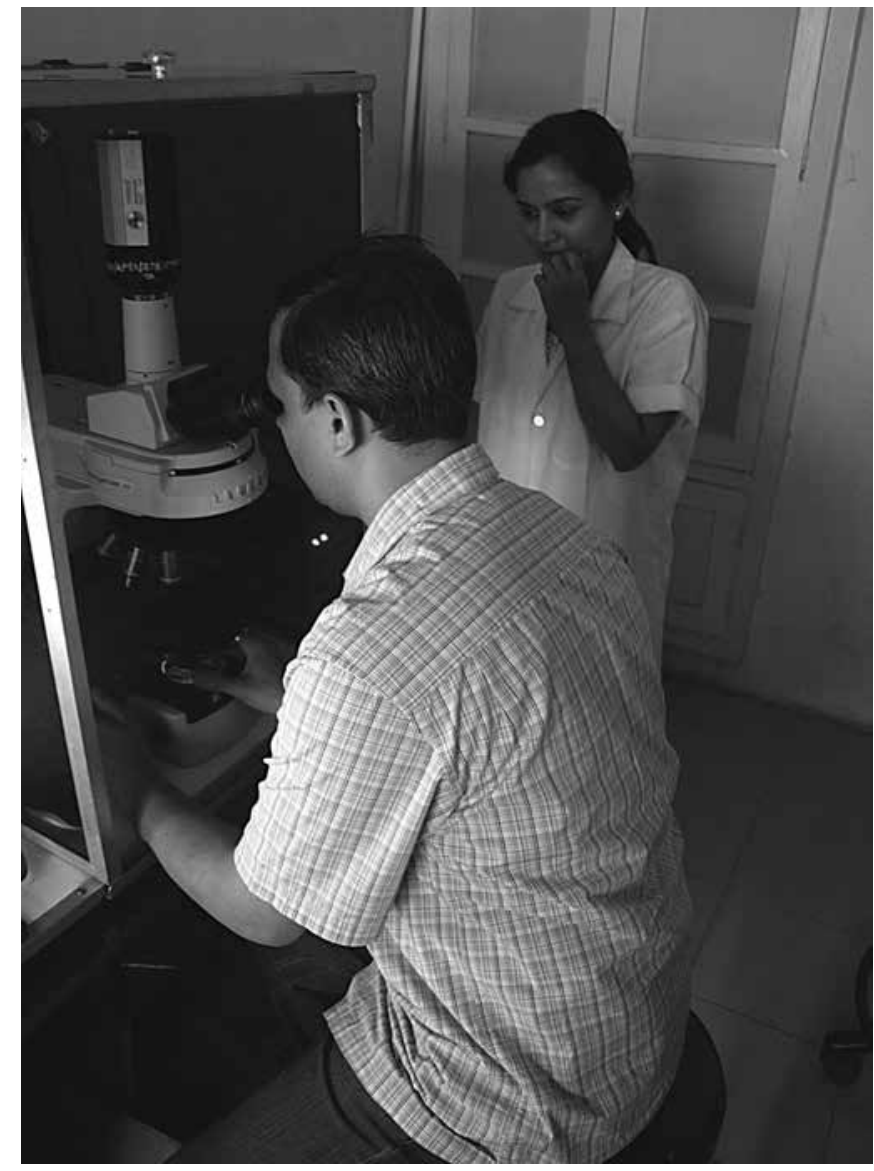

Image 26: A physicist in a biology lab: Dhananjay Bodas and Shailaja Agrawal as they re-perform the experiments in response to the comments by the reviewers (Pic: Author)

mentioned earlier, Bodas has a physics and instrumentation background and is considered the 'instrument man' in the CNB (Image 26). Not surprisingly, he had a key role to play in looking at the subject under the microscope, making the pictures, submitting the RAW images in the first instance, using Image the second time and in creating the interpretations and the representations. It was his decision to submit RAW images the first time, because for him this was the original, unprocessed and untouched data that gives you the correct picture of what has been done. It was something, he opined, that should not be tampered with:

When we do experiments (...) we tend to look at [them] as close to our disciplines (...). We thought those images are nice because we could deduce things - so we thought [that] for somebody else also (...) it might be easier. But then it was not (...). [Here], the difference between a biologist (...) and a physicist (...), or a person who knows image analysis comes into [the] picture (...). How the intensity is deduced from 
a particular image is not of interest for a biologist. (Bodas, Interview, July 2012).

It was Bodas' assessment that considering the nature of the journal, the reviewers must have had a biology and biotechnology background. It was his inference that they wanted processed images - this was the visualization they needed for "making the data meaningful" (Burri \& Dumit, 2008, p. 303). Bodas provided further evidence of his analysis by pointing to similar work they had done, but where the output was submitted to a journal in the field of micro-electronics engineering (S. Agrawal, Morarka, Paknikar et al., 2012). The comments received were not the same "because now this is a more physics oriented journal" (Bodas, Interview, July 2012).

The problem and the challenge might be laid squarely at the door of collaborative and interdisciplinary research; a physicist, otherwise, would not be making an image that a biologist has to understand and interpret. Was the image dumbed down by the physicist to make it visible and meaningful to the biologist? What does it mean to make the data meaningful? Is it an epistemic thing? What is the kind of image that a biologist understands? Whose responsibility is it to ask that question? Who should take up that challenge and how will that be decided?

In the cases of Agrawal and Kulkarni discussed earlier, the onus was taken on by the individual. The effort was needed from the individual to straddle two, if not more, disciplinary horses. Maybe, it is the context of physically being in the lab and doing the experiment oneself that creates this imperative. It is one dimension, perhaps, of the relevance and importance of tacit knowledge (Collins, 1985) and how it comes to be. Because new knowledge is important, people need to gain it and because they have to gain it, they are forced to move beyond their comfort zones. It is also relevant to bear in mind at the same time, however, that tacit knowledge becomes possible and relevant only when people move beyond their comfort zones.

The response from Bodas can be understood from a similar lens, though at a different level. The responsibility of recreating the image and of re-imagining becomes his if he has to create the immutable mobile (Latour \& Woolgar, 1986; Latour, 1987) that carries with it knowledge and information to the world outside and is, therefore, a fundamental measure of his and his group's success. And succeed they did because the revised submission was indeed accepted for publication.

This is also an epistemic thing. An image (and other things) can be created and be read by both the biologist and the physicist because, one might argue, a mediation and a meeting ground is possible. Though biology and physics might have two independent 'epistemic cultures' (Knorr Cetina, 1999), used here loosely as the 'goings-on' in a particular domain, they finally operate within the same broader epistemology of modern science. This is what makes the 
space and allows for the creation of boundary objects (Star \& Griesemer, 1989; Star, 2010), those "objects that are loosely structured in common practice, and tailored for local usage by particular social worlds when and as specific needs arise" (A.E. Clarke, 2010, p. 588). They can resonate, therefore, across disciplines and through disciplinary boundaries. A graph as a mode of visualization, for instance, is acceptable and is understood irrespective of whether the researcher has a background in physics, chemistry or biology. Much has to be negotiated for this collaboration to work within the lab and even beyond it, but work it does in the final analysis. In the case discussed above, for instance, the graphs and the images remained, only their content was changed. There is, after all, a broad agreement around the notions of place, space and time; the co-ordinates that construct these respective worlds are similar if not the very same.

What happens, then, if this world has to interface with another that has a significantly different conception of time, of space and of knowledge itself - a system where, for instance, there might be no use at all for a graph, where the texts used even today are many centuries old and yet knowledge is considered contemporary, and where knowledge is as much oral and experiential as it is textual? It is a question that is at the heart of the final example that makes up this chapter - this is the encounter that modern nanobioscience and technology is attempting in the $\mathrm{CNB}$ with Ayurveda - the traditional and centuries old practice of the Indian subcontinent that is translated literally as the 'science of life' - "the Sanskrit meaning of Ayu being life and Veda, knowledge or science" (Patwardhan \& Vaidya, 2009).

\subsection{A brief exploration of Ayurveda}

The fundamental idea here is of epistemological significance, related as it is, to a system of knowledge and knowledge claims that is paradigmatically different from that of a modern nanoscience and technology. Ayurveda is a system of medicine and of healing that has been practiced in large parts of India for many centuries. The earliest known written references to what came to be called Ayurveda can be found in the Atharva Veda, a text of about 6000 hymns and 1000 prose lines believed to have been written circa 1500 BC. It has an entire section that deals with the "wonderful structure of man', which lists 360 bones and 44 organs including viscera" and includes a large and impressive herbal formulary of many plants and formulations that continue to be used even today (Valiathan, 2006, p. 9). The 800 years period starting 1st Century AD is believed to be golden age of Ayurveda and is credited to the physician Caraka. It is here that Ayurveda got its name and also moved from being a faith-based system alone to one that was reason-based. Caraka's treatise known as the Caraka Samhita was encyclopaedic in its coverage of medicine and had spread in about 400 years to Tibet, and West and Central Asia as evidenced through the discovery of translations and of many texts in the parts that quoted Caraka extensively (Valiathan, 2006). 
There are other wide-ranging and complex dimensions to Ayurveda such as that of a sophisticated surgery that was practiced as early at 7 th century $\mathrm{BC}$, an extensive engagement with alchemy, and also the use of bhasmas (metal ashes) in the treatment of many conditions. Not only does Ayurveda have a deep history and a rich tradition, it also has distinctive foundational and conceptual understandings of the human body, of disease and of cure. The following two quotes from Valiathan (2006) are illustrative of this distinctiveness:

The Ayurvedic definition of health implied equanimity and cheerfulness (prasannata), which spring from a composite state of equilibrium (sâmya). The equilibrium was called for among the constituents of the body (dhâtus, dosas and agnis); between the constituents and the causative agents (hetu/nidâna) which always lurk within; and between the body and the surroundings (rtu) (...). Well being is the natural state of the body, and diseases are aberrations which generally tend to correct themselves (...). In the Ayurvedic view, countless causes exist within the body and outside, but they are innocuous so long as they remain in equilibrium with the body constituents. They cause disease only when the equilibrium is breached by the individual's imprudent use of his sensory and motor organs. As a corollary, the Ayurvedic management of diseases laid more stress on the restoration of equilibrium by a variety of measures, and less on the elimination of a cause (p. 21).

How do medicines act on the body? It was believed that all drugs produced pharmacological effects through three qualities inherent in them. These were taste (rasa), post-digestive taste (vipâka) and potency (vîrya). As chemical composition was unknown, chemical action was sought to be interpreted in terms of taste. (...). Ayurveda recognised 6 primary tastes and 63 combinations, which must have been difficult to identify and susceptible to misclassification. The taste of food and drugs would change after digestion in the gut with new chemical compositions, which was known as vipâka. An indication of this could be sensed during belching well after a meal. Potency (vîrya) is an inherent pharmacological power of substances, superior in effect to both taste and post-digestive taste. In medical practice, one does also come across instances where medicines act powerfully but not understandably in terms of taste, post-digestive taste or potency. This effect was called prabhâva, which would today be a candidate for inclusion in psychoneuropharmacology. The theory of rasa, vîrya, vipâka and prabhâva formed the basis of Ayurvedic pharmacology. Medicines were prepared in 23 different forms as pills, pastes, decoctions, ointments etc., for administration through the mouth, nose or rectum or for local application on the head, eye, skin (p. 25). 
Even a cursory reading of these quotes is enough to alert us to the fundamental epistemological differences between the world of Ayurveda and that of modern bio-medicine (and by extension of modern science and technology). Not surprisingly, there have been and continue to be significant differences and debates in India about Ayurveda and other traditional medical practices.

\section{Debates surrounding Ayurveda}

There are critics, for instance, who vehemently question the value, efficacy and relevance of Ayurveda, while proponents and believers (who exist in their millions) think there might be nothing better. Parasnis (2004), in an insightful overview that would undoubtedly have many takers, asks incisive questions of Ayurveda as he does of its current believers and practitioners:

there is a tendency of saying 'Ayurveda knew it all', and of representing it as a panacea. This, said in many publications and websites (q.v.), already makes it suspect. (...) Claims [are made] that if everybody lived as prescribed by Ayurveda, all disease would vanish from the earth. Can we take such statements seriously? (p. 1329).

He suggests further (p. 1332) that if Ayurveda as an organized system of thought or practice is to be called a 'science', it must satisfy criteria that would be composed of the well-recognized discrete characteristics of science secularity, rationality, continual expansion of the unknown boundary, continual transformability, awareness of own limitations, self-regulating and self-correcting mechanism, absence of rituals, and falsifiability, the reigning criterion of science. It is clear that Parasnis' critique emanates from deep within the paradigm of modern science and yet it is important to note that his is not a complete rejection of Ayurveda:

Centuries ago when, for example, Ayurveda began and grew, it satisfied some of these criteria and could be called 'science' (...). Today, one is not sure. In particular, the criterion of falsifiability is not satisfied by Ayurveda. This is not to deny its potential, but only to cite reasons why it is not taken seriously (p. 1332).

The reality on the ground complicates the situation further as modern medicine and traditional systems such as Ayurveda continue their practices parallel to each other, and where care and cure seekers often jump across from one to the other quite effortlessly. Traditional systems that include Ayurveda, Unani and Siddha are legally recognized in India. There are estimated to be nearly 600,000 registered practitioners of these systems in the country today, more than half of whom are Ayurveda practitioners (M. Banerjee, 2009; Patwardhan \& Vaidya, 2009). Millions of citizens continue to seek their services that are 
in many cases cheaper and much more accessible in terms of geography and their social and cultural ethos (Patwardhan \& Vaidya, 2009; Valiathan, 2006). There is also a huge and growing Ayurvedic drug industry that has significant economic and financial implications. It is estimated to be now worth anywhere between Rs. 2000 and Rs. 5000 crores (approx. Euros 336-840 million) annually with an export market potential of between Rs. 500 and 1150 crores (approx. Euros 84-170 million) (M. Banerjee, 2009, p. 122; Valiathan, 2006, p. 25). This commercialization, standardization and resultant pharmaceuticalisation is also an important axis of Ayurveda's transformation and one that accounts for its simultaneous resilience and shrinkage (M. Banerjee, 2009). It is, Banerjee summarises in her richly insightful and multi-layered account of Ayurveda in contemporary times, a transformation that "cannot be seen as purely cognitive, technological or economic change, for it involves an irreducible political play between regimes of knowledge and exercise of state power" (ibid., back cover).

It is this play between "regimes of knowledge" and the vast differences between the two worlds that is of particular interest in our case. In the worldview that Parasnis (2004) (quoted above) represents, the frame of reference has to be the 'modern science' regime of knowledge. This is the frame that Ayurveda has to fit into, respond to and correspond with if it is has to have any legitimacy. What makes the interface of Ayurveda with modern bio-medicine particularly fascinating is that there are others (Patwardhan \& Vaidya, 2009; Shankar, 2010; Valiathan, 2006) who agree with the critique and the challenges articulated by Parasnis, but who approach the issue from the diametrically opposite end - from within Ayurveda. Their plea is for equality and equity - not for Ayurveda to be subservient and secondary to bio-medicine but for the two to come together as equals and collaborate in the hope of creating something meaningful and productive that has the best of both worlds. Darshan Shankar (Shankar, 2010, pp. 3-4), for instance, makes the explicit case for:

An Indian model for integrative medicine with an Ayurvedic pivot, (...) inspired by an appreciation of the sophistication of Ayurvedic theory and clinical practice rather than the mere fact of Ayurveda being Indian. (...) An obvious knowledge partner for Ayurveda in its integrative pursuit is biomedical science (...). It is, however, important to appreciate that while Ayurveda and Western biomedicine share the same spirit of earnest inquiry, their perspectives on Nature are different. Their philosophy, logic and medical theories are distinct. Sankhya and logical positivism shape their differing world-views. Nyaya and Vaisheshikha, as against Aristotelian logic, guide their logical propositions and Panchamahabhuta Siddhanta, Tridosha Vichar and cellular and molecular biology govern their respective medical theories. Due to these epistemological differences, the nature of knowledge 
discovered by Ayurveda is systemic and holistic, whereas knowledge in the biomedical sciences is structural and reductionist.

Evidently, the challenge is an overwhelming one. How does one even start to translate, leave alone understand the concepts of Sankhya, Vaisheshikha, or Tridosha Vichar and many others like these that are at the heart of Ayurveda. I find it remarkable that Shankar (2010) and Patwardhan \& Vaidya (2009), don't even attempt a translation of the Sanskrit terms in their particular texts and it is certainly not because they don't have the literary skills or the conceptual clarity to offer these translations. My suspicion is that they choose deliberately not to - Shankar is suggesting, perhaps, that while Sankhya in Ayurveda is the equivalent of logical positivism in biomedicine (similarly, the other equivalences) they are still not the same; that if one has to understand Sankhya or Nyaya or Vaisheshikha, it has to be from within the world view and the epistemology of Ayurveda. We can see Shankar agreeing with Parasnis but in an entirely different way.

Shankar's concerns are much more profound and the tone is distinctly hopeful and optimistic as he shares his vision, the challenges and the rewards of trying to link the two disparate epistemologies:

The question whether Ayurveda and Biomedical Sciences can be linked is equivalent to asking the question whether the whole and its parts can be related. Or the question, whether fields and the several structures contained therein are associated.

It is obvious that the whole and part are related, but the key point to be understood is that the relationship is not one to one because the whole is not equal to the part, nor does the sum of parts add up to remake the whole. One should therefore not be seeking equivalence in developing the relationship between Ayurveda and Western sciences (...). Collaboration between Ayurveda and Biomedical sciences can be very fruitful. There are certain incredible details of parts that science uncovers that can enrich the understanding of the whole, and, similarly, there are new perceptions, insights that are revealed in a holistic view that can fundamentally alter the partial view (Shankar, 2010, p. 4).

Valiathan pushes the argument even further. Quoting the Susruta Samhita, one of Ayurveda's foundational texts, he notes:

No matter how complete and accurate the scientific accounts [of Ayurveda] might be, the whole truth would still elude them [modern science] because Ayurveda is more than the sum total of scientific studies. Instead, the philosophical tradition of Ayurveda would demand 
that we conceive of the reality of Ayurveda as a whole, which expresses itself not only in scientific insights, but also in innate disposition, beneficence, time, chance, destiny and the evolution of all that exists (Valiathan, 2006, p. 34).

Now, leave alone the implementation, even conceptualizing this 'part-whole-partwhole' dynamic appears a daunting proposition. How does one translate some of these fundamental philosophical (epistemological?) concepts into methodological precepts and operational systems? Does a frame of reference exist for an endeavor like this? What might be the implications of such an integrative system, if one is possible at all? How are the vast chasms to be bridged?

It is relevant here that these questions are not new and have been an integral part of the debates on the relationship between modern science and traditional knowledge systems, within the medical systems themselves, and in the encounter between the colony and the empire (Habib \& Raina, 2007c; D. Raina, 2003) $)^{57}$. Dhruv Raina (2003, p. 22) notes that an

important item on the agenda of the British Orientalists studying the natural knowledge systems of India during the early years was that of exploring the possibility of grafting modern scientific knowledge on to a Sanskritic base.

Using insights from Metcalf s (1986) study of the revitalization of Unani Tibb ${ }^{58}$ in late 19th century Delhi, Habib \& Raina (2007b, p. xxiii) note that traditional knowledge systems were not static and were "often reworked and reconfigured in the light of modern scientific knowledge". There is a relationship that can also be seen here between cultural revitalization and reassertion, and political assertion (Habib \& Raina, 2007a; B. Metcalf, 1986; Prakash, 2007).

The case of G. Srinivas Murti who was appointed in 1921 by the Madras government as the secretary of a committee to study indigenous medicine (Prakash, 2007, p. 270) is illustrative. A Tamil Brahmin and Sanskrit scholar, Murti (1948) sought to provide a scientific justification for Ayurveda, and the case provides key insights into the challenges and the dilemmas faced by traditional systems. Gyan Prakash (2007) observes in this context that

Ayurveda's revival could not avoid negotiation with Western science, but this did not mean the dissolution of its identity and authority. Murti

57 For a detailed account of the engagement of the modern with the traditional and of the emergence of hybridities as a consequence, see Akhil Gupta's (1998) account of agriculture in contemporary India.

58 Unani Tibb is the system of healing based on the Greek system founded by Hippocrates and developed further by Aristotle, Galen and other Greek authors. It is the same as what has been called 'Arabian Medicine' by European historians and medical men (Siddiqi, 2009). 
advanced this argument by first acknowledging that Ayurveda needed the language of modern instrumentation. The Hindu method, which was based on the perfection of the senses of observation to a degree that could a few could achieve, could benefit greatly from the external aids to observation develop by Western science. This scheme constituted, in his view, the statement of ancient wisdom in the language of modern science. (...) Poetry, which had once expressed Ayurveda so effectively, was no longer appropriate; now Hindu medicine required the rhetoric of modern instruments to communicate its science to the modern world.

If Ayurveda could now be expressed effectively only in translation, in the language of modern Western instruments, then what remained of its function as the sign of the Indian nation? Murti faced this question squarely, arguing that Ayurveda was ultimately untranslatable. He pointed out that 'while we may attempt some sort of equating at the level of physical matter known both to Ayurveda and Allopathy, there is as yet nothing in the latter in terms of which things at the levels of the vitality and psychic principle could be explained'. Translation (some sort of equating) meant not dissolution but demonstration of irreducible difference, the expression of Hindu science's untranslatability (Prakash, 2007, p. 282).

That the debates have not been resolved is evident from the writings of Parasnis and Shankar that I have quoted earlier and narrative also shows, at the same time, that intersections have always been attempted between modern science and traditional knowledge systems.

Importantly, these engagements and collaborations continue in many places and in different ways even in the contemporary landscape - in the setting up by the Government of India, for instance, of the Department of Ayurveda, Unani, Siddha and Homeopathy (AYUSH) ${ }^{59}$; in the creation of institutions like the Institute for Transdisciplinary Health Sciences and Technology (IHST) ${ }^{60}$; in the conceptualization and articulation of a new category of a "vaidya-scientist' to catalyse a much needed Ayurveda renaissance" (Patwardhan, Joglekar, Pathak \& Vaidya, 2011); in the existence of a journal such as the Journal of Ayurveda and Integrative Medicine (J-AIM) that I have quoted Shankar (Shankar, 2010) from; the fact that Valiathan's report (Valiathan, 2006) that I have also quoted from extensively was commissioned by none other that the Indian Academy of Sciences; and in the existence of attempts and interfaces in institutions such as the Centre for Nanobioscience. Amit Prasad (2006, p. 226) gives a similar example of the All India Institute of Medical Sciences (AIIMS) and the Institute

59 see http://indianmedicine.nic.in/

60 see http://ihstuniversity.org/; it used to be called the Institute for Ayurveda and Integrative Medicine (I-AIM). 
of Nuclear Medicine and Allied Sciences (INMAS), both in New Delhi, where "scientists are conducting functional MRI [magnetic resonance imaging] studies to investigate the impact of the 'Gayatri Mantra' ${ }^{61}$ on the brain." It is the kind of research, Prasad points out, that "embod[ies] multiple subjectivities and draw[s] from different knowledge systems all the time" (A. Prasad, 2006, p. 226).

Two things emerge from the above discussion: one, that there exists a big discourse around the engagement of modern science and technology with a traditional knowledge system like Ayurveda and two, that even as these debates continue there are a number of efforts in modern laboratories, like in AIIMS and $\mathrm{CNB}$, where scientists are trying to work with different knowledge systems. Yet, and like I have pointed out in Chapter 1 (also see A. Prasad, 2006), we have little of the specifics and details of these engagements, encounters and attempts of collaboration. There have been few, if any, attempts to explore the real time material and discursive practices in and of multiple spaces where different partners are already involved in some sort of a conversation - in what might be called an inter-epistemic collaboration. What is needed is to enter these black boxes - to document and describe the details of what happens in these spaces and to understand the nature, outcomes and implications of these collaborations. This, in fact, is what I will do in the following section and the entire purpose of this relatively elaborate narrative of context is to set the stage for one such collaboration between modern science and Ayurveda that I saw playing out in the Centre for Nanobioscience.

\subsection{Ayurveda in the CNB}

I have to make it clear at the outset that providing a comprehensive account of this encounter in all its possibilities is not my intention. What is on offer here is more like an invitation to see (and wonder) what happens when two different systems of knowledge interface and seek to collaborate in a modern laboratory; to also wonder simultaneously how a conversation might even be possible when the frameworks and paradigms are so different. And like in the earlier instances in this chapter, there are two specific efforts in the lab that I will use to explicate the point that I seek to make.

\section{Swarn bhasma and an Ayurveda practitioner in the CNB}

To illustrate how confounding the questions and challenges can be, let me go back to what has been my point of reference in this particular narrative from the very beginning. This is the very first interview I had conducted with Paknikar in December 2010, the conversation in which he told me how the CNB had come to be.

61 The Gayatri Mantra is a popular hymn in Hinduism that is dedicated to the sun god, Lord Surya (also known as Savitr) and is believed to have the powers of bestowing wisdom and enlightenment on those who chant it regularly (Radhakrishnan, 1947, 2008, p. 55) 
He had also told me in some detail then of CNB's first engagement with Ayurveda - with a formulation called swarn bhasma that is well known for its anti-arthritic properties. Translated literally as gold ash (swarn - gold and bhasma - ash), it is part of a prominent tradition in Ayurveda called Rasashasthra that uses bhasmas of a variety of metals like gold, copper, tin, lead, silver, iron and even mercury for treating a range of ailments (Umrani et al., 2013; Valiathan, 2006). One part of this particular research project at the CNB involved the preparation of the swarn bhasma by traditional methods, followed by its characterization and physicochemical analysis using modern scientific methods and instrumentation ${ }^{62}$ (D.S. Agrawal, 2006; Brown et al., 2007).

The intricacy of 'incineration with mercury' as the final step in the preparation of the swarn bhasma by the traditional method is evident in the details and in the process description below:

Purified gold foils were cleaned thoroughly and cut into very small pieces. The small pieces (approx. $10 \mathrm{~g}$ ) were added to $20 \mathrm{~g}$ of pure mercury, placed in stone mortar pestle and rubbed. The amalgam formed was placed into an earthen crucible along with sulpur in a 1:1 proportion. The crucible was covered by placing another inverted earthern crucible on top of it and sealed by three layers of cotton cloth and wet clay. The assembly was heated for 8 hours inside cow dung cakes (four, $250 \mathrm{~g}$ each) in a pit. The maximum temperature during heating was $~ 900$ degree C. After cooling, the incinerated matter was ground and the same procedure of heating with sulphur (1:1 proportion) was repeated. The procedure of grinding, heating with sulphur and cooling was repeated 42 times to obtain a homogenous brown red powder, i.e., Swarna bhasma (Brown et al., 2007, p. 247).

Subsequent analysis using atomic absorption spectroscopy, FT Infrared spectroscopy (FTIRS), Transmission Electron Microscopy (TEM), Atomic Force Microscopy (AFM) and X-Ray Diffraction (XRD) Analysis showed that the swarna bhasma thus prepared contained $92 \%$ gold - mainly globular, zero valent gold nanoparticles of an average size of $56 \mathrm{~nm}$ having no trace of mercury or any organic compound, "indicating proper incineration yielding a highquality product with better potential acceptability" (Brown et al., 2007, p. 249).

This research project involving swarn bhasma can be read almost like a direct response to the challenges laid out by Parasnis - that 'Ayurveda satisfy criteria composed of the well-recognized discrete characteristics of science'. The hierarchy of operation is clear, the fundamental structure is evident and premise

62 The other part of the research project was related to the use of colloidal gold (average size of gold nanoparticle being $27+/-3 \mathrm{~nm}$ ) to treat experimentally-induced arthritis in rat-models. 
is laid out without any ambiguity. It is the traditional practice that is to be validated; it is modern science that will validate. Prima facie, it might seem that there is not much that is remarkable about the example - it is regular science using conventional tools and methodologies, but with substances that come from a particular source, an Ayurvedic preparation in this case. Focusing on just these details, however, will be at the cost of missing out the larger frame of the engagement and the interface.

As an example of this point I would like to draw attention to the preparation in the CNB itself of the swarna bhasma by the traditional method prescribed in the ancient texts, ${ }^{63}$ some details of which have been quoted above. The reason this was possible at all was because of the direct involvement of Durga Shankar Agrawal $^{64}$ (Agrawal Sr), a young Ayurveda practitioner with a Bachelor's Degree in Ayurvedic Medicine and Surgery (BAMS) from the Devi Ahilya University, Indore, in Central India. He had registered himself for a Master's degree - Doctor of Medicine (MD) - in Ayurveda in 2003 with the University of Pune and came to the CNB to conduct this Master's research on swarn bhasma (see D.S. Agrawal, 2006). The presence of an Ayurveda practitioner in a modern nanotechnology lab is not very common and this looks, already, like a promising first, though challenging step across boundaries. None but a trained Ayurveda practitioner could have prepared the bhasma in the way it was done and this underlines the importance of his presence in the CNB. Paknikar acknowledged it in as many words and it is particularly relevant for the context he set his acknowledgement within:

I was fortunate that I could get this person [Agrawal Sr] who was interested in this. Because the other problem with these people is that their language and modern science language doesn't match. They don't understand what we are saying and we don't understand what they are saying. Because they talk in some language we don't understand, we can't interpret [it] into modern science (Paknikar, Interview, 23 December 2010).

In Paknikar's exasperated words one can clearly see the dilemma the practitioner of one world faces in engaging with the other. I have no doubt that Paknikar and his team are firmly rooted in and operate from within modern science, which like Parasnis (2004) has stated, has to validate Ayurveda. At the same time one also sees a sensitivity to the other system, a willingness to engage with it and the acceptance of its value and relevance. But where and how does one begin when even the languages are not decipherable, not mutually comprehensible? It is in

63 Rasaratnasamucchaya-Vijnanabodhini and Sarangadhara-Samhita (Brown et al., 2007, references 40 \& 41).

$64 \mathrm{He}$ is the elder brother of Shailaja Agrawal. 
the ultimate analysis, a profoundly epistemological question and this is where the test of innovation, innovative practice and the culture of innovation really lies.

\section{Jasda Bhasma and a pharmacologist in the CNB}

Let me explore this further through a complementary story - that of Rinku Umrani who came to the CNB in 2006, seven years after getting her Master's degree in Pharmacology. Five of these seven years were spent researching pharmacology and toxicology in two of India's best known pharmaceutical industries. She came to $\mathrm{CNB}$ for a $\mathrm{PhD}$ when she realized she was not getting anywhere professionally and needed that $\mathrm{PhD}$ label to be taken seriously. The $\mathrm{CNB}$ at ARI was a good choice for personal reasons (her husband was moving from Ahmedabad to Pune) and also because of the overlap of her interests with that of the CNB. Her background in the industry had convinced her that she was interested primarily in applications based research and her pharmacologist's skill set of handling lab animals made her a good candidate for work involving the biological applications of nanotechnology. In any case, in her opinion, it could only be a lab that understood the relevance of interdisciplinary work that would have had space for her.

Diabetes had been the subject of Umrani's interest and work while in the industry and she decided to carry it over into her doctoral work when she registered for it in 2007. The locus for this would be the Ayurvedic preparation jasda bhasma, a zinc based preparation, "which is cited in [Ayurveda] literature for use in the treatment of diabetes and several other conditions that include anemia, neuromuscular diseases and as a wound healing, anti-microbial and anti-aging agent" (Umrani et al., 2013, p. 811).

Umrani's research project, much like that of Agrawal Sr., had a twofold aim - first, to validate the use and efficacy of jasda bhasma in treating diabetes and second, to research the use of commercially available Zinc Oxide $(\mathrm{ZnO})$ nanoparticles for treating diabetes. The earlier work at the CNB involving swarna bhasma set the template for Umrani's research. Physicochemical characterization studies using a range of modern laboratory instrumentation and techniques including Diffuse Reflectance Spectrometry (DRS), Scanning Electron Microscopy (SEM), High Resolution Transmission Electron Microscopy (HRTEM), XRD and AFM revealed that the jasda bhasma prepared in-house (by a team including Agrawal Sr. and by the traditional method) had 200 to 500 nanometer (nm) sized crystalline zinc particles of a spherical shape. Efficacy tests showed a significant lowering of blood glucose in the lab rats treated with jasda bhasma along with an improvement in oral glucose tolerance. No behavioral abnormality or adverse effects were reported and other standard parameters such as SGOT, SGPT and serum urea were also not significantly altered (Umrani et al., 2013; Umrani \& Paknikar, 2011a), leading to the conclusion that: 
Ayurvedic medicine Jasda bhasma (zinc ash) comprises of sub-micronic particles, predominantly of zinc oxide. Anti-diabetic activity of Jasada bhasma has been pharmacologically validated using both type 1 and type 2 diabetes rat models (...). Pharmacokinetic data confirm systemic absorption of zinc ash after oral administration. The study also suggests that the preparation is free of heavy metals and is safe for use even at 100 times the efficacy dose. To the best of our knowledge, this is the first comprehensive study of its kind validating/endorsing the extensive use of zinc ash preparation in Ayurveda for the treatment of diabetes (Umrani et al., 2013, p. 821).

In a parallel process, Umrani also worked with commercially available zinc oxide nanoparticles of a size $<10$ nanometers. The experiments and tests to check for their efficiency and efficacy in treating diabetes in rat models concluded that these zinc oxide nanoparticles were indeed a promising anti-diabetic agent and warranted further studies and investigation (Umrani \& Paknikar, 2011b, 2013).

Umrani's research work (Umrani, 2011) follows the same pattern as the earlier project involving swarn bhasma and continues in the mode of modern science validating traditional practice. And just like in the earlier case, it would be limiting and restrictive to understand and interpret Umrani's project from just that window. Umrani's training, unlike that of Agrawal Sr., comes from within the paradigm of modern science and yet her effort of evaluating the Ayurvedic jasda Bhasma, I would like to argue, is not merely a scientific exercise; it also has a prominent, though un(der)-stated epistemological underpinning. It comes through when she notes that zinc is known to play a definite role in glucose metabolism in the human body, and yet it has been written off in the context of modern medicine as not workable:

Ayurveda [has] used $\mathrm{Zn}$ based therapy for the treatment of diabetes [for millennia]. So, here is a science which is validated from centuries, (...) and [yet] modern science is not ready to believe it. So, we [tried] (...) to validate whether the Ayurvedic preparation really works or is it just a gimmick. So, using our pharmacological approach, using animals, we found out that, yes, it works. It has [the] beneficial effect of lowering the glucose levels which is the primary aim of anti-diabetic therapy (Umrani, Interview, 01 April 2011).

The epistemological tension is evident, for instance, when Umrani accepts Ayurveda as a "science validated from centuries" and yet needs modern tools and methods to validate it from a modern science perspective. It is exemplified in the strong skepticism from within Ayurveda that she has had to deal with: 
[My research] will not add anything to Ayurveda practitioners because they believe they have their wisdom and they don't need to convince anyone. (...). They don't want us, honestly. When I put [up] this proposal for the 1st time, at least the few [Ayurveda practitioners] that I had interacted [with] (...) were not very keen in this work. (...) They have formed a negative impression that I will prove this will not work, [though] I had not set out with a known result in my head. I wanted to actually check whether it works or not. [The] Ayurvedic community perhaps does not need people like me. They believe their practice will continue, their patients have faith - that is all fine. Sitting over here I don't know even $0.01 \%$ of Ayurvedic knowledge. (...) It is a very vast subject - you have to look into a number of things. But at least I have learnt enough to know that it is such a vast science and I have learnt to appreciate it. That is my learning in the process (Umrani, Interview, 13 June 2011).

Not only does Umrani have to convince the world of modern medicine that zinc might offer a viable alternative in treating diabetes, she has to also deal with Ayurveda's continued skepticism of what modern science has to offer.

The question is not and should not merely be about the success achieved from within a certain frame or what the parameters of this success will be. The much more interesting opportunity and challenge is to see how and where these encounters are allowed? How has this inter-epistemic collaboration (with all its limitations) been made possible; where and under what circumstances has this been set up? The principle challenge as noted by Banerjee (2009, p. 207) is that "of translation between texts and epistemes and the legitimation of all forms of evidence other than the positivist kind." The challenge is a difficult one because it demands a breaching of the epistemologies at the same time as it demands an effort at bridging the divides. How is that possible, if it is possible at all? Will it be about language, about symbols; will it be about methods or will it have to something entirely different and much more fundamental? An answer will perhaps emerge from the coming together of the conceptual thinking and challenges laid out by Shankar and Valiathan, in institutional efforts like the creation by the Government of India, of AYUSH, and the collaborative science and research being attempted at the interface in laboratories like the CNB.

\subsection{In conclusion}

The point I would like to note in conclusion is not about the way in which the interfaces are set up, how the collaborations pan out or what these efforts deliver. These are very important, but what is more interesting, even intriguing, is to notice that these encounters are possible at all and ask how they are allowed 
to happen. It is to realize that an ancient Ayurveda continues to march on in parallel with modern bio-medicine even though their fundamental premises are antithetical to each other in many ways. It is to acknowledge that this is possible because of the larger historical, cultural and social context that allows space for nanotechnology even as it allows space for Ayurveda and many other such traditional practices to continue in diverse forms. It is to see how technological jugaad can contribute to the making of a modern scientific instrument just as is it to see that modern scientific instrumentation and methods can explicate for us the working of an Ayurvedic bhasma.

The challenge is, of course, not merely to use a modern instrument to validate a bhasma, but to go a step (many steps) ahead to see how two cultures, worldviews and epistemologies will be able to talk to each other as equals. The culture of innovation is contingent on the simultaneous existence in the same place, same space and at the same time of these two epistemologies, allowing for, even demanding collaborative work that is inter-epistemic. Might there be a possibility in the future, for instance, that knowledge in Ayurveda is called upon to validate some claims from bio-medicine? What kind of world will that be? Not many geographies might be able to claim that reality in contemporary times as emphatically as we find it here in India, and it is in meeting this challenge and operationalizing this potential, it is my contention, that a rare opportunity of and for innovation lies before us. 



\section{User's matter: A low cost nano-silver option for water-purification}

\subsection{Research and development at ARCI}

The Hyderabad based International Advanced Research Centre for Powder Metallurgy and New Materials (ARCI) is one of 24 institutions that forms an elite constellation under the umbrella of the Government of India's Department of Science and Technology (DST). Four of these are specialised knowledge institutions, five are professional bodies and 15 are research institutions that conduct research on topics as diverse as microbiology (Agharkar Research Institute, Pune), soft matter research (Centre for Soft Matter Research, Bengaluru) nanoscience and technology (Jawaharlal Nehru Centre for Advanced Scientific Research, Bengaluru), paleobotany (Birbal Sahni Institute of Palaeobotany, Lucknow), geology (Wadia Institute of Himalayan Geology, Dehradun) and astronomy and astrophysics (Indian Institute for Astrophysics, Bengaluru).

ARCI, which was established in 1997, is not only one of youngest of the DST family, it is also distinct in having been "set up with a mission to develop unique, novel and techno-commercially viable technologies in the area of advanced materials and subsequently transfer them to industries" (ARCI, 2008, inside front cover). The institute is constituted by 10 Centres of Technical Research ${ }^{65}$ and an 11th one that is the Centre for Technology Acquisition, Transfer and International Cooperation. The thrust research areas for ARCI include Nanomaterials, Engineered Coatings, Ceramic Processing, Laser Materials Processing, and Fuel Cells and a perusal of reports from ARCI and the DST suggest that the organization has indeed been successful in meeting the remit of developing technologies for industrial and commercial use. These include among others the development of "a simple, cost effective and scalable process for preparing pure rutile titania nanoparticles of $15 \mathrm{~nm}$ size"; a Electro Spark Coating (ESC) technology to provide carbide, cermet and metallic coatings on a wide variety of engineering components made from metals and alloys; the synthesis of "nanocrystalline inorganic fullerene-like (IF) as well as nanosheets of tungsten disulfide (WS2) by a novel route"; "development and transfer of a technology of nano-silver suspensions for antibacterial textile applications"; and development and demonstration of "sol-gel based nanocomposite coatings for

65 These are the Centres, respectively, for Nanomaterials, Engineered Coatings, Ceramics Processing, Laser Processing of Materials, Fuel Cell Technology, Non-Oxide Ceramics, Carbon Materials, Sol-Gel Coatings, Structural and Chemical Characterization and Mechanical and Microstructural Characterization 


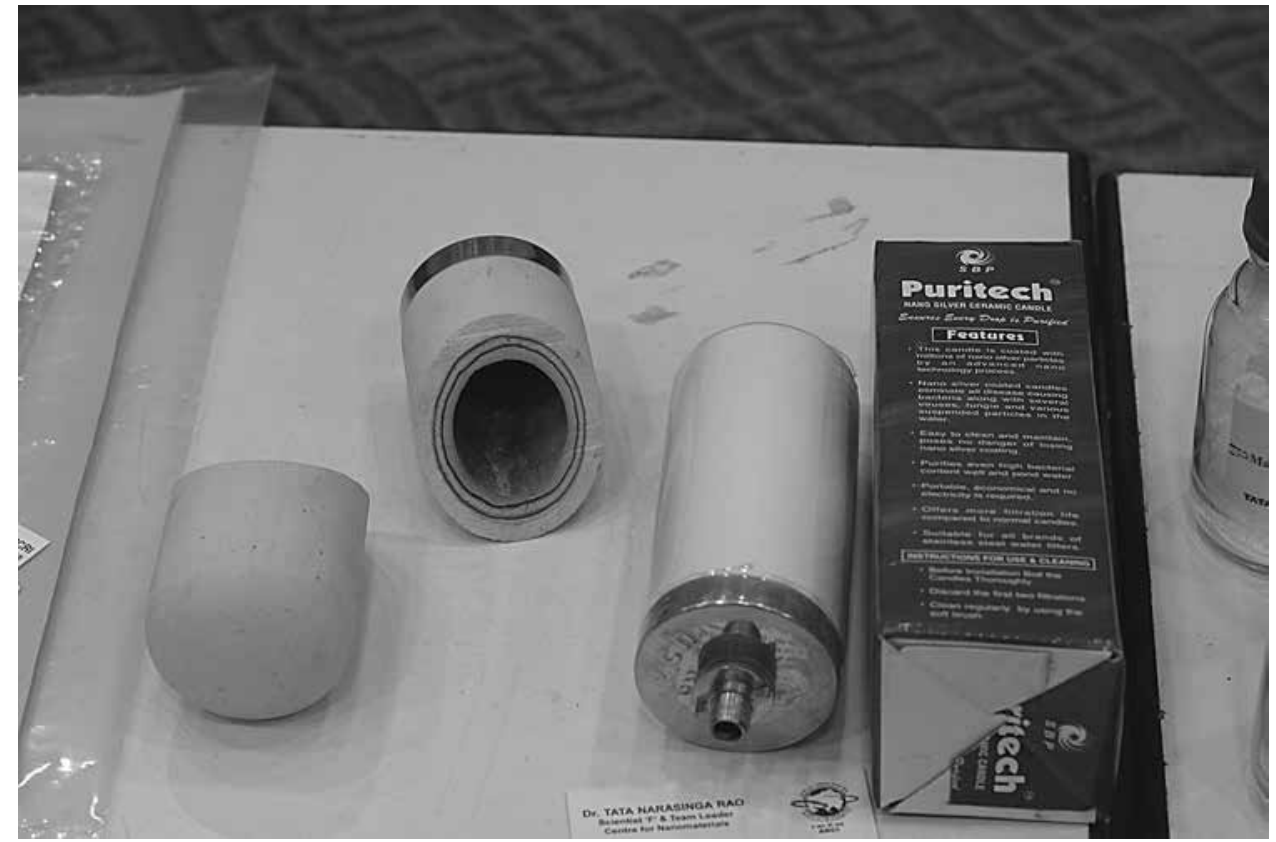

Image 27: The Puritech brand of nano-silver enabled ceramic candle water filter (Pic: Author)

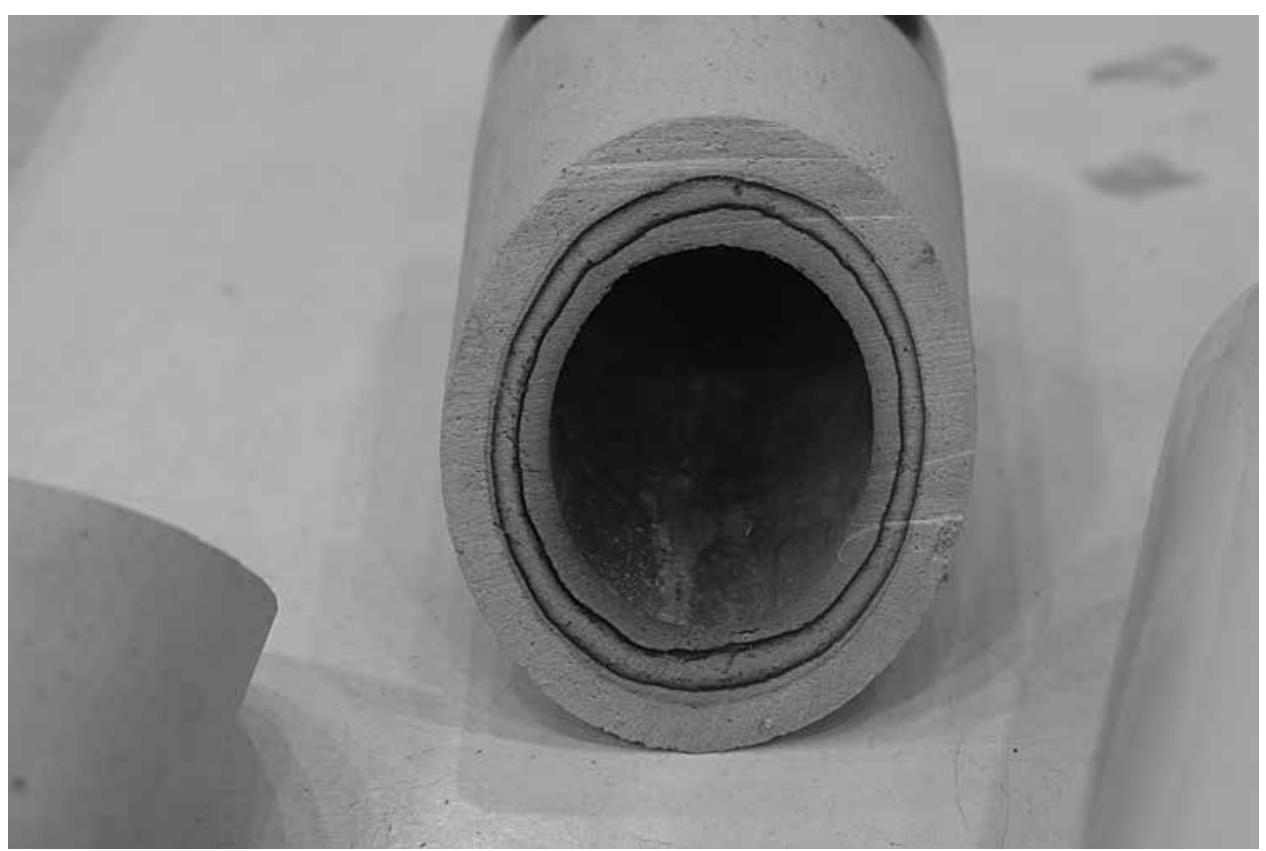

Image 28: A cross-section of the nano-silver ceramic candle based on the technology developed by ARCI (Pic: Author) 
surface engineering of different substrates for a wide variety of applications" (ARCI, 2008; DST, 2011, 2012; TN Rao, 2012).

While most of this research at ARCI appears directed towards industrial, defence and other high cost uses, there is one that stands out for being located at the opposite end of the application spectrum - this is the development of the "nano-silver incorporated ceramic candles for drinking water disinfection" as a low cost, point of use (PoU) water filtration device (DST, 2011). It was developed at the Centre for Nanomaterials in 2006-2007 (ARCI, 2008) and has been available in the market since then through an arrangement with a small Hyderabad based entrepreneur (Images 27 \& 28). The technology offers safe drinking water at an additional cost of not more than Rs. 250 (about four Euros), and the excitement and optimism about this filter at ARCI is evident in the institution's 2008 annual report:

\begin{abstract}
ARCI is proud to transfer its first nanomaterial-based technology on drinking water disinfection to an Indian company (...) [The] Nanosilver-candle filter technology has been successfully transferred (...) and the product is in the market with the brand name of PURITECH. This is the first low cost nanotechnology based product released in the market that does not require any electricity or pressurized water and meets the standards in terms of bacterial disinfection in rural areas (...). [It] also serves [the] urban community who face occasional bacterial contamination of the municipal water either due to cross contamination through supply pipelines (especially in rainy season) or by supply through improperly cleaned over-head storage tanks (...). The product was field tested for an year in about 40 villages for drinking water disinfection and has been tested in the laboratory as per IS and EPA guidelines. The company has setup a plant in Hyderabad with a production capacity of 1000 candles per day (ARCI, 2008, p. 2).
\end{abstract}

Prima facie, this appears to be a case of the development of a technology that has all the ingredients needed for a successful recipe - developing country, emerging nanotechnology, high tech research, government scientific institutions, industrial participation, technology transfer, low cost, NGO facilitation, appropriate technology, bottom of the pyramid - all the elements of an elusive assemblage that need to, but rarely if ever, come together. And yet, in only about four years since it was launched in the market, this nano-enabled ceramic water filter has been written off as a complete failure. In June 2012, when I started research on the Puritech water filter as part of my doctoral project, the product was difficult to find in the market, the production unit had been scrapped and G Bharath Kumar, the Managing Director of SBP Aqua Tech Pvt. Ltd. that was manufacturing and marketing the water filter had resigned himself to failure and considerable financial losses: 
More or less it is a failure. I told ARCI also - you may be claiming it is good. I don't deny that, but (...) it is not clicking in the market. Whatever the technology may be, it should work in the general perception, in the general public. Once that is not working it is as good as failure (...). Sixteen lakhs [approx. Euros 27,000] we have spent [for] publicity and raw materials. [The] raw materials are still lying with me, [and the] many machines we have purchased (...) [are] almost scrap now (...). I know the product is good, but no takers - what to do? (...) Was [there was an] (...) error of judgement [on my part]? That's true (Bharath Kumar, Interview, 2012).

The contrast between the ARCI's and the entrepreneur's initial optimism and the latter's subsequent resignation is indeed stark and is at the heart of the questions I seek to explore in this chapter: Why did the water filter fail even though the framework conditions seemed just right and all in place? What are the kind of resources needed to ensure success? Can, or should success be measured differently at different points of the development/innovation process? What bearing does failure (or success) in the market place have on claims of success (or failure) by the scientist, the technology developer or the entrepreneur? What roles do these various actors perform or conversely, do actors perform the roles they are supposed to? Is there an optimum point where industry and the entrepreneur should get involved in the technology development process? What is appropriate technology; similarly what is obsolete technology? What happens when an emerging technology interfaces with one going obsolete? The development in ARCI of this "nano-silver incorporated ceramic candles for drinking water disinfection" not only throws up many such questions, it also provides interesting insights into many of the related issues.

\subsection{The Social Construction of Technology}

In the narrative that follows I present a detailed account of the various aspects and stages in the journey of ARCI's nano-silver enabled water filter - from the conceptualization stage to the development of the technology, its transfer and finally the reception it received in the market. The methodological and theoretical framework underpinning this chapter is the Social Construction of Technology (SCOT) (Bijker, 1995b; Pinch \& Bijker, 1987), which I will use to present and (re)construct the story of the water filter from different perspectives and to go beyond the standard narratives of technology development, success and failure that emerge.

Key to understanding and using SCOT is the analyst's concept of the 'relevant social group' (RSG) that is "used to denote institutions and organisations (...) as well as organized or unorganized groups of individuals (...) [and where] all members of a certain social group share the same set of meanings, attached 
to a specific artifact" (T. Pinch \& Bijker, 1987, p. 30). Following this, I identify three social groups that are most relevant in the water filter story - the scientist/ technologist who developed the technology in the laboratory, the entrepreneur who takes the technology to the market and the user (or the market) that the efforts of the scientist and entrepreneur are both directed towards.

As one explores the water filter from the perspectives of each of the relevant social groups, we realize that each has a different understanding of the artifact and a different story to tell. As one understands and unpacks these stories one thing emerges clearly - there are multiple explanations, and each actor makes meaning in a different way depending on the nature of relationships as also the stakes involved. In seeing how different social groups understand and explain the situation, the water filter is no more a single entity. This is the 'interpretive flexibility', the 2nd core concept in SCOT where "there is flexibility in how people think of or interpret artifacts but also that there is flexibility in how artifacts are designed" (Pinch \& Bijker, 1987, p. 40).

The 3rd key concept in SCOT is that of 'closure and the stabilization of the artifact' (Pinch \& Bijker, 1984, 1987). This is the process "where scientists and engineers resolve controversies and engineer consensus (...) [and] facts and artifacts [are vested] with authority and permanence" (Misa, 1992, p. 109). This closure can either be rhetorical where the problem need not be solved "in the common sense of the word", but where the "relevant social groups see the problem as being solved" (Pinch \& Bijker, 1987, p. 44). A key role is played here by a "crucial experiment" or a "knock-down argument" due to its appeal to a "wider and less expert audience" and not just "the core set of scientists" (Bijker, 1995b, p. 86). Closure can also be achieved by a "redefinition of the problem", which as Pinch and Bijker showed in the case of air tyre in the bicycle, involved translating the meaning of the tyre "to constitute a solution to another problem" (Pinch \& Bijker, 1984, p. 428). Misa (1992, p. 110), quoting a number of different authors, also points to other mechanisms of closure - through "argumentation and negotiation" in the case of scientific controversies involving a core set of scientists (Collins, 1981, 1985) and in the forming of the "black box" under the actor-network model (Bowker, 1987; Latour, 1987; Law \& Callon, 1992). Closure leads to the diminishing of interpretive flexibility, a decrease in the "pluralism of artifacts" and the subsequent emergence of a "consensus among the different relevant social groups about the dominant meaning of an artifact" (Bijker, 1995b, p. 86).

Misa (1992, p. 111) notes that "Closure (...) render[s] [a] particular artifact, system or network as necessary or logical", and that it plays a key role in the process of change by frequently restructuring power relationships. Much is obviously at stake and this is why actors seek a closure that is favourable to them. According to Misa (1992, p. 110) "closure mechanisms (...) stabilize social groups as well as artifacts" and "stabilization occurs if and when 
a social group and an artifact meld together." This stabilization can happen in different ways:

Little can be said about this process [of stabilization] in the abstract. It may take the form of compromise - some kind of negotiated settlement. It may look like politics, bureaucratic or otherwise. It may look like the exercise of naked power (...). The differences may be expressed in or through a variety of forms, shapes, or media: words, technologies, physical actions, organizational arrangements (Bijker \& Law, 1992, p. 10).

While closure is focused on the elimination of the different meanings attributed to an artifact by different relevant social groups, stabilization highlights the "continuous character of technical change" within one relevant social group, underscoring the point that "technical change cannot be the result of a momentous act of a heroic inventor" (Bijker, 1995b, p. 86). Misa (1992, p. 110) also notes that the concept of "momentum" which Hughes $(1987,1989)$ describes as the "social processes by which large technological systems shape their own growth and appear to become autonomous" may also be brought about by the process of stabilization.

The 4th key SCOT concept is that of the 'technological frame' which is composed of "concepts and techniques employed by a community in its problem solving" and where the technological frame can be a combination of "current theories, tacit knowledge, engineering practice (...), specialized testing procedures, goals and handling and using practice" (Bijker, 1987, p. 168). The technological frame, by being "a frame with respect to technology, rather than (...) the technologist" allows for symmetry and affords an equal inclusion of all the different relevant social groups, including the "social groups of nonengineers (...). [It] is intended to apply to the interaction of various actors" and is therefore "located between actors, not in actors or above actors" (Bijker, 1987, pp. 171-172). A technological frame is contingent to interaction around an artifact and "can be used to explain how the social environment structures an artifact's design" (ibid., p. 173).

As one explores the water filter from within the SCOT framework, the multiplicities of meanings and interpretations become evident. A constant flux is evident as the actors that make up the relevant social groups seek to understand and adapt to the world that is also constantly changing around them. As the situation changes, one sees the interpretive flexibility in relation to the artifact. In the first instance, the entrepreneur and the technologist can be seen as included in the same technological frame - that of a technically effective and low cost artifact. The stability and closure that appears to have been achieved is disturbed by dis-agreement and de-stabilisation when a new relevant social group (the market) is introduced into the picture and the product is seen to have failed 
here. While there is now an acceptance of the failure, a disagreement emerges (and continues) between the technologist and the entrepreneur on the cause of this failure - there is no closure in this matter yet. While the technologists argue that the product failed because it was not marketed effectively, the entrepreneur now interprets the ceramic water filter candle in a completely different way - for him it was an obsolete technology to begin with and was bound, the nano-silver and nanotechnology notwithstanding, to fail.

Obsolescence, in fact, emerged for me as an unexpected explanatory rubric in the story and I conclude the chapter with a brief engagement with and some reflections on the notion of the obsolete and of obsolescence. I would like to draw particular attention to this aspect because obsolescence is an important marker in the narrative of modern technological development and yet, STS has engaged with it only from the margins. Much might be possible in further engaging, understanding and unpacking what obsolescence is all about and the linkages it has/might have with ideas of technology, technological development, progress, innovation and waste.

\subsection{The challenge of clean water in India}

Before I go ahead into the various details and understandings of this particular water filter, it would be useful to explore the larger context within which the filter is located. This is the critically important challenge of clean water availability across the length and breadth of India. A snapshot of how this problem looks for those at the receiving end comes from the life experiences of Tata N Rao, the scientist at ARCI who led the project for the development of the nano-silver enabled ceramic water filter. He shares here his memories of growing up in a small village in rural Andhra Pradesh:

I have a rural background - I was born [there]. (...) I also drank the same water. I know [the] kind of problems (...). [On one] side of the pond people wash their cattle, their cows (...); the other side people take a bath. (...). You take your bath and go a little bit inside, put a sari or a cloth and then filter water. That is how it works (Rao, Interview, 5 April 2012).

This individual experience scaled up in time and space is what the consolidated figures from various sources reveal as the magnitude of the problem and the challenges in India today. An estimated 100 million people have no access to safe drinking water, nearly a third of the country's rivers are polluted and groundwater has plummeted to unprecedented levels on account of overexploitation for irrigation and domestic supply (Mujumdar, 2015). Water borne infections such as diarrhea, gastroenteritis, cholera, and some forms of hepatitis continue to be common, leading to high levels of morbidity and mortality. 
Nearly one in 10 deaths in India is linked to poor sanitation and hygiene and the case of diarrhea, which is easily preventable, is particularly instructive. Five percent of all deaths in India annually are caused by this disease, with $88 \%$ (nearly 450000 individuals) being children below the age of five (MDWS, 2011; NCMH, 2005). Community based studies indicate additionally that a large number of children in this age group have two-three episodes of diarrhea every year - a cumulative number that then runs into many million cases annually (PC, 2002). There are other areas of serious concerns as well: between 62 and 66 million people in the country are affected by high concentration of fluoride in water (P.C., 2002; Pradeep \& Anshup, 2009) and nearly 14 million are victims of arsenic poisoning of ground water (P.C., 2002). These are just what one might call the technical dimensions. There are also large inequities that are caused by these problems in some cases and in others, the cause of the problems themselves, making life even more difficult for the vulnerable and the marginalized communities such as those of women, adivasi (tribals) communities, dalits, and the urban poor.

Over the years there has been considerable effort and investment on part of the state machinery in dealing with this challenge. For the 25-year period 1980-2005, the Government of India spent nearly Rs 3500 crore (Euros 583 million) for various water, drainage and sewage projects. Realising the scale of the challenge, recent years have seen a many orders of magnitude increase in the investment in this sector. Nearly Rs 43,000 crore (Euros 7200 million) were sanctioned, for instance, for the water and sanitation sector under the Indian Government's ambitious Jawaharlal Nehru National Urban Renewal Mission (JNNURM) for the period 2005 and 2011. Even this, it has been realized, is nowhere near enough.

The Planning Commission (P.C.) of India estimated recently that the capital investment needed in the next 20 years is Rs 7,54,627 crore - nearly 20 times of what has already been invested. Even this may be an underestimation given the increasing costs of treating water and of sewage drainage and treatment. According to India's Central Pollution Control Board, the country can only treat 30 per cent of the human waste generated in urban areas and here too a significant majority of the installed capacity is concentrated in big metropolitan cities such as New Delhi and Mumbai. Many cities "do not even have the beginnings of a sewage network" and where they do exist, there is a "massive backlog of incomplete sewage systems or systems [are] in serious need for refurbishment and repair" (P.C., 2011, pp. 7-10).

It is clear that the state machinery has been unable to meet the basic needs of water of the citizenry, leading to the widespread use of point of use (PoU) solutions for water filtration and purification at the individual household level. These include among others, straining water with an ordinary cloth, flocculation using alum (aluminum sulphate), boiling water, use of the ceramic candle filter 
and also more modern technologies such as those based on reverse osmosis (RO) and ultra violet (UV) dis-infection methods (Bhakta \& Munekage, 2009; Clasen et al., 2008; Jalan, Somanathan \& Chaudhari, 2003; J.E. Nelson, 1997). There is a large unmet need out there and, as might be expected, the prospect of a huge market as well. The PoU water filter market in India is reported to have generated Rs. 2,460 crore (approx. Euros 410 million) in 2010 and is expected to grow to Rs. 7,480 crore (approx. Euros 1246 million) by 2015 (Malkani, 2013). From a collective national problem of gigantic proportions to individual, atomized solutions and back again to a huge market - the flipping of scale is as dramatic as it is instructive. This also explains in large measure the increasing scientific, technological and corporate interest in creating PoU solutions for the water problem, and Tata Rao and his team at ARCI are only one amongst a host of others in the country (and also worldwide) who are attempting nano (and also other) technology based solutions to deal with the situation. There is considerable diversity, of course, depending on knowledge and technologies available, on the capacities and skills of the individuals involved, and on institutional cultures and their mandates. Importantly, however, it is all about the 'point of use' water filter.

\title{
5.4 ARCI's nano-silver ceramic candle
}

An important moment in the water filter story from ARCI's institutional context was the setting up here of the Centre for Nanomaterials under Rao's leadership in the year 2003:

\begin{abstract}
The Centre for Nanomaterials at ARCI has been established to develop technologies for large scale synthesis of nanomaterials to meet the requirements of Indian industries as well as to develop and demonstrate the innovative application technologies followed by transfer to interested industries. ARCI is working on about 15 technology related projects out of which one has been transferred to an industry and few more are in developing stage in collaboration with some reputed Indian companies (ARCI 2008, p. 2).
\end{abstract}

A 1994 doctorate in Chemistry from the Banaras Hindu University in Varanasi, Rao, had just returned to India after spending seven years abroad. He was at the Department of Applied Chemistry, Faculty of Engineering, at the University of Tokyo, Japan, where he was, first, a post-doctoral fellow and then an Assistant Professor. His work in Tokyo was significantly application oriented and this fitted well with the general remit at ARCI and the specific responsibility that was given to Rao. The challenge for him here was to deliver something relevant: "For the Indian context, health and water [are] the two issues. So, I thought (...) we should start with that," he told me when I met him for the first time in April 2012 on the sidelines of a conference in Goa. For Rao and his team at the ARCI 
that included K. Murugan, J. Revathi and Neha Hebalkar, the decision was to focus on the ceramic candle.

A typical ceramic candle water filter comprises two containers, which are generally made from stainless steel. One or more porous ceramic candles are screwed into the base of the top container and the water is filtered as it passes through these candles and drips slowly into the lower container (for an overview of how ceramic cleans water see Bhakta \& Munekage (2009)). Over the years a large number of these water filters have been in use in India on account of their low cost and ease of use, including the fact that no electricity or pressurized water is needed to operate them. The de-centralised and de-centred nature of the industry means it is difficult to get consolidated and reliable figures of actual production and use. A 1997 management case study (J.E. Nelson, 1997) estimated conservatively that nearly eight million households were using such ceramic candle filters in India, while Murcott (2006) suggests that 18 million such candles are manufactured in the country annually. Whatever variation the numbers might suggest, it is clear that there has been substantial scale where the production and use of these candles is concerned.

This was the water filter that the ARCI researchers, the first of the relevant social groups in our narrative, decided to work with. If the ceramic water filter is cheap, easy to use and is considerably popular, why not work towards making it safer, more effective and efficient? The idea was to "not-reinvent the wheel" but to pick up an "already proven one and (...) build on [it]" (Rao, Interview, 5 April 2012). The old ceramic candle would be given the nano-silver edge.

\section{The nano-silver edge}

Silver is a known anti-bacterial with multiple uses and dispensations that go back more than 2000 years into history (Pradeep \& Anshup, 2009). The idea at ARCI was to use it to enhance the life and the effectivity of the ceramic candle. As J. Revathi, a doctoral researcher involved in the project since 2005 explained:

Even the bare ceramic filter candle, (...) because of electrostatic force of attraction (...) can filter the bacteria (...). But the challenge, the problem (...) is that with time this will lead to bio-film formation and that bio-film will become a bacterial breed. Even if the tap water [has a] bacterial count [of] only $1000 \mathrm{cfu}$, the filtered water will have $10000 \mathrm{cfu}$. (...). [The silver prevents] bio-film formation; it will prevent bacterial growth in the filter candle and it also removes the bacteria [from] the water itself (Revathi, Interview, 4 June 2012).

The focus was to be on simplicity and cost - procure the ceramic candle from the market and impregnate it with nano-silver to ensure that the filtered water was completely free of bacteria. The cost and effort needed would only be of an 
incremental nature and the rewards, proportionately, much higher. It is a step away from the 'making do' and 'catching up' that characterises Technological Jugaad (Chapter 3) to what might be considered an effort at 'making happen' in the domain of innovation. The idea was not to just 'get by' but to create a product for the market that would be easily available and one that would be commercially viable. A societal need, a much in use ceramic candle filter and a traditionally well established anti-bacterial on the one hand and a modern nanoscience and nanotechnology platform were to be brought together to create a product that looked similar to the one that existed but delivered much more for only a marginal increase in cost. One can see that the idea is Schumpeterian and fits in, at the same time, with the frame of social innovation that were discussed in Chatper 2.

For the scientists the key challenges were technical - first that the production process had to be safe and then, that the nano-silver would adhere well and not leach during use. The initial process that they developed resulted in the generation of a carcinogenic by-product and had, therefore, to be abandoned. It is in the subsequent development and use of another process that one of the key technical innovations was involved. This new process for the in-situ nucleation and impregnation of the ceramic candle with nano-silver was developed in about two years and an Indian patent (2786/DEL/2005) for the process was filed for in October 2005. The candle was put through a battery of tests to check for two main parameters - its anti-bacterial action and the leaching of silver. The challenge, as Revathi put it, was

to fine tune and optimise the concentration of silver required for antimicrobial activity (...). Suppose you dump too much of silver, definitely you gonna see a lot of silver in the filtered water also. If it is too less you will have to compromise with the anti-microbial activity (Revathi, Interview, 4 June 2012).

Tests were first carried out in a government run laboratory, then in two private labs - Vimta Laboratories (V.L., 2007, 2008a, 2008b, 2008c) (Image 29) and Lucid Laboratories - and also in the Kamineni Hospital in Hyderabad. The antibacterial performance was good and life cycle analysis showed no leaching of silver, suggesting that there need be no concerns regarding toxicity. For the latter, the candles were also subjected to an accelerated test by immersing them in boiling water for 30 minutes to evaluate the strength of silver adherence. The results were found to be "within the permissible limits as recommended by the World Health Organisation (WHO) for silver in drinking water and the United States Environment Protection Agency (USEPA) for colloidal silver intake by humans" (ARCI, 2008, p. 2; T.N. Rao, 2012, p. 3). 


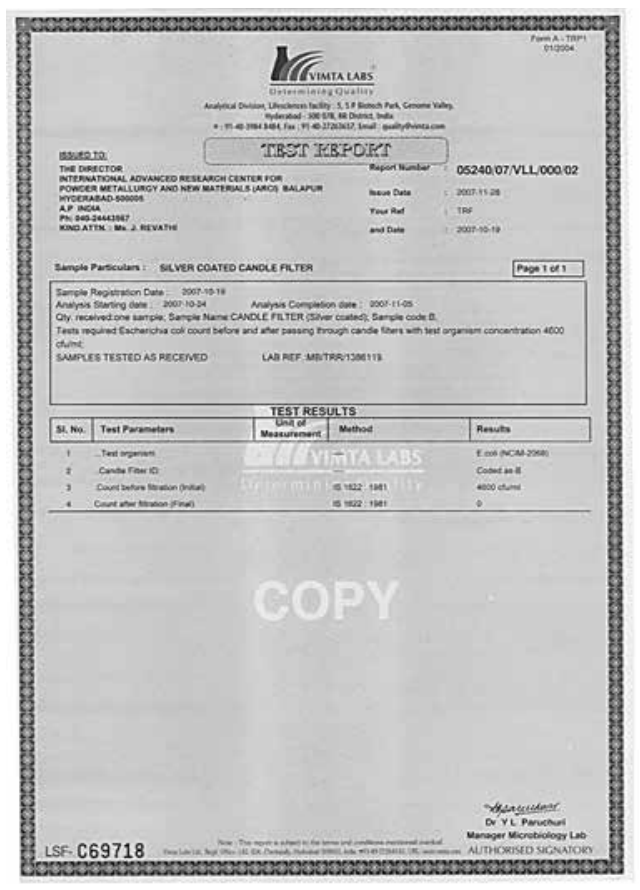

Image 29: Certificate from Vimta labs

\section{Field testing the new product}

Field-testing of this new water filtration system was then carried out in rural Andhra Pradesh in collaboration with the Byrraju Foundation (ARCI, 2008), a prominent non governmental organization (NGO) that was itself looking for options and alternatives to deal with the poor water condition in the areas that they were working. The facilitation was helped immensely by the fact that an officer from the Department of Science and Technology, the parent institution of ARCI, was on deputation with the NGO:

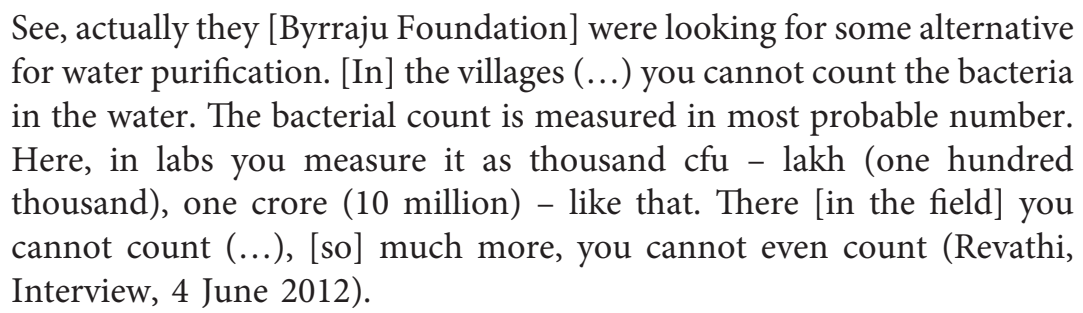

100 of these nano-silver enabled ceramic candle units were then installed in government run health centres in about 40 villages where the foundation had a presence. Their activity and water output was monitored for nearly a year and results regularly reported to the team at ARCI. The simple Hydrogen Sulphide 
$\left(\mathrm{H}_{2} \mathrm{~S}\right)$ test based on dipping a peptone-coated strip of tissue paper was put to use by nurses and health workers in the villages to check the efficacy and efficiency of these water filters. $\mathrm{H}_{2} \mathrm{~S}$ released during the growth and metabolism of the bacteria turns the filter paper black, the time taken for which indicates the concentration of the bacteria present. The results were gratifying:

The water [initially] (...) was completely turbid. It was just like close to coffee, black coffee. The water is actually that bad. (...) In most of the cases, before filtration, the colour change [of the tissue paper as part of the $\mathrm{H}_{2} \mathrm{~S}$ test] would happen in less than 24-30 hours whereas in our case even after 72 hours we did not obtain any colour change. (...). We then recovered the filter candles and tested the anti-bacterial activity. And even after one year the activity was retained in the filter candle (Revathi, Interview, 4 June 2012).

The product, as far as this relevant social group was concerned, was performing well. The leaching of silver had already been checked and studies in the field proved that the anti-bacterial activity was both, strong and sustained. The product was ready!

\section{The entrepreneur - the 2nd relevant social group}

It was about a year later, with these ARCI developed nano-silver enabled ceramic candles now visible in the media, that the entrepreneur entered the picture. It was while surfing the internet with a friend that G. Bharath Kumar, formerly with the Indian Air Force and now Managing Director of Aqua Tech Pvt. Ltd., a small Hyderabad based enterprise, first learnt of these candles. He set up a meeting with the scientists involved, first Dr. S.V. Joshi who was Associate Director at ARCI and then Rao who had led the project for the development of this technology.

Bharath Kumar's journey as an entrepreneur might be described, at best, as one of constant exploration and searching. Starting off with washing machines in the early 1990s after he completed commission from the Air Force, he moved on to making air coolers, inverters and un-interrupted power supply (UPS) units and then into the manufacturing of stainless steel products such as water filters and kitchen utensils. He was now looking to diversify:

I thought why not have value addition to that existing [ceramic water filter] candle. In that process I came into contact with ARCI. (...) They [said they] had this very novel thing - it's anti bacterial [and] very cheap - with one gram of silver (...) you will get this water free from bacteria (Bharath Kumar, Interview, 5 June 2012). 
Much like the scientists at ARCI, though from an entrepreneur's perspective this time, Bharath Kumar saw the nano-silver enabled ceramic candles as good valueaddition and a viable business opportunity to capitilise upon. Bharath Kumar's experience of being in the water filter business suggested to him that an estimated 70,000-80,000 ceramic candles, most of them imported from Gujarat, were being sold annually in and around Hyderabad at that time. A single regular ceramic candle that was available for between Rs. 20 \& 30 (less than 50 Euro cents) would cost about Rs. 100 (Euros 1.5) if it was to be impregnated with nano-silver using the ARCI process. If he could tap into just $20 \%$ of the existing market and sell about $16,000-18,000$ of the nano-silver enabled candles annually, it would work for him. It seemed like a doable business proposition and a technology transfer agreement was signed between the two parties in June 2007. For an additional cost of only about Rs. 250 (assuming each water filter has three candles), an existing, cost-effective and easy to use product could provide much more value to the customer. Bharath Kumar rented a production unit close to where ARCI was situated, started production and the 'Puritech Nano Silver Ceramic Candle' was launched in the market. The nano component of the technology and silver's well known anti-microbial properties were prominently implanted in the identity of the product and conspicuously foregrounded in the communication and publicity materials produced (Images 30-33).

In the SCOT framework, the water filter that Bharath Kumar constituted was a financial entity - that of a (potentially) profitable product. His key parameter of evaluation was the business viability just as that of the technologist was of the technical performance. The successful technological product was the same here as the successful business product and the two relevant social groups can be seen occupying the same technological frame - that of a technically effective and low cost, and therefore, successful water filter.

Within the limited means he had, Bharath Kumar stressed, he did all he could to publicise this new product. He exhibited his improved water filter in exhibitions in different parts of the city of Hyderabad, produced and distributed pamphlets and simple information materials in English, Hindi and Telugu (Images 30-32), used low cost advertising avenues such as posters and stickers in local means of public transportation like auto rickshaws (Image 33), and simultaneously approached distributors of ceramic candles and water filters in the traditional stainless steel markets of Hyderabad.

Selling just 16,000 ceramic candles embedded with cutting edge technology in a city of more than six million people did not seem like a difficult task at all and Bharath Kumar was banking on this potential. He additionally took his product to other smaller cities and towns of Andhra Pradesh such as Nellore, Prakasam, Warangal and Mahboobnagar as well - the kind of places where the field testing had been done, efficacy proven and a product like this, potentially, very welcome. 


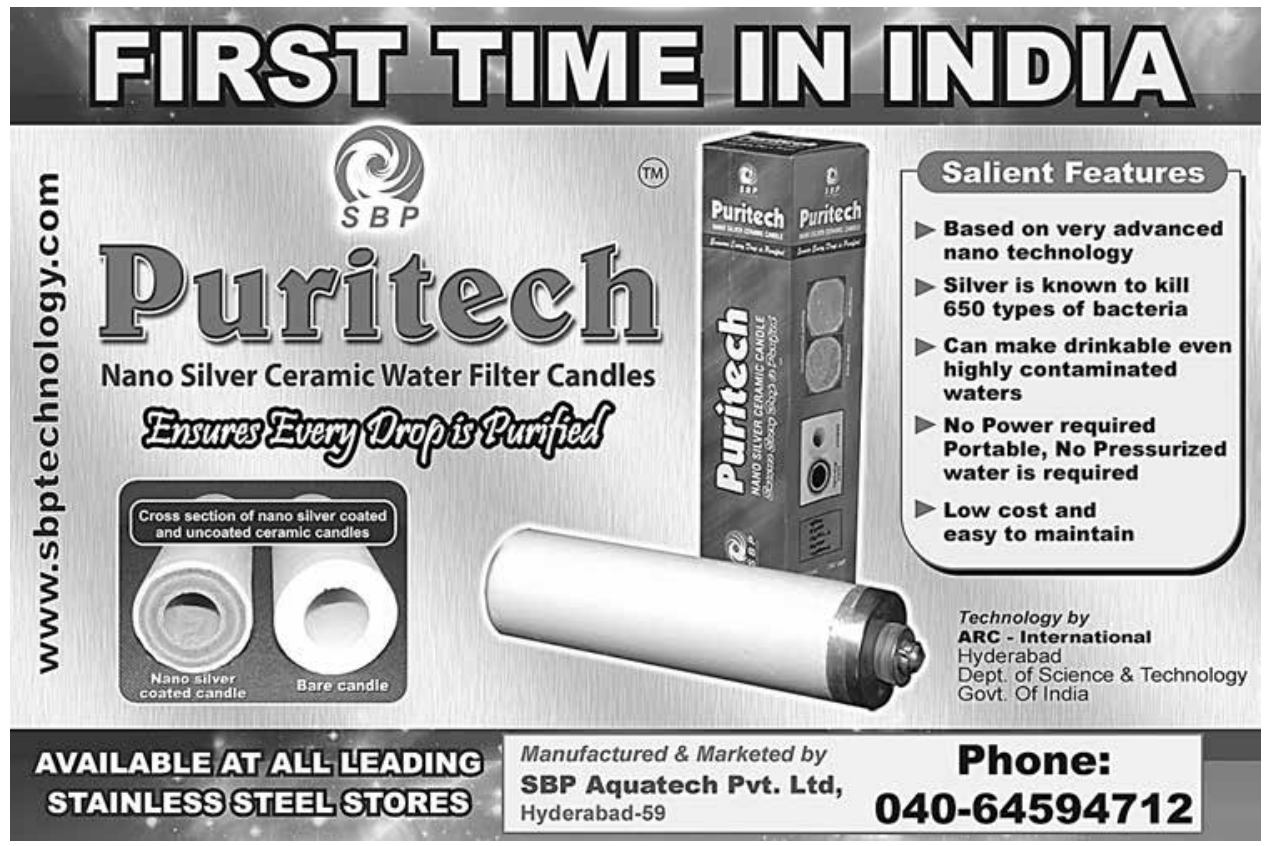

Image 30: English poster promoting the Puritech Water filter (Pic: G. Bharath Kumar)

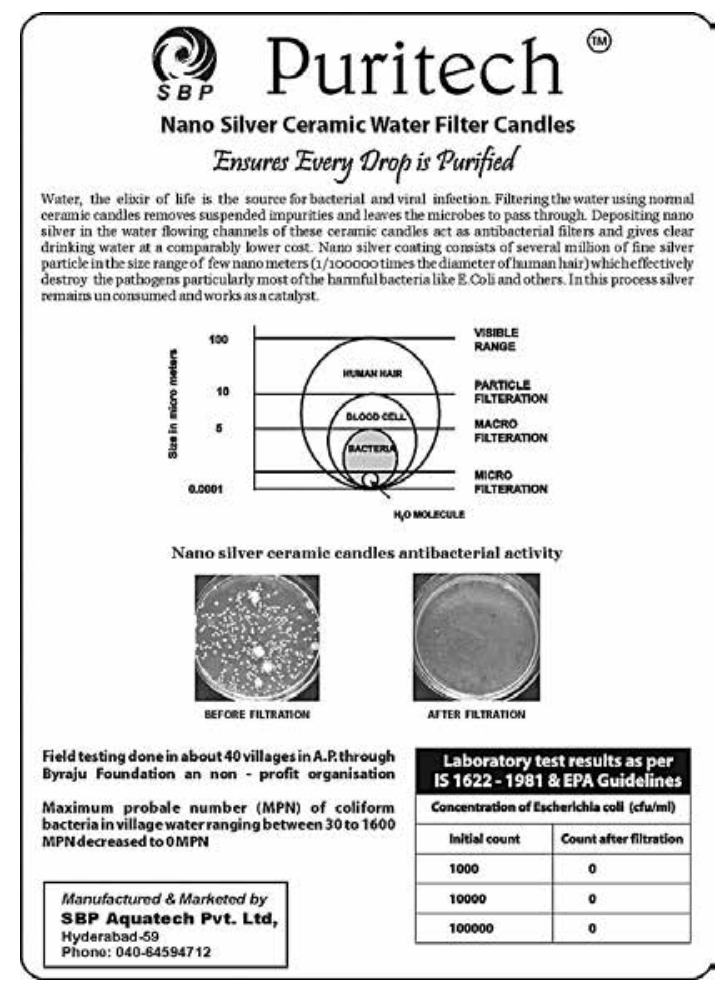

Image 31: Information pamphlet accompanying the Puritech Water Filter (Pic: G. Bharath Kumar) 


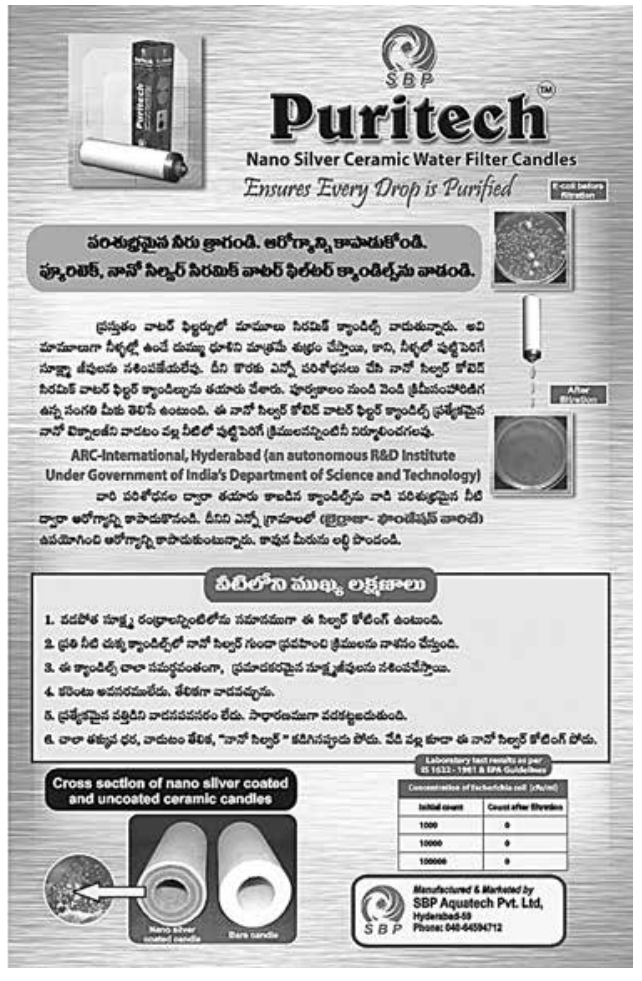

Image 32: The Puritech information pamphlet in Telugu, the local language (Pic: G. Bharath Kumar)

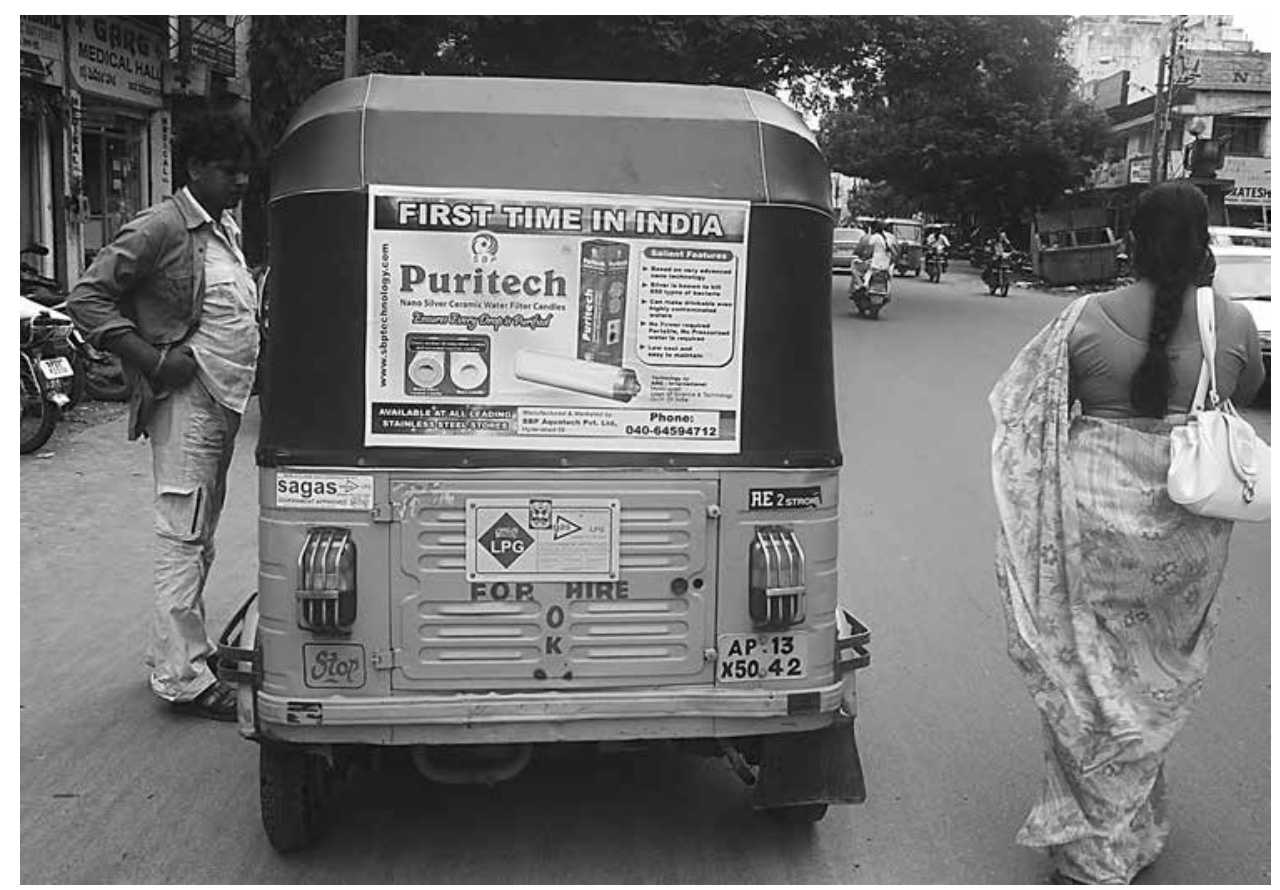

Image 33: A Puritech poster on the back of an auto rickshaw (Pic: G. Bharath Kumar) 


\section{The customer and the market - the 3rd relevant social group}

Bharath Kumar's business proposition was based on his understanding and conceptualization of the market and of the customer that constituted this market for him. This, as Bharath Kumar's calculations above indicated, needed to be a few thousand urban customers and perhaps some more in adjoining rural areas and communities.

Needless to say, the customer and the market, whether rural or urban, is a complexly stratified and diverse entity, and it is extremely difficult if not impossible, to make a generalization. I found this out myself as I tried to explore just one prominent market of the city I live in for the Puritech water filter. One of the largest and oldest markets in Secunderabad (the twin city of Hyderabad) is known as General Bazaar. Like many such markets in cities across India this one too appears to spread out in a random crawl. The larger main streets break up into smaller ones that further split into even smaller lanes and by-lanes. These are choc-a-bloc full with traders and their little and large shops. Everything under the sun - from books to bangles, pins to pyjamas, toys to televisions and from mangoes (in the season) to mouse traps (through out the year) can be bought here; the challenge is to find out which part of this market you need to get to. It is like a maze that a first time visitor will, most likely, find difficult to make sense of. In reality, however, these bazaars are rather well organized, there are clear divisions and there is a pattern to the seemingly random crawl of the market that has grown and spread organically over the years. You only need to ask a bystander, or better still one of the shopkeepers, and you will get crisp and precise directions.

\section{General Bazaar's steel market}

My destination, the steel market in General Bazaar, was not difficult to find as it branches off prominently from the arterial Rashtrapati (R.P.) Road. What was revealing was how the water filter market was, itself, stratified internally. The prominently branded ones that use more modern technologies such as ultraviolet filtration or reverse osmosis were to be found in the shops that were situated on this main, R.P. Road itself. Here one found these water filters in the company of such consumer goods as refrigerators, water coolers and in some cases, television sets as well.

The ceramic water filter, on the other hand, was to be found only in what one might call the traditional stainless steel shops, alongside products such as buckets, and others that are typically associated with the kitchen or the dining table - storage utensils, plates, cups, glasses and spoons. The traditional vs. the modern divide, if one can call this so, is as prominent as it is rich with possibilities. These shops were in adjacent lanes, but there were notable differences that separated them - the set of products that they were selling, the way the shop floors were laid out, the average cost of an item available and even 
in the perception that they carried about themselves. All of these are likely to have significant implications on the profile of the customer that walks in, on the product that s/he might be looking for, on the capacity to pay and the kind of communication and service that might be expected.

There was one particular stainless steel shop that I was looking for in General Bazaar. The owner was a long time acquaintance of Bharath Kumar and the shop, the best bet for someone looking to buy a nano-silver enabled ceramic candle. Before getting to him, however, I attempted an ad hoc survey of the market here. I visited a series of stainless steel shops asking, first, for a regular ceramic candle filter and then for the Puritech brand that was nano-silver enabled. A variety of brands of the regular candle filter were indeed available in these shops but none could offer me Puritech. Many did not even know of the brand and no one knew what this nano-silver thing was all about. Evidently, this new and improved Puritech filter had not been able to make inroads in the most important and obvious of market spaces. If it was not to be found in these shops, it was unlikely it would be found anywhere else.

\section{Meeting the shopkeeper}

The shop I was looking for had a small flight of steps that led up into a space that was crammed with steel stuff of all shapes and sizes and was manned by two individuals. I introduced myself to the owner, mentioned that I had been sent here by Bharath Kumar and that I was looking for the Puritech ceramic candle. He looked pleasantly surprised and asked his staff to quickly get me one. He asked me to sit down and offered me a glass of water.

A small conversation ensued. Shyam (not his real name) told me that his was the only shop in this market here that stocked the Puritech water filter candles. He had known Bharath Kumar for over a decade and this relationship seemed to be the reason why these candles were still available here. Less than a 100 had been sold, he told me, and neither had Bharath Kumar ever come to collect any payments. Shyam clearly held Bharath Kumar in high regard, particularly for the time, money and effort he had spent in bringing this particular product to the market. "Bharath Kumar could have easily made much more money", Shyam told me, "if he had not tried to help society".

Shyam was a regular user of the water filter himself, and his extended family had four of these filters (a total of 12 candles) installed in their house. He was also very happy with the performance of the Puritech filter. He seemed technically well informed as well - stuff like bacterial counts and how the nano-silver enabled candle performed better than the others. He even gave me a convincing run down and cost break up of one of the most popular and aggressively marketed water filter brands in the present Indian market - how it was much more expensive, needed a lot more maintenance and other regular and recurring costs such as those for replacing batteries. 
Puritech's nano-silver enabled candle was much simpler and better in comparison, he argued.

Shyam was of the opinion that Bharath Kumar had indeed made considerable efforts at popularizing the product and was surprised when I told him that the unit making these candles had been shut down. For Shyam there were two main reasons why this filter had not succeeded. One, importantly, was the cost factor. The nano-silver enabled candle might perform much better than the regular one, but it looked no different from the relatively less expensive original. Customers, in his experience, were therefore unwilling to pay that additional cost. What looked like only a marginal cost increase to the technologist and the entrepreneur appeared not acceptable to the market in light of what the additional benefits were perceived to be or not be. For Shyam this was linked to the fact that the customers were unaware, first, of the product itself and then also the benefits that it offered. If they knew (better), he said, they might have been willing to pay the additional price.

The narrative above is proof, as mentioned earlier, of the diversity of the market and customer and of the serious limitations, therefore, of trying to club them all under a single umbrella. There is a serious methodological challenge in proposing just one relevant social group but there is also a methodological imperative here for my suggestion that the market and the customer, combined, be considered the $3^{\text {rd }}$ social group that is relevant to our understanding of the case.

This becomes even more significant because the user here is, in fact, the non-user (Wyatt, 2003). The water filter constituted by this (non) user and the (non) market, the 3rd RSG in our case, is completely different from the water filter constituted by the other two. For the 3rd RSG there was nothing new or remarkable about this product, which was at the same time more expensive as well. The nano-silver, which was an important element in the artifact constituted by the 1st two RSGs is conspicuous by its absence in the case of the 3rd. The interpretive flexibility is evident and the failure of the water filter can be explained by its constitution as a different artifact by each of the different relevant social groups and the fact that the customer never got included in the technological frames of either the technically effective or the low cost water filter.

The implications for the entrepreneur were evident and serious. In the first round of production, Bharath Kumar's SBP Aqua Tech Pvt. Ltd. had produced about 11,000 of these nano-silver impregnated ceramic candles. Four years later, when I first met Bharath Kumar in June 2012, he estimated that nearly 50\% of that inventory was still with him. Of the candles that were still with the various distributors in different parts of Hyderabad and other cities, he estimated that not more than a few 100 had been sold. He had also stopped pursuing them for payments, because when he did, he would be asked to take back his candles. The plant he had put up for impregnating the candles with nano-silver had been completely dismantled, moved from its original location and dumped in one 
corner of the activated carbon production unit that he was operating now with a new business partner at a new location.

\subsection{Social construction of the (water filter) failure}

It is striking that even as the entrepreneur had consigned his production unit to scrap, was counting his losses and had deemed the effort a big failure, the story being told from within the S\&T establishment was a diametrically opposite one. All accounts of research and development of nanoscience and technology in India (Asthana, 2011; V. Patel, 2012; T.N. Rao, 2012; Sundararajan \& Rao, 2010; Sundararajan, 2011; TARA, 2011) discuss the development of and transfer to industry of the nano-silver enabled ceramic candle as a success and an achievement to be highlighted prominently.

In personal discussions, presentations and in some more recent literature (Purushotham, 2012), the failure is beginning to be acknowledged, but the responsibility is placed entirely at the door of the entrepreneur and the market: 'SBP Aqua Tech Pvt Ltd was too small a player, the entrepreneur's catchment was limited and that his marketing reach, insufficient; he did not have enough financial resources, he did not advertise enough, there are too many competitors in the market with much larger visibility and financial and advertising muscle'. This is what a scientist who is intimately aware of the situation but did not want to be identified had to say:

I should say frankly - it is not doing [well]. (...) The company is not pro-active. (...) They are good people but being good has no meaning unless you have a proactive business mind. So that's where they are not doing so well. (...) Other water filters (...) advertise so much. (...) Because he [Bharath Kumar] is a small player, he is not able to invest too much into marketing and educating the people (Interview, June 2012).

Follow this line of argument and two complementary inferences emerge - small time entrepreneurs with limited financial resources are doomed to failure even before they begin and the big timers with all the financial and media muscle should have it easy all the way through. Stating that this is incorrect is only stating the obvious because there is enough evidence to show that explanations of success (or failure) are far more elusive than to pin down to some such obvious markers. History is replete with innumerable examples of the failure of large, rich and powerful conglomerates and/or their products just as it is with the success of an equally large number of small entities and their products (Christensen, 1997). The reality, clearly, is messier and more complex than that ${ }^{66}$.

66 Also see the example discussed in Chapter 3 (Section 3.3) of the failure in the market of the Nano car, produced even though it is, by one of India's most powerful and resource-rich corporate houses, the Tatas. 


\section{The entrepreneur explains failure}

Till the time the product came into the market - the two relevant social groups of the technologist and the entrepreneur were aligned in their understanding and expectations of the artifact. It was, however, the response from the market and the experiences of those like Shyam that forced a re-calibration for the entrepreneur. Bharath Kumar agreed, though to a limited extent, that lack of marketing and advertising capabilities, the increased cost of the nano silver ceramic candle and the availability of many alternatives were part of the reason that his Puritech filter had failed. The market is certainly a key marker where a technology is concerned and conventional logic says that a product fails when the consumer does not buy it. It would however be naïve to believe that this is all there is to it. It is the failure that needs to be explained - "it should be the explanandum, not the explanans" (T. Pinch \& Bijker, 1987, p. 24). While the point of sale is the most visible and obvious point of analysis, the frame of SCOT in particular and that of the social studies of S\&T in general tells us that there have to be other nodes where things happened; moments, perhaps, where something could have been done differently; invisible junctures, which if brought to light, might provide new understanding.

One such moment of insight jumped through during the interview I conducted with Bharath Kumar. A chemist friend and colleague of his who had been a consultant and entrepreneur himself for about three decades joined us just as Bharath Kumar was trying to explain how the nano-silver enabled ceramic candle filter had failed inspite of his best efforts and also the fact that this seemed a good technology. His colleague volunteered an opinion and an emphatic explanation that caught me quite by surprise:

Basically, you can say that this is a technology that is getting obsolete. Many new parties have come into the market. They are offering [water filters] for a very low price. (...) People are showing interest in a new product rather than with the existing ones (Interview, June 2012).

It was his implication that the Puritech nano-silver enabled ceramic candle was bound to fail because the platform it was built on - the ceramic candle itself - was becoming obsolete as a water purification technology. It was a line of argument that had not even crossed my mind. I put that question to Bharath Kumar who agreed immediately and fully with the analysis of his colleague:

Q): If you had, say, more capacity financially for marketing, do you think that would that have solved the problems, or like he said, this is basically a technology that is getting obsolete.

A): That is true (Bharath Kumar, Interview, 5 June 2012). 
This was an interesting falling apart as contradictory narratives emerge along two complexly related axes of the market and of technology. For one actor the technology developer - this was successful development of an appropriate technology that failed once it moved out of their domain; for the other - the entrepreneur - failure had been coded in from the very beginning. A technology that was new and offered an attractive business proposition just a few years ago was now seen as obsolete and therefore doomed to failure from the very beginning. The table below illustrates this interpretive flexibility in the constitution of the water filter, the changing experiences and positions and the iterative processes of closure, stabilization, de-stabilisation and disagreement.

Table 4: Illustrating the interpretive flexibility in the constitution of the water filter

\begin{tabular}{|c|c|c|c|c|c|}
\hline $\begin{array}{l}\text { Relevant } \\
\text { Social } \\
\text { Group }\end{array}$ & \multicolumn{2}{|c|}{$\begin{array}{l}\text { Artifact constituted } \\
\text { ( } \underline{\text { Before }} \text { water filter went to the } \\
\text { market) }\end{array}$} & & \multicolumn{2}{|c|}{$\begin{array}{l}\text { Artifact constituted } \\
\text { (After water filter went to the } \\
\text { market and 'failed') }\end{array}$} \\
\hline $\begin{array}{l}\text { Technolo- } \\
\text { gist }\end{array}$ & $\begin{array}{l}\text { Technically } \\
\text { effective, low cost } \\
\text { water filter }\end{array}$ & \multirow{4}{*}{$\begin{array}{l}\text { Easy } \\
\text { closure and } \\
\text { stabilization. } \\
\text { High degree } \\
\text { of inclusion } \\
\text { of the } 1 \text { st two } \\
\text { RSGs in the } \\
\text { technological } \\
\text { frames of } \\
\text { technically } \\
\text { effective and } \\
\text { low cost. }\end{array}$} & \multirow{2}{*}{$\begin{array}{l}\text { De- } \\
\text { stabilisation } \\
\text { after } \\
\text { introduction } \\
\text { and failure } \\
\text { in the } \\
\text { market. }\end{array}$} & $\begin{array}{l}\text { Technically } \\
\text { effective, low } \\
\text { cost water filter }\end{array}$ & \multirow{4}{*}{$\begin{array}{l}\text { No closure } \\
\text { because } \\
\text { of dis- } \\
\text { agreement } \\
\text { on the cause } \\
\text { of failure }\end{array}$} \\
\hline $\begin{array}{l}\text { Entrepre- } \\
\text { neur }\end{array}$ & $\begin{array}{l}\text { Technically } \\
\text { effective, low cost, } \\
\text { commercially viable }\end{array}$ & & & \multirow[t]{2}{*}{$\begin{array}{l}\text { Obsolete } \\
\text { technology }\end{array}$} & \\
\hline & water filter & & & & \\
\hline $\begin{array}{l}\text { Customer } \\
\text { /Market }\end{array}$ & ---- & & & $\begin{array}{l}\text { Technically } \\
\text { regular, } \\
\text { expensive } \\
\text { water filter }\end{array}$ & \\
\hline
\end{tabular}

It is a classic case of the need and the call for application of the principle of symmetry (Bijker, 1995b; Wyatt, 2008). As Bijker (1995b) notes:

The "working" of a machine is not an intrinsic property of the artifact, explaining its success; rather it should figure as a result of the machine's success. Thus the success or failure (...) are to be explained symmetrically, by the same conceptual framework (p. 14-15), [that] the "working" and "nonworking" of an artifact are socially constructed assessments (p. 75) [and also that] machines "work" because they have been accepted by relevant social groups (p. 270).

The physical product might be the same but it now means different things to the different social groups. The nano-silver enabled water filter is still cheaper than many competitors in the market, is easy to use, does not need either electricity or pressurized water and effectively contains bacterial contamination. 
Yet, it is a failure because the relevant social groups also agree that this is the case.

\section{Is the ceramic candle going obsolete?}

Now, whether the ceramic candle is going obsolete is an important question and one that may not have an immediate and easily verifiable empirical answer. It is, however, important to consider because it is a key characteristic of the artifact as (re)constituted by one of the relevant social groups. Bharath Kumar not only agreed that the ceramic candle water filter technology was going obsolete, he also described it at different points in the latter part of the interview as an application that was "outmoded" and "outdated", and the culture of use of the ceramic candle as one that "was almost going away". It was also his opinion that sales of the basic ceramic water filter had also come down substantially in the Hyderabad in the five years since he signed the agreement with ARCI for the Puritech filter.

It is an understanding that is likely to be widely shared and one that I broadly agree with myself. The ceramic candle water filter, which was at one time an integral part of my life, has completely vanished from my house as well as those of my friends and extended family. Added to this, as we have seen already, is the presence in today's market of a number of options that not only claim to have better technology but are also branded strongly and marketed aggressively. It is likely that the ceramic candle has disappeared or is disappearing from people's lives just as it has done from mine. It might not have disappeared yet, but its current trajectory might well be in that direction.

Obsolescence, it might be argued, is one of the prime imperatives (both as cause and effect) of the modern technological enterprise and once its claim had been thrown into the ring by one of the actors, the frames of the discussion would have to be altered. Modern technology and a considerable part of the modern economy is built on the edifice of consumption and obsolescence. The current growth model that emerged in the post war period in the US, Europe and Japan is based on an "infinite demand for more material consumer goods" (Soete, 2008, p. 7) and has become the exemplar for the rest of the world. In this world and a world economy increasingly driven by consumption, the only way forward is for the old to make way for the new - the greater the intensity of this shift, the larger the potential profit; the faster the turnover, greater the growth.

The flip side, or perhaps an important contributory element is visible in the realisation that "there appears to be a direct relationship between the newness of technology and its fragility" (Stille, 2006). In the very specific case of data storage technologies, Stille notes that the clay tablets that record the laws of ancient Sumer are still on display, the paper correspondence from the Renaissance, though faded, is still in good condition, but books printed on modern acidic paper are already turning to dust. The trajectories are similar, be it from black 
and white to colour photographs or from celluloid cinema to videotapes to the most modern of digital technologies (Stille, 2006).

Newer products seem to emerge into the market even before an old one has managed to settle in and make its presence felt: the "time of obsolescence (...) has, for the first time in the life of mankind and its material culture now become shorter than the life-time of one generation of the product" (J.P.S. Uberoi, 1989, p. 2543). This is particularly relevant for us because the innovation-technologyobsolescence link is a prominent aspect of received wisdom: "Innovation makes old technology obsolete," Glass \& Saggi (1998, p. 372) claim in the case of international technology transfer to developing countries, but evidently, the statement can be applied more generally as well.

As we have seen in the case of the water filter, however, obsolescence is not and cannot be seen as an intrinsic property of the artifact or of a technology. It is a function of the acceptance or rejection by the relevant social group/s and it is a characteristic constituted by them. There are important implications if this claim is to be accepted. A case can now be made that no artifact or technology can be consigned to history or to the dustbin because of itself. Within each 'failed' product or technology lies the promise and the possibility of new meaning, of revival, of new use and certainly of re-use. This idea, in fact, was at the heart of the innovation and the efforts at ARCI. It was implicitly embedded in their decision to work with the existing ceramic water filter candle and not trying 'to reinvent the wheel'. In resource constrained economies this can itself be a significant resource and therein lies its unexplored value, particularly in renegotiating the meanings and processes of innovation.

\section{A counter-intuitive innovation trajectory}

Prominent notions of both, innovation and obsolescence are dominated by linearity - the movement, therefore, is uni-directional - inputs, ideas and innovation at the beginning, obsolescence and waste at the end. There seems to be no space and no possibility of building on the old and this is what makes the story of the 'nano-silver enabled ceramic candle' very interesting but also challenging at the same time. ARCI's innovation lay precisely in working with the old and that which is common. This is counter-intuitive and goes against the grain because innovation here was not about making the old obsolete. It seeks to do just the opposite - to renew the old and give it new meaning. The nano-silver enabled ceramic water candle even fits the Schumpeterian idea "of innovation as "new combinations" of existing knowledge and resources" (Schumpeter (1934), as quoted in Langlois (2012) and Fagerberg et al. (2012, p. 1132)). It fits in, but slips through as well as it seems to occupy a liminal space that is neither here, nor there. It is, at once, old and also new. At the same time, ironically, it is neither old nor new and it is quite likely that this liminality might have played a role in its failure in the market place as well. 
Written into the ARCI initiative, in making the synchronic and the diachronic more interdependent and less independent of each other (JPS Uberoi, 1989), is an implicit challenge to the idea of the obsolete. The old in not just the end, it can also be a new beginning. The obsolete is not meant only to be discarded; a new nano-technology can embed new value and new meaning. The significant shift the ARCI scientists made in their innovation was from the linear to the cyclic, from the chain to the seamless circle.

If there is one place, however, where this movement breaks down in the case of the nano-silver enabled ceramic water filter, it is, ironically, in ARCI itself. If the choice of the old candle filter as the starting point oparated, intuitively and implicitly, on the premise of the cyclic and made the notion of the obsolete irrelevant, the explicit commitment to linearity when the product moved out of the laboratory catalyzed obsolescence quickly back into the equation. The last arc of the circle was left unconnected.

A lot of recent innovation related research, including in STS, has shown the importance of involving users in the research and technology development process (Oudshoorn \& Pinch, 2003a; Soete, 2008; von Hippel, 2005) (Also see Chapters $1 \& 2)$. Interacting with and learning from users and taking their needs into account almost always enhances the chance of success (Lundvall, 2011) and yet, as we have seen, the user had almost no role to play in the case of this nanosilver enabled ceramic candle water filter. Not everyone agrees, and the explicit argument was made to me that the water filters were indeed tested successfully in the 40 odd health centres in collaboration with the Byrraju Foundation. While this is true and it is commendable in an Indian context that such field testing was carried out, discussions with those involved directly in its implementation in the field revealed that the role that the end user played was marginal - it was limited to confirming and validating what the technologists sought to check and confirm. There was no attempt made, for instance, to understand what the user was really looking for, and there was no space for a dialogue and a discussion. It is a point that underlines the key challenges of ensuring inclusion, not only so that the solutions reach the people who need them the most, but also for the technology to be accepted by the potential user and for it to become a success.

Ensuring inclusion and providing access is then as big a task as having the clean water to provide in the first place. The two, perhaps, are two sides of the same coin: the political, the social, economic and the technological have to work together if they have to work at all. In the present case of the nanosilver enabled ceramic water filter candle this could have led, perhaps, to the consideration of a number factors that have been left out. Maybe cost is not the only important issue for the customer today. Is it possible, for instance, that changing aspirations have made the market a lot more sensitive to aesthetics and branding? Should some thought and resources have gone into the designing the looks of the final product? How would the customer differentiate this new and 
improved candle from the old one s/he had been using for decades? Could a product designer have made a difference? Should ARCI and the scientists have played a larger role in the marketing of the product? Could the entrepreneur have been an earlier partner? What is it that the entrepreneur could have done differently himself? What contribution could the users have made if they had been explicitly included? Might it have helped to take the water filter to those who needed it most rather than those who were most easily accessible? What if the entire development had indeed been constructed and conducted like a cycle, a process that was more iterative, even dialectical, where the research and proof of concept stage, the field testing for technical performance, production, the user and the market response could have played more interactive roles. One might even argue that it was not a good idea to leave the fate of such a product entirely to market forces; maybe, a different economic model, one that offers partial subsidy could have been considered to make it more attractive for all involved.

\subsection{Conclusion}

Going back one sees that it was not until the scientists had developed a product they thought was fit to go out into the world, that there was some interface with the other relevant social groups. It is a point that lies at the crux of the argument that I seek to make here - that when innovations directed at solving societal problems are attempted in the market paradigm as is the case today, we need to actively think about and weave in those dimensions; innovation that is considered successful in the lab will not, on its own, also become successful in the market and in society.

Much of this might sound speculative, but this is what the analyst looking through the STS window can discern as possibilities underscored with alternative promises. There is also the benefit of hindsight that the analyst has; the ifs and buts are big ones too but it is still proof that the trajectory that was finally charted out was only one of many possibilities. The reasoning that it was an obsolete technology to begin with' is, for instance, only a rational reconstruction - the classical Whiggish argument (Bijker, 1995b, p. 45; Bowker, 1992, p. 71) that has been shown as misleading. It ignores completely the social dimension and the other cultural and economic factors that play key roles. As has been shown many times, things could have easily been different.

And because that is the case, there is no reason why this nano-silver enabled 'old-new' ceramic candle needs to be forgotten as a failure. The disagreement is still alive and there is no closure yet to the dispute about the causes of the failure. A re-negotiation and re-calibration is still possible; the key players are still around and active, the filters are still available and so is the technology. A new reality is still possible because this is not an account pulled out from the pages of an historical archive; it is a story that is unfolding even as it is being written! 


\section{Reconfiguring subjectivities: nanotechnology for the treatment of Retinoblastoma}

\subsection{Introducing Retinoblastoma}

Retinoblastoma is the most common malignant eye tumour in infant children in India (ICMR, 2010) with average age at diagnosis being 18 months. According to the population based Cancer Registries in India, it is one of the top five childhood cancers in the country; the others being leukemia, lymphoma, central nervous system neoplasm and renal tumours. It accounts for between four and seven percent of pediatric malignancies, and is reported in one in 14,000-34,000 live births. It is estimated that there are 1,200-1,600 new cases per annum in India and the country has the highest number of children with retinoblastoma in the world (Bakhshi, Gupta, Gogia \& Ravindranath, 2010; Honavar \& Reddy, n.d.; ICMR, 2010; Joseph et al., 2006; Krishnakumar et al., 2004; Parveen, Mitra, Krishnakumar \& Sahoo, 2010; Sachdeva, 2010; Sahu et al., 1998).

Retinoblastoma was a condition that was associated with certain death till about a century ago but the situation has improved significantly with the development of a range of medical technologies and treatment protocols. Shields \& Shields (1992) note that early tumour recognition along with a finer technique for enucleation contributed to an improved survival rate - from 5\% in 1896 to $81 \%$ in 1967. Further technical advances and methods of treatment that include, among others, chemotherapy, external beam radiation therapy, cryotherapy, photocoagulation and thermotherapy have all contributed to better treatment and care of Retinoblastoma patients (Honavar \& Reddy, n.d.; Khetan, Gupta \& Gopal, 2011). The treatment protocol is now reasonably well established and doctors and medical institutions report considerable success in treating it if detected in good time (Bakhshi et al., 2010). Significantly, however, enucleation or removal of the eye continues to be a common method of managing an advanced stage of the condition (Honavar \& Reddy, n.d.; Sengupta, Krishnakumar, Biswas, Gopal \& Khetan, 2011). This is particularly important in an Indian context because lack of awareness about the need for early detection and other social constraints often result in a delay in seeking medical help (Ali, Reddy, Honavar \& Naik, 2011).

Efforts also continue towards finding new technologies and protocols, and one prominent line of investigation and development is linked to the use of nanotechnology, particularly for targeted drug delivery. As D Balasubramanian, Head of Research at the LV Prasad Eye Institute in Hyderabad explained to me: 
It will be very nice if I were to actually reach the target [Retinoblastoma] tissue in a manner that the concentration that is demanded is actually sufficient; not too high and not too low (...). So what we are really looking for is (...) on the spot delivery (...) - a magic bullet. It goes only there and not elsewhere. Nano particles seem to answer this very very well. (...) What is a nanoparticle? It is a sponge. It could be a sponge, it could also be a shell (...) which I can coat (...). We are considering the use of nano material at the moment only as delivery vehicles, post offices, messengers. Okay? They go courier really, they deliver the stuff, but they must be of such a kind that they themselves do not cause any problem to the target tissue (Balasubramanian, Interview, 12 June 2010).

Use of nano-delivery mechanisms for targeted drug delivery has generated great interest in the field of cancer treatment in general (Ayers \& Nasti, 2012; Heath \& Davis, 2008; Mansoori, Mohazzabi, McCormack \& Jabbari, 2007) and extensive research is being carried out worldwide to realize the potential and promise that is offered. Retinoblastoma is no exception (Nair, Thevenot, Hu \& Tang, 2008) and eye care and treatment institutions in India like the L.V. Prasad Eye Institute, Hyderabad and Sankara Nethralaya, Chennai, which are at the heart of this case study, have also been actively involved in this research.

\section{An orphan disease}

Part of the challenge in dealing with a disease like Retinoblastoma is its institutional neglect in multiple contexts, prompting one clinician-scientist to attach to it the epithet of an "orphan cancer":

Retinoblastoma is an orphan cancer. So, pharma companies are not interested. [An] orphan cancer [does not] mean much commercially. It is not like breast cancer or prostatic cancer where millions of people are affected. (...). When I was talking to [a senior doctor in the USA a few years ago] he [said], 'retinoblastoma is a problem of India. Why must [we] give money to you? You [must] get money from the Government of India' (X1, Interview, 3 July 2012).

This metaphor of the 'orphan' does not apply just to the agendas and priorities of the international community or to corporate entities; it can also be deployed through the lens of public health, of setting of priorities and the allocation of limited resources, particularly, in the context of the larger and overall disease burden in a country like India. In a country where an estimated 4,50,000 (nearly half a million) children die annually due to the easily preventable disease of diarrhea (NCMH, 2005), it is not surprising that the more complex and costlierto-treat Retinoblastoma with only 1600 new cases every year gets ignored and neglected. And diarrhea is just one of a score of diseases which could be used to 
make the same point as Dr. Vikas Khetan, the oncologist at Sankara Nethralaya, explained to me:

Even in paediatric oncology, Retinoblastoma is not on the higher side. (...). That is the reason we don't get funding for research in Retinoblastoma. Again, like I said, the incidence [of Retinoblastoma] is one in 15,000 or 20,000 . When we have 200 [times] the cases of malaria [over 3,00,000 annually], where would you put your money? On malaria or on Retinoblastoma? So for the government, (...) if they actually take the case of cholera, malaria, or other acute disorders, if they can prevent all that from happening, the impact will be much larger (Khetan, Interview, 3 July 2012).

It is a classic public health policy dilemma and treating the disease is as much a challenge as it is to garner resources and raise awareness about the cause as well as the solution to the condition. Yet, these larger issues find little reflection in the more general literature on Retinoblastoma (Ali et al., 2011; Honavar \& Reddy, n.d.; ICMR, 2010; Khetan et al., 2011) that exists presently. The National Guidelines in the Management of Retinoblastoma (ICMR, 2010) do not as much as mention the social conditions or public health challenges that accompany Retinoblastoma. The others include, at best, a paragraph or two on issues such as awareness, education and outreach. There is hardly, if any, discussion on more complex matters, and issues such as those of gender disparities, economic challenges and religious beliefs find virtually no mention at all.

It is only in recent years, for instance, that a more integrated approach has been adopted in India to monitor Retinoblastoma - to get a scientific understanding of its etiology and also its larger social context. It was only about five years ago that the Indian Council for Medical Research (ICMR) set up the Retinoblastoma registry involving 10 centres in the country that deal with the disease. The hope is that once the systems are all in place, all information about all cases will be available in one central database and this would help in a better and more comprehensive assessment of the disease (LVPEI, 2012b). The current figure of about 1600 new cases per year is only an estimate and even here, only about 800 cases enter the existing system; there is no account of the 800 odd that don't come in.

One can immediately discern that we are talking here of challenges that pan out along multiple, though inter-related axes such as those of the medical, the technological, the economic and also the social. And this chapter is an attempt at exploring precisely these challenges, complexities and their inter-relatedness through a narrative that is anchored around the work and the experiences of two institutions where the orphan Retinoblastoma has found a home. These are the Hyderabad based L.V. Prasad Eye Institute (LVPEI) and the Chennai based Sankara Nethralaya (SN), two of the most prominent eye research and eye care 
institutions in India, and importantly in the context of this thesis, institutions that have a dedicated nanotechnology for Retinoblastoma research program.

The key idea that I seek to illustrate in this chapter is that users not only influence producers, they actually play a key role in constituting producer identities as reflected in the title of the chapter. It emerges through the narrative of the clinician and the analyst that the user, specifically the girl child who comes to the clinic with a tumour in the eye, is an aggregate of multiple (non) users. In responding to the one-as many and many-as-one user at the same time as fulfilling the institutional mandate of engaging in translational research we see that the clinician emerges as an entity with multiple identities - a 'clinicianscientist-social activist'. The user no more just influences the producer (care provider in this case) but plays a crucial role is forging and configuring his many identities and subjectivities.

\section{Introducing the institutions}

Established in 1987, The L.V. Prasad Eye Institute is a World Health Organisation Collaborating Centre for the Prevention of Blindness with a focus on developing eye health models for under-served areas of the developing world. It is a notfor-profit, non-governmental organization with the main campus in the city of Hyderabad and three tertiary centres, one each in the cities of Bhubaneshwar, Vijayawada and Visakhapatnam, all on the east coast of India. As of June 2012 it also had 10 secondary eye care centres and 89 vision centres that focus on primary eye care, primarily in rural areas. The institute's work is multi-dimensional and includes clinical services, eye banking, education in eye care and treatment, basic research into genetic, molecular, cellular biology and microbiology aspects of eye disorders, clinical research including clinical trials and public health research, and also public health and rural outreach. Over 25 years of its existence it "has served over 15 million people, more than half of whom were treated free of cost, irrespective of the complexity of the care required" (LVPEI, 2012a, p. 2, 2012b).

There are two aspects here that are important in the context of this thesis' key aim of understanding the 'culture of innovation'. One is the focus at LVPEI on translational research, the other being the conscious fostering of the interface between the clinic and the laboratory. The two are closely linked:

All the research that goes on [here] (...) hopes to be translational, where the basic research will find a direct application to the clinical setting (...), one which can actually be used as a clinical service. And so even the problems we choose (...) to work on, even in terms of basic science are really driven by what we see downstairs in the patient population. As you notice this is a single building thing and we deliberately made it a single building. The reason for that is you keep on bumping into each other. The clinicians and the scientists must talk to each other. One of the defects that India and perhaps also neighbouring countries have in 
terms of clinical application and clinical research is there is not enough of a dialogue that happens between the basic scientist or the laboratory scientist and the clinician who actually does the diagnosis, the treatment and the, you know, therapy (Balasubramanian, Interview, 12 June 2010, emphasis by the interviewee).

Dr. Javed Ali, the ocular oncologist at LVPEI who has been quoted at the very beginning of this thesis, explained how the institution explicitly and consciously mandates that clinicians engage in research in the laboratory:

At the 'Institute' many things regarding your career growth (...) are all based greatly on research (...). You might be a great clinician (...) [but] if do not have a good research background, you are not a favoured person here (Javed Ali, Interview, 14 August 2010).

The situation at Sankara Nethralaya (SN) mirrors that at LVPEI in more ways than one; there is also a strong focus here, for instance, on translational research and on facilitating the clinician-researcher interface. Sankara Nethralaya, which is headquartered in the city of Chennai seeks to provide total eye care solutions of the highest standards to all sections of society and is also committed

to create a CENTRE of excellence for ophthalmic professionals for continuously updating their knowledge through education, training and carrying [out] innovative India centric research to benefit the entire ophthalmic community (SN, 2013, p. 4).

The institution has nine centers in the state of Tamil Nadu and two each in West Bengal and Andhra Pradesh. The Sankara Nethralaya Academy is its academic wing that offers educational programs ranging from certificate to doctoral level programs in various fields including eye related sciences, ophthalmic nursing, and hospital \& health system management. It collaborates with four universities (three national and one international) where 47 students were registered for doctoral research on various conditions of the eye in 2013.

Of the three people I met here who are part of the nanotechnologyRetinoblastoma research effort at $\mathrm{SN}$, only one was a scientist with a recent doctorate in nano-biotechnology from Chennai's Anna University. The other two were clinicians - Dr. Krishnakumar Subramanian, a trained pathologist and Dr. Vikas Khetan, an ocular oncologist - both with research interests that span many diseases and conditions of the human eye. Krishnakumar is Deputy Director Research, Vision Research Foundation at SN, while Khetan treats Retinoblastoma patients here and had just registered himself for a $\mathrm{PhD}$ program at the M.G. Ramachandran University in Chennai. 
What I saw at both the institutions was the creation, through a particular configuration of the institutional mandates of service to society, translational research and a commitment to scientific research, of what might be called the clinician-researcher or the clinician-scientist hybrid entity. This is a complex entity characterized by shifting positions and subjectivities on account of being located at the intersection of the multiple axes mentioned above. One can also discern that the problem or object oriented strategy of these institutions is broadly, even if not fully, in alignment with Mode 2 knowledge production (Gibbons et al., 1994; Nowotny et al., 2001) that has been discussed in Chapter 2 already, and there are useful insights to be gained on that account as well.

\subsection{The Retinoblastoma-nanotechnology interface - the LVPEI story}

The 'nanotechnology for Retinoblastoma' research initiative at LVPEI was only a few months old when I first visited the institution in the summer of 2010 . It was using as its singular reference a scientific study carried out elsewhere and whose clinical relevance was that the mouse model used "provides a basis to test carboplatin nanoparticles for the treatment of human Retinoblastoma" (Kang, Duriaraj, Kompella, O’Brien \& Grossniklaus, 2009, p. 1043). The study was trying to evaluate the therapeutic effect of a single sub-conjunctival injection of nanoparticle (anti-cancer) carboplatin in mice models:

To enhance the delivery of the drug to the eye, we used the nanoparticle form of carboplatin. Advantages of nanoparticle-based drug delivery are that it improves the solubility of poorly water-soluble drugs, prolongs the half-life of drug systemic circulation by reducing immunogenicity, releases drugs at a sustained rate, lowers the frequency of administration, delivers drugs in a target manner to minimize systemic adverse effects, and enables delivery of 2 or more drugs simultaneously for combination therapy to generate a synergistic effect and suppress drug resistance (Kang et al., 2009, p. 1045).

It sounds very much like the "magic bullet" that Balasubramanian was looking for and the initial effort of the research initiative at LVPEI was an explicit attempt at replicating the outcomes achieved by Kang and his colleagues.

\section{A four-tiered research structure}

The research initiative at LVPEI was being executed through what might be called a 'four-tiered' research structure. At the top (tier 1) was Director of Research, D. Balasubramanian, a senior scientist with extensive experience and a formidable reputation in the scientific community. He was not directly involved in the research, but offered the overall framework and the guidance for its execution. 
The Principal Investigator (tier 2) of the project was Dr. Javed Ali, the young medical doctor with a specialty in oncology and plastic surgery, but with limited knowledge of nanotechnology. This knowledge too, he admitted, he had picked up only recently. His involvement with the project was linked primarily to his expertise in the treatment of Retinoblastoma and the fact that a significant number of these cases at the institute were referred to him. Tier 3 was made up of non-clinicians, S.A. and R.P., the two scientists actually working in the labs of the institute. Both were PhD students themselves; SA in the final few months of his research where he was studying the genetic make-up of Retinoblastoma (he has subsequently finished and moved on) and R.P., who was studying the protein structure of cataract as part of his doctoral research. For both these students, the nanotechnology-for-Retinoblastoma project was a small part of their research portfolio. It did not fit in with their main doctoral work and was being done in addition to their formal research and responsibilities.

The connection for SA was a more obvious and direct one as his doctoral work was centrally about Retinoblastoma. In the case of RP, interestingly, it was his experience and expertise with spectroscopy he had gained as a Master's student before he came to LVPEI that made him relevant in this particular case. He was using spectroscopy to evaluate their efforts here in trying to load carboplatin into the Poly (amido-amine) (PAMAM) dendrimic ${ }^{67}$ nanoparticles.

The 4th tier of the project was and is still located outside the institute, where other laboratories and institutions were engaged for particular inputs and experimental analysis. One of these was the National Geophysical Research Institute (NGRI) in Hyderabad whose involvement was limited to analyzing the samples generated at LVPEI and to help evaluate the success achieved in loading the nanoparticles with the anti-cancer drug. The other was the Department of Biotechnology in the University of Hyderabad where the involvement was, as we will see later, much more substantial and also collaborative.

As an outsider, the sense I got was of a research team that had been 'cobbled together' with what was available - no research personnel were dedicated entirely to this project and those involved had limited knowledge or experience of nanotechnology, and in one case of Retinoblastoma itself. While on the one hand a situation like this might seem rather counter-productive, it could also be read as an innovative and adaptive strategy of allocating and synergizing valuable material, financial and human resources. When knowledge and expertise are distributed and resources are limited, it surely makes sense to collate and to collaborate.

R.P.'s example is instructive. His own research project was related to cataract, he knew nothing about Retinoblastoma and had very limited knowledge

67 Dendrimers are a novel class of hyperbranched polymers that are nanosized with a number of surface functional groups. Poly (amido-amine) (PAMAM) dendrimers have been widely used as delivery systems for various therapeutics in cancer and arthritis (Kang et al., 2009, p. 1044). 
of nanotechnology. Yet, as he indicated with pride, he was able to contribute meaningfully:

Mmmm, mine is just (...) technical support, actually. (...) Actually I helped SA. He doesn't know how to dialyse the sample (...). That's why my boss called me to help. (...) He told me to help him for one or two hours only. Then I went into the field, (...) I got some ideas (...) and my boss also encouraged me. It's not my major project, actually (...). It is not that I don't need any hi-fi things [but with these] simple things also we can also [get] some good results (R.P., Interview, 2010).

R.P. had helped innovate in the spectroscopy and characterization work by using the basic equipment available at the institute. He had conceptualized an efficient and cost effective method that enabled them to get an approximate idea of how much carboplatin they had managed to load into the nanoparticle. This initial platform helped them optimize their resources as they now needed to access the expensive and time consuming sophisticated facilities at the NGRI only as and when absolutely necessary.

\section{A quick failure and change in strategy}

If replicating the results of a published article was one key characteristic of the research initiative at LVPEI, the other important one was that these researchers did not have the benefit of working directly with the authors of the article, and had had only limited interaction with those who did the original work. All the three researchers at LVPEI acknowledged that their research was being impeded because they had neither the full details of the original experiment nor access to that experience and expertise:

Yes, yes. It was tried in animal models before (...). They have succeeded till $30 \%$ of the drug was entrapped. I don't know what procedures they have used, but (...) the instruments that we are using are completely different. We are using [a] magnetic stirrer and they might be using [some] other stirrer - we don't know (S.A., Interview, 13 September, 2010).

The situation was not panning out the way the researchers at LVPEI had hoped and the above quote is only one illustration of the challenges and frustrations they were facing. The LVPEI team was able to achieve only limited success in their replication efforts. They soon realized that this was not going to work out, and sometime in the middle of 2012, only a couple of years after they had begun, the entire effort was given up completely. It had become clear that the original results would be extremely difficult, if not impossible, to replicate. Even loading the equivalent amount of drug into the nanoparticle had not been 
possible; getting to the stage of animals models or clinical testing was not even on the horizon. The effort had indeed failed - a confirmation, perhaps, of the relevance of tacit knowledge and expertise in scientific experimentation. The experience of the LVPEI team was strikingly similar to the observations made by Collins (1990, p. 4) where he "found [that] scientists who tried to build a radically new type of laser (...) while working only from published sources were uniformly unsuccessful."

Two prominent changes came about as a consequence of this 'failure' - one was institutional, the other more technical. The effort at LVPEI is now directed at a collaboration with a partner much closer home - Dr. Anand Kondapi of the Department of Biotechnology at the University of Hyderabad. The significant technical change is related to the expertise that Kondapi brings to the table. In the initial case, the nanoparticle being used was the PAMAM dendrimer, an inert polymer, while Kondapi works mainly with proteins. He has achieved considerable success in ensuring regression of hepatocellular carcinoma in a rat cancer model and in inhibiting HIV-1 replication in vitro using apotransferrin loaded nanoparticles (Gandapu, Chaitanya, Kishore, Reddy \& Kondapi, 2011; Krishna, Mandaraju, Kishore \& Kondapi, 2009). Similar lines of investigation have now been opened up to see if such a protein based nano-carrier can be found and used for treating Retinoblastoma as well.

\subsection{The girl as the disadvantaged child}

Having explored the institutional dimensions and also the technological aspects, let me now come to the other key pivot of this story - this is the social dimension and the position, in particular, of the girl child in Indian society. My primary point of entry into both the institutions, as I've noted earlier, had been the nanotechnology that the clinician-researchers were investigating for the diagnosis and treatment of Retinoblastoma. In both the instances, the researchers also noted that nano related research for Retinoblastoma was still in its infancy, and applications, if any at all, would reached the patient only a decade from now. From here on my discussions with them quickly moved into many different territories and other dimensions - the orphan disease being a prominent one, the clinic-laboratory interface being the other. The nano component soon receded to being a backdrop, with the social, cultural and the economic contexts, and userproducer $^{68}$ configurations coming prominently front-stage. Nothing was more striking than the status and the fate of the girl child in India.

This particular thematic came centre-stage in the very first interview with Javed Ali as he explained the relevance of nanotechnology in the treatment of retinoblastoma. I have already highlighted the content and intensity of his quote

68 I use the more general term 'producer' here to refer to the 'clinician-scientist' - the individual who provides the medical care as a clinician but is also involved in developing new technologies and treatment protocol for the treatment of Retinoblastoma. 
that appears in the very beginning of this thesis, and also the impact it had on me. Exactly two years later, in July 2012, I was speaking to another clinicianresearcher involved in nanotechnology for Retinoblastoma research in another city and this is what he had to tell me when I asked him of the problems and challenges of treating Retinoblastoma:

\begin{abstract}
See, imagine, somebody coming [with a] female child [with] retinoblastoma. Then the father tells no, I don't want to treat my female child and the child dies. See, there are social implications [of having a girl child]. Why do they want to treat a female child? (...) Also you are telling (...) you will remove the eyes. Who is going to marry these children? (...) Unfortunately, all these children are from poor socio-economic background and by the time they come, [it is a] highly advanced stage (X1, Interview, 2012).
\end{abstract}

Another time, another place, another person, but the sentiment was virtually the same, and it came across to me as a manifestation of a larger social reality that transcends involvement with a particular individual or a family. Those expressing the concerns were, after all, specialist clinicians and not the traditional family physician whose involvement with the family is deeper and whose effort is to "understand how the complexity of the lives of patients, issues of home, family, community and environment, influence the way the disease occurs or affects the way treatments are followed" (Bhattacharji, 2010, p. 104). The critique, in fact, has been that "the doctor who was [in the past] a friend, philosopher and guide, has been replaced by the specialist who has years of expensive training, needs a lot of investigative support and is more disease-oriented that patient-oriented" (Bhattacharji, 2010, p. 107). The Retinoblastoma case suggests, however, that the specialist, even if less patient- and more disease-oriented, cannot but be influenced by the larger realities of the patient that comes to his clinic.

\title{
The fate of the girl child
}

The girl child ${ }^{69}$ in India has been historically disadvantaged and discriminated against. Right from the time she is a foetus in the mother's womb to her marriage and beyond, there are various practices that are prejudiced against her, sometimes subtly, sometimes with extreme violence. While there are considerable regional differences within the country, the overall picture is evident from statistics of the situation on the ground:

The [2001] census has counted 531 million males and 496 million females giving rise to an overall sex ratio of 933 females per 1,000 males;

69 I am aware that there is no single 'girl child' anywhere. I still use the term, primarily as a rhetorical tool to emphasise the challenges that many women and girl children have historically faced in India and continue to do so even today. 
registering an improvement of six points on the 1991 sex ratio of 927 females for every 1,000 males, which is a matter of some satisfaction. But a matter of deep concern is the decline in sex ratio of population in 0-6 age group (henceforth called child sex ratio) from 945 in 1991 to 927 in 2001 (Premi, 2001, pp. 1875-76).

This difference in numbers is explained by the well-acknowledged preference for the male child in many sections of Indian society, and the resultant and considerably wide spread practice of female infanticide and foeticide. The girl child is killed as soon as she is born or even earlier, through "sex selective abortions" (T. Patel, 2004, p. 887). Modern technology is used and abused extensively for the purpose by a conniving section of the medical community that helps, first, to determine the sex of the unborn child and then to terminate the pregnancy ("Saving the Girl Child," 2008). So severe has been the problem that determination of the sex of an unborn child has been made a criminal offence in India under the provisions of the 'Preconception and Pre-Natal Diagnostic Technique (PNDT) (Prohibition of Sex Selection) Act - 2003'.

The preference for the male child is linked in large measure to the demands placed on the girl's family at the time of marriage in a system where marriage "remains universal and socially compulsory (...), forcing parents to marry daughters to whoever, wherever and at whatever cost" (Kaur, 2010, p. 16). Huge amounts of dowry need to be paid by the girl's family and the girl, from the moment she is born, tends to be looked at as a liability for her parents (Dogra, 1997; Kaur, 2010). If additionally, the girl has some other 'drawback', like a physical deformity (a missing eye, for instance), getting her married becomes difficult, and the dowry to be paid is that much higher. There are also innumerable cases of harassment and violence inflicted on the bride by the husband and his family if 'sufficient' dowry is not given. In extreme cases this leads to the murder of the woman or to suicide, often by self-immolation (V, Kumar, 2003). The gravity of the situation is highlighted by figures from India's National Crime Records Bureau (NCRB) that reports an average of 7000 dowry deaths every year ("More than 6000 dowry related cased registered yearly: Govt.," 2008).

It is not surprising then that those offering removal of the eye (enucleation) as a solution to the condition come up repeatedly against this prominent social reality. Parents of little girls with Retinoblastoma, as the clinicians noted, have repeatedly expressed opposition to the removal of their child's eye even if this non-removal would lead to the quick spread of the cancer and the eventual death of the child. In many cases they simply refused to come back for treatment. These issues, even though non medical and non technical, become pivotal, and not responding to these social realities is not an option any more. 


\subsection{Responding to these challenges - the creation of the clinician-scientist-social activist}

Vikas Khetan, the clinician at Sankara Nethralaya, has created a team of social workers that engages with the families of the Retinoblastoma affected and is trying among other things, to put in place a monitoring and tracking system to ensure the children come back for treatment at the prescribed intervals. There are significant logistical challenges, however, in making this system work:

See, places where there is a centralised health care system, where people don't have to pay from their pocket, none of these problems exist. (...) Places where you have a social security number, there you can track down the patients. (...) In a country like ours, where there are very few centres that take care of Retinoblastoma children, most of them are private - not government hospitals. So as far as the treatment goes, they have to shell out money from their pocket. We do have systems in place here [in SN] where majority of our patients are treated for free. That is different but this does not happen elsewhere. So money is a concern, travel is a concern [and then] not many people are aware that they have the disease. How do you spread the message across to 120 million people in the country? So, lots of issues in our kind of system. People come to Chennai, they take a mobile number, use it for 10 days, go back and it gets lost. (...) You can't even reach them. Even this SMS system that I am talking to you about - how far it is going to be effective, we will only know in due course of time. (...) And there are times we call up the family $(. .$.$) - 1st time, they'll listen to us; 2nd time they will not.$ They know this phone is coming and they will not even entertain our call (Khetan, Interview, 2012b).

Arasu Kumar, a member of this social-worker team, narrated how he has had to travel far and wide to reach families and persuade them to bring back the child for treatment; how in some instances families refused to recognize him and then went on to threaten him if he didn't stop interfering in their personal matters; and how in one case, the father called a few months later saying the child had died and how he wished he had continued with the treatment.

Khetan also noted that he often scolded parents and families for being irresponsible in not bringing their children for treatment. When asked if this was going beyond the medical and therefore beyond his brief, he was emphatic he was not:

No, I don't think so. Personally I don't feel bad at all. I think it is my job. But a lot of people leave it to the families. (...) I was taught by my mentors that you have to do the best for your patient and if you think that is the right thing to do, go ahead and do it. I may be proven wrong 
tomorrow, but as of today, I am trying to do what is the best. Even my colleagues [in L.V. Prasad Eye Institute] are very firm on bringing children back. So they also have a system in place (Khetan, Interview 2012).

Evidently, these larger issues and concerns are deeply embedded in the daily practices of these clinician-scientists - sometimes explicitly, sometimes implicitly and in ways that might be difficult to discern. The responses too are as challenging as they can be uncharacteristic and innovative. Successful innovations, it becomes evident, have to be socially and culturally embedded and have to be sensitive to the prevailing social mores, even as they try to work against them. The implications too are profound as they run simultaneously along multiple axes of the medical and the scientific, social and ethical, the personal and the public. That most, if not all of these, have remained restricted to these individualized contexts and individual action is indicative, perhaps, of the institutional limitations and challenges that come in the way of their wider acceptance and inclusion. Khetan recounted to me another specific situation that helped underline the complex ambiguities and challenges involved:

I still remember a patient who came. We advised him enucleation. They went back and came after a year and a half and the child [was] (...) very bad (...). I literally started shouting at the father. I said what the hell - if you can't take care of a child why do you give birth to children. I went to the extent of, you know, saying that. He didn't say a word. He kept listening to me and then with tearful eyes he said that at the time I came here my mother had a heart attack at home. I am the only earning member of the family. My mother has taken care for me all my life. You think, I could, you know, let her die? For me it was a choice between letting my child die [or] my mother die (Khetan, Interview, 2012b).

This is as challenging and difficult a situation as one can possibly imagine. What does one indeed do? The question is as relevant for the father of the patient as it is for the clinician, for whom the otherwise hidden social, financial and cultural context of the patient's family have come, suddenly and unexpectedly, to the front stage now.

\section{During outpatient consulting}

I gained another similarly revealing insight as I observed Javed Ali with patients during the outpatient consulting component of his practice at LVPEI. It is striking in its resemblance to Khetan's account above and worth recounting in some detail. What follows are my diary notes from one such consultation: 
The next file was ready and as I followed Javed into the room - he turned around to me and said, "You'll find this interesting - it's a case of Retinoblastoma". Inside was a couple with a little eight-and-a-half months old child in the hands of the mother. One could make out that the eyes were almost closed and Javed noted to his assistant that the baby was already squinting.

He looked at the papers again and [told the parents] that one eye had gone and the 2 nd one was in bad shape too. He had mentioned to me just as we entered that these people were two months late in coming. They had known about this but were trying some homeopathy treatment, and I knew from his demeanour he was not very happy with what had happened.

He was blunt with the parents too. He stressed that they had come two months too late (...). Not only could he not guarantee the eyes of the baby, he would not rule out danger to its life as well. I tried to see if there was any emotion/reaction on the face of the parents, particularly the mother. I don't think I could see anything, but I don't really know. (...) Dr. Javed Ali had been blunt, even brutal and I could only feel sympathy for the parents. (...)

Once out, I commented to the doctor that these must be difficult situations for him to deal with and asked how he managed? My question was more about the emotional responses/challenges that a doctor must face, but for Javed it was not so much an issue. He said something about being a psychology student, about having to regularly deal with situations like that and then said something that was rather striking. One feels a sense of vengeance for these parents, he said. I want them to be punished for what they have done to their child. If they had come to me two months earlier, I could have done something. Now, I don't know' (Diary Notes, January 7, 2011).

Javed Ali's response was very much in line with what he had said to me in his first interview - his primary sympathies lay with the welfare of the little helpless infant. It was here, however, that a paradox was also visible $\mathrm{e}^{70}$. The clinician who appeared extremely aware of the social reality of the disadvantaged girl child in India, seemed to be unaware, even unconcerned about the social reality of the parents. This threw up a whole set of related questions that, I thought, had not been considered by him - what is it that is happening in that family's world that they could not/did not bring their baby to the hospital earlier than they had? What is the material/financial/social situation of these parents today? What, if there was, as in the case of Khetan's patient, a larger crisis at home? Maybe, it was better in that social world for the baby to die? The question then, was not what would happen 15 or 20 years from now when she would be of a marriageable age,

70 I'd like to thank Annapurna Mamidipudi for bringing this to my notice. 
but of tomorrow, or two months, or even a year from now? But how could one even know all of this? In a subsequent discussion with Javed Ali it did become clear to me that he was acutely aware of this larger social reality. In this more reflexive context, he narrated a number of instances where he, like Khetan, was himself faced with many dilemmas that had no clear resolutions.

\section{The clinician-scientist-social activist}

From the outside, a medical professional's life appears to exist as two concentric circles - the smaller world of the profession that is itself enveloped in the large world that we all live in. The back stage I glimpsed suggested to me that there might be another, intermediary circle that links the two worlds through multiple intersections. This is the circle of the clinician's institution, the conditions, mandates and agendas of which moderate and catalyse the clinician's personal identity, professional practice, and in some senses, even his world view!

A medical institution that demands translational research from its clinicians must evidently create a clinician different from one in an institution where there is no laboratory and no need to be a researcher. This is that (partially hidden) world that facilitates, even demands multiple interactions and therefore produces multiple outputs. It enlarges the canvas. Nano science and technology intersect and weave themselves in in a manner that any linearity (if it existed at all) is lost. Any point is a good point of entry, because the other identities and considerations will ensure that the playing field is leveled out in the end.

This is what I believe is happening here as well: treating the cancer becomes as important as the patient's marriage, which is as important as a journal publication, which in turn is as important as the institution's mandate to carry out translational research. The individual who was the 'clinician-scientist' becomes the 'clinician-scientist-social activist': one-as-many and many-as-one. $\mathrm{He}$ is a doctor, a researcher and a social activist all at the same time, but as we see, the roles are played out interchangeably. One role or one identity thrusts itself to occupy ascendancy - the position of 'first amongst equals' - but only for a brief and interchanging moment. The nodes of the triumvirate remain, but the shape of the triangle they constitute is constantly changing; forever forging new angles and meanings, new challenges and understandings.

\subsection{How the user matters}

We assumed in the preceding section that the primary identity of the individual at the point of entry into the profession is medical. We saw further that the institution's mandate to do scientific research generates an additional demand even as it creates space for improving treatment through newer technological/ scientific possibilities. The constant interaction with the patients and their different worlds through the clinical practice also catalyses an acute awareness of the social context of the disease and the disease carrier. The clinic forces 
Javed Ali to feel and think for the girl child he hardly knows, just as it compels Khetan to create a social work team that will ensure the child is not lost to the medical establishment. It is this child that is, in fact, the key purpose of the entire enterprise. This is the key user of technological, medical and other services that Javed Ali, Khetan and their respective institutions have on offer - it is this user and the key role s/he plays that I turn to now.

Just like the person who enters the medical profession appears to have the primary identity of a clinician, the patient who comes to the clinic with a tumour in the eye appears to be a helpless infant with no voice of her own. As the story unfolds through the eyes of the 'clinician-scientist-social activist' and as mediated by the analyst (and not the user, because she has not spoken at all), it becomes clear that there are at least four users that we are talking about and whom the clinician has to cater to - a) the helpless infant of today, b) the 'to be married' woman of tomorrow, c) the infant's immediate family that decides on her behalf and d) the eventual non-user, which is both the family and the individual with Retinoblastoma. It is what might be called the 'aggregate of users' to underline their simultaneous existence as a singular entity at the same time as it is a collective. The notion of diversity that has been a key concept in feminist studies of technology (Harding, 1998; Oudshoorn \& Pinch, 2008) plays a key role here as well. The answer to the question "who is the user", is, indeed, "far from trivial" (Oudshoorn \& Pinch, 2008, p. 546).

In the first instance it is the helpless child, who can't speak for herself, who is the primary user. This is all about her and yet, someone else has to speak for her, someone else has to take the decisions that need to be taken. She is as much the end user "affected downstream by products of technological innovation" (Casper \& Clarke, 1998, quoted in Oudshoorn \& Pinch, 2003, p. 6) as she is the lay end user who is not part of the expert discourse (Saetnan et al., 2000, quoted in Oudshoorn \& Pinch 2003, p. 6). She is also, at the same time, the implicated actor "who is silent or not present but affected by the action" (A. Clarke, 1998, quoted in Oushoorn \& Pinch 2003, p. 6). It is as much a gendered configuration as it is symbolic because this helpless infant of today is simultaneously constructed as the 'to-be-married' young woman of tomorrow. The configuration would be different if the helpless infant was a male or if the family came from a different socio-cultural-economic background; it would also be different if that young woman was indeed allowed a voice. If the choice was between living unmarried as against not being allowed to live at all, she might well have chosen the former.

\section{The non-user}

But she cannot choose and it is in this context that the immediate family is configured as a user as well. The fate of the infant has an important bearing on this family just as the choices made by its members have on the fate of this infant. 
The family speaks for the infant and so does the clinician when he reminds the father of his responsibility towards his own child. It points to the important and "interesting issue that users may represent other groups as end-users while at the same time promoting their own interests" (Oudshoorn \& Pinch, 2008, p. 542). The clinician here is then dealing as much with the medical condition of the infant as he might be dealing with the cultural, social, economic, and religious realities: a family that does not have the money needed for the treatment, a grandmother who believes that removal of the eye is against the tenets of their religion, a father who has to chose between his infant who has Retinoblastoma and a mother who is dying of a heart condition.

It is in this particular configuration in the present story that the user emerges as the 'intractable patient' - "patients who were falling short of the ideal behavior that was expected of them (...), [patients] not toeing the line, not obeying rules of treatment or following the advice given to them by the doctor" (Kutty, 2010, p. 226). In choosing not to come back for continued treatment in the case of the girl child, the user becomes the non-user (Wyatt, 2003), a becoming that is not as voluntary as it might appear because there is an implicit and explicit imposition of the larger socio-cultural reality. Wyatt's taxonomy that identifies four types of non-users based on her study of internet (non) users (Wyatt, 2003), is indeed useful in our case too, but it is also evident that this particular non-user does not fit neatly into any of the proposed categories of the 'resister', the 'rejecter', the 'excluded' or the 'expelled' (Wyatt, 2003, p. 76). Our non-user seems, in fact, to embody all these characteristics and all of them at the same time because

many aspects to the person, her life, and her world actually come into play that are excesses or deficits in relation to the ideality of the "case". (...) Patients, their families and sometimes their communities are (...) involved in the heavy labour of mediating medicine; sometimes to cut medicine (down) to the size of their cloth; at other times frantically putting together difficult-to-gather physical, emotional and monetary resources with which to measure up to medicine's requirements (A. Zachariah, Srivatsan \& Tharu, 2010b).

The "disjunctures or gaps between the patient and the medical system are [indeed] political as well as technological in their formation" (A. Zachariah, Srivatsan \& Tharu, 2010a, p. 21) and we see an explicit manifestation of this in the one-asmany and many-as-one user who comes to the clinic to seek a treatment for Retinoblastoma and the producer who will meet her there.

A separation actually is not possible because of the complexity and the inter-relatedness, leading us to ask a question of the problem itself. Is it a problem of the social status of the girl child or is it one of a medical profession that offers enucleation as the best solution for the disease of Retinoblastoma? We could take 
one step even more fundamental in the analysis and the questioning - if there was more awareness and equality in society, if women were not discriminated against, if the girl child was not a liability from the day she was born, if she did have to die as an infant because no one would marry her when she reached womanhood, if a nanotechnologist never met a girl child with Retinoblastoma, and yet if a nanotechnology based protocol is indeed available to the clinician as a cure for Retinoblastoma, then what?

A medical intervention is useless if those who need it can't or don't access it, whatever the reason might be. And even if families and societies do start tomorrow to value their girl children, medicine and technology will be needed to deal with that tumour in the eye. The solution can only lie in the coming together of various strands - in the clinician entering (or being forced to enter) the lab even as he constitutes a social work team to ensure he does not lose his patients; in the use of nano and other new and emerging technologies in fighting the tumour even as strident efforts are made to raise the status of women and the girl child (the user) in society.

\section{The user configures the producer}

User studies in a range of scholarship that includes innovation studies, the social construction of technology (SCOT), feminist and semiotic approaches (cf. Oudshoorn \& Pinch, 2008, 2003a) (also see Chapter 1), have shown convincingly that users matter - that they influence technologists, designers, engineers and others. In the creation of the 'clinician-scientist-social activist' triumvirate that seeks to find a solution for the (non)users and the many conditions of Retinoblastoma, we can go a step forward by proposing that the configuration of the producer's identity triumvirate is, itself, a function of the interaction with the users. The reserve will be just as true and as the following Figure 2 illustrates, each influences the other in symmetrical, though different ways.

Figure 2: Reconfiguring the subjectivities of the user and the producer

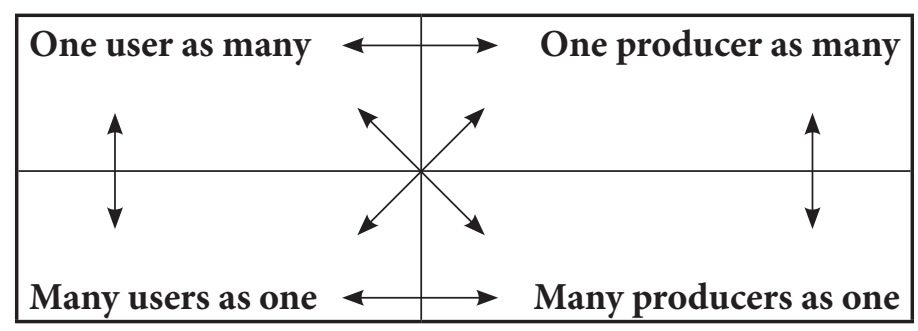

"Users [then] force [not just] the analyst (...) to cross boundaries" (Oudshoorn \& Pinch, 2008, p. 557), they force the producers to do the same as well. Users don't just influence; they play a key role in the very construction of the producers and their identities. The social worlds these users inhabit, the multiple identities 
they carry and "their "context of use"- the society and the web of other artifacts within which [the users and the] technologies are embedded" (Oudshoorn \& Pinch, 2003b), infiltrate the world of the clinic very very deeply indeed. If after all this, the users in all their manifestations don't become part of the problem articulation, we might take it as a lesson, they will also not be part of the solution. Because in this case, more than most others, is not enough "to produce more innovations or better identify user-driven innovations (...); the wider goal [has to be one] of political emancipation" (Oudshoorn \& Pinch, 2008, p. 548).

\subsection{The innovation question}

What does this then tell us about innovation - because this is the question that is supposed to be answered? The point of entry, as I have mentioned earlier, was the nanotechnology that was being researched for use by the clinicians in the two institutions. Had this not been visible, I would have never reached these institutions. My primary idea was to engage with the clinicians, the researchers and their labs to see what innovation might be happening, to look out for the emergence of what one might call a 'culture of innovation' involving the use of nanotechnology for development.

Innovative practices that find reflection in different bodies of innovation literature discussed in Chapter 2 were visible at different levels and in multiple domains - in the lab, in the clinic and in society. As pointed by Balasubramanian, it started in LVPEI in the planning and the architecture of the building itself, in explicitly creating a space and a place (cf. Henke \& Gieryn, 2008) that ensures a constant interaction between the clinic and the laboratory, in the commitment to translational research, and in creating the clinician-researcher. In the more technical realm, the clinicians in both the institutions identified their efforts at creating a nano-delivery mechanism as the key innovation attempt from their end. In $\mathrm{SN}$, at the same time, the creation of a team of social workers was a more explicit attempt at dealing with the patient and society as part of the challenge itself.

Implicitly, and perhaps even unknowingly, the attempts in both the places were directed towards identifying the complex jigsaw and bringing together as many of its myriad pieces as possible. Even though it was not articulated in this manner nor explicitly structured for it, the cumulative effort that I as an analyst could discern, was precisely this. Embedded in the web and in the jigsaw is the realisation and the demand that each piece be treated with as much importance as the other if a meaningful and lasting solution is to be found.

I might well articulate the innovation effort here as one that had no nanotechnology in it. For that matter it had no technology at all and yet there would be no debit to that account. On the contrary, a significant credit for this particular mosaic of innovations would reflect in the account of nanotechnology. If we choose to take nanotechnology as the starting point, we would see that 
the promise of nanotechnology lies, implicitly or perhaps, even explicitly, in the possibilities it offers in many worlds - as much in the changing of medical practice, as it is for changing the fate of, at least, some little girls. 


\section{Conclusion: Enculturing nanotechnology, Enculturing Innovation}

The thesis shows the enculturing of nanotechnology and of innovation via the journeys made through laboratories engaged in nanoscience and technology (NS\&T) research in India. The six inter-related steps by which innovation is encultured have already been outlined in the introductory chapter, and in the pages that follow I first explore these in some detail. I will then discuss the thematic that has emerged as the central idea of the thesis - the diversity of practices, of worldviews and knowledge systems that were visible in the work of the laboratories. I will then discuss the policy implications of accepting and acknowledging this diversity and conclude by illstrating how this enculturing of innovation and the diversity that characterizes it, are at the heart of the idea of the 'de-centred' cultures of innovation.

\subsection{Enculturing innovation: the six inter-related steps}

a) Innovation is an iterative, non-linear process where differently located social groups and actors, different knowledge systems and different ways of knowing and doing, all play an important role; it does not necessarily start with the producer and end with the consumer and neither does it begin with an invention that is discarded in the end as waste or obsolete.

b) Innovation has to be historically and culturally situated, even as we recognise that it endlessly transforms the different cultural logics that bring it into being in the first place.

These are the multi-dimensional aspects of innovation and its social construction that the case studies make visible as we travel through the modern scientific laboratory working with an emerging nanotechnology. In the STM lab in the University of Pune we saw how the notion of waste (materials gathered from scrap markets) was being challenged through the reconfiguring of materiality at the same time as training and creating a new generation of scientists. The jugaad paradigm of innovation was prominently in operation here, even though it is acknowledged and accepted with difficulty. In the case of the ARCI water filter, it was not just old objects that were given a new meaning; in giving it the nano-silver edge, the ceramic water-filtering technology itself was being imagined anew. Obsolescence was not the end of the process or of the life of the product - it was being innovated and re-imagined afresh as a response to societal challenges on the one hand and the challenges of cost and available 
infrastructure, on the other. In the nanobioscience lab at the ARI in Pune, engagements are being attempted that are not only inter- or trans-disciplinary, but inter-epistemic. Newer modes of dialogue are being sought between two worldviews that otherwise appear irreconcilable, and while the outcomes are not known, the situation is alive with many possibilities. The point I have tried to emphasise, however, is that the dialogue is possible at all because the lab is located within a geography and a culture (of innovation) that allows for these different worldviews to live on simultaneously in the same space and at the time. And finally in the labs and clinics in LVPEI and in SN we saw how innovation was about negotiating, even fighting, with the non-user of today to ensure a future for the woman of tomorrow. The individual was as implicated in the process as was the larger societal frame.

c) The scientific laboratory is an important site of innovation.

d) Empirically and conceptually, innovation in the laboratory straddles different domains, and dominant metrics of citations, patents and commercialisation are insufficient to capture the depth, breadth and richness of the innovation processes.

Historically speaking, the laboratory has been the locus of much of the discourse around discovery and invention. It is in the laboratory, it has been claimed, that some of the greatest discoveries have been made at the frontiers of knowledge and about the truth of nature, all in splendid isolation and independence from society. Innovation, a relatively more recent idea, has been something else, and the discussion is centred in large measure, as we have seen in Chapter 2, around the firm, economic activity and the idea of profit. These characterisations, evidently, are simplifications, and while work in STS over the years has shown that these categories cannot be so explicitly differentiated, it cannot also be denied that the ideas have endured and continue to have currency.

The lab ethnographies that constitute this thesis tell us that invention is not enough to explain what happens inside the lab, just as they show that there is no splendid isolation from society for the laboratory. They loosen and broaden the idea of innovation even as they illustrate that the scientific and the technological is only one axis along which innovation happens. If the other domains of society, culture and politics are not involved, there is a good chance that the technological and scientific will turn out to be ineffective.

By implication then, the understanding and explanation of innovation as 'making profit' is difficult if not entirely impossible to accept even in the context of the laboratory. This was particularly evident in the STM case study where the main questions that were asked of the research group were those of the commercialization of the instruments. The idea that the purpose of innovation is to convert "science into money" (Mashelkar, 2011b) is problematic because it does not account for good quality science or the pedagogic value of instrument 
making like in the case of Dharmadhikari and his research group. There is a lot of recent commentary (Balaram, 2012a, 2012b; Piston, 2012) that one of the biggest challenges faced by science administrators today is the shortage of skills and training that can optimally use the sophisticated and expensive equipment that laboratories have access to. Yet, this seems to be forgotten when the work of scientists like Dharmadhikari is discussed and evaluated.

Needless to say, the problem does not lie in the profit argument per se, but in its application as if this alone is innovation. What the lab does is different from what the firm does and the metrics used to evaluate the success or failure of the firm can be applied only partially to evaluate the success or failure of the lab. Patents and publications as quantitative metrics of evaluating innovation in the lab are important and even necessary, but they are not sufficient if one is to try and understand a 'culture of innovation'. Culture, as we have seen, is a much larger, even all-encompassing category of which quantifications of various kinds (money, patents, citations etc.) are only one constituent. The increased use of these quantitative measures to evaluate innovation and output is equalizing and flattening the processes of scientific enquiry and research by ignoring the diversity of what happens inside the black box of science and the black box of the laboratory.

The output - a publication or a patent - from the laboratory may be the same but how was it achieved? What were the methods used? What were the resources available? What kinds of knowledge were mobilised? What were the instrumentalities operationalised? Why was this particular question chosen for the research project to begin with? In the case of the $\mathrm{CNB}$, for instance, it is modern bio-science that is superior in hierarchy as it is being called upon to validate the claims of Ayurveda, and the output of this interface was another scientific publication in a peer reviewed journal. I have shown at the same time, however, that the engagement is far more nuanced, complicated and challenging than any publication can reveal and it is this negotiation that tests and pushes the innovative opportunities and capabilities. The action that is happening back-stage is as important as what is visible to us from the outside. Dharmadhikari's case is also illustrative. Localized and contextualized jugaad methods were used for the construction of the STMs and AFMs, which then delivered top quality results in spite of all the doubts of the jugaad paradigm of innovation. We also saw in the case of the water filter that the product failed inspite of the fact that it had a patent and was initially seen to have good commercial prospects.

e) Innovation in the laboratory is a multi-scalar process; the three scales that become obvious through the empirical material in the thesis are respectively, i) the micro (within the laboratory), ii) the institutional that gives rise to inter-disciplinarity and iii) the macro where social 
and cultural processes are inextricably inter-twined with the scientific and the technical.

f) Processes that allow wider participation are more likely to lead to successful innovations, particularly when S\&T is being increasingly mandated to find solutions that are directly needed and relevant in society.

I have shown that innovation happens at multiple levels. In Dharmadhikari's laboratory it was the micro level where the primary engagement of the scientist was with his science and his instruments. Even this lab was deeply infiltrated by the world around, but the primary work the scientist saw for himself was to make the instruments and to make the instruments work. In the case of the Centre for Nanobioscience, we saw research and innovation move one scale higher. The mandate of the lab to do application based science forces the scientist to move through boundaries and to engage in collaborative work across classical disciplines such as those of biology, chemistry and physics. The larger, cultural and historical context further allows, even demands, an interepistemic effort as we saw nanobioscience seeking to engage and collaborate with Ayurveda that prescribes to a completely different world-view and paradigm of knowledge.

In the final two case studies - of the low cost water filter and nanotechnology's engagement with Retinoblastoma - the social and the political are inescapable parts of the scientific and the technological because the primary mandate is to intervene in society. The water filter fails as it is unable to enter the lives and homes of the users; in the Retinoblastoma case, on the other hand, the potential user does not enter the clinic on account of social, medical and technological reasons, and remains the non-user, therefore. (Non-) users (Wyatt, 2003, 2008) became key in both these narratives, reinforcing the point made in user focused studies (Oudshoorn \& Pinch, 2008, 2003a) that we need to pay a lot more attention to users, their contexts and their capacities. The relevance of the social group of the user has to be acknowledged and the user has to be allowed participation - in that sense the innovation has to become more participatory and multi-locational.

In the case of the STM, the process of innovation was led entirely by the user, while in the water filter case we saw the users had no role till the very end, and that too, only as the consumer of a technology that the scientist had developed and the entrepreneur had brought to market. In the Retinoblastoma case we saw the user participate, but in a relationship that was layered and complicated, leading to the creation of multiple subjectivities. The case studies show, therefore, that there is no uniform category of user participation. Each is contingent to the specific situation and context, which in turn makes the idea of participation challenging to understand, conceptualise and implement because we may not even know who the user is or should be. 
The solutions sought through this mélange, it emerges clearly, are not just scientific; they are equally political, economic and developmental and just as emphatically. It is not only about innovating with nanotechnology or innovating for nanotechnology, it is about innovating nanotechnology itself at the same time as it about innovating cultures and society. Innovation happens not just in established and accepted domains of technology, of the market, in finance or in society alone. It surely happens in all of these but more importantly, it happens along intersecting axes that run across and through these domains.

The lab, where the scientific question is asked and answered, is constantly infiltrated by the larger social, cultural, economic and political fabric within which it is located. This lab is not only about patents it garners and the publications it generates. It is also about English as the language of modern science and its hegemony over Marathi, Hindi, Gujarati and many such mother-tongues in which many researchers have had their primary education; it is about a system where researchers can be seen running from pillar to post to get a few 100 rupees sanctioned and yet delivering top quality publications; it is to see how the fate of the girl child infiltrates so deeply that identities are completely re-configured; it is to wonder why there is so much research in Indian laboratories on finding ways to provide clean drinking water to the people; it is also to understand how and why a modern nano-scientist is not able to interpret into modern science the language of Ayurveda. It is to realize that innovation is as much constructed by society and culture as it, itself, constructs and influences society and culture.

\subsection{An underlying diversity}

What this points to, then, is the existence of significant diversity, in the problems that were being researched for sure, but also in the institutional frameworks and institutional and individual aspirations; in the methods, skills and intuitions that were being engaged; in languages, histories and knowledge systems that were in operation; and in the social contexts of their location. All of these are important constituents, at different places and at different points of time, of the culture of the laboratories and their cultures of innovation. The challenge this throws up for the articulation of a culture of innovation is evident - how does one account in one single articulation for such diverse realities as technological jugaad that makes cutting edge scientific instruments with what has been discarded as waste material, of the existence of an ancient Ayurveda in a modern nanobioscience lab, of efforts to re-invent and innovate the standard ceramic candle water filter with the help of nanotechnology or to find a solution that is simultaneously technical and social in the case of the girl child with Retinoblastoma.

This diversity can be looked at as an impediment because negotiating a way through it is always difficult and challenging. But, and this is my key 
point, this diversity also offers an opportunity. Diversity (of religion, caste, class, language, geography, history, culture, world views, knowledge systems and a lot more) is one of the key constituents of life and society in India, and it is only natural that the same would be reflected in modern S\&T institutions. The key response of dealing with this diversity in Indian society has been that of syncretism, of accepting, allowing for, and living with this variety and diversity (Aiyar, 2015; L. Tyabji, 2015). This is, in fact, an imperative as much for survival in such a society as it is for the survival of society itself. It is my submission that prominent elements of this diversity, its acceptance and operationalization, are embedded in the lab and the culture of innovation in the lab as well.

There are two trajectories along which we can take forward the discussion on the culture of innovation. One is to look into our laboratories and recognise the diversity that exists there already. That indeed is my key contention - that the diversities exist and they continue to manifest themselves inspite of the hierarchies, hegemonies and biases that are prominently in operation. I must also add that there is nothing explicit about this diversity in the lab and neither is it stated anywhere that an effort has to be made towards incorporating and working with it. I present its existence as the sub-text of the research and innovation in the laboratory as revealed through the ethnographies.

And then there is the other trajectory. This is the one going forward with the challenges of the future and the opportunities that this brings with it. If the culture of innovation is indeed characterized by diversity in an implicit and un(der)stated manner as I am proposing, what if we were to make it an explicit articulation? Even a goal? We know it exists and we know it will always be there because of the larger context and the larger narrative. My proposal is that we explicitly accept these diversities, different skills and methods and the differing knowledge systems; we don't make them impediments but look upon them as resources and productive challenges. The idea would to be cherish the diversity, the different world views and the different worlds themselves, and to pull all of these together in the pursuit of knowledge, scientific understanding and of solutions needed for problems in society.

\section{Policy Implications}

There will be significant policy implications if one was to accept this understanding of innovation and of a culture of innovation. To explore what these might be, I return to India's Science Technology and Innovation policy (STIP) (MST, 2013) that was discussed in detail in Section 2.2. We saw there that a number of authors (Abrol, 2013; Mani, 2013; C.S. Prasad, 2014) have been critical of STIP for its thrust on economic performance and growth, global competitiveness and high technology, for only paying lip service to the idea of inclusive innovation, and for clearly privileging the expert over the lay citizen. 
The journeys made through the laboratories in this thesis have also illustrated the mismatch between the experiences in the laboratory and the key thrusts of STIP. There are entire sections in STIP that are devoted to such issues as "attracting private sector investments in R\&D" (p. 11) and "gaining global competitiveness through collaboration" (p. 15), but only a passing mention, for instance, of "leveraging traditional knowledge through modern science for finding solutions to national problems" (p. 14). Technological jugaad and the scientist who might use such methods has limited, if any acknowledgement in STIP (he might even be un-desirable); the user who was so crucial in the case of the water filter and of treating Retinoblastoma is limited in the policy formulation to being a recipient and a beneficiary; and there is no mention at all of the citizen as a scientist-innovator and of the thousands of innovations that have been documented through efforts such as those of the Honey Bee network (Anil Gupta, 2006; Anil Gupta et al., 2003).

It will also be relevant here to reflect on the recent comments made in the journal, Nature ("Priorities for science in India," 2015), by a set of ten research leaders on the state of science in India today. There is considerable divergence and diversity one sees in their formulations as also the solutions that are being suggested. Some of the researchers identified a deficit in funding and world class infrastructure (Ganesh, 2015), a failing tertiary education system (Singh, 2015) and bureaucratic interference (Mujumdar, 2015) as key impediments in the development of science and technology in India. Others have highlighted the mismatch that exists between science and policy (Hiriyakkanavar, 2015), an exclusive focus on the problems as a "science-and-technology issue" at the cost of attention to the "socio-economic" (J1 Roy, 2015, p. 152), and a constant attempt to ape the "developed countries and the best endowed institutions in the world" (Gadagkar, 2015, p. 153) as the key challenges.

Naba Mondal (2015) asks for greater attention to be paid to those researchers who are interested in making instruments, and Gadagkar and Sunita Narain (2015) ask for an increased attention in science to local problems like those of endemic communicable diseases, ground-water contamination, traditional methods of biodiversity conservation, and sewage disposal. This attention to the local and to the poor, they argue in different ways, will help develop S\&T and an innovation and reward system that would be locally relevant.

A look at the institutions these researchers work with and/or represent underlines a salient drift: eight of the ten institutions represented are an integral part of India's mainstream S\&T establishment ${ }^{72}$. They are all located in metropolitan India (four in the city of Bengaluru alone) and are well-endowed,

71 The specific sector this observation refers to is the energy sector, but the same can be said of others too. 
premier institutions that are able to attract the best talent and significant amounts of financial resources. They are part of the same S\&T establishment that formulated STIP and yet we see that the primary thrusts of STIP don't map on completely to the comments, critiques and solutions that these researchers have articulated. When STIP is not able to account for the diversity and messiness that exists within the formal establishment, one can only imagine the magnitude of the slippage if the different diversities, opinions, histories and interests that constitute Indian society have to be accounted for. This is visible even within this set of perspectives - in Narain's observation, for instance, that "everyday challenges are not top priorities for research and innovation. Indian science has always been fascinated by the 'masculine' agendas of space and genetics, not reinventing the toilet" (Narain, 2015, p. 155).

This detour into what senior researchers in Indian S\&T have to say in a prominent journal like Nature only compliments the findings and conclusions of this thesis. We see that the richness of methods, knowledge systems and worldviews that ethnographies of the laboratory reveal as integral parts of laboratory life find very limited, if any, acknowledgement in the policy that applies to these very laboratories. It might be difficult to believe that these ethnographies and this STIP are, respectively, the micro and macro accounts of the very same spaces. The diversities that are made visible through ethnographies in the lab (and even in the opinions of prominent researchers) have been flattened out, even erased in STIP. It is possible that policy makers are un-informed or ignorant of what happens inside laboratories, or, may be, they choose to ignore these realities. Either way the policy implications are evident. The edifice of an effective and relevant innovation policy can only be built on a foundation that is alive to the realities of the society and the S\&T system it is meant to be about. It is unlikely it will succeed otherwise.

The case studies that make up this thesis and the conclusions drawn from them have shown that life, work and innovation in laboratories in India is messy, multi-layered, and multi-locational, and it is incumbent, therefore, on any policy formulation to account for and do justice to this reality. It is also not my case that efforts in these directions do not exist and the entire discourse on social or grassroots innovation (Section 2.5) is one attempt in that direction. Another is the demand for Knowledge Swaraj (SET-DEV, 2009) which creates space for diversity, seeks a broader engagement of society and of the citizen in S\&T research and development. An innovation policy will be incomplete and unproductive if it does not account for all this and more.

72 Of the other two, one researcher is at the University of Chicago in the USA, while the other institution is the Centre for Science and Environment (CSE) which is a non-governmental organization based in New Delhi. 


\subsection{De-centred/De-centring Cultures of Innovation}

Let me now go a step further from here to state that these ideas of diversity have already been operationalized in the general context of innovation, even if in a limited way. It is my contention that different systems of knowledge and innovation are already in effective play leading simultaneously to a de-centring of the cultures of innovation at the same time as it makes a case for the existence, already, of de-centred cultures of innovation. It is this idea that I will engage with and explicate in the following and concluding section of my thesis.

The idea of the de-centred cultures of innovation is a response to the centrality and to the position of pre-eminence that certain ideas and notions of (a culture of) innovation have come to occupy in literature, policy frameworks and in the mainstream discourse. India's Science Technology and Innovation Policy (STIP), which I have discussed in detail in Sections 2.2 and 7.2, is a good illustration of this. The diversity in the laboratory, the multiple realities of society and different narratives around innovation (Chapter 2) notwithstanding, STIP's focus is limited and centred on just a few elements. S\&T is one important locus, the corporate firm is another and the expert can be seen to be the third. The number of patents and successful commercialization are prominent metrics of evaluating success in this formulation, and innovation continues to be seen as a linear process where the citizen is restricted to mainly being a recipient. There is little place for recognizing messiness, lack of control, and diversity. The implication of this is that innovations are supposed to happen only in particular ways and in particular spaces - spaces that are endowed, for instance, with certain kinds of knowledge, and with access to power and resources. What this also implies at the same time is that innovation cannot happen if these are not part of the constellation; that, indeed, a culture of innovation cannot exist without these elements. It is not stated in as many words, but can be read between the lines as the subtext of formulations like in STIP. These formulations are as much about a centralized and homogenized understanding of a culture of innovation as they are about the centralizing and homogenizing of these cultures.

My key contention here is that the culture of innovation constituted by these elements is only one culture of innovation. Many other cultures of innovation exist simultaneously, and importantly, these intersect with each other in different ways. Science \& technology are important, for instance, but there are other forms of knowledge and knowledge systems that also play important roles: the corporate sector innovates and produces wealth, but there are other constituents of society that also innovate and produce value of a different kind; one kind of innovation moves in a linear fashion from research in the laboratory to a product in the landfill, but there are other cultures of innovation that are inherently cyclic and iterative and where waste is a resource; the expert has an important kind of knowledge and understanding of the world, but the lay citizen has another that too can be mobilized to find solutions to societal challenges. 
The different epistemologies that construct knowledge in different ways can thus meet in conflicting yet productive engagements. It is this simultaneous existence, relevance and interaction that I refer to when I speak of the de-centred cultures of innovation.

Evidence of this is available in the literature on social innovations and in STS that I have discussed in Chapter 2; it has also been explicitly demonstrated through the lab ethnographies in this thesis where different knowledge systems, messiness, diversity, the lay citizen, waste materials and non-quantifiable and non-commercial considerations influence innovation processes. They are, in fact, integral constituents of the culture of innovation itself and this applies, I would like to argue, as much to different contexts and disciplinary fields as it does to different geographies.

To take the discussion forward, I will pick up the idea of Technological Jugaad and use it as an exemplar of how what is quintessentially Indian also allows for a more general understanding of the enculturing of innovation. We have seen in Chapter 3 the conceptualization and characterization of Technological Jugaad as something explicitly Indian for its location in a culture of languages across large parts of Northern India, for the broad sweep of its canvas from rural agricultural and poor urban India on the one hand to the modern scientific laboratory on the other, to the context of economic and resource constraints that circumscribe life in large parts of the country (including in the laboratory), to a particular understanding of waste that allows for the reconfiguring of materiality, to a culture of recycling that feeds and is fed by the imperatives of survival and also to the existence of alternative, often traditional, systems of knowledge - something that is also evident nanotechnology's interface with Ayurveda in Chapter 4 .

In all of this, Technological Jugaad can be constructed as a stand-alone and an exemplary way of doing things that is confined to certain parts of India. What then of other places around the world with different cultural, social, economic and political conditions? It is possible that Technological Jugaad with a different name may be found in other parts of the world too, albeit with localized variations and contextualized nuances?

Evidence of this is not difficult to come by and the conceptualisations that I would like to highlight as illustrations include "The reassembled cars of Taiwan" (Lin, 2009) where 'reassembled', like jugaad, also has a negative social connotation - often meaning "unprofessional, unsafe or insecure" (ibid., p. 92); the French idea of 'bricolage' (Levi-Strauss, 1966) where the bricoleur "is (...) someone who works with his hands and uses devious means compared to that of the craftsman" (Levi-Strauss, 1966, pp. 16-18); 'user-driven' innovation where the charge of new development is led by the user (von Hippel, 1988, 2005) and 'jua kali' in Swahili in Kenya, which is translated literally as 'hot sun' (UNEVOC, 1998) but is used more expansively to mean 'hard work in the hot sun'. These 
are five terms from five different languages, cultures and histories that span the globe and yet one sees common threads that bind them together. They appear interchangeably usable ${ }^{73}$ and at the same time there are factors embedded in the social, cultural and economic contexts that makes each one unique.

Jugaad and bricolage, for instance, are different in that they come from different languages, are based in different geographies and in the set of people of who use them. If use of "devious" means (Levi-Strauss, 1966) was, however, the parameter for evaluation, bricolage and jugaad (of which technological jugaad is a derivative) are considerably similar. The "whimsicality (...) accompanied by bricolage in instrument building, [where STM] probes [were made] from pencil-leads [and] (...) AFM tips from hand-crushed, pawn-shop diamonds glued to tinfoil cantilevers with brushes made from their [researcher's] own eyebrow hairs" that Mody (2006, p. 66) describes of a laboratory in the west, could well have been an account of what happened in Dharmadhikari's lab, only that the contexts were different. Observing that the jugaad-like elements used by Dharmadhikari in his STM-building are ubiquitous in American universities, Cyrus Mody notes that perhaps there is "an ideological vision of what counts as "science" or "high technology" that's shared by many in both India and the US but which gets applied asymmetrically - i.e., US scientists can put their STM in a refrigerator and be seen as creative bricoleurs, but when Indian scientists do the same thing they get criticized for relying too much on jugaad by the various anti-jugaad authors" (Pers. Comm., Email, 13 May 2013).

I see Mody's observation as an important comment on the nature of power in political and knowledge hierarchies at the same time as it is a call to correct that balance, to acknowledge that different cultures of innovation exist side-byside and to accept that each is as valuable and productive as the other. There is no reason, for instance, that jugaad should not be treated with symmetry and with the same academic rigour and respect as one deals with bricolage or any other culture of innovation. It is to also acknowledge that jugaad is not an appendage to innovation like in the case of 'jugaad innovation' (Radjou et al., 2012), but a legitimate 'culture of innovation' in its own right.

User-driven innovation, similarly, is what a lot of technological jugaad is about, but where those involved in technological jugaad are not von Hippel's "lead users, [who are] ahead of the rest with respect to a related and important market trend" (von Hippel, 2005, p. 4). Whether it is the maker of the reconfigured automobile in rural north India or the STM inside the laboratory, those doing jugaad are more often than not, trying only to 'catch up'. There is a difference and there is an overlap. Jugaad stands out as a survival strategy in situations of poverty and deprivation, and also for its status and (non) acceptance in the academic and other worlds. Bricolage and user-driven

73 See Birtchnell (2011) and A Sharma (2008) for one example of this interchangeability between jugaad and bricolage. 
innovation are well established and accepted conceptualisations; jugaad, on the other hand, evokes mixed feelings and technological jugaad is not even part of the discussion yet. This does not mean that 'technological jugaad' as a culture of innovation does not exist - it only suggests that it is not being accounted for.

What this implies then is that there cannot be one central culture of innovation, that context decides the relevance and nature of innovation practices, and that one form of innovation is not necessarily better than another. And this is the case because innovation is both encultured and de-centred; the de-centring and the enculturing are, in fact, like two sides of the same coin.

Different world views, knowledge systems and cultures of innovation are already at play, even if in an highly unequal world where many remain on the peripheries and have to struggle to survive. That many are not visible is on account of the limited scope of the articulations and the narratives in the so called mainstream of science, technology, innovation, development and progress. Alternative narratives are possible - they already exist, in fact. All that is needed is for us to be sensitive to their possibilities and to be open to what they might have to offer! 


\section{Annexures}

\section{A) Photo feature: Scientists and their favourite instruments}

The scientists, their favourite instruments and why they are important... The photo feature is the outcome of an exercise I conducted in the CNB wherein I requested the researchers to identify equipment in the laboratory they thought was most interesting and to also explain why (pp. 110-111). The answers varied across the spectrum - from the micro-pipette and the humble voltmeter on the one hand to the sophisticated and expensive Atomic Force Microscope on the other. The images, framed deliberately and in a particular way, show the interpretive variability of the choices scientists make in the laboratory and illustrate how differently the scientists relate to specific tools and to the same working environment. (Also see Latour and Woolgar, 1986). 


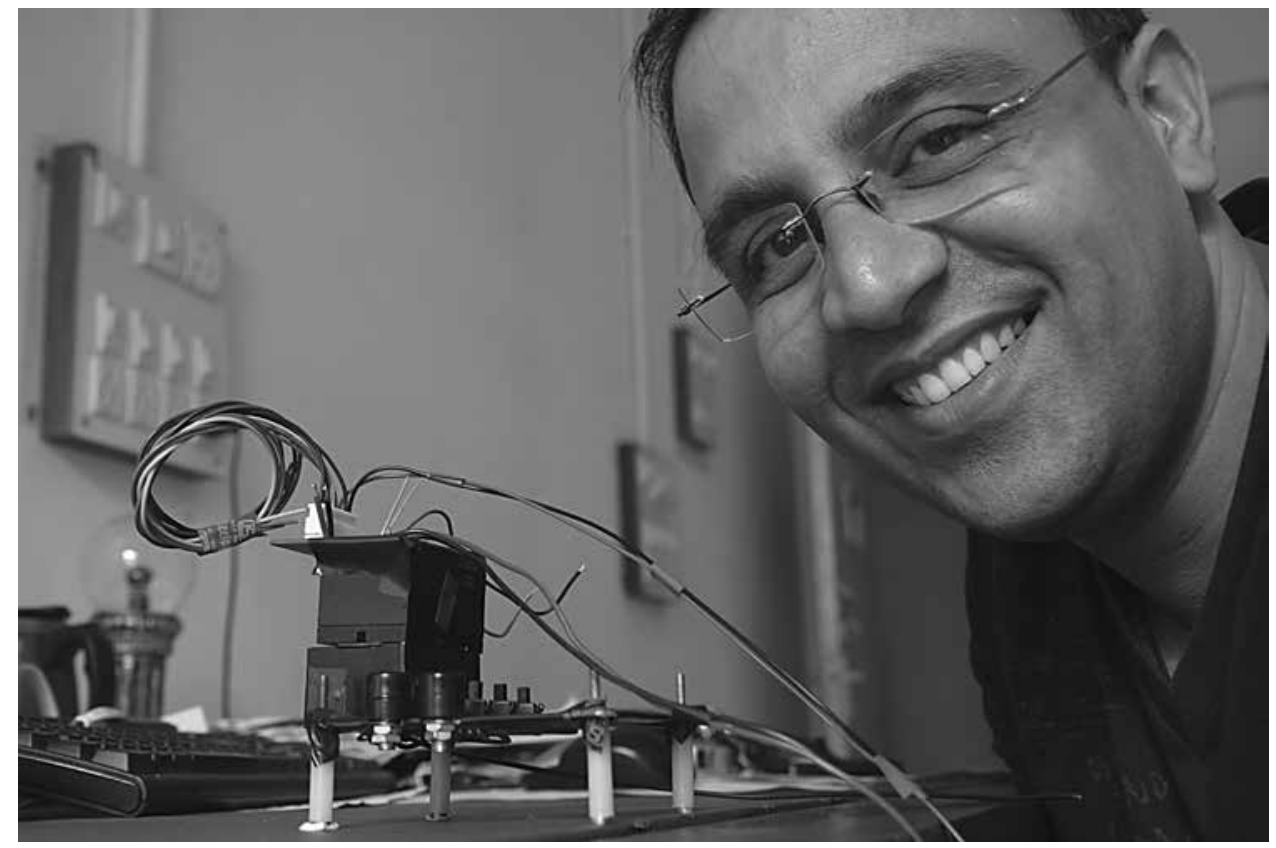

Dhananjay Bodas

"This instrument was designed and developed by me and my student Shailaja (for her thesis which she successfully defended recently) and hence is very close to my heart. This also happens to be the first device I've developed when at ARI. A lot of research and thinking went into the development of the device. It does not have a name as such, but can be called the high sensitivity microfluidic biosensor. It is used for the detection of pathogens from water and food sources." 


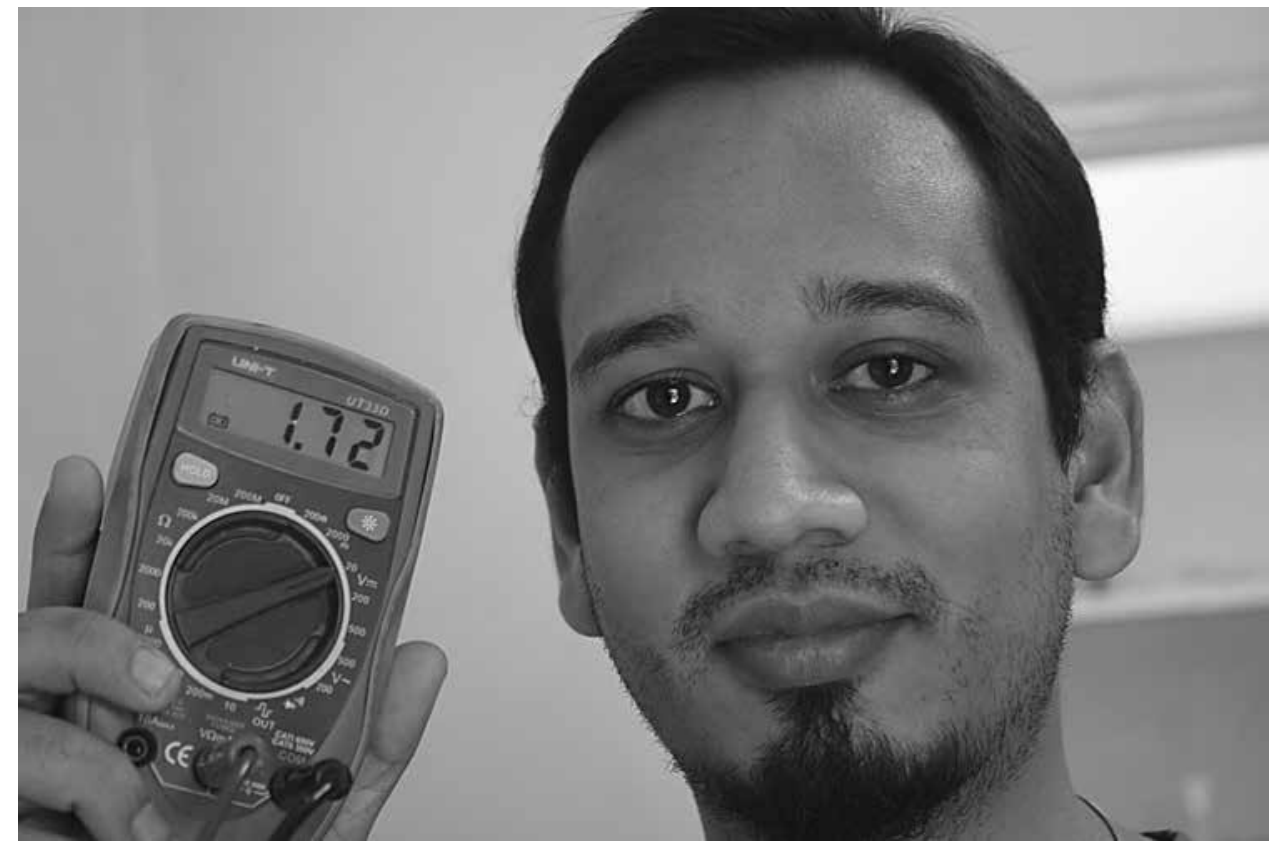

Shreyas Pradhan

"The voltmeter is a hand held electronic measuring instrument, combining several measurement functions like voltage and current. It has always been there for me as a fault detector and major decision-maker." 


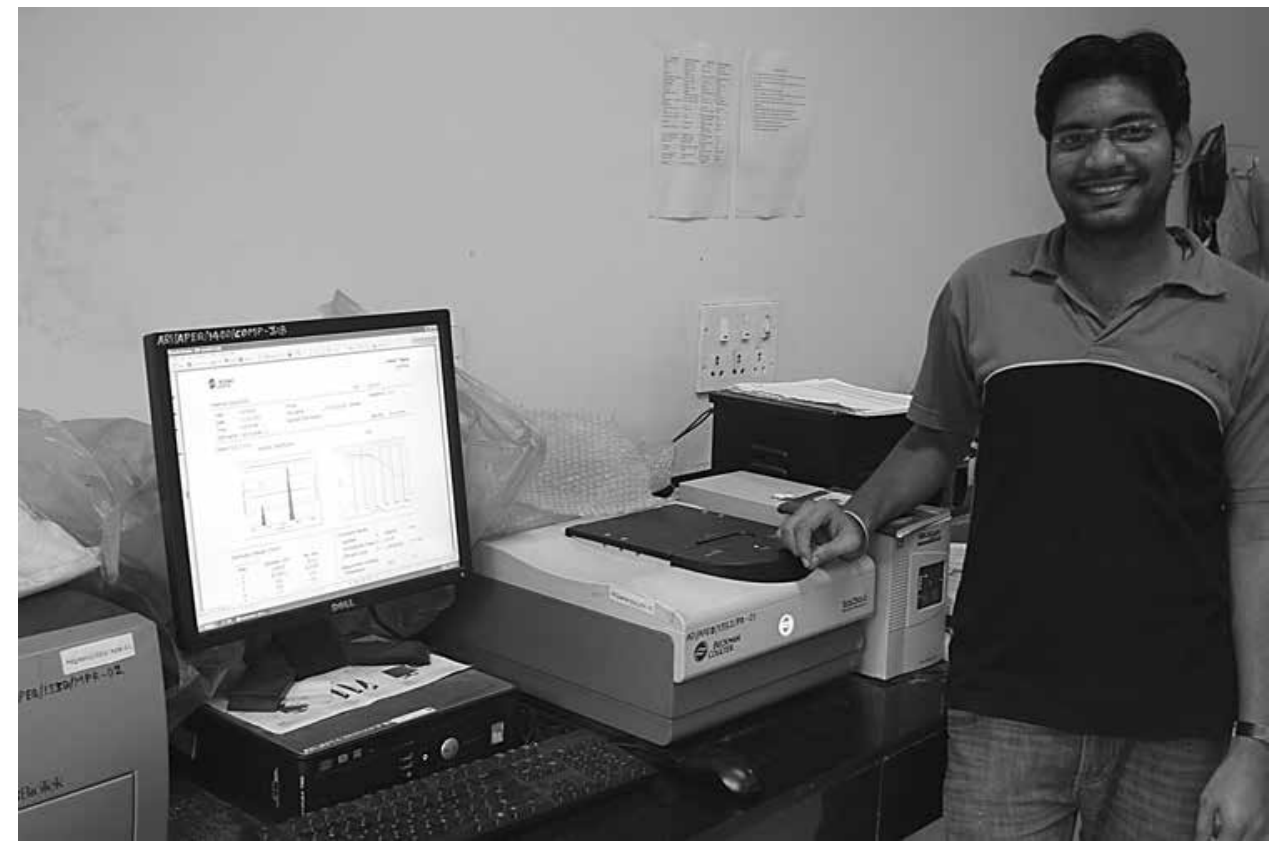

Paresh Deshpande

"This is a zetasizer (Delsa nano make). This instrument is used for nanoparticles characterization, specifically for the detection of nanoparticles size and surface charge, based on the principle of dynamic light scattering. The instrument is also called the DLS. This is also a very sensitive instrument and very useful for each one working in the field of nanotechnology. DLS gives the experimental data i.e. size and surface charge of the nanoparticles without much sample preparation and is very user friendly." 


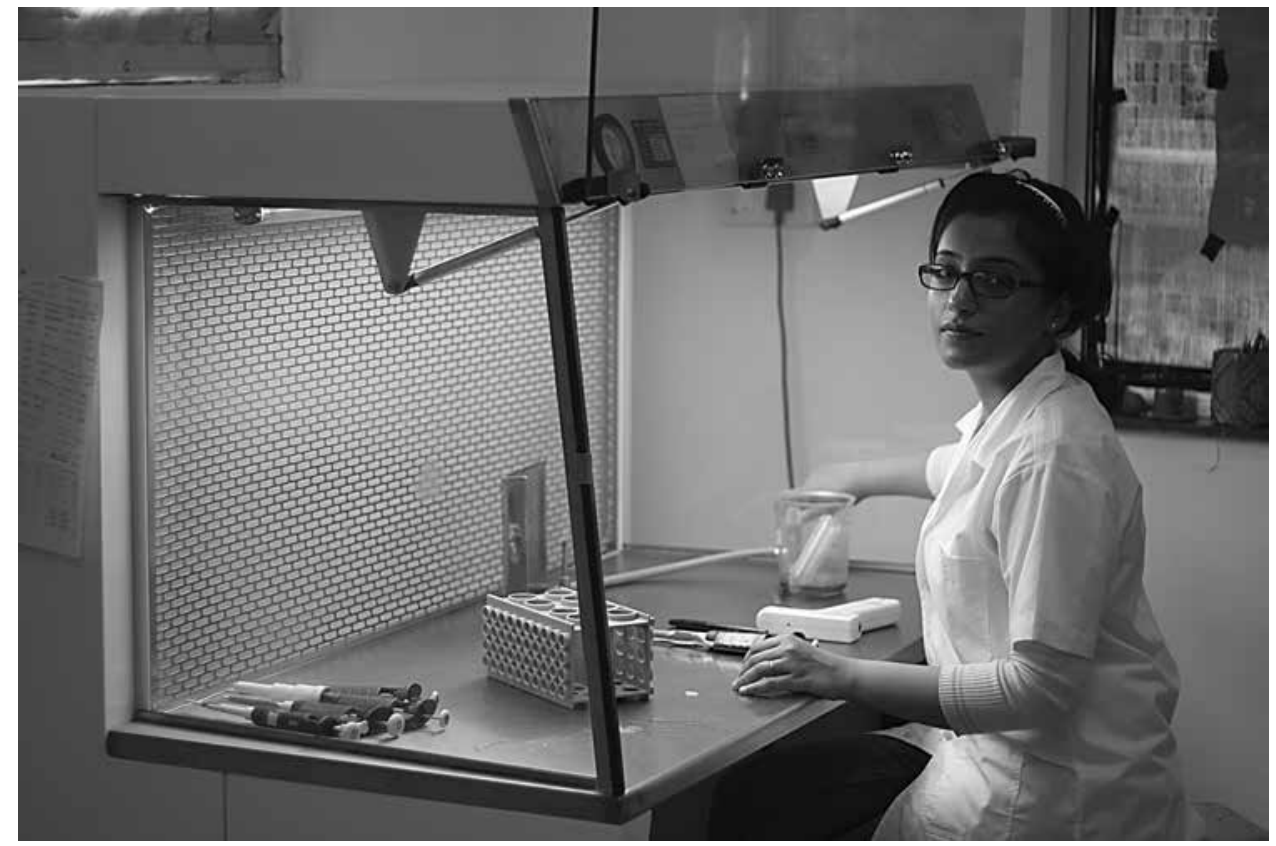

Vaishnavi Kulkarni

"A laminar flow hood is a sterile area where I work with human cancer cells. I give them food (nutrient medium) and shelter (the flasks) and see how they respond to anti-cancer treatments. Without a laminar, cell culture work would be impossible and it is fundamental to my work." 


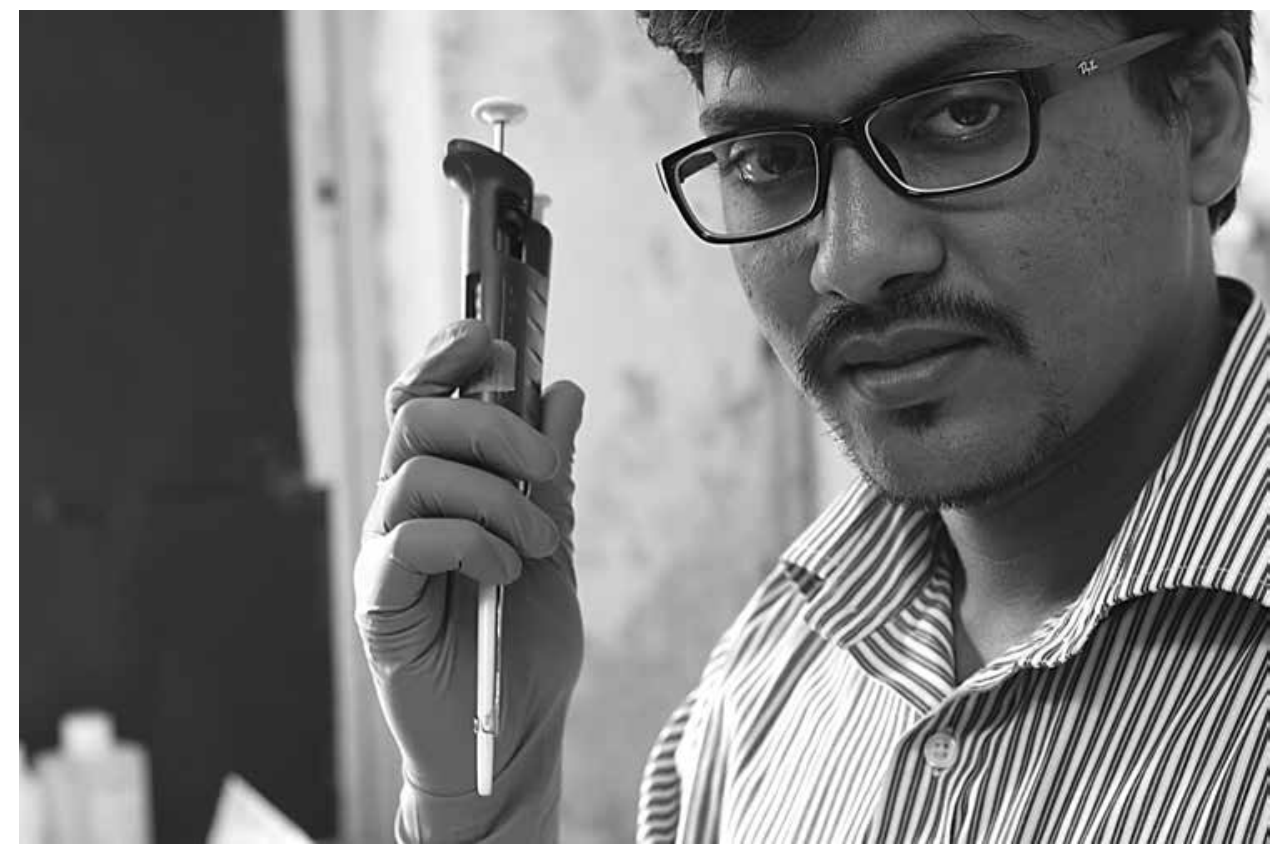

Vivek Kamat

"The reason I like the micropipette is that it is the most basic tool to perform any research work. Measuring definite volumes for any experiment is a key requisite - that is the beauty of this instrument and that is why I like it in first place. It also has a very ergonomic design, and I like to carry it with myself all the time." 


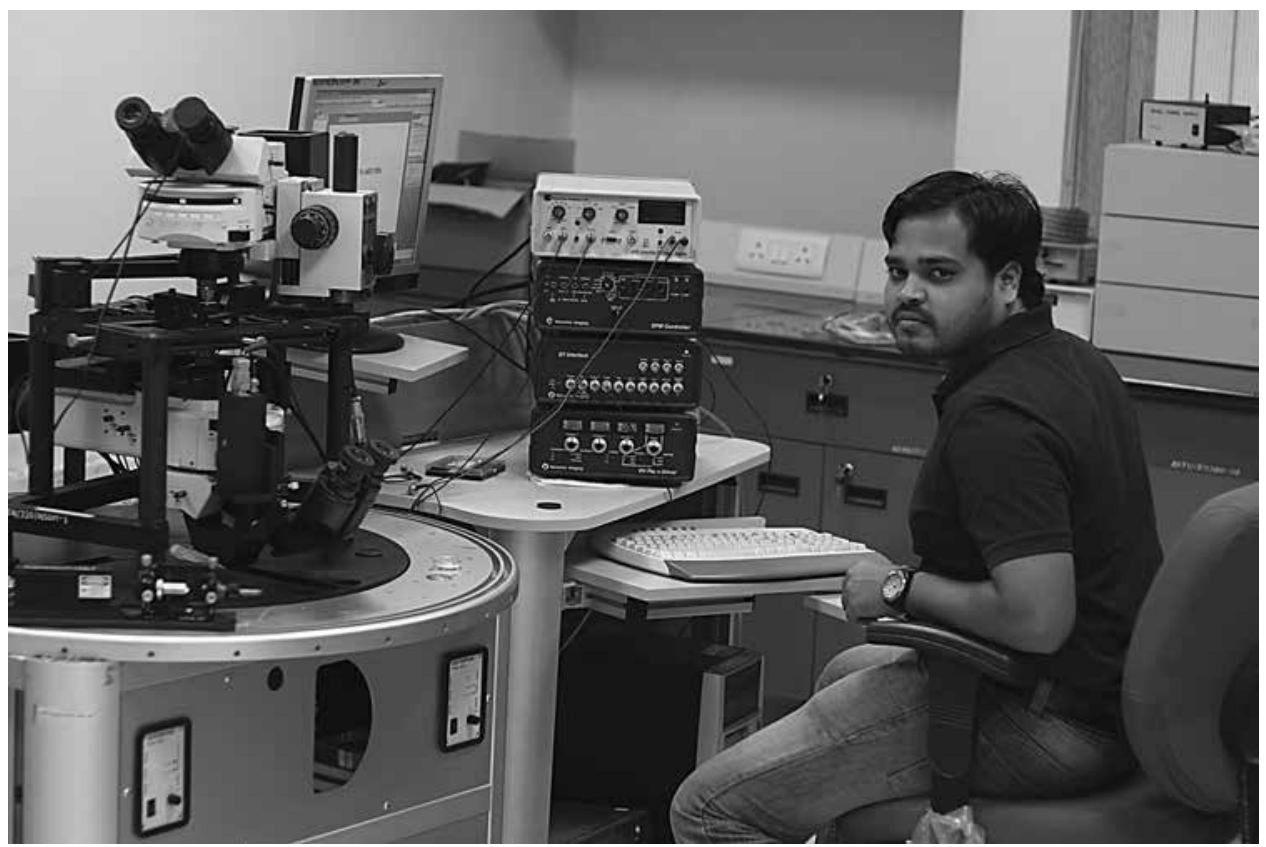

Milind Choudhari

"The atomic force microscope satisfies my curiosity of looking at small things. Its existence, so large yet small, so complex yet simple helps me connect myself with the machine and do amazing imaging." 


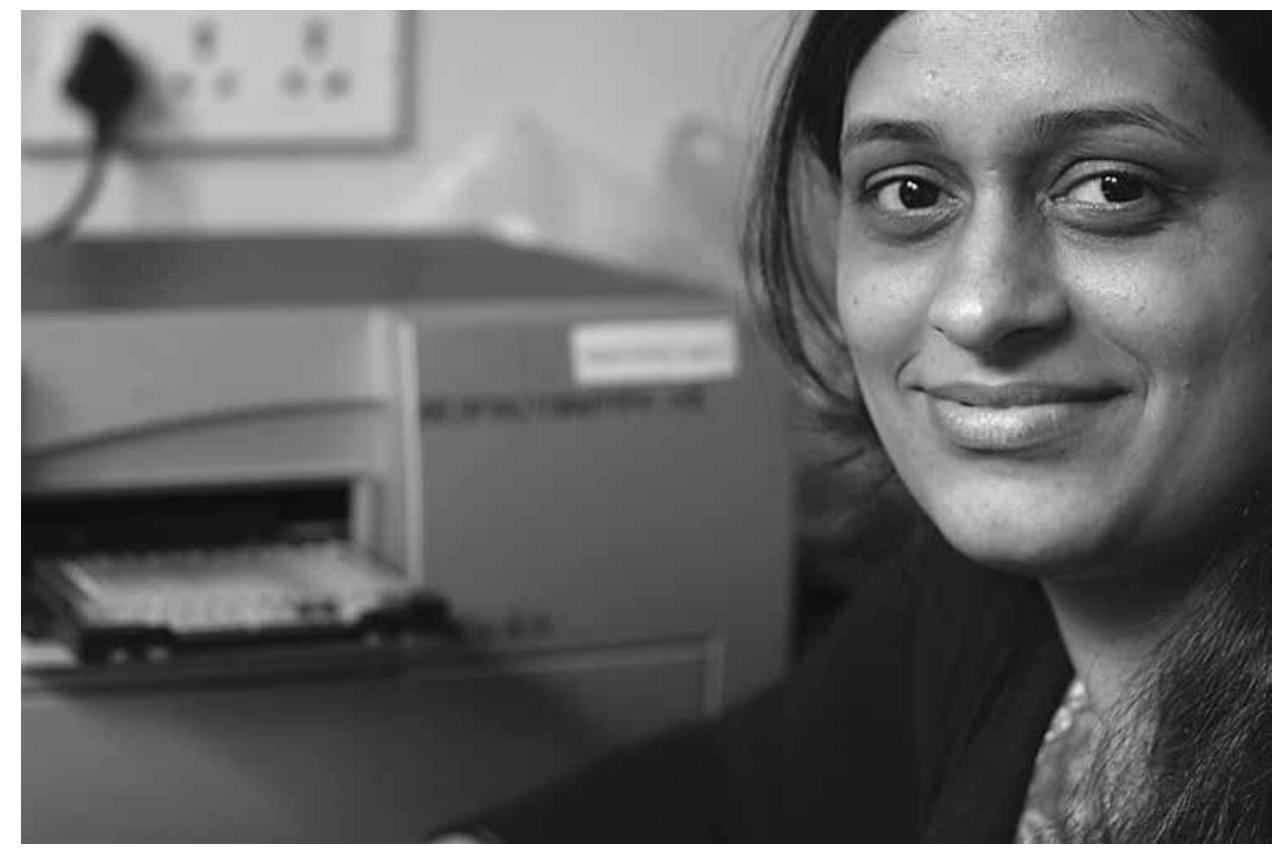

Nimisha Singh

"The Biotek micro plate reader is used for fast processing and when the sample volume required for analysis is very low (200 $\mathrm{uL})$. We can use 96 different samples at a time. It also provides dye reduction or utilization kind of assay based on florescence intensity. Most of the work in my project needs this instrument." 


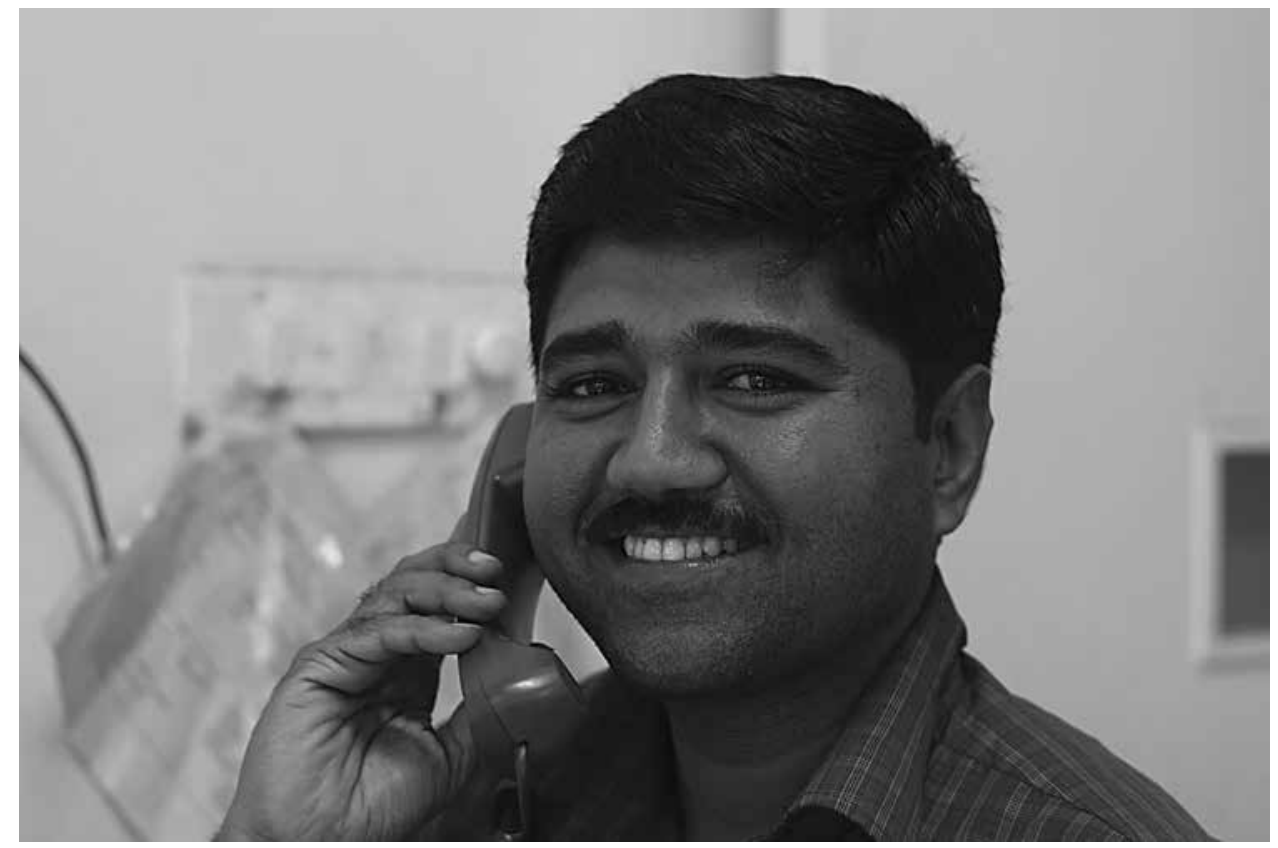

Shailesh Waghmare

"The telephone in hand tells that there is work either in admin, accounts, stores or instrumentation. It can even be calling for outsourcing of different things like glass repair, cash purchase of things, delays in process etc." 


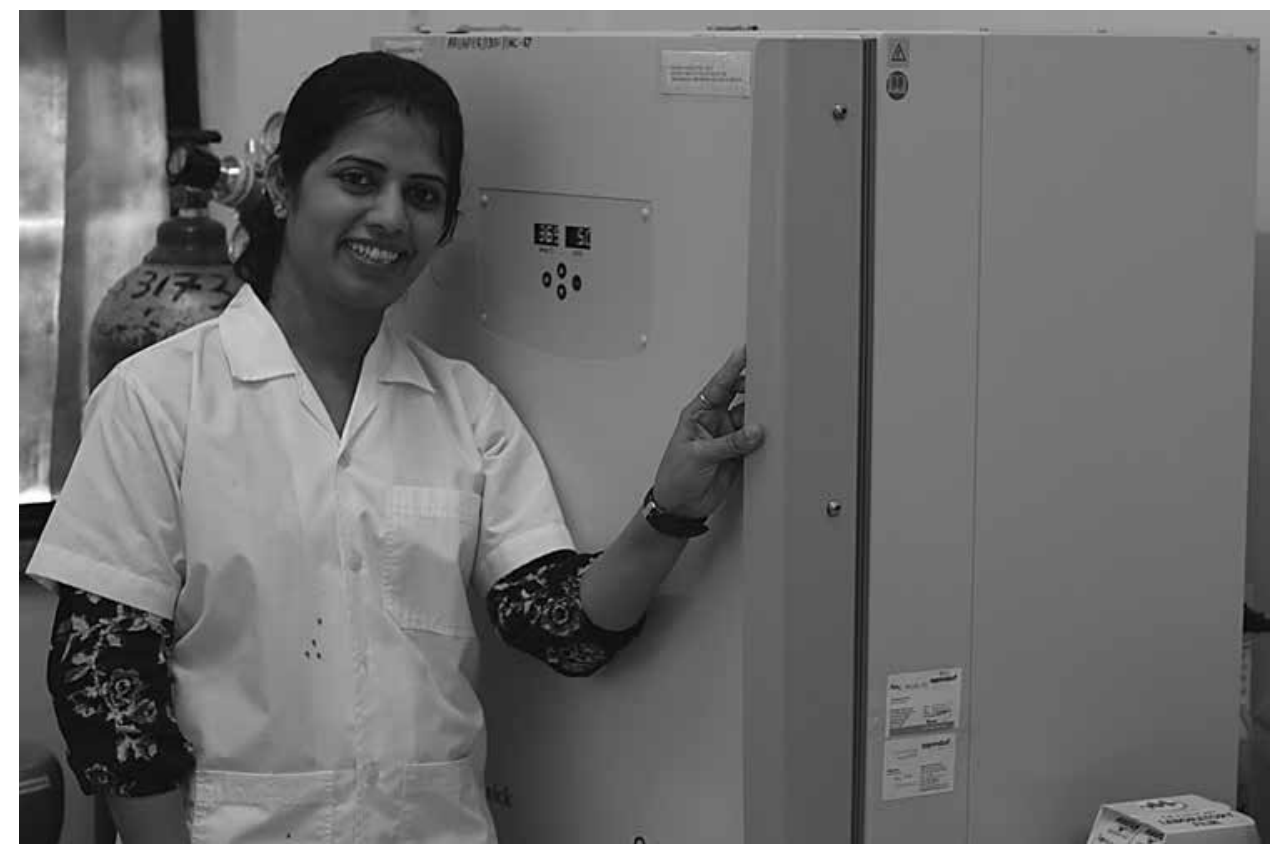

Swati Asani

"In my PhD work the model system I am using is in-vitro cell lines. For growing these cell lines the $\mathrm{CO}_{2}$ incubator is an indispensable instrument as it maintains the optimum environmental conditions such as humidity, temperature and $\mathrm{CO}_{2}$ content. Without this incubator it is impossible to grow the cells and study the further assays." 


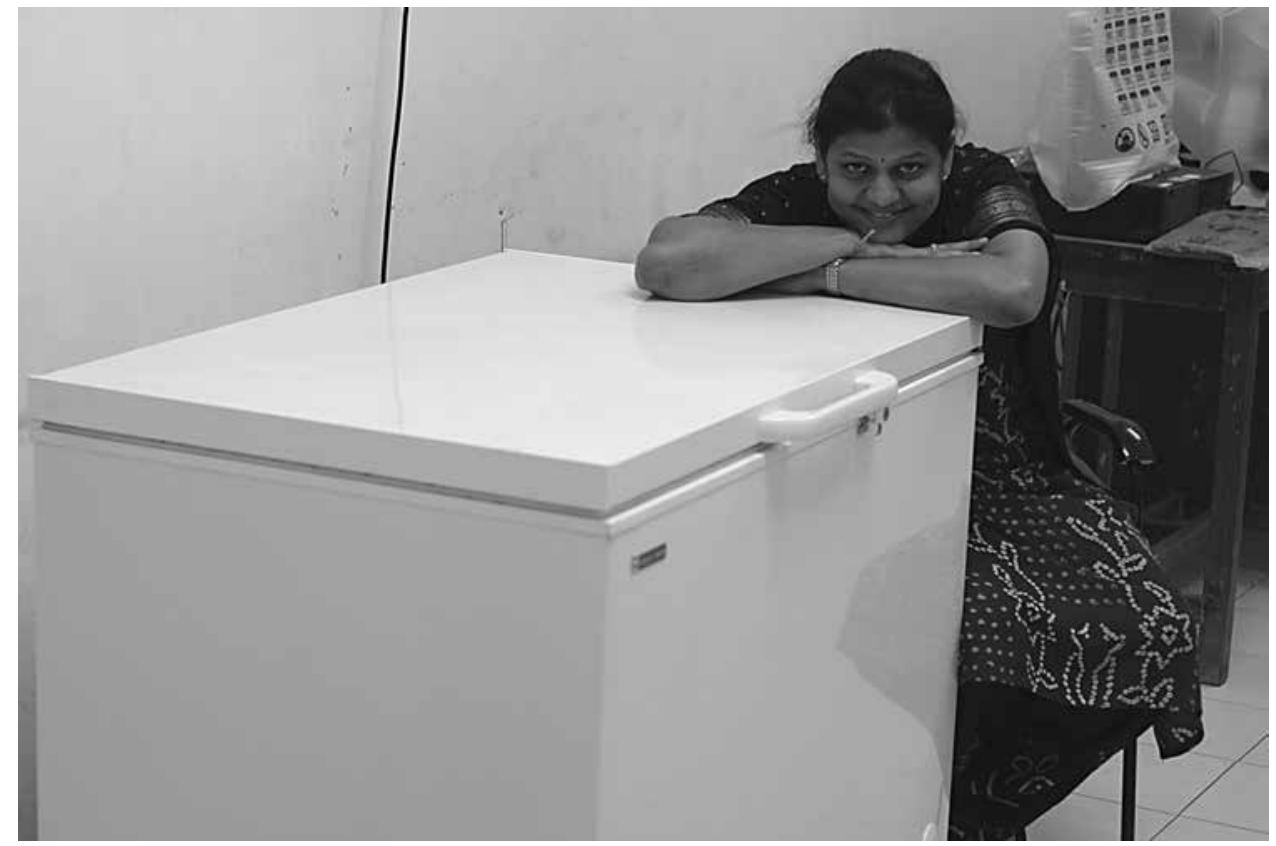

Rinku Umani

"My research work relies heavily on in-vitro testing models viz. cell lines and the deep freezer is where these cell lines are maintained. My costly chemicals and kits require specific storage temperatures, and the deep freezer enables that as well. Without these chemicals, my research would be badly affected." 


\section{B) Details of programmes supported and outputs generated from the DST supported NSTI and Nano Mission programs (2001-2011)}

\begin{tabular}{|c|c|c|c|c|}
\hline Program & Output & & & \\
\hline $\begin{array}{l}\text { Individual } \\
\text { scientist-centric } \\
\text { projects (196 } \\
\text { projects funded } \\
\text { till 2009) }\end{array}$ & $\begin{array}{l}1884 \text { papers; } \\
\text { Impact } \\
\text { factor/paper: } \\
2.1\end{array}$ & 512 PhDs & $\begin{array}{l}626 \mathrm{MSc} / \mathrm{MTech} \text { thesis } \\
1048 \mathrm{BTech} / \mathrm{UG} \\
\text { students trained/212 } \\
\text { technical personnel } \\
\text { trained }\end{array}$ & 7 patents \\
\hline Units/Centres & 2109 papers & $174 \mathrm{PhDs}$ & 775 MTech/MSc theses & 76 patents \\
\hline $\begin{array}{l}\text { Industry- } \\
\text { Academia } \\
\text { collaborations }\end{array}$ & \multicolumn{4}{|c|}{$\begin{array}{l}\text { - Nano fillers for tyre applications; MG University, Kottayam and } \\
\text { Apollo Tyres } \\
\text { - Nanomaterials and photodynamic therapy-IIT Madras with } \\
\text { Carborandum Universal and Orchid Pharma } \\
\text { - Solar Photovoltaics; Amrita and BEL, Bengaluru } \\
\text { - Smart and Interactive Textiles; IIT Delhi, ARCI Hyderabad and } 3 \\
\text { - textile/Auto Filter Companies } \\
\text { - SI tube and Sheet production - Punjab University, Patiala, GGSIP } \\
\text { University, Delhi and Instapower Ltd., Delhi } \\
\text { - Biomedical applications - CCMB Hyderabad and US Ltd., Mumbai }\end{array}$} \\
\hline $\begin{array}{l}\text { MSc/MTech } \\
\text { program }\end{array}$ & $23 \mathrm{MSc}$ & 143 MTechs & $\begin{array}{l}\text { Model syllabus develope } \\
\text { uploaded on the website } \\
\text { use by institutions in the }\end{array}$ & $\begin{array}{l}\text { fand } \\
\text { for possible } \\
\text { country }\end{array}$ \\
\hline $\begin{array}{l}\text { Post doctoral } \\
\text { fellowships }\end{array}$ & \multicolumn{4}{|c|}{$\begin{array}{l}19 \text { PDFs availed the fellowship in various institutions across the } \\
\text { country }\end{array}$} \\
\hline $\begin{array}{l}\text { Advanced } \\
\text { Schools }\end{array}$ & \multicolumn{4}{|c|}{$\begin{array}{l}\text { About } 125 \text { research students trained by leading scientists of the } \\
\text { country }\end{array}$} \\
\hline
\end{tabular}

Source: (Asthana, 2011) 


\section{C) Conferences on Nanoscience and Technology held in India in the year $\mathbf{2 0 1 0}$}

\begin{tabular}{|c|c|c|c|}
\hline No. & Title & Date & Venue \\
\hline 1 & Bio Asia 2010 & Feb 3-6 & $\begin{array}{l}\text { Hyderabad, } \\
\text { India }\end{array}$ \\
\hline 2 & $\begin{array}{l}\text { International Conference on Nanoscience and } \\
\text { Technology (ICONSAT) } 2010\end{array}$ & Feb $17-20$ & Mumbai, India \\
\hline 3 & National Convention of Electrochemists & Feb 18-19 & Vellore, India \\
\hline 4 & $\begin{array}{l}\text { National Seminar on Application of } \\
\text { Nanotechnology in Mechanical Engg }\end{array}$ & Feb $19-20$ & $\begin{array}{l}\text { Ernakulam, } \\
\text { India }\end{array}$ \\
\hline 5 & $\begin{array}{l}\text { International Conference on Advancement in } \\
\text { Polymer Materials (APM - 2010) }\end{array}$ & Feb $20-22$ & $\begin{array}{l}\text { Bhubaneshwar, } \\
\text { India }\end{array}$ \\
\hline 6 & $\begin{array}{l}\text { International Conference on Nanoscience and } \\
\text { Nanotechnology (ICONN 2010) }\end{array}$ & Feb 24-26 & $\begin{array}{l}\text { SRM University, } \\
\text { Chennai, India }\end{array}$ \\
\hline 7 & $\begin{array}{l}\text { Carbon nanotubes and carbon in } \\
\text { Nanotechnology - A short term course }\end{array}$ & Mar 1-5 & Kanpur, India \\
\hline 8 & $\begin{array}{l}\text { International Conference on Characterisation, } \\
\text { Synthesis, Consolidation and Modelling of } \\
\text { Nanomaterials (ICON 2010) }\end{array}$ & Mar 5-6 & $\begin{array}{l}\text { PSG College } \\
\text { of Technology, } \\
\text { Coimbatore, } \\
\text { India }\end{array}$ \\
\hline 9 & $\begin{array}{l}\text { International Conference on Advances in Electron } \\
\text { Microscopy and Related Techniques }\end{array}$ & Mar 8-10 & Mumbai, India \\
\hline 10 & $\begin{array}{l}\text { National Conference on Introduction to } \\
\text { Nanoscience, Nanotechnology and Applications } \\
\text { (INTA2010) }\end{array}$ & Sept 2-3 & $\begin{array}{l}\text { Jawaharlal } \\
\text { Nehru } \\
\text { Technology } \\
\text { Univ of } \\
\text { Hyderabad, } \\
\text { India } \\
\end{array}$ \\
\hline 11 & $\begin{array}{l}\text { International Conference on Novel Applications } \\
\text { of Nanotechnology (Nano T10) }\end{array}$ & $\begin{array}{l}\text { Sept } 29- \\
\text { Oct } 1\end{array}$ & $\begin{array}{l}\text { Arunai Engg } \\
\text { College, } \\
\text { Tiruvanamalai, } \\
\text { Tamil Nadu, } \\
\text { India } \\
\end{array}$ \\
\hline 12 & $\begin{array}{l}\text { International Conference on NANO Technology - } \\
\text { Materials \& Composites for Frontier applications }\end{array}$ & Oct $14-15$ & Pune, India \\
\hline
\end{tabular}




\begin{tabular}{|c|c|c|c|}
\hline No. & Title & Date & Venue \\
\hline 14 & $\begin{array}{l}\text { International Conference on Applications of } \\
\text { Small Angle X-Ray Scattering (SAXS) in the field of } \\
\text { nanoscience and nano Technology }\end{array}$ & Oct 23-24 & Rourkela, India \\
\hline 15 & Nanotech India 2010 & Nov $19-21$ & Cochin, India \\
\hline 16 & 3rd Bengaluru Nano & Dec 8-9 & $\begin{array}{l}\text { Bengaluru, } \\
\text { India }\end{array}$ \\
\hline 17 & $\begin{array}{l}\text { National Symposium on Trends in Nanoscience } \\
\text { and Related Areas }\end{array}$ & Dec 9-10 & Kolkata, India \\
\hline 18 & $\begin{array}{l}\text { International Conference on Nanomaterials and } \\
\text { Nanotechnology }\end{array}$ & Dec 13-16 & $\begin{array}{l}\text { KSR College of } \\
\text { Technology, } \\
\text { Tiruchengode, } \\
\text { Tamil Nadu, } \\
\text { India }\end{array}$ \\
\hline 19 & $\begin{array}{l}\text { International Conference on Carbon } \\
\text { Nanotechnology Potential and Challenges }\end{array}$ & Dec 15-17 & Kanpur, India \\
\hline 20 & $\begin{array}{l}\text { International Conference on Nanoscience, } \\
\text { Nanotechnology and Advanced Materials }\end{array}$ & Dec 17-19 & $\begin{array}{l}\text { Visakhapatnam, } \\
\text { India }\end{array}$ \\
\hline 21 & $\begin{array}{l}\text { International Conference on Quantum Effects in } \\
\text { Solids of Today (I-ConQuEST) }\end{array}$ & Dec 20-23 & $\begin{array}{l}\text { New Delhi, } \\
\text { India }\end{array}$ \\
\hline
\end{tabular}




\section{D) Some of the nano technology-based products commercialized by Indian SMEs/Institutions}

\begin{tabular}{|c|c|c|c|}
\hline No. & Name of the product/technology & Company & $\begin{array}{l}\text { Source of } \\
\text { Technology }\end{array}$ \\
\hline 1 & $\begin{array}{l}\text { Nano-silver suspensions for } \\
\text { antibacterial textiles }\end{array}$ & $\begin{array}{l}\text { Resil Chemicals, } \\
\text { Bengaluru }\end{array}$ & ARCI, Hyderabad \\
\hline 2 & $\begin{array}{l}\text { Nano silver loading on ceramic } \\
\text { water filter candles for disinfection } \\
\text { of drinking water }\end{array}$ & $\begin{array}{l}\text { SBP Technologies, } \\
\text { Hyderabad }\end{array}$ & ARCI, Hyderabad \\
\hline 3 & $\begin{array}{l}\text { Nano-bioceramic for dental, } \\
\text { orthopedic and bone graft } \\
\text { applications }\end{array}$ & $\begin{array}{l}\text { Eucare } \\
\text { Pharmaceuticals, } \\
\text { Chennai }\end{array}$ & $\begin{array}{l}\text { National } \\
\text { Metallurgical } \\
\text { Laboratory (NML), } \\
\text { Jamshedpur }\end{array}$ \\
\hline 4 & $\begin{array}{l}\text { A process for the manufacture of } \\
\text { hydrogel wound dressing }\end{array}$ & $\begin{array}{l}\text { ABS Medicare Pvt. } \\
\text { Ltd., Vadodara }\end{array}$ & $\begin{array}{l}\text { Bhabha Atomic } \\
\text { Research Centre } \\
\text { (BARC), Mumbai }\end{array}$ \\
\hline 5 & $\begin{array}{l}\text { A new process for the preparation } \\
\text { of carbon nano tube-based thrust } \\
\text { pads useful for carbon thrust } \\
\text { bearings }\end{array}$ & $\begin{array}{l}\text { Omkar Engineers, } \\
\text { Rajkot }\end{array}$ & $\begin{array}{l}\text { National Physical } \\
\text { Laboratory (NPL), } \\
\text { New Delhi }\end{array}$ \\
\hline 6 & $\begin{array}{l}\text { Nano silver-based water filter for } \\
\text { the removal of dissolved pesticides } \\
\text { in water }\end{array}$ & $\begin{array}{l}\text { Eureka Forbes Ltd., } \\
\text { Mumbai }\end{array}$ & IIT - Madras \\
\hline 7 & $\begin{array}{l}\text { Nano sensor-based typhoid } \\
\text { detection kit }\end{array}$ & $\begin{array}{l}\text { M/s Cadila Pharma, } \\
\text { Ahmedabad }\end{array}$ & $\begin{array}{l}\text { IISc, Bengaluru and } \\
\text { Defence Research } \\
\text { and Development } \\
\text { Establishment } \\
\text { (DRDE), Gwalior }\end{array}$ \\
\hline 8 & $\begin{array}{l}\text { Nano particles of inorganic } \\
\text { compounds to form non-viral } \\
\text { carriers in drug delivery }\end{array}$ & $\begin{array}{l}\text { American Bioscience } \\
\text { Inc., USA }\end{array}$ & University of Delhi \\
\hline 9 & CNTs-based liquid flow sensors & $\begin{array}{l}\text { Trident Metrologies, } \\
\text { USA }\end{array}$ & IISc, Bengaluru \\
\hline 10 & $\begin{array}{l}\text { Liposomal-based Amphotericin B } \\
\text { formulation }\end{array}$ & $\begin{array}{l}\text { Lifecare Innovations } \\
\text { Pvt. Ltd., Gurgaon }\end{array}$ & $\begin{array}{l}\text { Post Graduate } \\
\text { Institute of Medical } \\
\text { Education and } \\
\text { Research (PGIMER), } \\
\text { Chandigarh }\end{array}$ \\
\hline
\end{tabular}




\begin{tabular}{|c|c|c|c|}
\hline No. & Name of the product/technology & Company & $\begin{array}{l}\text { Source of } \\
\text { Technology }\end{array}$ \\
\hline 11 & $\begin{array}{l}\text { Nano-sized lithium iron phosphate } \\
\text { for making electrode for Li-ion } \\
\text { batteries }\end{array}$ & $\begin{array}{l}\text { United } \\
\text { Nanotechnology } \\
\text { Products, Kolkata }\end{array}$ & $\begin{array}{l}\text { International } \\
\text { Collaboration - NEI } \\
\text { Corporation, USA }\end{array}$ \\
\hline 12 & Carbon Nano Tubes & $\begin{array}{l}\text { Monad Nanotech, } \\
\text { Mumbai }\end{array}$ & $\begin{array}{l}\text { In-house } \\
\text { development }\end{array}$ \\
\hline 13 & $\begin{array}{l}\text { Metal nano gels and palladium } \\
\text { nano particles }\end{array}$ & $\begin{array}{l}\text { Nano cutting Edge } \\
\text { Technologies, } \\
\text { Mumbai }\end{array}$ & ARI, Pune \\
\hline 14 & Bio-nano chip \& DNA-based drugs & $\begin{array}{l}\text { Velbio nanotech, } \\
\text { Bengaluru }\end{array}$ & In-house \\
\hline 15 & $\begin{array}{l}\text { Nano blaster to blast cancer cells in } \\
\text { the human brain }\end{array}$ & CARD, Bengaluru & In-house \\
\hline 16 & $\begin{array}{l}\text { Nano particle loaded drugs for drug } \\
\text { delivery (estrogen therapy) }\end{array}$ & $\begin{array}{l}\text { Bharat Biotech, } \\
\text { Hyderabad }\end{array}$ & $\begin{array}{l}\text { International } \\
\text { Collaboration - } \\
\text { Novvax, USA }\end{array}$ \\
\hline 17 & MEMS & $\begin{array}{l}\text { Crane Software, } \\
\text { Bengaluru }\end{array}$ & In-house \\
\hline 18 & Nanocid & $\begin{array}{l}\text { SSB Technologies, } \\
\text { Mumbai }\end{array}$ & $\begin{array}{l}\text { International } \\
\text { Collaboration - Tide } \\
\text { Waters, Iran }\end{array}$ \\
\hline 19 & $\begin{array}{l}\text { Smart Hydrogel nanoparticles for } \\
\text { drug delivery systems (ophthalmic) }\end{array}$ & $\begin{array}{l}\text { Panacea Biotech, } \\
\text { New Delhi }\end{array}$ & In-house \\
\hline 20 & $\begin{array}{l}\text { Nanotech-based drug delivery } \\
\text { systems }\end{array}$ & $\begin{array}{l}\text { Lifecare Innovations } \\
\text { Pvt. Ltd., Gurgaon }\end{array}$ & University of Delhi \\
\hline 21 & Unstainable textiles & Arrow, Mumbai & IIT-Delhi \\
\hline 22 & $\begin{array}{l}\text { Nano silver and nano gold (powder } \\
\text { and suspensions) }\end{array}$ & $\begin{array}{l}\text { Auto Fiber Craft, } \\
\text { Jamshedpur }\end{array}$ & In-house \\
\hline 23 & Nano silicon, nano alumina binders & Beechems, Kanpur & In-house \\
\hline 24 & $\begin{array}{l}\text { Metal and oxide nanoparticles, } \\
\text { peptides and other bio-chemicals }\end{array}$ & $\begin{array}{l}\text { Nano biochemical, } \\
\text { Belgaum }\end{array}$ & In-house \\
\hline 25 & $\begin{array}{l}\text { Breast cancer nano drug - } \\
\text { Abraxane }\end{array}$ & BIOCON, Bengaluru & $\begin{array}{l}\text { International } \\
\text { Collaboration }\end{array}$ \\
\hline 26 & $\begin{array}{l}\text { Drug delivery systems for cancer } \\
\text { treatment }\end{array}$ & $\begin{array}{l}\text { Dabur Pharma, New } \\
\text { Delhi }\end{array}$ & University of Delhi \\
\hline 27 & $\begin{array}{l}\text { Anti-counterfeiting security } \\
\text { technologies for drugs }\end{array}$ & BILCARE Ltd., Pune & In-house \\
\hline 28 & $\begin{array}{l}\text { Nano silver-based water purifier - } \\
\text { Tata Swach }\end{array}$ & $\begin{array}{l}\text { Tata Chemicals, } \\
\text { Mumbai }\end{array}$ & In-house \\
\hline
\end{tabular}




\begin{tabular}{|c|c|c|c|}
\hline No. & Name of the product/technology & Company & $\begin{array}{l}\text { Source of } \\
\text { Technology }\end{array}$ \\
\hline 29 & Nano-treated anti-microbial textiles & $\begin{array}{l}\text { Raymonds \& Mohan } \\
\text { Clothing, Mumbai }\end{array}$ & $\begin{array}{l}\text { Resil Chemicals, } \\
\text { Bengaluru (based } \\
\text { on ARCI technical } \\
\text { know-how) } \\
\end{array}$ \\
\hline 30 & Nanotechnology into hearing aids & Starkey India, Noida & $\begin{array}{l}\text { International } \\
\text { Collaboration (USA) }\end{array}$ \\
\hline 31 & Nano filtration plant & $\begin{array}{l}\text { Thermax Ltd., } \\
\text { Chennai }\end{array}$ & $\begin{array}{l}\text { International } \\
\text { Collaboration } \\
\text { (Germany) }\end{array}$ \\
\hline 32 & Nano silver coated activated carbon & $\begin{array}{l}\text { Purisys RO } \\
\text { Technology, New } \\
\text { Delhi }\end{array}$ & $\begin{array}{l}\text { International } \\
\text { Collaboration } \\
\text { (Republic of Korea) }\end{array}$ \\
\hline 33 & Metal oxide nano materials & $\begin{array}{l}\text { Bharat Heavy } \\
\text { Electricals Ltd. } \\
\text { (BHEL), Bengaluru }\end{array}$ & In-house \\
\hline 34 & Nano paints & ICAN Nano, Kolkata & In-house \\
\hline 35 & $\begin{array}{l}\text { Multi-wall and single wall carbon } \\
\text { nano tubes }\end{array}$ & $\begin{array}{l}\text { Innovations Unified } \\
\text { Technologies } \\
\text { Mumbai }\end{array}$ & In-house \\
\hline 36 & Nano positioning systems & $\begin{array}{l}\text { Qtech Nanosystems, } \\
\text { Bengaluru }\end{array}$ & $\begin{array}{l}\text { International } \\
\text { collaboration } \\
\text { (Singapore) }\end{array}$ \\
\hline 37 & $\begin{array}{l}\text { Multi-layered nano coating for } \\
\text { cutting tools }\end{array}$ & Nano CET, Mumbai & In-house \\
\hline 38 & Nano fluids & $\begin{array}{l}\text { Tata Steel, } \\
\text { Jamshedpur }\end{array}$ & In-house \\
\hline 39 & $\begin{array}{l}\text { Production of nano-sized stabilized } \\
\text { ZrO2 and nano ceramics sized } \\
\text { white pigments }\end{array}$ & $\begin{array}{l}\text { Raj Purohit Group of } \\
\text { Enterprises, Beawar }\end{array}$ & In-house \\
\hline 40 & $\begin{array}{l}\text { Magnetic nano particle for bio- } \\
\text { separation }\end{array}$ & $\begin{array}{l}\text { IB Scientific, } \\
\text { Mumbai }\end{array}$ & In-house \\
\hline 41 & $\begin{array}{l}\text { Nano fibres and plasma assisted } \\
\text { nano finishing }\end{array}$ & $\begin{array}{l}\text { El Macro India, } \\
\text { Mumbai }\end{array}$ & $\begin{array}{l}\text { International } \\
\text { Collaboration }\end{array}$ \\
\hline 42 & Biosynthesis of gold nano triangles & $\begin{array}{l}\text { Tata Chemicals, } \\
\text { Mumbai }\end{array}$ & In-house \\
\hline 43 & Pt/CNT electro catalysts & $\begin{array}{l}\text { Micro Materials, } \\
\text { Bengaluru }\end{array}$ & In-house \\
\hline 44 & $\begin{array}{l}\text { Synthesis of photoactive nano } \\
\text { titania composition }\end{array}$ & KMML, Kerala & In-house \\
\hline
\end{tabular}




\begin{tabular}{|l|l|l|l|}
\hline No. & Name of the product/technology & Company & $\begin{array}{l}\text { Source of } \\
\text { Technology }\end{array}$ \\
\hline 45 & $\begin{array}{l}\text { Nano emulsions (Injectables- } \\
\text { NDDS) }\end{array}$ & $\begin{array}{l}\text { Bharat Serums \& } \\
\text { Vaccines, Mumbai }\end{array}$ & In-house \\
\hline 46 & Nano particles/ CNTs & Nanoshel, Panchkula & In-house \\
\hline 47 & $\begin{array}{l}\text { Nanotech-based generic version of } \\
\text { breast cancer drug (Abraxane) }\end{array}$ & $\begin{array}{l}\text { NATCO Pharma, } \\
\text { Hyderabad }\end{array}$ & In-house \\
\hline 48 & $\begin{array}{l}\text { Carbon nano tubes/Graphene/ } \\
\text { nano composites }\end{array}$ & $\begin{array}{l}\text { Quantum Material } \\
\text { Pvt. Ltd., Noida }\end{array}$ & In-house \\
\hline 49 & $\begin{array}{l}\text { Carbon nano tubes/ Graphene/ } \\
\text { Inorganic nano materials }\end{array}$ & $\begin{array}{l}\text { Redex Technologies } \\
\text { Pvt. Ltd., Noida }\end{array}$ & In-house \\
\hline 50 & $\begin{array}{l}\text { Nano powders/CNTs } \\
\text { Sisco Research } \\
\text { Laboratories, } \\
\text { Mumbai }\end{array}$ & In-house \\
\hline 51 & $\begin{array}{l}\text { Nano glass } \\
\text { Sa }\end{array}$ & $\begin{array}{l}\text { Saint-Gobain Glass } \\
\text { India Ltd., Mumbai } \\
\text { microwave devices }\end{array}$ & In-house \\
\hline
\end{tabular}

Source: (Purushotham, 2012, pp. 28-29) 


\section{E) List of Interviews}

\begin{tabular}{|c|c|c|c|}
\hline & Name & Institution & Date (Place) \\
\hline 1. & Adholeya, Alok & $\begin{array}{l}\text { The Energy Research Institute, } \\
\text { New Delhi }\end{array}$ & 27 July 2010 (New Delhi) \\
\hline 2. & Agrawal, Shailaja & $\begin{array}{l}\text { Centre for Nanobioscience, } \\
\text { Agharkar Research Institute, } \\
\text { Pune }\end{array}$ & $\begin{array}{l}23 \text { December 2011, } 05 \\
\text { January 2012, } 19 \text { July } \\
2012 \text { (Pune) }\end{array}$ \\
\hline 3. & Ahmed, Farhan & $\begin{array}{l}\text { Department of Biotechnology, } \\
\text { University of Hyderabad, } \\
\text { Hyderabad }\end{array}$ & $\begin{array}{l}23 \text { December } 2010 \\
\text { (Hyderabad) }\end{array}$ \\
\hline 4. & Amrita & $\begin{array}{l}\text { Indian Institute of Technology - } \\
\text { Madras, Chennai }\end{array}$ & 04 July 2012 (Chennai) \\
\hline 5. & Anshup & $\begin{array}{l}\text { Indian Institute of Technology - } \\
\text { Madras, Chennai }\end{array}$ & 05 July 2012 (Chennai) \\
\hline 6. & Asani, Swati & $\begin{array}{l}\text { Centre for Nanobioscience, } \\
\text { Agharkar Research Institute, } \\
\text { Pune }\end{array}$ & 19 April 2011 (Pune) \\
\hline 7. & $\begin{array}{l}\text { Balasubramanian, } \\
\text { D. }\end{array}$ & $\begin{array}{l}\text { L.V. Prasad Eye Institute, } \\
\text { Hyderabad }\end{array}$ & $\begin{array}{l}03 \text { March 2010, } 12 \text { June } \\
\text { 2010, } 17 \text { December } \\
2011 \text { (Hyderabad) }\end{array}$ \\
\hline 8. & Bharath Kumar & $\begin{array}{l}\text { SBP Aqua Tech Pvt. Ltd., } \\
\text { Hyderabad }\end{array}$ & $\begin{array}{l}05 \text { June } 2012 \\
\text { (Hyderabad) }\end{array}$ \\
\hline 9. & Bodas, Dhananjay & $\begin{array}{l}\text { Centre for Nanobioscience, } \\
\text { Agharkar Research Institute, } \\
\text { Pune }\end{array}$ & $\begin{array}{l}07 \text { June 2011, } 21 \\
\text { December 2011, } 20 \text { July } \\
2012 \text { (Pune) }\end{array}$ \\
\hline 10. & Bootharaju & $\begin{array}{l}\text { Indian Institute of Technology } \\
\text { Madras, Chennai }\end{array}$ & 04 July 2012 (Chennai) \\
\hline 11. & Choudhari, Milind & $\begin{array}{l}\text { Centre for Nanobioscience, } \\
\text { Agharkar Research Institute, } \\
\text { Pune }\end{array}$ & 19 April 2011 (Pune) \\
\hline 12. & Deshpande, Paresh & $\begin{array}{l}\text { Centre for Nanobioscience, } \\
\text { Agharkar Research Institute, } \\
\text { Pune }\end{array}$ & 14 June 2011 (Pune) \\
\hline
\end{tabular}




\begin{tabular}{|c|c|c|c|}
\hline & Name & Institution & Date (Place) \\
\hline 13. & $\begin{array}{l}\text { Deshmukh-Kelkar, } \\
\text { Shraddha }\end{array}$ & $\begin{array}{l}\text { Centre for Nanobioscience, } \\
\text { Agharkar Research Institute, } \\
\text { Pune }\end{array}$ & 14 June 2011 (Pune) \\
\hline 14. & Dey, Subhendu & $\begin{array}{l}\text { Formerly, Department of Physics, } \\
\text { University of Pune, Pune }\end{array}$ & 20 July 2011 (Pune) \\
\hline 15. & Dharmadhikari, C.V. & $\begin{array}{l}\text { Department of Physics, } \\
\text { University of Pune, Pune; } \\
\text { Currently, Indian Institute of } \\
\text { Science Education and Research } \\
\text { (IISER), Pune }\end{array}$ & $\begin{array}{l}13 \text { December 2010, } 02 \\
\text { March 2011, } \\
24 \text { April } 2011 \text { (Pune) }\end{array}$ \\
\hline 16. & $\begin{array}{l}\text { Dharmadhikari, } \\
\text { Mona }\end{array}$ & & 25 April 2012 (Pune) \\
\hline 17. & $\begin{array}{l}\text { Ghormade, } \\
\text { Vandana }\end{array}$ & $\begin{array}{l}\text { Centre for Nanobioscience, } \\
\text { Agharkar Research Institute, } \\
\text { Pune }\end{array}$ & $\begin{array}{l}26 \text { December } 2011 \\
\text { (Pune) }\end{array}$ \\
\hline 18. & Gokhale, Satish & Design Directions, Pune & $\begin{array}{l}25 \text { September } 2012 \\
\text { (Pune) }\end{array}$ \\
\hline 19. & Haram, Santosh & $\begin{array}{l}\text { Department of Chemistry, } \\
\text { University of Pune, Pune }\end{array}$ & $\begin{array}{l}14 \text { December } 2010 \\
\text { (Pune) }\end{array}$ \\
\hline 20. & lyyer, S.B. & $\begin{array}{l}\text { Formerly, Department of Physics, } \\
\text { University of Pune, Pune; } \\
\text { Currently, Ahmednagar College, } \\
\text { Ahmednagar }\end{array}$ & 24 October 2011 (Pune) \\
\hline 21. & $\begin{array}{l}\text { Javed Ali, } \\
\text { Mohammed }\end{array}$ & $\begin{array}{l}\text { L.V. Prasad Eye Institute, } \\
\text { Hyderabad }\end{array}$ & $\begin{array}{l}14 \text { August 2010, } 09 \\
\text { September 2010, } \\
\text { (Hyderabad) }\end{array}$ \\
\hline 22. & Joshi, Vrushali & $\begin{array}{l}\text { Department of Chemistry, } \\
\text { University of Pune, Pune }\end{array}$ & $\begin{array}{l}14 \text { December } 2010 \\
\text { (Pune) }\end{array}$ \\
\hline 23. & Kailas, Satish & $\begin{array}{l}\text { Indian Institute of Science, } \\
\text { Bengaluru }\end{array}$ & $\begin{array}{l}01 \text { August } 2012 \\
\text { (Bengaluru) }\end{array}$ \\
\hline 24. & Khetan, Vikas & Sankara Nethralaya, Chennai & 03 July 2012 (Chennai) \\
\hline 25. & $\begin{array}{l}\text { Khetan, Vikas and } \\
\text { team }\end{array}$ & Sankara Nethralaya, Chennai & $\begin{array}{l}17 \text { September } 2012 \\
\text { (Chennai) }\end{array}$ \\
\hline 26. & Kondapi, Anand & $\begin{array}{l}\text { Department of Biotechnology, } \\
\text { University of Hyderabad, } \\
\text { Hyderabad }\end{array}$ & $\begin{array}{l}23 \text { December } 2010 \\
\text { (Hyderabad) }\end{array}$ \\
\hline 27. & $\begin{array}{l}\text { Krishnan, } \\
\text { Rishikesha }\end{array}$ & $\begin{array}{l}\text { Indian Institute of Management } \\
\text { Bengaluru, Bengaluru }\end{array}$ & 06 July 2011 (Bengaluru) \\
\hline 28. & $\begin{array}{l}\text { Kshirsagar, } \\
\text { Rajendra }\end{array}$ & $\begin{array}{l}\text { Formerly Department of Physics, } \\
\text { University of Pune, Pune }\end{array}$ & 21 October 2011 (Pune) \\
\hline
\end{tabular}




\begin{tabular}{|c|c|c|c|}
\hline & Name & Institution & Date (Place) \\
\hline 29. & Kulbhushan, Prabir & $\begin{array}{l}\text { Centre for Nanobioscience, } \\
\text { Agharkar Research Institute, } \\
\text { Pune }\end{array}$ & $\begin{array}{l}18 \text { April 2011, } 03 \\
\text { January } 2012 \text { (Pune) }\end{array}$ \\
\hline 30. & Kulkarni, Prabhakar & $\begin{array}{l}\text { Centre for Nanobioscience, } \\
\text { Agharkar Research Institute, } \\
\text { Pune }\end{array}$ & $\begin{array}{l}13 \text { December } 2010 \\
\text { (Pune) }\end{array}$ \\
\hline 31. & Kulkarni, Vaishnavi & $\begin{array}{l}\text { Centre for Nanobioscience, } \\
\text { Agharkar Research Institute, } \\
\text { Pune }\end{array}$ & $\begin{array}{l}13 \text { July 2011, } 03 \text { January } \\
2012 \text { (Pune) }\end{array}$ \\
\hline 32. & Malik, Nikita & $\begin{array}{l}\text { Centre for Nanobioscience, } \\
\text { Agharkar Research Institute, } \\
\text { Pune }\end{array}$ & 04 January 2012 (Pune) \\
\hline 33. & Mashelkar, R.A. & $\begin{array}{l}\text { National Chemical Laboratory, } \\
\text { Pune }\end{array}$ & 08 June 2011 (Pune) \\
\hline 34. & Morarka, Amit & $\begin{array}{l}\text { Centre for Nanobioscience, } \\
\text { Agharkar Research Institute, } \\
\text { Pune }\end{array}$ & 07 June 2011 (Pune) \\
\hline 35. & Nair, Sreekumaran & $\begin{array}{l}\text { Amrita Centre for Nanosciences } \\
\text { and Molecular Medicine, Kochi }\end{array}$ & $\begin{array}{l}15 \text { September } 2012 \\
\text { (Chennai) }\end{array}$ \\
\hline 36. & $\begin{array}{l}\text { Narayanan } \\
\text { Janakiraman }\end{array}$ & Sankara Nethralaya, Chennai & 02 July 2012 (Chennai) \\
\hline 37. & Nandy, Sabaleel & Tata Chemicals Pvt. Ltd., Mumbai & $\begin{array}{l}08 \text { August } 2012 \\
\text { (Mumbai) }\end{array}$ \\
\hline 38. & Oke, Anuja & $\begin{array}{l}\text { Centre for Nanobioscience, } \\
\text { Agharkar Research Institute, } \\
\text { Pune }\end{array}$ & 05 January 2012 (Pune) \\
\hline 39. & Paknikar, Kishore & $\begin{array}{l}\text { Centre for Nanobioscience, } \\
\text { Agharkar Research Institute, } \\
\text { Pune }\end{array}$ & $\begin{array}{l}13 \text { December } 2010 \\
\text { (Pune) }\end{array}$ \\
\hline 40. & Patil, Shivaprasad & $\begin{array}{l}\text { Formerly Department of Physics, } \\
\text { University of Pune, Pune; } \\
\text { Currently Indian Institute of } \\
\text { Science Education and Research } \\
\text { (IISER), Pune }\end{array}$ & 09 March 2011 (Pune) \\
\hline 41. & Patil, Sumati & $\begin{array}{l}\text { Department of Physics, } \\
\text { University of Pune, Pune }\end{array}$ & 24 October 2011 (Pune) \\
\hline 42. & $\begin{array}{l}\text { Pillai, } \\
\text { Vijaymohanan }\end{array}$ & $\begin{array}{l}\text { Central Electrochemical Research } \\
\text { Institute, Karaikudi }\end{array}$ & 04 April 2012 (Goa) \\
\hline 43. & Pradeep, T. & $\begin{array}{l}\text { Indian Institute of Technology } \\
\text { Madras, Chennai }\end{array}$ & 03 July 2012 (Chennai) \\
\hline
\end{tabular}




\begin{tabular}{|c|c|c|c|}
\hline & Name & Institution & Date (Place) \\
\hline 44. & Prasada Raju, D.R. & $\begin{array}{l}\text { Department of Science and } \\
\text { Technology, Government of } \\
\text { India, New Delhi }\end{array}$ & $\begin{array}{l}09 \text { September, } 2013 \\
\text { (New Delhi) }\end{array}$ \\
\hline 45. & Rajwade, Jyutika & $\begin{array}{l}\text { Centre for Nanobioscience, } \\
\text { Agharkar Research Institute, } \\
\text { Pune }\end{array}$ & 13 June 2011 (Pune) \\
\hline 46. & Rao, C.N.R. & $\begin{array}{l}\text { Jawaharlal Nehru Centre for } \\
\text { Advanced Scientific Research } \\
\text { (JNCASR), Bengaluru }\end{array}$ & $\begin{array}{l}03 \text { August } 2012 \\
\text { (Bengaluru) }\end{array}$ \\
\hline 47. & Rao, Tata Narsing & $\begin{array}{l}\text { Advanced Research Centre for } \\
\text { Powder Metallurgy and New } \\
\text { Materials (ARCI), Hyderabad }\end{array}$ & 05 April 2012 (Goa) \\
\hline 48. & Rao, T.N.V.V. & $\begin{array}{l}\text { Underwriters Laboratories, India, } \\
\text { Bengaluru }\end{array}$ & $\begin{array}{l}15 \text { September } 2012 \\
\text { (Chennai) }\end{array}$ \\
\hline 49. & Rautaray, Deb & $\begin{array}{l}\text { Innovation Centre, Tata } \\
\text { Chemicals Pvt. Ltd., Pune }\end{array}$ & 09 August 2012 (Pune) \\
\hline 50. & Raychaudhuri, Arup & $\begin{array}{l}\text { SN Bose National Centre for } \\
\text { Basic Sciences, Kolkata }\end{array}$ & $\begin{array}{l}22 \text { January } 2012 \\
\text { (Hyderabad) }\end{array}$ \\
\hline 51. & $\begin{array}{l}\text { Reddy, P.J., } \\
\text { Rao, T.N.V.V. }\end{array}$ & & $\begin{array}{l}01 \text { August } 2012 \\
\text { (Bengaluru) }\end{array}$ \\
\hline 52. & Revathi, J. & $\begin{array}{l}\text { Advanced Research Centre for } \\
\text { Powder Metallurgy and New } \\
\text { Materials (ARCI), Hyderabad }\end{array}$ & $\begin{array}{l}04 \text { June } 2012 \\
\text { (Hyderabad) }\end{array}$ \\
\hline 53. & Rohini & $\begin{array}{l}\text { LV Prasad Eye Institute, } \\
\text { Hyderabad }\end{array}$ & $\begin{array}{l}13 \text { September 2010, } \\
23 \text { March } 2012 \\
\text { (Hyderabad) }\end{array}$ \\
\hline 54. & Sahoo, Sanjib & $\begin{array}{l}\text { Institute of Life Sciences, } \\
\text { Bhubaneshwar }\end{array}$ & $\begin{array}{l}05 \text { July } 2011 \\
\text { (Bhubaneshwar) }\end{array}$ \\
\hline 55. & Sarpotdar, Sachin & $\begin{array}{l}\text { Centre for Nanobioscience, } \\
\text { Agharkar Research Institute, } \\
\text { Pune }\end{array}$ & 13 June 2011 (Pune) \\
\hline 56. & Sastry, Murali & $\begin{array}{l}\text { Formerly Tata Chemicals Ltd. } \\
\text { Pune; Currently DSM India, } \\
\text { Gurgaon }\end{array}$ & $\begin{array}{l}14 \text { March } 2012 \\
\text { (Gurgaon), } 24 \text { July } 2012 \\
\text { (Pune) }\end{array}$ \\
\hline 57. & Sengupta, Shoujit & $\begin{array}{l}\text { Indian Institute of Technology } \\
\text { Madras, Chennai }\end{array}$ & 04 July 2012 (Chennai) \\
\hline 58. & Shahapurkar, Gauri & $\begin{array}{l}\text { Centre for Nanobioscience, } \\
\text { Agharkar Research Institute, } \\
\text { Pune }\end{array}$ & $\begin{array}{l}26 \text { December } 2011 \\
\text { (Pune) }\end{array}$ \\
\hline 59. & Shankar, Darshan & A-IIM, Bengaluru & 06 July 2011 (Bengaluru) \\
\hline
\end{tabular}




\begin{tabular}{|c|c|c|c|}
\hline & Name & Institution & Date (Place) \\
\hline 60. & Shetty, Yashas & $\begin{array}{l}\text { Shrishti School of Art, Design and } \\
\text { Technology, Bengaluru }\end{array}$ & 06 July 2011 (Bengaluru) \\
\hline 61. & Singh, Nimisha & $\begin{array}{l}\text { Centre for Nanobioscience, } \\
\text { Agharkar Research Institute, } \\
\text { Pune }\end{array}$ & 14 July 2011 (Pune) \\
\hline 62. & Sinha, Shashank & Eureka Forbes Pvt. Ltd, Mumbai & $\begin{array}{l}08 \text { August } 2012 \\
\text { (Mumbai) }\end{array}$ \\
\hline 63. & Uday Shankar & $\begin{array}{l}\text { Indian Institute of Technology } \\
\text { Madras, Chennai }\end{array}$ & 04 July 2012 (Chennai) \\
\hline 64. & Umrani, Rinku & $\begin{array}{l}\text { Centre for Nanobioscience, } \\
\text { Agharkar Research Institute, } \\
\text { Pune }\end{array}$ & $\begin{array}{l}15 \text { April 2011, } 13 \text { June } \\
2011 \text { (Pune) }\end{array}$ \\
\hline 65. & Verma, Seema & $\begin{array}{l}\text { Indian Institute of Science } \\
\text { Education and Research (IISER), } \\
\text { Pune }\end{array}$ & $\begin{array}{l}11 \text { November } 2010 \\
\text { (Pune) }\end{array}$ \\
\hline 66. & Vijaya Lakshmi, K. & Development Alternatives, Delhi & $\begin{array}{l}10 \text { September } 2013 \\
\text { (New Delhi) }\end{array}$ \\
\hline 67. & $\begin{array}{l}\text { Waghmare, } \\
\text { Shailesh }\end{array}$ & $\begin{array}{l}\text { Centre for Nanobioscience, } \\
\text { Agharkar Research Institute, } \\
\text { Pune }\end{array}$ & 20 April 2011 (Pune) \\
\hline 68. & $\begin{array}{l}\text { Group discussion } \\
\text { involving } 4 \\
\text { researchers }\end{array}$ & $\begin{array}{l}\text { The Energy Research Institute, } \\
\text { New Delhi }\end{array}$ & 26 July 2010 (New Delhi) \\
\hline 69. & NA & $\begin{array}{l}\text { Science and Technology Park, } \\
\text { University of Pune, Pune }\end{array}$ & $\begin{array}{l}05 \text { April 2011, } 08 \text { April } \\
2011 \text { (Pune) }\end{array}$ \\
\hline 70. & $\mathrm{RP}$ & $\begin{array}{l}\text { L.V. Prasad Eye Institute, } \\
\text { Hyderabad }\end{array}$ & $\begin{array}{l}13 \text { September 2010, } \\
17 \text { December } 2011 \\
\text { (Hyderabad) }\end{array}$ \\
\hline 71. & SA & $\begin{array}{l}\text { L.V. Prasad Eye Institute, } \\
\text { Hyderabad }\end{array}$ & $\begin{array}{l}13 \text { September } 2010, \\
20 \text { January, } 2011 \\
\text { (Hyderabad) }\end{array}$ \\
\hline 72. & $\mathrm{X} 1$ & & 02 July 2012 \\
\hline
\end{tabular}




\section{Acknowledgements}

The journey of this thesis would not have been possible without the help, support and good wishes of a number of people and I am extremely grateful to all of them.

I would like to thank, first and foremost, the project team at Maastricht University who have been co-passengers in this journey - Wiebe Bijker, who was as much friend as he was supervisor, and also for being the ideal kite-flier - allowing for carefree flights even as he held me rooted firmly to the ground; Aalok Khandekar for his incisive questions, sharp conceptual clarity and deep engagement that helped crucially in the final structure of the thesis, Ragna Zeiss for her constant interest and support and my fellow doctoral candidates Koen Beumer, Trust Saidi and Charity Urama.

Others at the Faculty of Arts and Social Sciences (FASOS) at Maastricht University whom I had the opportunity to interact with and learn from included Karin Bijsterveld, Geert Somsen, Jo Wachelder and Esha Shah. I would also like to thank the entire class of the CAST Masters of 2011 - Ranjit Singh, Bart Zwegers, Ana Teresa Pires, Aline Reichow, Rick Holsgens, Trust Saidi, Annapurna Mamidipudi, Jeremias Herberg, Charity Urama, Tuur Ghys, Megan Curtis and Brian Keller. The four months I spent with them inside and outside class in 2009 was my first introduction to STS and what it was all about. Special thanks are due to Ranjit Singh and to Samir Passi. They offered me constant and unconditional company whenever I was in Maastricht and I remain eternally grateful for the many meals of rajma-chaval they cooked for me, and the endless conversations I've had with them. Both of whom have now gone on to a doctoral program at Cornell University in the USA and I'm looking forward to meeting them, whenever, because it has been quite a while.

A special thanks also to the Bijker family - Wiebe, Else, Liselotte and in particular, Tonny, for the warmth of their friendship and support whenever I was in Maastricht. It is something I am extremely grateful for and will cherish forever.

Secretarial support at FASOS, particularly from Sabine Kuipers, but also from Lidwien Hollanders was so smooth that it was invisible, the key characteristic, as I've learnt in STS, of good infrastructure - one that is never seen, but crucial for things to keep happening. My heartfelt thanks to the both of them.

Many thanks also to Willem Halfman and Teun Zuiderent-Jerak, the coordinators of the WTMC workshops and summer schools and the many co- 
doctoral candidates I had the opportunity of meeting, talking to and learning from during this period.

In India, of course, the thesis would not have been possible without the openness and interest showed by a host of scientists who agreed willingly to become a subject of my research - Alok Adholeya, Shailaja Agrawal, Farhan Ahmed, Manish Anand, Amrita, Anshup, Swati Asani, D. Balasubramanian, Indrani Barpujari, Bharath Kumar, Dhananjay Bodas, Bootharaju, Milind Choudhari, Paresh Deshpande, Shraddha Deshmukh-Kelkar, Subhendu Dey, CV Dharmadhikari, Mona Dharmadhikari, Vandana Ghormade, Satish Gokhale, Santosh Haram, S.B. Iyyer, M. Javed Ali, Vrushali Joshi, Satish Kailas, Vikas Khetan, Sadhu Kolekar, Anand Kondapi, Rishikesha Krishnan, Rajendra Kshirsagar, Prabir Kulbhushan, Prabhakar Kulkarni, Vaishnavi Kulkarni, Arasu Kumar, Nikita Malik, R.A. Mashelkar, Amit Morarka, Sreekumaran Nair, Narayanan Janakiraman, Sabaleel Nandy, Arun Nigvekar, Anuja Oke, Kishore Paknikar, Shivaprasad Patil, Sumati Patil, Vijaymohanan Pillai, T. Pradeep, D.R. Prasada Raju, Jyutika Rajwade, C.N.R. Rao, Tata Narsing Rao, T.N.V.V. Rao, Pulla Rao, Deb Rautaray, Arup Raychaudhuri, P.J. Reddy, J. Revathi, Rohini, Sagar, Sanjib Sahoo, Shilpanjali Sarma, Joseph Satish, Sachin Sarpotdar, Murali Sastry, M.V. Sastry, Shoujit Sengupta, Gauri Shahapurkar, Darshan Shankar, Yashas Shetty, Nimisha Singh, Shashank Sinha, Nidhi Srivastava, Krishnakumar Subramanian, Shankar Uday, Rinku Umrani, Seema Verma, K. Vijaya Lakshmi and Shailesh Waghmare. In welcoming me into their labs, their research and their lives, they made this research and this thesis possible. It's a huge act of trust and faith and I am deeply indebted to them and to their institutions for this.

Thanks also to my team of supervisors in India, E Hari Babu, Prajit Basu and C Shambu Prasad and the participants in the workshop we organized in Hyderabad in November 2011 as part of the project. Others helped in different ways and this includes Usha Raman, Sasheej Hegde, Manish Anand, Jyoti Bachani, and Madhuvanti Anantharajan.

My special thanks to Annapurna Mamidipudi for conspiring to get me into this $\mathrm{PhD}$ program, for her friendship and the many conversations and insights she has offered over the years.

To my parents and brother Peeyush, for everything all these years, and last but certainly not the least, Latha, without whose willingness, companionship, patience and support, this thesis would have never come to be. There is also little Kabir, five years old now, and a bundle of joy and energy. My most enduring memory of this thesis is related to the many pre-dawn mornings I have spent sitting in bed, working on my computer, Latha and Kabir both fast asleep besides me. There is a certain warmth and comfort in that experience and memory I don't think I can convey in words. It is also the one thing I will miss the most from the six years that have just gone by... 


\section{References}

Abraham, I. (2000). Landscape and postcolonial science. Contributions to Indian Sociology, 34, 163-187.

Abraham, I. (2006). The Contradictory Spaces of Postcolonal Techno-Science. Economic and Political Weekly, (January 21, 2006), 210-217.

Abrol, D (2013). Where is India's Innovation Policy Headed? Social Scientist, 41(3-4), 65-80.

Agrawal, D.S. (2006). Physico-chemical characterization of Swarn bhasma (Gold Ash) and its effect on Matrix metalloproteinase enzymes (MMPs) implicated in rheumatoid arthritis (MD thesis). University of Pune, Pune.

Agrawal, S, Morarka, A, Bodas, D \& Paknikar, KM (2012). Multiplexed Detection of Waterborne Pathogens in Circular Microfluidics. Applied Biochemistry and Biotechnology, 167, 1668-1677.

Agrawal, S., Morarka, A., Paknikar, K.M. \& Bodas, D. (2012). In situ synthesis of $\mathrm{Au}$ nanoparticles in 3D circular microchannels in PDMS using a simple and reliable molding method. Microelectronic Engineering, 90, 104-107.

Aiyar, M.S. (2015). Celebrating diversity. Seminar, (667), 52-56.

Ali, M.J., Reddy, V.A.P., Honavar, S.G. \& Naik, M. (2011). Orbital retinoblastoma: Where do we go from here? . Journal of Cancer Research and Therapeutics, 7(1), 11-14.

Anand, U. (2012). Apex court wants jugaad out, asks states for reports. Retrieved from http://www.indianexpress.com/news/apex-court-wants-jugaad-outasks-states-for-report/988890/

Anderson, R.S. (2011). Nucleus and Nation: Scientists, International Networks, and Power in India (First Indian Edition). Chicago \& New Delhi: The University of Chicago Press \& Supernova Publishers \& Distributors Pvt Ltd.

Anderson, W. (2002). Postcolonial Technoscience. Social Studies of Science, 32(5/6), 643-658.

Anderson, W. \& Adams, V. (2008). Pramoedya's Chickens: Postcolonial Studies of Technoscience. In E.J. Hackett, O. Amsterdamska, M. Lynch \& J. Wajcman (Eds.), The Handbook of Science and Technology Studies (pp. 181-204). Cambridge, Massachusets: The MIT Press.

Anon. (1996). INDO-US Project Title: Scanning Tunneling Microscope.

ARCI (2008). ARCI Annual Report 2007-08. Hyderabad: International Advanced Research Centre for Power Mettalurgy and New Materials. 
ARI (2013). Agharkar Research Institute. Retrieved from http://www.aripune. org/

Asthana, P. (2011, June). Nano Research In India - Some Encouraging Trends. Nano Digest, 50, 50.

Ayers, D. \& Nasti, A. (2012). Utilisation of Nanoparticle Technology in Cancer Chemoresistance. Journal of Drug Delivery, 2012. doi:10.1155/2012/265691

Baird, D. (2004a). Navigating Nano through Society. University of South Carolina.

Baird, D. (2004b). Thing Knowledge: A Philosophy of Scientific Instruments. Berkeley: University of California Press.

Bakhshi, S., Gupta, S., Gogia, V. \& Ravindranath, Y. (2010). Compliance in Retinoblastoma. Indian Journal of Pediatrics, 77(5), 535-540.

Balakrishnan, P. (Ed.). (2011). Economic Reforms \& Growth in India - Essays from the Economic and Political Weekly. Hyderabad: Orient BlackSwan.

Balaram, P. (1999). Sanctions. Current Science, 76(9), 1171.

Balaram, P. (2012a). Innocence and Sophistication: Users and Equipment. Current Science, 102(9), 1241-1242.

Balaram, P. (2012b). Tools as Drivers of Science. Current Science, 103(12), 13831384.

Banerjee, M. (2009). Power, Knowledge, Medicine - Ayurvedic Pharmaceuticals at Home and in the World. New Perspectives in South Asian History. Hyderabad: Orient Blackswan Pvt. Ltd.

Banerjee, P. (Ed.). (2009). India Science and Technology 2008: Summary. New Delhi: National Institute of Science, Technology and Development Studies (NISTADS), CSIR.

Barker, T., Lesnick, M., Mealey, T., Raimond, R., Walker, S., Rejeski, D. \& Timberlake, L. (2005). Nanotechnology and the Poor: Opportunities and Risks. Washington D.C.: Maidian Institute.

Bendre, S. (1987). Design of Micromanipulator for STM (MSc thesis). Department of Physics. University of Pune, Pune.

Bendre, S. \& Dharmadhikari, C.V. (1988). Design, Construction and Calibration of a PZT Micromanipulator for Scanning Tunneling Microscope (STM). Journal of Optics, 17(July-Sept 1988), 67-70.

Beumer, K. \& Bhattacharya, S. (2013). Emerging technologies in India: Developments, debates and silences about nanotechnology. Science and Public Policy, 40, 628-643.

Bhakta, J. \& Munekage, Y. (2009). Ceramic as a Potential Tool for Water Reclamation: A Concise Review. Journal of Environmental Protection Science, 3, 147-162.

Bhattacharji, S. (2010). Working the Contradictions - Three Decades. In A. Zachariah, R. Srivatsan, \& S. Tharu (Eds.), Towards a Critical Medical 
Practice - Reflections on the Dilemmas of Medical Culture Today (pp. 97-108). Hyderabad: Orient Blackswan Pvt. Ltd.

Bhattacharya, S., Pushkaran, J.A., Shilpa \& Bhati, M. (2012). Knowledge Creation and Innovation in Nanotechnology: Contemporary and Emerging Scenario in India. New Delhi: CSIR-National Institute of Science, Technology and Development Studies (NISTADS).

Bhattacharya, S., Shilpa \& Pushkaran, J.A. (2012). Nanotechnology Research and Innovation in India: Drawing Insights from Bibliometric and Innovation Indicators. CSIR-NISTADS Policy Brief - II, July 2012. New Delhi: CSIRNational Institute of Science Technology and Development Studies.

Bijker, W.E. (1987). The Social Construction of Bakelite: Toward a Theory of Invention. In W.E. Bijker, T.P. Hughes \& T. Pinch (Eds.), The Social Construction of Technological Systems (pp. 159-187). Cambridge: MIT Press.

Bijker, W.E. (1995a). Democratisering van de Technologische Cultuur (Inaugurele Rede). Maastricht: Universiteit Maastricht.

Bijker, W.E. (1995b). Of bicycles, bakelites, and bulbs: toward a theory of sociotechnical change. Inside technology. Cambridge, Mass.: MIT Press.

Bijker, W.E. (2006). The Vulnerability of Technological Culture. In H Nowotny (Ed.), Cultures of Technology and the Quest for Innovation (pp. 52-69). New York: Berghahn Books.

Bijker, W.E., Hughes, T.P. \& Pinch, T. (Eds.). (1987). The Social Construction of Technological Systems. New Directions in the Sociology and History of Technology. Cambridge, Mass.: The MIT Press.

Bijker, W.E. \& Law, J. (Eds.). (1992). Shaping Technology/Building Society. Studies in Sociotechnical Change. Cambridge, MA: MIT Press.

Bijsterveld, K. (Ed.). (2010). Science and Technology Studies at Maastricht University - An Anthology of Inaugural Lectures. Maastricht: Maastricht University.

Binnig, G. \& Roehrer, H. (1986). Scanning Tunneling Microscopy - From Birth to Adolescence. Nobel Lecture.

Birtchnell, T. (2011). Jugaad as systemic risk and disruptive innovation in India. Contemporary South Asia, 19(4), 357-372.

Bonner, A. (1990). Averting the Apocalypse: Social Movements in India Today. Duke University Press. Retrieved from http://books.google.co.in/ books?id=uxJlAgRemHgC\&dq='temples+or+tombs+dams\&source=gbs_ navlinks_s

Bound, K. \& Thornton, I. (2012). Our Frugal Future: Lessons from India's Innovation System. London: Nesta.

Bowker, G. (1987). A Well Ordered Reality: Aspects of the Development of Schlumberger, 1920-39. Social Studies of Science, 17, 611-655. 
Bowker, G. (1992). What's in a Patent? In W.E. Bijker \& J. Law (Eds.), Shaping Technology/Building Society: Studies in Sociotechnical Change (pp. 53-74). Cambridge, Massachusets: The MIT Press.

Braczyk, H.-J., Cooke, P. \& Heidenreich, M. (1998). Regional Innovation Systems: The Role of Governance in a Globalized World. London: Routledge.

Brown, C.L., Bushell, G., Whitehouse, M.W., Agrawal, D.S., Tupe, S.G., Paknikar, K.M. \& Tiekink, E. (2007). Nanogold-pharmaceutics. Gold Bulletin, 40(3), 245-250.

Burri, R.V. \& Dumit, J. (2008). Social Studies of Scientific Imaging and Visualization. In E.J. Hackett, O. Amsterdamska, M. Lynch, \& J. Wajcamn (Eds.), The Handbook of Science and Technology Studies (pp. 298-317). Cambridge, Massachusets: The MIT Press.

Callon, M. (1987). Society in the Making: The Study of Technology as a Tool for Sociological Analysis. In W.E. Bijker, T.P. Hughes \& T. Pinch (Eds.), The Social Construction of Technological Systems. New Directions in the Sociology and History of Technology (pp. 83-103). Cambridge, MA: The MIT Press.

Cappelli, P., Singh, H., Singh, J. \& Useem, M. (2011). The India Way - How India's Top Business Leaders are Revolutionizing Management. Boston, Massachusets: Harvard Business Press.

Casper, M.J. \& Clarke, A.E. (1998). Making the Pap Smear into the "Right Tool" for the Job: Cervical cancer Screening in the USA, circa 1940-95. Social Studies of Science, 28(2), 255-290.

Chacko, P., Noronha, C. \& Agrawal, S. (2010). Small Wonder - the wonder of the nano. Chennai: Westland Ltd.

Chaki, N.K., Singh, P., Dharmadhikari, C.V. \& Vijayamohanan, K.P. (2004). Single-Electron Charging Features of Larger, Dodecanethiol-Protected Gold Nanoclusters: Electrochemical and Scanning Tunneling Microscopy Studies. Langmuir, 20(23), 10208-10217.

Chakrabarti, P (2004). Western Science in Modern India: Metropolitan methods, Colonial practices. Ranikhet: Permanent Black.

Chaudhary, M.V. (2011). Scanning Probe Microscopic investigations of metallic nanostructures: Electron Transport, Charge Storage and related processes (PhD thesis). Department of Physics. University of Pune, Pune.

Chaudhary, M.V. (2002). Development of Dynamic Michelson Interferometry for the Callibration of intertial translator (MPhil thesis). Department of Physics. University of Pune, Pune.

Choudhari, M.K. (2010). A method and kit for rapid recovery, identification and antimicrobial susceptibility of microorganisms. (IP Office, Ed.). India Patent Office; Application No. 3229/MUM/2010.

Choudhari, M.K., Punekar, S.A., Ranade, R.V. \& Paknikar, K.M. (2012). Antimicrobial activity of stingless bee (Trigona sp.) propolis used 
in the folk medicine of Western Maharashtra, India. Journal of Ethnopharmacology, 141, 363-367.

Christensen, C.M. (1997). The Innovator's Dilemma - When New Technologies

Cause Great Firms to Fail. Boston, Massachusets: Harvard Business Review Press.

Cientifica (2011). Global Funding of Nanotechnologies and Its Impact. London, UK.

Clarke, A. (1998). Disciplining Reproduction: Modernity, American Life and "The Problem of Sex". University of Chicago Press.

Clarke, A.E. (2010). In Memorium: Susan Leigh Star. Science Technology \& Human Values, 35(5), 581-600.

Clasen, T., McLaughlin, C., Nayaar, N., Boisson, S., Gupta, R., Desai, D. \& Shah, N. (2008). Microbiological Effectiveness and Cost of Disinfecting Water by Boiling in Semi-urban India. American Journal of Tropical Medicine and Hygiene, 79(3), 407-413.

CNB (2013). Centre for Nanobioscience. Retrieved from http://www.aripune.org/ index.php/centre-for-nanobioscience/

Cockburn, C. \& Ormrod, S. (1993). Gender \& Technology in the Making. London: SAGE Publications.

Collins, H.M. (1981). The Place of Core-Set in Modern Science: Social Contingency with Methodological Propriety in Science. History of Science, 19, 6-19.

Collins, H.M. (1985). Changing Order: Replication and Induction in Scientific Practice. London: Sage.

Collins, H.M. (1987). Expert Systems and the Science of Knowledge. In W.E. Bijker, T.P. Hughes \& T. Pinch (Eds.), The Social Construction of Technological Systems. New Directions in the Sociology and History of Technology (pp. 329-348). Cambridge: MIT Press.

Collins, H.M. (1990). Artificial Experts: Social Knowledge and Intelligent Machines. Cambridge MA: MIT Press.

Colton, R. (2005). Letter of Recommendation.

Constant, E.W. (1987). The Social Locus of Technological Practice: Community, System, or Organisation? In W.E. Bijker, T.P. Hughes \& T. Pinch (Eds.), The Social Construction of Technological Systems. New Directions in the Sociology and History of Technology (pp. 223-242). Cambridge: MIT Press.

Cooke, P. \& Gomez-Uranga, M. (1997). Regional innovation systems: institutional and organisational dimensions. Research Policy, 26(4/5), 475-491.

Cowan, R.S. (1987). The Consumption Junction: A Proposal for Research Strategies in the Sociology of Technology. In W.E. Bijker, T.P. Hughes \& T. Pinch (Eds.), The Social Construction of Technological Systems. New Directions in the Sociology and History of Technology (pp. 261-280). Cambridge: MIT Press. 
D’Monte, D. (1985). Temples or Tombs? Industry versus Environment: Three Controversies. Delhi: Centre for Science and Environment.

D’Souza, R. (Ed.). (2012a). Environment, Technology and Development. Hyderabad: Orient BlackSwan.

D’Souza, R. (2012b). Introduction. In R. D’Souza (Ed.), Environment, Technology and Development - Critical and Subversive Essays (pp. 1-16). Hyderabad: Orient BlackSwan.

Dagnino, R., Brandao, F.C. \& Novaes, H.T. (2004). Sobre o macro analiticoconceitual da technologia social. In A.D. Paolo, C.J. Mello, L.P.dN. Filho \& T. Koracakis (Eds.), Technologia social: umaestrategia para o desenvolvimento. Rio de Janeiro: Fundacao Banco do Brasil.

Dambe, A.T. (1995). Development and Application of Electronic System for Scanning Tunneling Microscopy (MPhil thesis). Department of Physics. University of Pune, Pune.

Datar, S. (2004). Some Aspects of Investigation of Nanostructures using Scanning Tunneling Microscopy (STM)/Atomic Force Microscopy (AFM) and Related Techniques (PhD Thesis). Department of Physics. University of Pune, Pune.

Datar, S., Patil, S., Iyyer, S. \& Dharmadhikari, C.V. (2004). Scanning Force Microscopy and amplitude versus distance measurements on singlecrystal oxide surfaces. Surface and Interface Analysis, 36, 213-219.

Datta, P. (2010). A Case Study Special on Innovation - Making Aspirations Count (Editorial). In P. Datta (Ed.), (p. 4). New Delhi: BusinessWorld.

Datta, S. (2013). "Development" Theologists, Temples and Tombs. DNA. 13 October. Retrieved from http://www.dnaindia.com/analysis/standpointdevelopment-theologists-temples-and-tombs-1903122

DBT (2008). Annual Report 2007-08. New Delhi: Dept. of Biotechnology, GoI.

Deloitte (2012). Indian Higher Education Section - Opportunities aplenty, growth unlimited. Retrieved from https://www2.deloitte.com/content/dam/ Deloitte/in/Documents/IMO/in-imo-indian-higher_education_sectornoexp.pdf

Denning, P.J. (2004). The Social Life of Innovation. Communications of the ACM, 47(4), 15-19.

Dey, S. (2010). Design and Development of Photo Emitting STM to study the optical properties of individual nanostructures (PhD thesis). Department of Physics. University of Pune, Pune.

Dey, S., Pethkar, S., Adyanthaya, S.D., Sastry, M. \& Dharmadhikari, C.V. (2008). New Approach towards imaging $\lambda$-DNA using scanning tunneling microscopy/spectroscopy (STM/STS). Bulletin of Material Science, 31(3), 309-312.

Dharmadhikari, C.V. \& Gomer, R. (1984). Diffusion of Hydrogen and Deuterium on the (111) Plane of Tungsten. Surface Science, 143, 223-242. 
Dogra, B. (1997). Burden of Dowry System. Economic and Political Weekly, XXXII(44), 2855.

Doing, P. (2008). Give Me a Laboratory and I Will Raise a Discipline: The Past, Present, and Future Politics of Laboratory Studies in STS. In E.J. Hackett, O. Amsterdamska, M. Lynch \& J. Wajcamn (Eds.), The Handbook of Science and Technology Studies (pp. 279-295). Cambridge, Massachusets: The MIT Press.

Douglas, M. (1966). Purity and Danger: An analysis of Concept of Pollution and Taboo. Abingdon.

DST (2001). Annual Report 2001-02. New Delhi; Department of Science \& Technology.

DST (2007). Report of the Working Group on DST - Eleventh Five Year Plan 2007-12. New Delhi: Ministry of Science \& Technology.

DST (2008). Annual Report 2007-08. New Delhi; Department of Science \& Technology.

DST (2011). Annual Report 2010-11. New Delhi; Department of Science \& Technology.

DST (2012). Department of Science \& Technology - Annual Report 2011-12.

New Delhi: Ministry of Science \& Technology.

Eigler, D.M. \& Schweizer, E.K. (1990). Positioning single atoms with a scanning tunneling microscope. Nature, 344, 534-526.

ETC (2008). Downsizing Development - An introduction to Nano-Scale Technologies and the Implications for the Global South. UNCTAD/NGLS/2008/1.

Fagerberg, J., Fosaas, M. \& Sapprasert, K. (2012). Innovation: Exploring the knowledge base. Research Policy, 41, 1132-1153.

Fernandes, W. (2008). Paying the price for someone else's displacement. Retrieved July 21, 2015, from http://infochangeindia.org/agenda/migration-adisplacement/paying-the-price-for-someone-elses-displacement.html

Finlay, L. (2002a). Negotiating the swamp: the opportunity and challenge of reflexivity in research practice. Qualitative Research, 2(2), 209-230. doi:10.1177/146879410200200205

Finlay, L. (2002b). "'Outing' the Researcher: The Provenance, Principles and Practice of Reflexivity." Qualitative Health Research, 12(4), 531-45.

Fischer, M.M.J. (2007). Culture and Cultural Analysis as experimental systems. Cultural Anthropology, 22(1), 1-65.

Fonseca, P.F.C. \& Pereira, T. (2013). Emerging Responsibilities: Brazilian Nanoscientists' Conceptions of Responsible Governance and Social Technology Practices. In K. Konrad, C. Coenen, A. Dijkstra, C. Milburn \& H. van Lente (Eds.), Shaping Emerging Technologies: Governance, Innovation, Discourse (pp. 49-65). Amsterdam: IOS Press and AKA, Berlin. 
Fortun, K. (2001). Advocacy after Bhopal : environmentalism, disaster, new global orders. Chicago, IL: University of Chicago Press.

Fortun, K. (2003). Ethnography In/Of/As Open Systems. Reviews in Anthropology, $32,171-190$.

Freeman, C. (1987). Technology Policy and Economic Performance. Lessons from Japan. London: Pinter.

Fressoli, M., Arond, E., Abrol, D., Smith, A., Ely, A. \& Dias, R. (2014). When grassroots innovation movements encounter mainstream institutions: implications for models of inclusive innovation. Innovation and Development, 4(2), 277-292.

Fujimura, J.H. (1987). Constructing "Do-Able" Problems in Cancer Research: Articulating Alignment. Social Studies of Science, 17, 257-293.

Gadagkar, R. (2015). Solve local problems. Nature, 521, 153.

Gandapu, U., Chaitanya, R.K., Kishore, G., Reddy, R.C. \& Kondapi, A.K. (2011). Curcumin-Loaded Apotransferrin Nanoparticles Provide Efficient Cellular Uptake and Effectively Inhibit HIV-1 Replication In Vitro. PLoS One, (8).

Ganesh, K.N. (2015). Connect research with education. Nature, 521, 154.

Garcia, R. \& Calantone, R. (2002). A critical look at technological innovation typology and innovativeness terminology: a literature review. The Journal of Product Innovation Management, 19, 110-132.

Geertz, C. (1973). The Interpretation of Cultures. New York: Basic Books.

Geertz, C. (1976). From the native's point of view: On the nature of anthropological understanding. In Ke Basso \& H.A. Selby (Eds.), Meaning in Anthroplogy. Albuquerque, NM.: University of New Mexico Press.

Gibbons, M., Limoges, C., Nowotny, H., Schwartzman, S., Scott, P. \& Trow, M. (1994). The new production of knowledge: the dynamics of science and research in contemporary societies. London: Sage.

Giridharadas, A. (2010). A Winning Formula for Hard Economic Times. The New York Times. New York.

Glass, A.J. \& Saggi, K. (1998). International technology transfer and technology gap. Journal of Development Economics, 55, 369-398.

Godbole, V.P., Sumant, A.V., Kshirsagar, R.B. \& Dharmadhikari, C.V. (1997). Evidence for layered growth of (100) textured diamond films. Applied Physics Letters, 71(18), 2626-2628.

GoI (1958). Scientific Policy Resolution. New Delhi: Govt. of India.

GoI (1998). 9th Five Year Plan 1998-2002. New Delhi: Planning Commission,

Government of India.

GoI (2002). 10th Five Year Plan 2002-2007. New Delhi: Planning Commission,

Government of India.

GoI (2003). Science and Technology Policy. New Delhi: Govt. of India. 
GoI (2007). 11th Five Year Plan 2007-2012. New Delhi: Planning Commission, Government of India.

Govindarajan, V. \& Trimble, C. (2012). Reverse Innovation: Create Far from Home, Win Everywhere. Massachusets: Harvard Business Review Press.

Gregson, N. \& Crang, M. (2010). Materiality and waste: inorganic vitality in a networked world. Environment and Planning, 42(5), 1026-1032.

GTZ (2000). Ecosan-Closing the loop in wastewater management and sanitation.

In Werner, J. Schlick, G. Witte \& A. Hilderbrandt (Eds.), Ecosan-Closing the loop in wastewater management and sanitation (p. 327). Bonn, Germany: GTZ GmbH.

Guillemin, M. \& Gillam, L. (2004). Ethics, Reflexivity, and "Ethically Important Moments" in Research. Qualitative Inquiry, 10(2), 261-280.

Gupta, A. (1998). Postcolonial Developments: Agriculture in the making of modern India. Durham and London: Duke University Press.

Gupta, A. (2006). From Sink To Source: The Honey Bee Network Documents Indigenous Knowledge and Innovations in India. Innovations, Summer, 49-66.

Gupta, A. (2013a). Tapping the Entrepreneurial Potential of Grassroots Innovation. Supplement to the Stanford Social Innovation Review, 18-20.

Gupta, A. (2013b, July 1). The grassroots innovators. Mint.

Gupta, A., Sinha, R., Koradia, D., Patel, R., Patel, M., Rohit, P. \& Vivekanandan, P. (2003). Mobilizing grassroots' technological innovations and traditional knowledge, values and institutions: articulating social and ethical capital. Futures, 35, 975-987.

Habib, S.I. \& Raina, D. (2007a). Copernicus, Columbus, Colonialism, and the Role of Science in Nineteenth-century India. In S.I. Habib \& D. Raina (Eds.), Social History of Science in Colonial India (pp. 229-252). Oxford Univeristy Press.

Habib, S.I. \& Raina, D. (2007b). Introduction. In S.I. Habib \& D. Raina (Eds.), Social History of Science in Colonial India (pp. xiii-xl). New Delhi: Oxford Univeristy Press.

Habib, S.I. \& Raina, D. (Eds.). (2007c). Social History of Science in Colonial India. New Delhi: Oxford Univeristy Press.

Hall, S. (1996). When was "the Post-colonial"? Thinking at the limit. In I Chambers \& L Curit (Eds.), The Post-Colonial Question: Common Skies, Divided Horizons (pp. 242-260). London: Routledge.

Haraway, D.J. (1991). Simians, Cyborgs, and Women: The Reinvention of Nature. New York: Routledge.

Hardikar, J. (2005). The destruction of “development." Retrieved July 21, 2015, from http://infochangeindia.org/defining-development/the-destructionof-development.html 
Harding, S. (1998). Is Science Multicultural?: Postcolonialisms, Feminisms, and Epistemologies. Indiana University Press.

Hassan, M.H.A. (2005). Small Things and Big Changes in the Developing World. Science, 309, 65-66.

Hazarika, S. (1987). Bhopal, The Lessons of a Tragedy. New Delhi: Penguin Books. Heath, J.R. \& Davis, M.E. (2008). Nanotechnology and Cancer. Annual Review of Medicine, 59, 251-265.

Henke, C.R. \& Gieryn, T.F. (2008). Sites of Scientific Practise: The Enduring Importance of Place. In E.J. Hackett, O. Amsterdamska, M. Lynch \& J. Wajcamn (Eds.), The Handbook of Science and Technology Studies (3rd ed., pp. 353-376). Cambridge, Massachusets: The MIT Press.

Hessels, L.K. \& van Lente, H. (2008). Re-thinking new knowledge production: A literature review and a research agenda. Research Policy, 37, 740-760.

Hiriyakkanavar, I. (2015). Support the bulk of students. Nature, 521, 152.

Honavar, S.G. \& Reddy, V.A.P. (n.d.). Retinoblastoma - They live and see. Hyderabad: LV Prasad Eye Institute.

Hughes, T.P. (1987). The Evolution of Large Technological Systems. In W.E. Bijker, T. Hughes P. \& T.J. Pinch (Eds.), The Social Construction of Technological Systems (pp. 51-82). Cambridge, Massachussetts: The MIT Press.

Hughes, T.P. (1989). American Genesis. A Century of Invention and Technological Enthusiasm. Harmondsworth: Penguin Books.

ICMR (2010). National Guidelines in the Management of Retinoblastoma. New Delhi: Indian Council of Medical Research.

India in danger of missing "nano bus": PM's Scientific advisor. (2011). Retrieved from http://www.deccanherald.com/content/174061/india-dangermissing-nano-bus.html

Iyyer, S.B. (1994). Development and Application of Electronic Control System for Scanning Tunneling Microscope (MPhil thesis). Department of Physics. University of Pune, Pune.

Iyyer, S.B. (2006). Design, Development and Application of Scanning Tunneling Microscopy (STM) Techniques for Nanolithography and Nanofabrication (PhD thesis). Dept. of Physics. University of Pune, Pune.

Jacobs, J.A. \& Frickel, S. (2009). Interdisciplinarity: A Critical Assessment. Annual Review of Sociology, 35, 43-65.

Jain, J., Arora, S., Rajwade, J.M., Omray, P., Khandelwal, S. \& Paknikar, K.M. (2009). Silver nanoparticles in therapeutics: development of an antimicrobial gel formulation for topical use. Molecular Pharmaceutics, 6(5), 1388-1401.

Jalan, J., Somanathan, E. \& Chaudhari, S. (2003). Awareness and the Demand for Environmental Quality: Drinking Water in Urban India: Discussion Papers in Economics. New Delhi: Indian Statistical Institute. 
Jasanoff, S. (1994). Learning from Disaster: Risk Management after Bhopal. Philadelphia: University of Pennsylvania Press.

Jolly, M. (2009). The Jugaad Country. Retrieved from http://www.vccircle.com/ columns/the-jugaad-country

Joseph, B., Madhavan, J., Mamatha, G., Ramprasad, V., Gopal, L. \& Kumaramanickavel, G. (2006). Retinoblastoma: A Diagnostic model for India. Asian Pacific Journal of Cancer Prevention, 7, 475-488.

Jugaad in not innovation: P.C. (2012, August 8). The Indian Express. Pune.

Kaiser, D. (Ed.). (2005). Pedagogy and the Practice of Science. Cambridge, Massachusets: The MIT Press.

Kale, S.N., Rajagopal, R., Arora, S., Bhayani, K.R., Rajwade, J.M., Paknikar, K.M. \& Ogale, S.B. (2007). Microwave Response of La0. $7 \mathrm{Sr} 0$. $3 \mathrm{MnO} 3$ Nanoparticles for Heating Applications. Journal of Biomedical Nanotechnology, 3(2), 178-183.

Kang, S.J., Duriaraj, C., Kompella, U.B., O’Brien, J.M. \& Grossniklaus, H.E. (2009). Subconjunctival Nanoparticle Carboplatin in the Treatment of Murine Retinoblastoma. Arch Opthalmol., 127(8), 1043-1047.

Kapila, U. (2010). Assessment of the Growth Experience: Poverty, Unemployment and Inflation. In U Kapila (Ed.), Indian Economy since Independance (21st Editi., pp. 857-906). New Delhi: Academic Foundation.

Kaplinsky, R. (2009). Schumacher meets Schumpeter: Appropriate technology below the radar. IKD Working Paper No. 54. The Open University.

Kaur, R. (2010). Bengali Bridal Diaspora: Marriage as a Livelihood Strategy. Economic and Political Weekly, XLV(5), 16-18.

Khandekar, A. (2010). Engineering the Global Indian: Skills, Families and Cosmopolitanism in Circuits of Highly Skilled Migrations between India and the United States (PhD thesis). Rensselaer Polytechnic Institute, Troy, NY, USA.

Khandekar, A. (2013). Education Abroad: engineering, privatization, and the new middle class in neoliberalizing India. Engineering Studies, 5(3), 179-198. doi:10.1080/19378629.2013.859686

Khandekar, A., Beumer, K., Mamidipudi, A., Sekhsaria, P. \& Bijker, W.E. (2016, forthcoming). STS for development. In C.A. Miller, U. Felt, R. Fouché \& L. Smith-Doerr (Eds.), The Handbook of Science and Technology Studies. Khetan, V., Gupta, A. \& Gopal, L. (2011). Retinoblastoma: Recent trends - A mini review based on published literature. Oman Journal of Opthalmology, 4(3), 108-113.

Kleinman, D.L. (1998). Untangling context: Understanding a University Laboratory in the Commercial World. Science, Technology \& Human Values, 23(3), 285-314.

Kline, R. (2003). Resisting Consumer Technology in Rural America: The Telephone and Electrification. In N. Oudshoorn \& T. Pinch (Eds.), How 
users matter - The co-construction of users and technologies (pp. 51-66). Cambridge, MA: MIT Press.

Kline, R. \& Pinch, T. (1996). Users as Agents of Technological Change: The Social Construction of the Automobile in the Rural United States. Technology and Culture, 37(4), 763-795.

Knorr Cetina, K.D. (1981). The Manufacture of Knowledge: An Essay on the Constructivist and Contextual Nature of Science. Oxford: Pergamon Press.

Knorr Cetina, K.D. (1995). Laboratory Studies: The Cultural Approach to the study of science. In S. Jasanoff, G.E. Markle, J.C. Petersen \& T. Pinch (Eds.), Handbook of Science and Technology Studies (pp. 140-166). Thousand Oaks: Sage.

Knorr Cetina, K.D. (1999). Epistemic cultures: how the sciences make knowledge. Cambridge, Mass.: Harvard University Press.

Knorr Cetina, K.D. (2007). Culture in global knowledge societies: knowledge cultures and epistemic cultures. Interdisciplinary Science Reviews, 32(4), 361-375. doi:10.1179/030801807X163571

Kolekar, S. (2013). Study of Electron Transport across Nanostructures using combination of Scanning Tunneling/Atomic Force Microscopy and related techniques (PhD thesis). University of Pune.

Kowshik, M., Ashtaputre, S., Kharrazi, S., Vogel, W., Urban, J., Kulkarni, S.K. \& Paknikar, K.M. (2003). Extracellular synthesis of silver nanoparticles by a silver-tolerant yeast strain MKY3. Nanotechnology, 14, 95.

Kowshik, M., Deshmukh, N., Vogel, W., Urban, J., Kulkarni, S.K. \& Paknikar, K.M. (2002). Microbial synthesis of semiconductor CdS nanoparticles, their characterization, and their use in the fabrication of an ideal diode. Biotechnology and Bioengineering, 78(5), 583-588.

Kowshik, M., Vogel, W., Urban, J., Kulkarni, S.K. \& Paknikar, K.M. (2002). Microbial synthesis of semiconductor PbS nanocrystallites. Advanced Materials, 14(11), 815-818.

Krishna, ADS, Mandaraju, RK, Kishore, G \& Kondapi, AK (2009). An Efficient Targeted Drug Delivery through Apotransferrin Loaded Nanoparticles. PLoS One, 4(10).

Krishna, V.V. (2013). Changing Social Relations between Science and Society: Contemporary Challenges. Working Paper Series. Paris: Foundation Maison des sciences de l'home.

Krishnakumar, S., Mohan, A., Mallikarjuna, K., Venkatesan, N., Biswas, J., Shanmugam, M.P. \& Ren-Heidenreich, L. (2004). EpCAM Expression in Retinoblastoma: A Novel Molecular Target in Therapy. Investigative Opthalmology and Visual Science, 45(12), 4247-4250.

Krishnan, R.T. (2010). From Jugaad to Systematic Innovation - The Challenge for India. Bengaluru: The Utprerka Foundation. 
Kulkarni, P. (2010). Studies on sporopollenin for DNA preservation (PhD Thesis). University of Pune, Pune.

Kulkarni, S. (2012). Music of the Spinning Wheel - Mahatma Gandhi's Manifesto for the Internet Age. New Delhi: Amaryllis - An Imprint of Manjul Publishing House Pvt. Ltd.

Kumar, A. (2014). Nanotechnology Development in India: An Overview. New Delhi.

Kumar, A., Pattarkine, M., Bhadbhade, M., Mandale, A.B., Ganesh, K.M., Datar, S.S. \& Sastry, M. (2001). Linear Superclusters on Colloidal Gold Particles by Electrostatic Assembly on DNA Templates. Advanced Materials, 13(5), 341-344.

Kumar, V. (2003). Burnt Wives - a study of suicides. Burns, 29(1), 31-35.

Kutty, L. (2010). The "Intractable Patient" - Managing Context, Illness, Health Care. In A. Zachariah, R. Srivatsan \& S. Tharu (Eds.), Towards a Critical Medical Practice - Reflections on the Dilemmas of Medical Culture Today (pp. 226-245). Hyderabad: Orient Blackswan Pvt Ltd.

Langlois, R.N. (2012). Schumpeter and the Obsolescence of the Enterpreneur. Retrieved from http://digitalcommons.uconn.edu/econ_wpapers/200219

Latour, B. (1983). Give Me a Laboratory and I will Raise the World. In K.D. Knorr Cetina \& M. Mulkay (Eds.), Science Observed (pp. 141-170). London: Sage.

Latour, B. (1987). Science in Action: How to Follow Scientists and Engineers Through Society. Cambridge: Harvard University Press.

Latour, B. (1988). The Pasteurization of France. Cambridge, MA: Harvard University Press.

Latour, B. \& Woolgar, S. (1986). Laboratory Life: The Social Construction of Scientific Facts. New Jersey: Princeton University Press.

Law, J. (1973). The Development of Specialties in Science: The Case of X-Ray Protein Crystallography. Science Studies, 3, 275-303.

Law, J. (1987). Technology and Heterogeneous Engineering: The Case of Portuguese Expansion. In W.E. Bijker, T.P. Hughes \& T. Pinch (Eds.), The Social Construction of Technological Systems (pp. 111-134). Cambridge: MIT Press.

Law, J. \& Callon, M. (1992). The Life and Death of an Aircraft: A Network Analysis of Technical Change. In W.E. Bijker \& J. Law (Eds.), Shaping Technology/Building Society. Studies in Sociotechnical Change (pp. 21-52). Cambridge, MA: The MIT Press.

Levi-Strauss, C. (1966). The Savage Mind. The Nature of Human Society Series. Oxford: Oxford Univeristy Press.

Leydesdorff, L. (2005). The triple helix model and the study of knowledge-based innovation systems. International Journal of Contemporary Sociology, $42(1)$. 
Leydesdorff, L. \& Etzkowitz, H. (1998). The triple helix as a model for innovation studies. Science and Public Policy, 25(3), 195-203.

Lin, C.h. (2009). The Silenced Technology: The Beauty and Sorrow of Reassembled Cars. East Asian Science, Technology and Society: An International Journal, 3(1), 91-131. doi:doi: 10.1007/s12280-009-9088-3

Lindsay, C. (2003). From the Shadows: Users as Designers, Producers, Marketers, Distributors, and Technical Support. In N Oudshoorn \& T Pinch (Eds.), How users matter - The co-construction of users and technologies (pp. 29-50). Cambridge, MA: MIT Press.

Lorenz-Meyers, D. (2012). Locating Excellence and Enacting Locality. Science Technology and Human Values, 37(2), 241-263. doi:10.1177/0162243911409249

Lundvall, B.-Å. (Ed.). (1992). National Systems of Innovation: Towards a Theory of Innovation and Interactive Learning. London: Pinter Publishers.

Lundvall, B.-Å. (2011). Notes on innovation systems and economic development. Innovation and Development, 1(1), 25-38. doi:10.1080/215793 0X.2010.551064

LVPEI (2012a). L.V. Prasad Eye Institute. Hyderabad: L.V. Prasad Eye Institute. LVPEI (2012b). L.V. Prasad Eye Institute: 2011-2012 Activity Report. Hyderabad: L.V. Prasad Eye Institute.

Lynch, M. (1985). Art and Artifact in Laboratory Science: A Study of Shop Work and Shop Talk in a Research Laboratory. Boston: Routledge \& Kegan Paul.

Lynch, M. (2000). Against Reflexivity as an Academic Virtue and Source of Privileged Knowledge. Theory, Culture \& Society, 17(3), 26-54.

Madhavan, N. (2013). Nano: The blemish on Ratan Tata's otherwise brilliant run. Retrieved from http://businesstoday.intoday.in/story/tata-nano-ablemish-on-ratan-tata-brilliant-record/1/191897.html

Malkani, A. (2013, May). The Raining of Filtered Water. Clean \& Hygiene Review, $\operatorname{XIII(3),~20-24.~Retrieved~from~http://issuu.com/cleanandhygienereview/~}$ docs/chr_may_june_12th_anniversary_issue

Mallick, S. (2014). The realm of commodified technoscience. Seminar, (654), $32-42$.

Mani, S. (2013). The Science, Technology and Innovation Policy: An Assessment. Economic and Political Weekly, 48(10), 16-19.

Mansoori, G.A., Mohazzabi, P., McCormack, P. \& Jabbari, S. (2007). Nanotechnology in cancer prevention, detection and treatment: bright future lies ahead. World Review of Science, Technology and Sustainable Development, 4(2/3), 226-257.

Manupriya (2011). Science Funding: Budget 2011-12. Current Science, 100(7), 964. 
Marcelle, G. (2015). Science, Technology and Innovation Policy that is Responsive to Innovation Performers. In S. Kuhlmann \& G.O. Matamoros (Eds.), International Research Handbook on Science, Technology and Innovation Policy in Developing Countries: Rationales and Relevance. Edward Elgar Publishing Ltd.

Marcus, G.E. (1995). Ethnography In/Of The World System: The Emergence of Multi-Sited Ethnography. Annual Review of Anthropology, 24, 95117.

Marcus, G.E. (1998). Ethnography through thick and thin. Princeton, NJ: Princeton University Press.

Mascarenhas, A. (2009, September 20). Now, a new way to store DNA: In pollen sacs. Indian Express. Pune. Retrieved from http://www.indianexpress. com/news/now-a-new-way-to-store-dna-in-pollen-sacs/519167/0

Mashelkar, R.A. (2011a). India @ 75: An innovation superpower? CSIR News, $61(19 \& 20), 225-232$.

Mashelkar, R.A. (2011b). Reinventing India. Pune: Sahyadri Prakashan.

McLain, S. (2013). Why the World's Cheapest Car Flopped. Retrieved from http://online.wsj.com/news/articles/SB1000142405270230452070457912 5312679104596

MDWS (2011). Report of the Working Group on Rural Domestic Water and Sanitation: Twelfth Five Year Plan - 2012-2017. New Delhi: Ministry of Drinking Water and Sanitation (MDWS), Government of India.

Menon, M.G.K. (1982). Basic Research as an Integral Component of a SelfReliant Base of Science and Technology. In Anon. (Ed.), The Shaping of Indian Science - Indian Science Congress Association Presidential Addresses - Vol. III: 1982-2003 (pp. 1271-1303). Hyderabad: Universities Press.

Metcalf, B. (1986). Hakim Ajmal Khan: Rais of Delhi and Muslim "Leader." In RE Frykenberg (Ed.), Delhi Through the Ages: Essays in Urban History, Culture and Society (pp. 299-315).

Metcalf, P. (2001). "Global Disjunctive" and the "Sites" of Anthropology. Cultural Anthropology, 16(2), 165-182.

Meyer, M. \& Persson, O. (1998). Nanotechnology - Interdisciplinarity, Patterns of Collaboration and Differences in Application. Scientometrics, 42(2), 195-205.

Misa, T.J. (1992). Controversy and Closure in technological Change: Constructing "Steel." In W.E. Bijker \& J. Law (Eds.), Shaping Technology/Building Society. Studies in Sociotechnical Change (pp. 109-139). Cambridge, MA: MIT Press.

Mody, C.C.M. (2004). How Probe Microscopists Became Nanotechnologists. In D. Baird, A. Nordmann \& J. Schummer (Eds.), Discovering the Nanoscale (pp. 119-133). Amsterdam: IOS Press. 
Mody, C.C.M. (2005). Instruments in Training: The Growth of American Probe Microscopy in the 1980s. In D. Kaiser (Ed.), Pedagogy and the Practice of Science: Historical and Contemporary Perspectives (pp. 185-216). Cambridge, Massachusets: The MIT Press.

Mody, C.C.M. (2006). Corporations, Universities and Instrumental Communities: Commercializing Probe Microscopy, 1981-1996. Technology \& Culture, $47,56-80$.

Mody, C.C.M. (2011). Instrumental Community. Cambridge, Massachusets: The MIT Press.

Mody, C.C.M. \& Kaiser, D. (2008). Scientific Training and the Creation of Scientific Knowledge. In E.J. Hackett, O. Amsterdamska, M. Lynch \& J. Wajcman (Eds.), The Handbook of Science and Technology Studies (pp. 377-402). Cambridge, Massachusets: The MIT Press.

Mondal, N. (2015). Build big physics facilities. Nature, 512, 155.

More, R.M. (1990). A Study of Scanning Tunneling Microscope and Development of a Simple Electronic Control System for the same (MPhil thesis). Department of Physics. University of Pune, Pune.

More than 6000 dowry related case registered yearly: Govt. (2008). Retrieved from http://articles.timesofindia.indiatimes.com/2008-03-10/ india/27780615_1_dowry-related-cases-dowry-prohibition-act-numberof-dowry-deaths

MST (2013). Science, Technology and Innovation Policy 2013. New Delhi: Ministry of Science \& Technology, Government of India.

Mujumdar, P.P. (2015). Share data on water resources. Nature, 521, 151.

Munshi, I. (2012). Introduction. In I. Munshi (Ed.), The Adivasi Question - Issues of Land, Forest and Livelihood (pp. 1-22). Hyderabad: Orient BlackSwan.

Munshi, P. (2009). Making Breakthrough Innovation Happen. New Delhi: HarperCollins Publishers.

Murcott, S. (2006). Implementation, Critical Factors and Challenges to Scale-Up of Household Drinking Water Treatment and Safe Storage Systems Draft Background Paper. Electronic Conference hosted by USAID/Hygiene Improvement Project (HIP).

Murti, G.S. (1948). Memorandum on 'Science and the Art of Indian Medicine. Government of India Committee on Indigenous Medicine.

Nair, A., Thevenot, P., Hu, W. \& Tang, L. (2008). Nanotechnology in the treatment and detection of Intraocular cancers. Journal of Biomedical Nanotechnology, 4(4), 410-418.

Nanda, M. (2003). Prophets Facing Backward - Postmodern Critiques of Science and Hindu Nationalism in India. Rutgers University Press.

Nandy, A. (1995). Alternative Sciences - Creativity and Authenticity in Two Indian Scientists. New Delhi: Oxford University Press.

Narain, S. (2015). Manage waste frugally. Nature, 521, 155. 
Narlikar, J.V. (2003). The Scientific Edge - The Indian Scientist from Vedic to Modern Times. New Delhi: Penguin Books.

NCMH (2005). Burden of Disease in India. New Delhi.

Nehru, J. (2003). Science in the Service of the Nation. In Anon. (Ed.), The Shaping of Indian Science - Indian Science Congress Association Presidential Addresses. Vol I: 1914-1947 (pp. 574-577). Hyderabad: Universities Press.

Nelson, J.E. (1997). Blair Water Purifiers India - Management Case. Vikalp, 22(3), 79-89.

Nelson, R.R. (1993). National Innovation Systems: A Comparative Analysis. New York: Oxford University Press.

NNI (2001). What is Nano? Retrieved from http://www.nano.gov/html/facts/ whatIsNano.html

Nowotny, H. (2008). Insatiable Curiosity - Innovation in a Fragile Future. Cambridge, Massachusets: MIT Press.

Nowotny, H., Scott, P. \& Gibbons, M. (2001). Re-thinking science: knowledge and the public in an age of uncertainty. Cambridge: Polity Press in assoc. with Blackwell.

NSTMIS (2006). Research and Development Statistics. New Delhi: Department of Science and Technology, Government of India.

Oudshoorn, N. \& Pinch, T. (2008). User-Technology Relationships: Some Recent Developments. In E.J. Hackett, O. Amsterdamska, M. Lynch \& J. Wajcamn (Eds.), The Handbook of Science and Technology Studies (pp. 541-566). Cambridge, Massachusets: The MIT Press.

Oudshoorn, N. \& Pinch, T. (Eds.). (2003a). How users matter: the co-construction of users and technologies. Inside technology. Cambridge, MA: MIT Press.

Oudshoorn, N. \& Pinch, T. (2003b). Introduction: How Users and Non-Users Matter. In N. Oudshoorn \& T. Pinch (Eds.), How users matter: the coconstruction of users and technologies (pp. 1-25). Cambridge, MA: MIT Press.

Paknikar, K.M. (2006). Anti-microbial activity of biologically stabilized silver nano particles. India Patent Office; 1688/MUM/2006.

Paknikar, K.M. (2007). Stabilizing solutions for submicronic particles, methods for making the same and methods of stabilizing submicronic particles. European Patent Office: EP Patent 1,761,330.

Paknikar, K.M. (2008). Stabilizing solutions for submicronic particles, methods for making the same and methods of stabilizing submicronic particles. South Africa Patent Office, ZA Patent 2006/08,551.

Paknikar, K.M. (2009). Stabilizing solutions for submicronic particles. SG Patent $127,299$.

Paknikar, K.M. \& Jeremic, A. (2007). Discovery of the cell secretion machinery. Journal of Biomedical Nanotechnology, 3(3), 218-222. 
Paknikar, K.M. \& Kowshik, M. (2008a). A process for manufacturing gold metal nanoparticles. India: India Patent Office; IN Patent 205,346.

Paknikar, K.M. \& Kowshik, M. (2008b). A process for manufacturing metal sulfide nanoparticles. India: India Patent Office; IN Patent 202,756.

Paknikar, K.M. \& Kowshik, M. (2008c). A process for manufacturing silver metal nanoparticles. India: India Patent Office; IN Patent 202,757.

Paknikar, K.M. \& Kulkarni, P. (2011). Preservation of biomaterials. WO Patent $\mathrm{WO} / 2011 / 058,573$.

Pakrashi, S.C. (2003). Science, Technology and Industrial Development in India. In Anon. (Ed.), The Shaping of Indian Science - Indian Science Congress Association Presidential Addresses - Vol. III: 1982-2003 (pp. 1822-1856). Hyderabad: Universities Press.

Palmberg, C., Dernis, H. \& Miguet, C. (2009). Nanotechnology: An Overview Based on Indicators and Statistics (No. 2009/7). Paris. Retrieved from http://dx.doi.org/10.1787/223147043844

Parasnis, A.S. (2004). Perceived bias against Ayurveda. Current Science, 87(10), 1329-1333.

Park, W.-S. (2013). Forging ahead with Cross-Sector Innovations. Supplement to the Stanford Social Innovation Review, 15-17.

Parveen, S., Mitra, M., Krishnakumar, S. \& Sahoo, S. (2010). Enhanced antiproliferative activity of carboplatin-loaded chitosan-alginate nanoparticles in a retinoblastoma cell line. Acta Biomaterialia, 6, 31203131.

Patel, T. (2004). Missing Girls in India. Economic and Political Weekly, 39(9), 887-889.

Patel, V. (2012, July). Current Scenario of Nano S\&T in India: A Comparative Analysis. Nanotech Insights, 3(3), 48.

Patel, V. \& Chander, R.V. (2012, April). Emerging Trends of Nanoscience and Nanotechnology in India. Nanotech Insights, 3(2), 39-45.

Patil, S. \& Dharmadhikari, C.V. (2002). Investigation of the electrostatic forces in scanning probe microscopy at low bias voltages. Surface and Interface Analysis, 33, 155-158.

Patil, S.M. (1994). Development and Applications of Probes for Scanning Tunneling Microscopy (MPhil thesis). Department of Physics. University of Pune, Pune.

Patil, S.V. (2002). Design and Development of Scanning Force Microscopic Techniques for Surface Characterisation (PhD thesis). Dept of Physics. University of Pune, Pune.

Patwardhan, B., Joglekar, V., Pathak, N. \& Vaidya, A. (2011). Vaidyascientists: catalysing Ayurveda renaissance. Current Science, 100(4), 476483. 
Patwardhan, B. \& Vaidya, A.D.B. (2009). Ayurveda: scientific research and publications. Current Science, 97(8), 1117-1121.

P.C. (2002). Water supply \& Sanitation: India Assessment 2002. New Delhi: Planning Commission, Government of India.

P.C. (2011). Report of the Working Group on Urban and Industrial Water Supply and Sanitation for the Twelfth Five-Year-Plan (2012-2017). New Delhi: Planning Commission, Government of India.

Philip, K., Irani, L. \& Dourish, P. (2012). Postcolonial Computing: A Tactical Survey. Science, Technology \& Human Values, 37(1), 3-29.

PIB (2014). Continuation of the Mission on Nano Science and Technology in the 12th Plan Period. New Delhi: Press Information Bureau, Govt. of India. Pinch, T. (1986). Confronting Nature. Dordrecht: Reidel.

Pinch, T. \& Bijker, W.E. (1984). The Social Construction of Facts and Artefacts: Or How the Sociology of Science and the Sociology of Technology Might Benefit Each Other. Social Studies of Science, 14(3), 399-441.

Pinch, T. \& Bijker, W.E. (1987). The Social Construction of Facts and Artifacts: Or How the Sociology of Science and the Sociology of Technology Might Benefit Each Other. In W.E. Bijker, T.P. Hughes \& T. Pinch (Eds.), The Social Construction of Technological Systems. New Directions in the Sociology and History of Technology (pp. 17-50). Cambridge, MA: The MIT Press.

Piston, D.W. (2012). Understand how it works. Nature, 484, 440-441.

Polanyi, M. (1958). Personal Knowledge. Chicago: Chicago University Press.

Porter, A.L. \& Youtie, J. (2009). How interdisciplinary is nanotechnology? Journal of Nanoparticle Research, 11, 1023-1041.

Pradeep, T. \& Anshup (2009). Noble metal nanoparticles for water purification: A critical review. Thin Solid Films, 517, 6441-6478. doi:10.1016/j. tsf.2009.03.195

Prahalad, C.K. \& Mashelkar, R.A. (2010). Innovation's Holy Grail. Harvard Business Review, (July-August 2010), 10.

Prakash, G. (2007). The Image of the Archaic. In S.I. Habib \& D. Raina (Eds.), Social History of Science in Colonial India (pp. 252-290).

Prasad, A. (2006). Beyond Modern vs Alternative Science Debate: Analysis of Magnetic Resonance Imaging Research. Economic and Political Weekly, 41(3), 219-227.

Prasad, C.S. (2001). Towards an Understanding of Gandhi's Views on Science. Economic \& Political Weekly, 36(39), 3721-3732.

Prasad, C.S. (2014). Revisiting science's social contract. Seminar, (654), 55-61.

Premi, M. (2001). The Missing Girl Child. Economic and Political Weekly, 36(21), 1875-1880.

Priorities for Science in India. (2015). Nature, 521, 151-155.

Purie, A. (2010). Editorial. India Today, 1. 
Purushotham, H. (2012). Transfer of nanotechnologies from R\&D institutions to SMEs in India: opportunities and challenges. Tech Monitor, (Oct.-Dec. 2012), 23-33.

Purushotham, H. (2013). CMNT Initiatives: Taking Nanotech to the market place. Nano Digest, 5(2), 14-15.

Rabinow, P. (1989). French Modern: Norms and Forms of Social Environment. Cambridge MA: MIT Press.

Radhakrishnan, S. (1947). Religion and Society. London: George Allen and Unwin Ltd.

Radhakrishnan, S. (2008). Indian Philosophy (Vol. 1) (1923). New Delhi: Oxford Univeristy Press.

Radjou, N., Prabhu, J. \& Ahuja, S. (2012). Jugaad Innovation - Think Frugal, Be Flexible, Generate Breakthrough Growth. San Francisco: Jossey-Bass.

Raina, D. (2003). Images and contexts: the historiography of science and modernity in India. New Delhi: Oxford University Press.

Raina, D. (2007). Science Since Independence. In I Pande (Ed.), India 60 (pp. 182-195). New Delhi: HarperCollins Publishers India.

Raina, D. (2014). The Problem. Seminar, (654), 12-14.

Raina, R. (2014). Beyond supply driven science. Seminar, (654), 69-74.

Rangaswamy, N. \& Sambasivan, N. (2011). Cutting Chai, Jugaad and Here Pheri: towards UbiComp for a global community. Personal Ubiquitous Computing, 15(6), 553-564.

Rao, C.N.R. (2011). Nanoworld-An Introduction to nanoscience and technology. Bengaluru: Navkarnataka Publications Private Limited.

Rao, T.N. (2012). Status of Activities at the Centre for Nanomaterials. Nanotech Insights, 3(1), 3.

Rasmussen, N. (1997). Picture Control: The Electron Microscope and the Transformation of Biology in America, 1940-1960. Stanford, Calif.: Stanford University Press.

Ray, P.C. (1902). A History of Hindu Chemistry (Vol. 1). Calcutta: Chuckererty \& Co and Kegan Paul.

Ray, P.C. (1907). A History of Hindu Chemistry (Vol. 2). Calcutta: Chuckererty \& Co and Kegan Paul.

Reddy, A. (2009a). Amulya Reddy - Citizen Scientist (R Rajan, Ed.). Hyderbad: Orient Blackswan.

Reddy, A. (2009b). Amulya Reddy: An Autobiography. In SR Rajan (Ed.), Amulya Reddy - Citizen Scientist (p. 373). Hyderabad: Orient BlackSwan.

Reddy, R.N. (2013). Revitalising Economies of Disassembly - Informal Recyclers, Development Experts and E-Waste Reforms in Bengaluru. Economic and Political Weekly, XLVIII(13), 62-70. 
Roco, M.C. \& Bainbridge, W.S. (2002). Converging technologies for improving human performance: Integrating from the nanoscale. Journal of Nanoparticle Research, 4, 281-295.

Rodin, J. (2013). Innovation for the next 100 years. Supplement to the Stanford Social Innovation Review, 2-5.

Roy, J. (2015). Train more energy economists. Nature, 521, 152.

Roy, R. (2010). A primer on the Taguchi method (2nd Edition). Michigan: SME. Sachdeva, S. (2010). Trend of reported cases of retinoblastoma under five hospital based cancer registries. Indian Journal of Cancer, 47(4), 473.

Saetnan, A., Oudshoorn, N. \& Kirejczyk, M. (2000). Bodies of Technology: Women's Involvement with Reproductive Technology. Ohio State University Press. Sahu, S., Banavali, D., Pai, S., Nair, C., Kurkure, P., Motwani, S. \& Advani, S.H. (1998). Retinoblastoma: Problems and Perspectives from India. Pediatric Hematology and Oncology, 15(5), 501-508.

Salamanca-Buentello, F., Persad, D.L., Court, E.B., Martin, D.K., Daar, A.S. \& Singer, P.A. (2005). Nantechnology and the Developing World. PLoS Medicine, 2(4: e97), 300-303. doi:10.1371/journal.pnmed.00220097

Sangvai, S. (2002). The River and Life. Kolkata: Earthcare Publications.

Sastry, M., Kumar, A., Datar, S., Dharmadhikari, C.V. \& Ganesh, K.M. (2001). DNA-mediated electrostatic assembly of gold nanoparticles into linear arrays by a simple drop-coating procedure. Applied Physics Letters, 78(19), 2943-2945.

Sathyamala, C. \& Jayaprakash, N.D. (2012). The Bhopal Disaster and Medical Research. Economic and Political Weekly, XLVII(49), 37-40.

Saving the Girl Child (2008). Economic and Political Weekly, 43(7), 6-7.

Sawant, S.S. (1994). Interferometric techniques for static and dynamic characterization of piezoelectric actuators: Design, Development and Application (MPhil thesis). Department of Physics. University of Pune, Pune.

S.C. Bans Farmers' "Jugaad." (2013). Retrieved from http://www.highbeam.com/ doc/1G1-329924197.html

Schneider, D. (1976). Notes toward a theory of culture. In K. Basso \& H.A. Selby (Eds.), Meaning in Anthroplogy. Albuquerque, NM.: University of New Mexico Press.

Schot, J. \& de la Bruheze, A.A. (2003). The Mediated Design of Products, Consumption and Consumers in the Twentieth Century. In N. Oudshoorn \& T. Pinch (Eds.), How users matter - The co-construction of users and technologies (pp. 229-245). Cambridge, MA: MIT Press.

Schumacher, F. (1973). Small is Beautiful. London: Blond and Briggs.

Schummer, J. (2004). Interdisciplinary Issues in Nanoscale Research. In D. Baird, A. Nordmann \& J. Schummer (Eds.), Discovering the Nanoscale (pp. 9-20). Amsterdam: IOS Press. 
Schumpeter, J.A. (1934). The Theory of Economic Development: An Inquiry into Profits, Capital, Credit, Interest, and the Business Cycle. New Brunswick (USA): Transaction Publishers (2012).

Schumpeter, J.A. (1939). Business cycles; a theoretical, historical, and statistical analysis of the capitalist process (1st ed.). New York; London: McGrawHill Book Company inc.

Schumpeter, J.A. (1942). Capitalism, Socialism and Democracy. New York: Harper and Row (1975).

Seal, B.N. (1915). The Positive Sciences of the Ancient Hindus. New Delhi: Motilal Banarsidas (1985 reprint).

Seelos, C. \& Mair, J. (2013). Innovate and Scale: A Tough Balancing Act. Supplement to the Stanford Social Innovation Review, 12-14.

Sekhsaria, P. (2011). Jugaad as a materials and conceptual commons. Common Voices, (8), 21-23.

Sekhsaria, P. (2013a). The making of an indigenous scanning tunneling microscope. Current Science, 104(9), 1152-1157.

Sekhsaria, P. (2013b). The making of an indigenous STM: Technological jugaad as a culture of innovation in India. In K. Konrad, C. Coenen, A. Dijkstra, C. Milburn \& H. van Lente (Eds.), Shaping Emerging Technologies: Governance, Innovation, Discourse (pp. 137-152). Amsterdam: IOS Press and AKA, Berlin.

Sekhsaria, P. (2014). The Last Wave - An island novel. New Delhi: HarperCollins Publishers India.

Selin, C. (2007). Expectations and the Emergence of Nanotechnology. Science, Technology \& Human Values, 32(2), 196-220.

Sengupta, S., Krishnakumar, S., Biswas, J., Gopal, L. \& Khetan, V. (2011). Fifteen-year trends in indications for enucleation from a tertiary care center in South India. Indian Journal of Opthalmology, 60(3), 179-182. doi:10.4103/0301-4738.95867

SET-DEV (2009). Knowledge Swaraj - An Indian Manifesto on Science and Technology. Hyderabad.

Seth, S. (2009). Putting knowledge in its place: science, colonialism, and the postcolonial. Postcolonial Studies, 12(4), 373-388.

Shah, A. (1998, January 19). For the Bookworm. The Indian Express. Pune.

Shankar, D. (2010). Conceptual framework for new models of integrative medicine. Journal of Ayurveda \& Intergrative Medicine, 1(1), 3-5.

Shapin, S. (1988). The House of Experiment in Seventeenth-Century England. Isis, 79, 373-404.

Shapin, S. (1995). Here and Everywhere: Sociology of Scientific Knowledge. Annual Review of Sociology, 21, 289-321.

Sharma, A. (2008). Portrait of a science teacher as a bricoleur: A case study from India. Cutlural Studies of Science Education, 3, 811-841. doi:10.1007/ s11422-008-9120-2 
Sharma, B. (2006). Bhopal Gas Tragedy. Economic and Political Weekly, $X L I(1613-1616)$.

Sharma, S. (2014). Development from whom and whose cost: Displacement due to dams in India. Indian Journal of Public Administration, LX(1), 19-34.

Shields, J.A. \& Shields, C.L. (1992). Intraocular tumors - A text and Atlas. Philadelphia, PA, USA: WB Saunders Company.

Siddiqi, M.Z. (2009). The Unani Tibb (Greek Medicine) in India. In D.M. Bose, S.N. Sen, \& B.V. Subbarayappa (Eds.), A concise history (pp. 332-339). Hyderabad: University Press and Indian National Science Academy.

Singer, H., Cooper, C., Desai, R.C., Freeman, C., Gish, O., Hill, S. \& Oldham, G. (1970). Draft introductory statement for the world plan of action for the application of science and technology to development, Annex II. In Science and Technology for Development: Proposals for the Second Development Decade. New York: United Nations, Dept of Economic and Social Affairs.

Singh, V. (2015). Improve tertiary education. Nature, 521, 153.

Sismondo, S. (2004). An introduction to Science and Technology Studies. Oxford: Blackwell Publishing.

Smith, B.L.R. \& Barfield, C.E. (1996). Technology, R\&D, and the economy. Washington, D.C.

Smith, P. (2001). Cultural Theory - an introduction. Oxford: Blackwell Publishing.

SN (2013). Medical Researh Foundation - Annual Report \& Accounts 2012-2013. Chennai: Sankara Nethralaya.

Soete, L (2008). Science, Technology and Development: Emerging concepts and visions. Atlanta Conference: Challenges and Opportunities for Innovation in the Changing Global Economy. Maastricht: United Nations University - Maastricht Economic and Social Research and Training Centre on Innovation and Technology (UNU-MERIT).

SSD (2015). Millennium Development Goals - India Country Report 2015. New Delhi.

Star, S.L. (2010). This is Not a Boundary Object: Reflections on the Origin of a Concept. Science Technology \& Human Values, 35(5), 601-617.

Star, S.L. \& Griesemer, J.R. (1989). Institutional Ecology, "Translations" and Boundary Objects: Amateurs and Professionals in Berkeley's Museum of Vertebrate Zoology, 1907-39. Social Studies of Science, 19, 387-420.

Stille, A. (2006, February). Are We Losing Our Memory? or The Museum of Obsolete Technology. Lost Magazine, (3).

Subba Rao, I.V. (2006). Integrated Rural Development: Science and Technology. In The Shaping of Indian Science: Indian Science Congress Association Presidential Addresses. Vol IV: 2004-2010 (pp. 2064-2086). Hyderabad: Universities Press. 
Sundararajan, G. (2011, June). "Nano has created excitement among the next generation.” Nano Digest, 3(1), 3.

Sundararajan, G. \& Rao, T.N. (2010, June). Nanomaterials: Application Development at ARCI. Nano Digest, 2(1), 2.

Sur, A. (2011). Dispersed Radiance: caste, gender and modern science in India. New Delhi: Navayana Publishing.

Sustainable development goals: all you need to know. (2015). Retrieved from http://www.theguardian.com/global-development/2015/jan/19/ sustainable-development-goals-united-nations

Taguchi, G. (1986). Introduction to quality engineering: designing quality into products and processes. The Asian Productivity Organization.

TARA (2011). Access to Safe Water for the Bottom of Pyramid: Strategies for Disseminating Technology Research Benefits - First Half Yearly Progress Report. New Delhi: Society for Techology and Action for Rural Advancement (TARA) \& Department for International Development (DFID).

Teitelman, R. (1989). Gene Dreams, Wall Street, Academia and the Rise of Biotechnology. New York: Basic Books.

The Missing Revolution (2012, February 28). Mint. Hyderabad.

Tiwari, R. (1987). Tehri: temple or tomb? Retrieved from http://www.himalmag. com/component/content/article/3370-.html

Traweek, S. (1988). Beamtimes and lifetimes: the world of high energy physicists. Cambridge, Mass.: Harvard University Press.

Trescott, M.M. (1979). Dynamos and Virgins Revisited: Women and Technological Changes in History, An Anthology. Metuchen, NJ: Scarecrow Press.

TRSAS (1986). Press Release. Retrieved from http://www.nobelprize.org/nobel_ prizes/physics/laureates/1986/press.html

Turnbull, D. (2003). Masons, Tricksters and Cartographers: Comparative Studies in the Sociology of Scientific and Indigenous Knowledge. Abingdon Taylor \& Francis.

Tyabji, L. (2015). In the eyes of the other. Seminar, (667), 16-19.

Tyabji, N. (2011). Jawaharlal Nehru and Science and Technology: 1958 Scientific Policy Resolution Reconsidered. In R.L. Hangloo (Ed.), History of Science and Technology: Exploring New Themes (pp. 300-306). Jaipur: Rawat Publishers.

Uberoi, J.P.S. (1984). The Other Mind of Europe. New Delhi: Oxford Univeristy Press.

Uberoi, J.P.S. (1989). Technology of Obsolescence. Economic and Political Weekly, 2543-2544.

Umrani, R. (2011). Studies on anti-diabetic activity of zinc based submicronic preparations (PhD Thesis). Department of Biotechnology. University of Pune, Pune. 
Umrani, R., Agrawal, D.S. \& Paknikar, K.M. (2013). Anti-diabetic activity and safety assessment of Ayurvedic medicine, Jasada bhasma (zinc ash) in rats. Indian Journal of Experimental Biology, 51(10), 811-822.

Umrani, R. \& Paknikar, K.M. (2011a). Ayurvedic Medicine Zinc Bhasma: Physicochemical Evaluation, Anti-Diabetic Activity and Safety Assessment. Journal of Biomedical Nanotechnology, 7(1), 148-149.

Umrani, R. \& Paknikar, K.M. (2011b). Zinc Oxide Nanoparticles Show AntiDiabetic Activity in Rats. Diabetes, 60(Suppl 1), A315.

Umrani, R. \& Paknikar, K.M. (2013). Zinc oxide nanoparticles show antidiabetic activity in streptozotocin-induced Types-1 and 2 diabetic rats. Nanomedicine, (0), 1-16.

UN (2005). Innovation: Applying Knowledge in Development. Task Force on Science, Technology and Innovation. London: UN Millenium Project.

UN (2015). India and the MDGs - Towards a sustainable future for all. New Delhi.

UNESCO (2006). The Ethics and Politics of Nanotechnology. Paris.

UNEVOC (1998). Under the Sun or in the Shade? Jua Kali in African Countries. National Policy Definition in Technical and Vocational Education: Beyond the Formal Sector. Berlin: UNESCO.

Urama, K. \& Acheampong, E.N. (2013). Social Innovation Creates Prosperous Societies. Supplement to the Stanford Social Innovation Review, 9-11.

Vadukut, S. (2011). Die Jugaad, Die. Mint. Hyderabad.

Valiathan, M.S. (2006). Towards Ayurvedic Biology: A decadal vision document - 2006. Bengaluru: Indian Academy of Sciences.

Varma, P.K. (2004). Being Indian - The Truth about why the 21st century will be India's. New Delhi: Penguin Books.

Varughese, S.S. (2014). The public life of expertise. Seminar, (654), 21-26.

Venkateswaran, S. (1994). Managing Waste: Ecological, Economic and Social Dimensions. Economic and Political Weekly, 2907-2911.

Visvanathan, S. (1985). Organising for Science: The Making of an Industrial Research Laboratory. New Delhi: Oxford Univeristy Press.

Visvanathan, S. (1997). A carnival for science: essays on science, technology, and development. Delhi; New York: Oxford University Press.

Visvanathan, S. (2001). Democracy, Governance and Science: Strange case of the missing discipline. Economic and Political Weekly, (29 September), 3684-3688.

Visvanathan, S. \& Parmar, C. (2012). A Biotechnology Story. In R. D’Souza (Ed.), Environment, Technology and Development - Critical and Subversive Essays (pp. 35-57). Hyderabad: Orient BlackSwan.

VL (2007). Test Report No. 05240/07/VLL/000/02. Hyderabad: Vimta Labs.

VL (2008a). Test Report No. 03027/08/VLL/000/01-03. Hyderabad: Vimta Labs.

VL (2008b). Test Report No. 07469/07/VLL/000/01. Hyderabad: Vimta Labs. 
VL (2008c). Test Report No. 07469/07/VLL/000/02. Hyderabad: Vimta Labs.

Von Hippel, E. (1988). The Sources of Innovation. New York: Oxford University Press.

Von Hippel, E. (2005). Democratizing Innovation. Cambridge, Massachusets: The MIT Press.

Westley, F. (2013). Tapping the Entrepreneurial Potential of Grassroots Innovation. Supplement to the Stanford Social Innovation Review, 6-8.

Wyatt, S. (2003). Non-Users Also Matter: The Construction of Users and NonUsers of the Internet. In N. Oudshoorn \& T. Pinch (Eds.), How users matter - The co-construction of users and technologies (pp. 67-79). Cambridge, MA: MIT Press.

Wyatt, S. (2008). Technological Determinism is Dead; Long Live Technological Determinism. In E.J. Hackett, O. Amsterdamska, M. Lynch \& J. Wajcamn (Eds.), The Handbook of Science and Technology Studies (pp. 166-180). Cambridge, Massachusets: The MIT Press.

Wyatt, S., Thomas, G. \& Terranova, T. (2002). They came, they surfed, they went back to the beach: Conceptualizing the use and non-use of the internet. In S. Woolgar (Ed.), Virtual Society? Oxford University Press.

Yehia, A.O.A. (1999). A Study of Nucleation and Growth of Thin Films Using Scanning Tunneling Microscopy and Related Techniques (PhD thesis). Department of Physics. University of Pune, Pune.

Zachariah, A., Srivatsan, R. \& Tharu, S. (2010a). Introduction: The Dilemmas of Medical Culture Today. In A. Zachariah, R. Srivatsan \& S. Tharu (Eds.), Towards a Critical Medical Practice - Reflections o the Dilemmas of Medical Culture Today (pp. 1-34). Hyderabad: Orient Blackswan Pvt. Ltd.

Zachariah, A, Srivatsan, R. \& Tharu, S. (Eds.). (2010b). Towards a Critical Medical Practice - Reflections on the Dilemmas of Medical Culture Today. Hyderabad: Orient Blackswan Pvt Ltd.

Zachariah, B. (2014). Science, nationalism and the state. Seminar, (654), 15-20.

Zachariah, M. \& Sooryamoorthy, R. (1994). Science in Participatory Development: The achievements and Dilemmas of a Development Movement. London: Zed Books.

Zonabend, F. (1993). The Nuclear Peninsula. New York: Cambridge University Press. 
The thesis is an outcome of the effort to understand the 'Culture(s) of innovation' in nanoscience and technology (NS\&T) research for development in India. The research is qualitative in nature and uses methods such as open-ended interviews, historical analysis and laboratory ethnography that are drawn primarily from sociology and anthropology. It is about a 'culture of innovation' that links the macro with the micro, and what is done within the lab with the world outside - a world that is a much bigger influence than is generally believed.

This dissertation responds to three broad questions with the overall endeavor being to understand the 'cultures of innovation' in nanoscience and technology (NS\&T) in India:

1) What is the character of techno-scientific knowledge practices within Indian NS\&T laboratories?

2) What is the role of scientific laboratories in processes of innovation in contemporary Indian contexts?

3) How are these to be understood within the broad political, social, cultural and developmental contexts of contemporary India?

Research to answer these questions was conducted in collaboration with five different groups of researchers/scientists involved in NS\&T research in different parts of the country - the Centre for Advanced Studies in Materials Science and Solid State Physics, Department of Physics, University of Pune; Centre for Nanobioscience (CNB), Agharkar Research Institute (ARI), Pune; Centre for Nanomaterials, International Advanced Research Centre for Powder Metallurgy and New Materials (ARCI), Hyderabad; the L.V. Prasad Eye Institute, Hyderabad and Sankara Nethralaya, Chennai.

The empirical material is a set of case studies that explore four different contexts, locations and realities of NS\&T research and development. Each case study is threaded along what might be considered a particular characteristic of Indian society (see Table 1 ).

The 1st is the context of economic and material constraints - where a university lab takes the lead in developing indigenous Scanning Tunneling Microscopes in situations of severe resource constraints. Starting in the late 1980s the lead scientist and his students at the Center for Advanced Studies in Materials Science and Solid State Physics at the Department of Physics in the University of Pune, developed a number of scanning probe microscopes by using a range of material and human resources. This included waste materials 
Table 1: The structure of the thesis:

\begin{tabular}{|l|l|l|l|l|}
\hline $\begin{array}{l}\text { Case Study/ The } \\
\text { Laboratories }\end{array}$ & $\begin{array}{l}\text { The STM } \\
\text { story/Dept of } \\
\text { Physics, Pune } \\
\text { University,Pune }\end{array}$ & $\begin{array}{l}\text { In a } \\
\text { nanobioscience } \\
\text { lab/CNB, ARI, } \\
\text { Pune }\end{array}$ & $\begin{array}{l}\text { Water filters/ } \\
\text { ARCI, Hyderabad }\end{array}$ & $\begin{array}{l}\text { LVPEI, Hyderabad } \\
\text { \& SN, Chennai/ } \\
\text { Retinoblastoma } \\
\text { and the girl child }\end{array}$ \\
\hline Social context & $\begin{array}{l}\text { Resource } \\
\text { constrains }\end{array}$ & $\begin{array}{l}\text { Traditional } \\
\text { practices and } \\
\text { knowledge } \\
\text { systems }\end{array}$ & Social exigency & Patriarchy \\
\hline $\begin{array}{l}\text { Scale at which } \\
\text { innovation } \\
\text { happens }\end{array}$ & $\begin{array}{l}\text { Innovation in } \\
\text { the lab at the } \\
\text { micro level - lab } \\
\text { practices }\end{array}$ & $\begin{array}{l}\text { Innovation in and } \\
\text { around the lab at } \\
\text { the meso level - } \\
\text { organizational, } \\
\text { institutional, } \\
\text { interdisciplinary }\end{array}$ & $\begin{array}{l}\text { Innovation in and } \\
\text { around the lab } \\
\text { at the interface } \\
\text { with society }\end{array}$ & $\begin{array}{l}\text { Innovation in } \\
\text { the lab and } \\
\text { simultaneously in } \\
\text { society }\end{array}$ \\
\hline $\begin{array}{l}\text { The conceptual } \\
\text { frame }\end{array}$ & $\begin{array}{l}\text { Technological } \\
\text { Jugaad }\end{array}$ & $\begin{array}{l}\text { Inter-epistemic } \\
\text { collaborations }\end{array}$ & Users matter & $\begin{array}{l}\text { Reconfigured } \\
\text { subjectivities }\end{array}$ \\
\hline
\end{tabular}

from the city's scrap markets, ideas and concepts from the science happening in important centres around the globe, human resources and capacities from local small-scale industry and aspects of traditional knowledge systems as well. Not only did the lab do science that was then published in some of the world's leading peer reviewed journals, it also created a generation of scientists who were very confident and capable of making and working with sophisticated instrumentation. The key conceptual frame that the thesis explores to discuss the work in this lab is technological jugaad, a local variant of bricolage, where innovation is an activity of the commons that involves, among others, the reconfiguring of materiality and recycling of waste in situations of resource constraints.

The 2nd case study highlights the continued relevance of traditional practices and knowledge systems that can be seen in operation in India even today. It is an account from the Centre for Nanobioscience in Pune's Agharkar Research Institute where scientists are attempting to engage nanotechnology with the traditional practice of Ayurveda. The key challenge here for the scientists is to bridge the vast difference in the worldviews as represented by the different knowledge systems of modern science on the one hand and Ayurveda on the other. The nature of the collaboration between the two knowledge systems in not just inter-disciplinary; it can be understood as inter-epistemic. The hierarchy is clear in that modern science is being called upon to validate the traditional knowledge system and yet, the encounter is rich in the possibilities it offers for the reason that diametrically different ways of knowing and understanding the world are being brought together as part of the same conversation.

The 3rd empirical chapter has as it's pivot the issue of the non-availability of clean drinking water for a large section of the people of this country. At the 
heart of this story is the effort of scientists at the Hyderabad based International Advanced Research Centre for Powder Metallurgy and New Materials (ARCI) to develop a nano-silver based low cost water filter technology that is affordable to even the poorest in society. The scientists were able to develop such an application by innovating upon the existing ceramic candle water filter, but the product was a complete failure in the market. The case study builds upon central concepts in the social construction of technology (SCOT) such as the relevant social group, interpretive flexibility and closure to argue that the users should matter and that, perhaps, the failure of the water filter can be explained by the fact that users were not as central to the technology development, design and marketing process as they should have been.

The 4th empirical chapter highlights the issue of patriarchy and the continued marginalization and neglect of the girl child in contemporary Indian society. This case study revolves around the work of two tertiary eye care centres - L.V. Prasad Eye Institute in Hyderabad and Sankara Nethralaya in Chennai - where a team of clinician-scientists are forced to also become social activists as they seek a nanotechnology based treatment protocol for Retinoblastoma, a cancer of the eye of small children. The bias against the girl child comes centre-stage when parents of the infant girl with the cancer don't seek treatment that will need removal of the eye to save her life. They'd rather let the girl die today because of the fear that tomorrow a one-eyed girl will not be accepted in marriage by anyone. The problem, it emerges, is neither social, nor is it techno-medical; it lies at the intersection of social, the technical and the medical. The patient and her family who comes to the clinic catalyses a significant reconfiguration in the subjectivities of the clinician, who in this case is also the technologist seeking to develop a nanotechnology based protocol for the particular condition.

This empirical material is, in the vast terrain it traverses, also an account of the wide repertoire of sources, resources, people, ideas, materials, instruments and knowledge systems that the labs are mobilizing in multifarious ways. It describes and interprets how people, their technical and social institutions and their combined practices influence and negotiate a particular technology in understanding it, and using it to meet the ends they seek to meet.

Using the learnings from the empirical material and the diversity it points to, the thesis concludes with the following six inter-related steps of how and why innovation is encultured:

a) Innovation is an iterative, non-linear process where differently located social groups and actors, different knowledge systems and different ways of knowing and doing, all play an important role; it does not necessarily start with the producer and end with the consumer and neither does it begin with an invention that is discarded in the end as waste or obsolete 
b) Innovation has to be historically and culturally situated, even as we recognise that it endlessly transforms the different cultural logics that bring it into being in the first place

c) The scientific laboratory is an important site of innovation

d) Empirically and conceptually, innovation in the laboratory straddles different domains, and dominant metrics of citations, patents and commercialisation are insufficient to capture the depth, breadth and richness of the innovation processes.

e) Innovation in the laboratory is a multi-scalar process; the three scales that become obvious through the empirical material in the thesis are respectively, i) the micro (within the laboratory), ii) the institutional that gives rise to inter-disciplinarity and iii) the macro where social and cultural processes are inextricably inter-twined with the scientific and the technical.

f) Processes that allow wider participation are more likely to lead to successful innovations, particularly when S\&T is being increasingly mandated to find solutions that are directly needed and relevant in society.

Leading on from the enculturing of innovation inside the laboratory there are two salient insights this thesis offers: a) diversities within and between laboratories are reflective of the larger socio-political-cultural milieu within which the Indian S\&T system and the labs themselves are located, and b) different cultures of innovation exist in parallel, and acknowledging this multiplicity challenges the idea that only some ways of innovating or only one particular culture of innovation can be successful. The cultures of innovation are characterized as being de-centred in different ways. 


\section{Relevance}

There are two broad relevances of the research results from this thesis; the first is related to the deficit, in the Indian context, of the social studies of science and technology while the second relates to ideas of innovation and the discourses that have become dominant in that context.

1) The social studies of S\&T in India: In the Indian context, in particular, there is an obvious deficit in the ethnographic studies in the scientific laboratory and of social studies of the backstage of science and technology. The thesis makes an important contribution in filling that gap, and in doing so, illustrates the possibility, relevance and importance of doing such studies. There are some aspects of the thesis that have already generated much interest and discussion in India, both on account of the methodologies used and also some of the insights that the case studies and analysis have thrown up.

The thesis provides evidence of the larger relevance of the social studies of science and technology in the Indian context and could catalyse new engagements along these lines in India by having showed (how) it can be done and that it can also throw up interesting results. These results are not just of academic interest, but could provide answers to some of the key challenges faced in the country related to poverty, lack of access to basic facilities and the development and use of technologies that are relevant and appropriate. The thesis makes a step as much in bringing STS to India and it brings India to STS.

2) A discussion on innovation: The other point is related to 'innovation', the central theme of the thesis. Certain narratives of and on innovation have taken centre-stage in the discourses today and it is my contention that these represent only certain cultures and certain cultures of innovation. Innovation is happening in many different ways in different cultures and also within cultures depending on the available material, intellectual and contextual resources. There is a need to understand all of them- also because they could be contributing to and learning from each other.

The thesis provides evidence of this 'difference' in the cultures of innovation. I am confident that it will help start discussions and debates on the nature of innovation and also on the nature of the narratives around innovation. It will broaden our general understanding of what innovation is and how it is operationalized and will help acknowledge ways of knowing and doing that are otherwise considered marginal and non-important. 


\section{Target groups for the thesis}

The thesis reaches out to a number of different groups. This includes, among others, the media, policy makers, researchers and activists in the non-governmental section and also academia, both in the social sciences and in the natural sciences.

The academic world, in particular, holds a special place in the hierarchy of society today and what this community has to say about science, technology and innovation tends to become the norm. It also, then, comes to be accepted as 'correct' and as received wisdom about the respective subjects, even though we know from experience on the ground that reality is much more complex and multi-dimensional, and needs engagements that are diverse and multi-faceted. It is, first and foremost, this academic community that I seek to influence through the results that have emerged from the research and my hope is that the debate will indeed be influenced. To the social sciences, STS offers pathways of studying S\&T that have been barely explored in the Indian context; to the natural sciences the thesis offers a mirror - glimpses and insights of what happens back-stage in their own world, something they take so much for granted that it is often missed out completely.

The thesis is relevant for the other groups in different ways, but for reasons that are common - and that is the central role that S\&T and innovation occupies in the discourses of nationalism and development today. The results of the thesis offer some important counter-points to the standard narratives of how science is done and technology is developed. They also challenge the received wisdom of what innovation is, what it should be and even who has the capacity to innovate. The results of the thesis, therefore, have the potential of challenging the policy maker who is engaging with science, technology and innovation at the same time as showing solidarity with the activists and communities on the margins who are either left out or neglected by the main discourses of innovation.

The media too will be offered new empirical material that is also coupled with a newer kind of analysis that the STS offers. There are new insights that the analysis offers and where implications go beyond the respective case studies. A good example of that would be the discussions around jugaad that are quite common in the Indian media. I am confident that the thesis, through the details of the case studies and through the creation of new conceptualisations like that of technological jugaad will force the media as well to look for jugaad in 'unexpected' spaces and bring in elements to the discussions that have been missing so far. This has, in fact, already begun to happen, some details of which have been outlined in the following sections.

\section{What next from here}

The main outputs going forward from here will be in the nature of multi-faceted engagements with different sections of society. This includes: 
a) A larger academic monograph that will add to and expand the existing debates and discussions around innovation and science and technology

b) Non-academic, long-form narrative non-fiction accounts of life and work within respective laboratories that make up the empirical chapters of the thesis with a potential theme being 'The biography of a laboratory'

c) Academic papers based on the key themes that emerge from the thesis

d) Shorter articles in newspapers that will explore the empirics of the respective laboratories and/or the key thematic areas that the thesis deals with

e) A series of lectures on STS in India with the focus being on the specific laboratories

f) Photographic exhibition/s based on the pictures taken during the course of the research work.

Some of this has already begun to happen:

a) An article on the making of indigenous STMs in India that is based on one of the case studies was published a couple of years ago in Current Science, India's leading science journal. It evoked very positive reactions from scientists and from social scientists. It generated interest in the media as well with one prominent national newspaper, The Telegraph, using that article as the basis for a feature on jugaad and on instrument making in Indian laboratories

b) I've begun presenting the specific case studies and the larger conclusions from the research in lectures depending on the opportunities available. Most recently I spoke on 'technological jugaad' and instrument making in the Indian laboratory at the Indian Institute of Technology in Mumbai which generated much interest in the students and faculty. A couple of students have been in touch and are interested in working further on similar lines

c) I helped organize and co-ordinate a workshop in September 2015 at the Students Conference on Conservation Science (SCCS) in Bengaluru in September 2015 on a theme that was influenced by my learnings from and experience of doing the $\mathrm{PhD}$. Titled 'What is behind a scientific article - what can sociological and anthropological investigations tell us about writing a scientific paper and doing science?' it brought together a panel of ecologists, social scientists and a historian to present their experiences and perceptions on the subject. This was a very well received and a 
'surprising' workshop for most of the students and faculty who attended.

The key element in the thesis and its methodology is its novelty, particularly in an Indian context. It comes as a surprise to many inside and outside the world of science that something called the sociology of science or STS even exists, that sociologists can study science and scientists just like they study other aspects of the society in which scientists live and work.

It is in this context that the work of the thesis can be considered innovative -

a) in the investigative and research methodologies the thesis is based on,

b) in the nature of the engagement with laboratories in India and

c) in the insights that are offered on the process of innovation within contemporary science and technology in India

The primary value of the thesis revolves around the possibilities it has created in participating in and influencing the discussions and discourse around S\&T and innovation.

I am hopeful that some of the activities and ideas outlined above will come to fruition in due course of time. A lot would depend, of course, on human and financial resources that I am able to mobilise and the opportunities I am able to access and exploit both inside and outside the academy. 


\section{Curriculum Vitae}

Pankaj Sekhsaria has a Bachelor's Degree in Mechanical Engineering (1994) from the University of Pune, Pune, India and a Master's Degree in Mass Communication (1997) from the A.J. Kidwai Mass Communication Research Centre, Jamia Milia Islamia, New Delhi, India. He has been a prolific photographer and journalist with nearly 200 published features in the Indian media on topics as diverse as wildlife conservation, tribal rights, the environment, and handlooms and handicrafts. Over the years he has been the awardee of five media fellowships for researching and writing on different aspects of the environment and development in India. He has published 10 peer-reviewed articles and contributed chapters to two books. He is also the author/editor of four books, the latest of which is The Last Wave (2014), his debut novel that is based on India's Andaman and Nicobar Islands. He has been associated with the environment and conservation movement in India for nearly 20 years and lectures extensively on related issues in schools, colleges and universities. For the last 18 years he has been editing the Protected Area Update, a newsletter on wildlife and conservation that is published every two months by the environmental NGO, Kalpavriksh. He was Assistant Professor at the Tata Institute of Social Sciences, Hyderabad, India, for the period September 2014-April 2015, where he taught courses in Science, Technology \& Policy and Public Policy and Local Governance. 




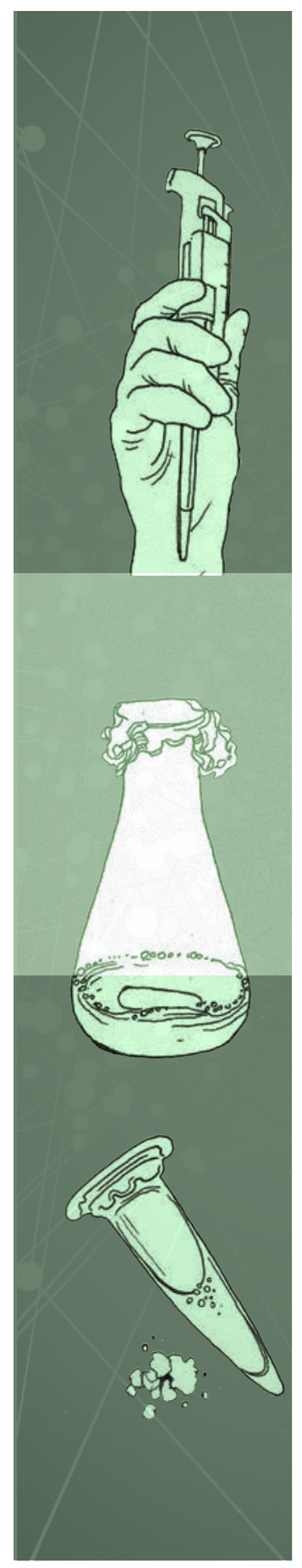

Enculturing Innovation: Indian engagements with nanotechnology is the outcome of an effort to understand the 'Culture(s) of innovation' in nanoscience and technology (NS\&T) research for development in India. Conducted across five NS\&T laboratories in three different Indian cities, it tries to understand the character of techno-scientific knowledge practices within the labs and their own location within the broad political, social, cultural and developmental contexts of contemporary India.

The thesis explores four different contexts, locations and realities of NS\&T research and development; the four case studies that make up its empirical core are, each, threaded along one particular marker of Indian society - the context of economic and resource constraints; the existence of multiple knowledge systems; the critical shortage of potable drinking water for a large section of people and the disadvantaged status of the girl child in this society.

This empirical material is, in the vast terrain it traverses, an account of the wide repertoire of sources, resources, people, ideas, materials, instruments and knowledge systems that the labs are mobilizing in multifarious ways. It describes and interprets how people, their technical and social institutions and their combined practices influence and negotiate a particular technology in understanding it, and using it to meet the ends they seek to meet. It is an account of a 'culture of innovation' that links the macro with the micro, and the inside of the lab with the world outside - a world that is a much bigger influence than is generally believed.

Using the learnings from the empirical material and the diversity it points to, the thesis concludes with a set of six inter-related steps of how and why innovation is encultured. It also notes that diversities within and between laboratories are reflective of the larger sociopolitical-cultural milieu within which the Indian S\&T system and the labs themselves are located, that multiple cultures of innovation exist in parallel, and it is important that we accept and acknowledge this multiplicity and diversity. 